\author{
Universidade de São Paulo \\ Escola de Engenharia de São Carlos \\ Departamento de Engenharia de Estruturas
}

Túlio Raunyr Cândido Felipe

\title{
Novo Método para a Avaliação do Risco de Colapso Progressivo em Edifícios de Alvenaria Estrutural
}

São Carlos - SP

2017 

Túlio Raunyr Cândido Felipe

\title{
Novo Método para a Avaliação do Risco de Colapso Progressivo em Edifícios de Alvenaria Estrutural
}

\author{
VERSÃO CORRIGIDA
}

A versão original encontra-se na Escola de Engenharia de São Carlos

Dissertação apresentada ao Departamento de Engenharia de Estruturas da Escola de Engenharia de São Carlos, Universidade de São Paulo, como parte dos requisitos necessários para obtenção do título de Mestre em Ciências (Engenharia de Estruturas).

Orientador: Dr Vladimir Guilherme Haach

São Carlos - SP

2017 
AUTORIZO A REPRODUÇÃO TOTAL OU PARCIAL DESTE TRABALHO, POR QUALQUER MEIO CONVENCIONAL OU ELETRÔNICO, PARA FINS DE ESTUDO E PESQUISA, DESDE QUE CITADA A FONTE.

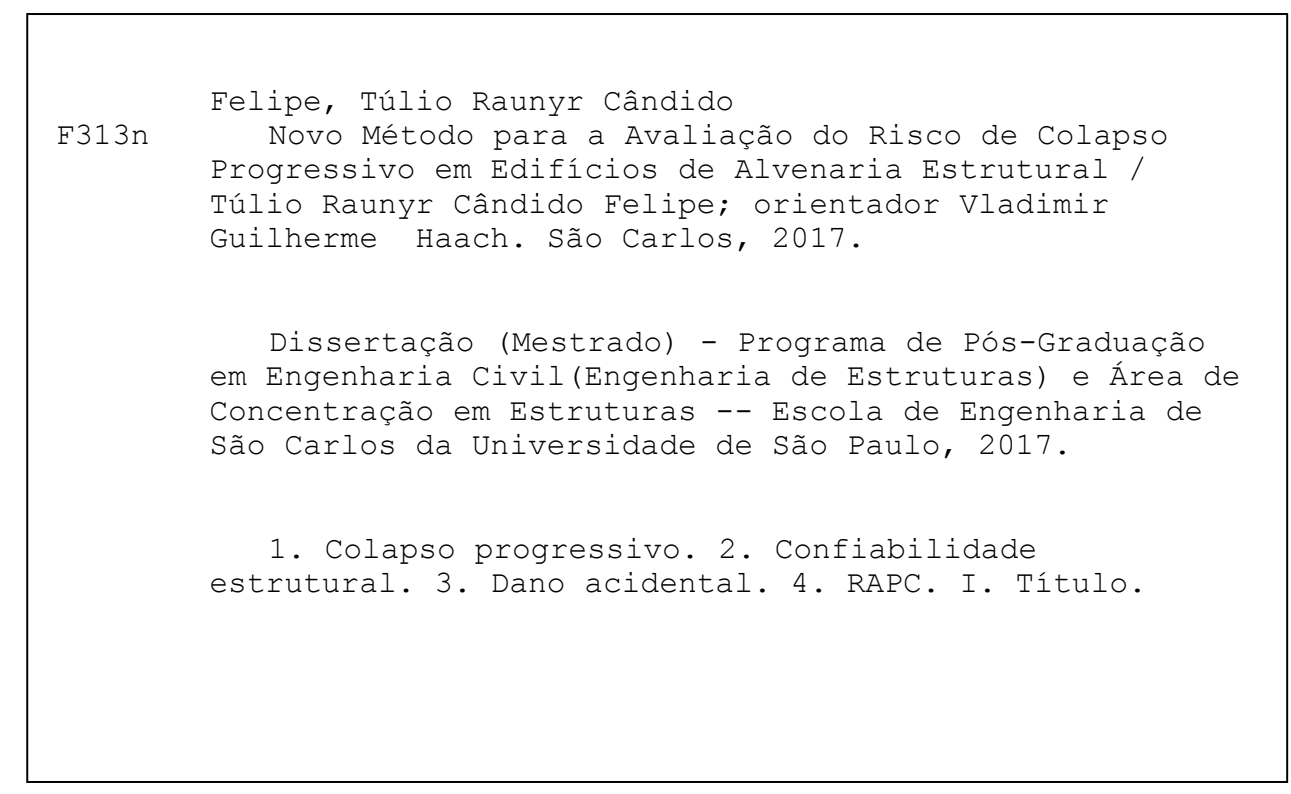




\section{FOLHA DE JULGAMENTO}

Candidato: Bacharel TÚLIO RAUNYR CÂNDIDO FELIPE.

Título da dissertação: "Novo método para a avaliação do risco de colapso progressivo em edifícios de alvenaria estrutural".

Data da defesa: 03/02/2017.

Comissão Julgadora:

Resultado:

Prof. Dr. Vladimir Guilherme Haach (Orientador)

APROVADO

(Escola de Engenharia de São Carlos/EESC)

Prof. Dr. Caio Gorla Nogueira APROVADO

(Universidade Estadual Paulista "Júlio de Mesquita Filho"/UNESP - Bauru)

Prof. Dr. Guilherme Aris Parsekian APROVADO

(Universidade Federal de São Carlos/UFSCar - São Carlos) (POR VIDEOCCNVFERENCIA)

Coordenador do Programa de Pós-Graduação em Engenheira Civil (Engenharia de Estruturas):

Prof. Titular Humberto Breves Coda

Presidente da Comissão de Pós-Graduação:

Prof. Associado Luís Fernando Costa Alberto 
A todos que por algum instante pensaram que eu poderia concluir mais esta etapa, em especial, a minha família e a Kaliandra. 


\section{Agradecimentos}

O meu primeiro agradecimento vai para Deus por sempre está presente na minha vida. Estendo aos meus familiares e minha noiva pelo incentivo e paciência neste período que fiquei distante.

O professor Vladimir Guilherme Haach, pela dose extra de conhecimento e incentivo, que minimizaram as minhas dificuldades na realização dessa pesquisa. Ao professor André Teófilo Beck, por ter participado ativamente através das suas contribuições referentes a confiabilidade estrutural.

Ao Departamento de Engenharia de Estruturas da EESC-USP e o Departamento de Engenharia Civil da UEPB, no conjunto de seus professores e funcionários, por proporcionarem um ensino de qualidade e a estrutura necessária para o desenvolvimento de minhas atividades acadêmicas.

Aos meus amigos da minha amada Paraíba, em especial, Advanaldo, Camila, Everton, Joaldo, Valter e Valdemar. Também a todos os meus novos amigos do Departamento de Engenharia Estruturas, em especial, Arthur, Dorival, Geovanne, Karolinne, Morkis, Rafael e Rodrigo que direta ou indiretamente participaram da realização deste trabalho, pessoas estas que sou eternamente grato.

Por fim, a Coordenação de Aperfeiçoamento de Pessoal de Nível Superior (CAPES), pela bolsa de estudo a mim concedida. 

[...] Não toque o aguardente venenoso que transforma os sábios em tolos e rouba deles suas visões [...]. 



\section{Resumo}

FELIPE, T. R. C. Novo Método para a Avaliação do Risco de Colapso Progressivo em Edifícios de Alvenaria Estrutural. 2017. 148 p. Dissertação de mestrado (Engenharia de Estruturas) - Escola de Engenharia de São Carlos, Universidade de São Paulo, São Carlos, 2017.

O evento do colapso progressivo começou a ser estudado, principalmente, após o acidente do edifício Ronan Point, em 1968, na cidade de Londres. Esse acidente fez o meio técnico rever as considerações normativas, sobretudo de maneira a adicionar recomendações que visem minimizar os danos causados à estrutura quando sujeita a um dano acidental. Entretanto, tais recomendações não realizam a análise do risco da estrutura colapsar. Essas também não conseguem analisar medidas de robustez e vulnerabilidade, e nem determinar qual é o elemento chave para a estrutura. Desse modo, partindo desses questionamentos, o presente trabalho desenvolveu uma nova metodologia nomeada aqui de Risk Analysis of the Progressive Collapse (RAPC). Este procedimento fornece uma medida mais precisa dos riscos, através de uma abordagem que utiliza a Teoria da Confiabilidade Estrutural. Assim, é deduzida uma expressão para a determinação da probabilidade de colapso progressivo, bem como são definidos os coeficientes de importância e vulnerabilidade para identificar o(s) elemento(s) chave. O elemento chave é definido como o que apresenta a maior interseção entre vulnerabilidade e importância para o colapso estrutural. Essas formulações desenvolvidas na metodologia do RAPC são implementadas em Fortran. Para isso, a modelagem do edifício de alvenaria estrutural é feita utilizando o software DIANA ${ }^{\circledR}$, no qual os esforços solicitantes são obtidos e utilizados como dados de entrada na análise de confiabilidade. Valores de probabilidades de falha individual por elemento, condicional e condicional dupla são calculados pelo First Order Reliability Method (FORM) e Importance Sampling Monte Carlo (ISMC) com auxílio do programa StRAnD. Um algoritmo em Fortran é implementado para acoplamento do DIANA ${ }^{\circledR}$ e StRAnD, além de mapear a probabilidade de falha dos elementos estruturais. Portanto, torna-se evidente que a identificação dos elementos mais vulneráveis, e do elemento chave em particular, é útil para abordagens diretas de concepção estrutural, tais como a melhoria da resistência local. Contudo, os coeficientes propostos também medem os efeitos dos procedimentos de projeto que conduzem à continuidade, ductilidade e redundância. Quando essas medidas trabalham para reduzir as probabilidades de propagação de dano ou colapso, isso se reflete nas vulnerabilidades de elementos eventualmente iniciando esses caminhos de falha. Sendo assim, conclui-se que a formulação do RAPC se mostra como uma ferramenta na determinação do risco do colapso progressivo nas estruturas.

Palavras-chave: Colapso progressivo. Confiabilidade estrutural. Dano acidental. RAPC. 



\section{Abstract}

FELIPE, T. R. C. New Method for Assessment the Risk of Progressive Collapse in Masonry Structural Buildings. 2017. 148 p. Master's Thesis (Structural Engineering) - School of Engineering Sao Carlos, University of Sao Paulo, Sao Carlos, 2017.

The progressive collapse event began to be studied, mainly, after the accident of the Ronan Point building, at 1968, in the city of London. This accident caused the engineers review their normative considerations, mainly in order to add recommendations aimed at minimizing the damage to structure when subjected to abnormal loading. However, such recommendations do not perform the risk analysis of the structure to collapse. These also fail to analyze measures of robustness and vulnerability, and either determine which is the key element of the structure. Thus, leaving of these questions, the present work to develop a new methodology named here of Risk Analysis of the Progressive Collapse (RAPC). This procedure provides a more accurate measure of risks through an approach that uses Structural Reliability Theory. Thus, an expression is deduced for the determination of the probability of progressive collapse, as well as the importance and vulnerability coefficients are defined to identify the key element (or key elements). The key element is identified as the one presenting the largest intersection between vulnerability and importance to collapse. These formulations developed in the RAPC methodology are implemented in Fortran. For this, the structural masonry building modeling is done using the DIANA ${ }^{\circledR}$ software, in which the requesting efforts are obtained and used as input data in the reliability analysis. Probabilities values individual, conditional, and double conditional are calculated by the First Order Reliability Method (FORM) and Importance Sampling Monte Carlo (ISMC) using the StRAnD software. A Fortran algorithm is implemented for DIANA ${ }^{\circledR}$ and StRAnD coupling, besides mapping the probability of failure of the structural elements. Therefore, it is clear that identification of the most vulnerable elements, and of the key element in particular, is useful for direct design approaches to structural design, such as local resistance enhancements. However, the coefficients proposed herein also measure the effects of design procedures leading to continuity, ductility or redundancy. When these measures work to reduce probabilities of damage propagation or collapse, this is reflected in the vulnerabilities of elements eventually initiating these failure paths. Therefore, it is concluded that the formulation of RAPC is shown as an tool in determining the risk of progressive collapse in structures.

Keywords: Progressive collapse. Structural reliability. Abnormal loading. RAPC. 



\section{Lista de ilustrações}

Figura 1 - Esquema da abordagem do RAPC. . . . . . . . . . . . . . . 32

Figura 2 - Limites recomendados de danos admissíveis. . . . . . . . . . . . . . 35

Figura 3 - Detalhes de construção que necessitam de uma atenção especial em edifícios de alvenaria estrutural em relação a danos acidentais. . . . . . 37

Figura 4 - Estágios da ocorrência do colapso progressivo. . . . . . . . . . . . . . . 41

Figura 5 - Esquema com as etapas do ESCP. . . . . . . . . . . . . . . 41

Figura 6 - Ponte sobre o Rio Pinheiros em São Paulo. . . . . . . . . . . . . . . . . 43

Figura 7 - Estrutura do aeroporto da Ilha da Madeira. . . . . . . . . . . . . . . . 43

Figura 8 - Tipos de amarrações incorporadas à estrutura para prover a integridade estrutural. . . . . . . . . . . . . . . . . . . 44 46

Figura 9 - Perda do apoio B. . . . . . . . . . . . . . 47

Figura 10 - Posição da deformada após a perda do apoio B. . . . . . . . . . . . . . 47

Figura 11 - Ação de balanço em uma edificação pré-moldada. . . . . . . . . . . . . . 49

Figura 12 - Ação de membrana em uma edificação pré-moldada. . . . . . . . . . . . 49

Figura 13 - Região de influência para as combinações de ações. . . . . . . . . . . . . 50

Figura 14 - Armadura adicional contra o colapso progressivo. . . . . . . . . . . . . 53

Figura 15 - Representação do domínio de falha e sobrevivência. . . . . . . . . . . . 56

Figura 16 - Probabilidade de falha em termo da variável normal padrão $\boldsymbol{Y}$. . . . . 58

Figura 17 - Métodos de transformação: FORM e SORM. . . . . . . . . . . . . . . . 59

Figura 18 - Ilustração da transformação composta $\boldsymbol{X} \rightarrow \boldsymbol{Z} \rightarrow \boldsymbol{Y}$. . . . . . . . . . . 60

Figura 19 - Ilustração do processo iterativo de busca do ponto de projeto. . . . . . 61

Figura 20 - Idealização de subsistemas em série . . . . . . . . . . . . . . . 63

Figura 21 - Idealização de subsistemas em paralelo . . . . . . . . . . . . . . . . . 63

Figura 22 - Representação do diagrama de Venn para a determinação do $E C$. . . . 70

Figura 23 - Esquema de colapso progressivo para a laje suportada por quatro paredes: a) estrutura íntegra; b) falha do primeiro elemento e redistribuição de esforços; c) falha do segundo elemento e colapso total (sem possibilidade de redistribuição de esforços). . . . . . . . . . . . . . . . . 71

Figura 24 - Representação da árvore de falha para à determinação do CID. . . . . 75

Figura 25 - Representação da árvore de falha para à determinação do $C I C$. . . . . 76

Figura 26 - Sistema de Daniels formado de $n$ barras paralelas de material frágil. . . 79

Figura 27 - Coeficiente de vulnerabilidade e importância para o Sistema de Daniels formado por $n$ barras paralelas de material frágil. . . . . . . . . . . 80

Figura 28 - Treliça hiperestática formada por 11 membros. . . . . . . . . . . . . . . 80

Figura 29 - Análise do coeficiente de redução $R . \ldots \ldots$. . . . . . . . . . . . 86

Figura 30 - Planta baixa do edifício em estudo (dimensões em $\mathrm{cm}$ ) . . . . . . . . 88 
Figura 31 - Esquema de numeração das paredes e posição da $q_{i}$. . . . . . . . . . . 89

Figura 32 - Tensão solicitante de cálculo em MPa. . . . . . . . . . . . . . . . . . . 90

Figura 33 - Valores de $C V \ldots \ldots \ldots$. . . . . . . . . . . . . . 92

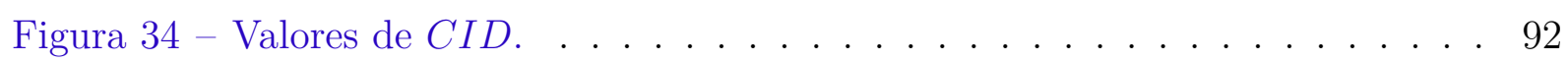

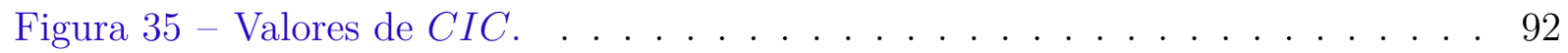

Figura 36 - Valores de $C V C \ldots \ldots \ldots$. . . . . . . . . . . . . . 92

Figura 37 - Notação para configuração comum. . . . . . . . . . . . . . . . . . 98

Figura 38 - Notação para configuração eventual. . . . . . . . . . . . . . . . . . . 98

Figura 39 - Laje retangular com uma borda livre: a) configuração comum e b) configuração eventual. . . . . . . . . . . . . . . . . . . . . . . 102

Figura 40 - Arquivo de entrada da rotina DIM-TCP. . . . . . . . . . . . . . . . . 104

Figura 41 - Exemplo de laje retangular simplesmente apoiada. . . . . . . . . . . . . 105

Figura 42 - Arquivo de saída da rotina DIM-TCP. . . . . . . . . . . . . . . . 105

Figura 43 - Exemplo de laje retangular com uma borda livre. . . . . . . . . . . . . 106

Figura 44 - Arquivo de entrada da rotina DIM-TCP. . . . . . . . . . . . . . . . . 106

Figura 45 - Arquivo de saída da rotina DIM-TCP. . . . . . . . . . . . . . 106

Figura 46 - Seção transversal retangular solicitada por momento fletor. . . . . . . . 107

Figura 47 - Laje no estado íntegro. . . . . . . . . . . . . . . . . . . . 110

Figura 48 - Algoritmo da metodologia do RAPC . . . . . . . . . . . . . . . . 112

Figura 49 - Numeração das lajes do pavimento tipo. . . . . . . . . . . . . . . . . 115

Figura 50 - Arquivo de entrada de dados para a DIM-TCP. . . . . . . . . . . 116

Figura 51 - Dimensionamento do pavimento tipo pela DIM-TCP. . . . . . . . . . . 116

Figura 52 - Modelagem das paredes de alvenaria estrutural. . . . . . . . . . . . . . 120

Figura 53 - Esquema da modelagem das paredes por barras rígidas. . . . . . . . . . 120

Figura 54 - Graus de liberdade dos nós com a consideração do recurso do nó mestre.121

Figura 55 - Elemento finito de barra L12BE. . . . . . . . . . . . . . . . . . 122

Figura 56 - Diagrama unifiliar das paredes em planta. . . . . . . . . . . . . . . 123

Figura 57 - Visão tridimensional do pavimento tipo. . . . . . . . . . . . . . . . . 124

Figura 58 - Coeficiente de vulnerabilidade $(C V)$ via FORM para o edifício. . . . . 127

Figura 59 - Coeficiente de desproporcionalidade para a propagação do dano $(C I D)$, dada a falha do elemento $E_{i} . \quad \ldots \ldots$. . . . . . . . . . . . 129

Figura 60 - Coeficiente de vulnerabilidade para a propagação de dano $(C I D)$ via FORM. . . . . . . . . . . . . . . . . . 130

Figura 61 - Coeficiente de desproporcionalidade para o colapso progressivo $(C I C)$, dada a falha do elemento $E_{i}$. . . . . . . . . . . . . . . . . . . 131

Figura 62 - Coeficiente de vulnerabilidade para o colapso estrutural $(C V C)$ via FORM. 


\section{Lista de tabelas}

Tabela 1 - Estatísticas para o problema em estudo. . . . . . . . . . . 81

Tabela 2 - Coeficientes $C V, C I D$ e $C V D$ para a treliça em estudo. . . . . . . . 82

Tabela 3 - Coeficientes $C I C$ e $C V C$ para a treliça em estudo. . . . . . . . . . . 82

Tabela 4 - Coeficientes $C V, C I D$ e $C V D$ para a nova análise da treliça em estudo. 84

Tabela 5 - Coeficientes $C I C$ e $C V C$ para a nova análise da treliça em estudo. . . 84

Tabela 6 - Estatísticas das variáveis aleatórias. . . . . . . . . . . . . 91

Tabela 7 - Determinação da $P\left[c_{i}\right]$ via FORM e ISMC . . . . . . . . . . . . . 93

Tabela 8 - Cálculo dos momentos adimensionais no regime elástico para lajes simplesmente apoiadas. . . . . . . . . . . . . . . . . 999

Tabela 9 - Cálculo dos momentos adimensionais no regime elástico para lajes simplesmente apoiadas com uma borda livre. . . . . . . . . . . . . 102

Tabela 10 - Estatísticas das variáveis aleatórias. . . . . . . . . . . . . . . 110

Tabela 11 - Dimensões das lajes em cm . . . . . . . . . . . . . . . . . 115

Tabela 12 - Análise das lajes no estado íntegro. . . . . . . . . . . . . . . 117

Tabela 13 - Valores de $P_{f}$ alvo para elementos estruturais no ELU. . . . . . . . . . 118

Tabela 14 - Determinação das tensões de compressão solicitantes de cálculo. . . . . 125

Tabela 15 - Estatísticas das variáveis aleatórias do edifício de alvenaria. . . . . . . 126

Tabela 16 - Análise das lajes no estágio de propagação de dano via ISMC. . . . . . 129

Tabela 17 - Probabilidades condicionais de colapso progressivo, dado a falha do elemento $W_{i}$ via FORM. . . . . . . . . . . . . . . . 133

Tabela 18 - Probabilidades condicionais de colapso progressivo, dado a falha do elemento $W_{i}$ via ISMC. . . . . . . . . . . . . . . . . . . . 134 



\section{Lista de abreviaturas e siglas}

\begin{tabular}{|c|c|}
\hline $\mathrm{ABNT}$ & Associação Brasileira de Normas Técnicas \\
\hline CI & Coeficiente de importância \\
\hline $\mathrm{CV}$ & Coeficiente de vulnerabilidade \\
\hline DCR & Demand Capacity Ratios \\
\hline DIM-TCP & Rotina de Dimensionamento das lajes \\
\hline DoD & Department of Defense \\
\hline $\mathrm{EC}$ & Elemento chave \\
\hline EEL-TCP & Rotina com a Equação de Estado Limite das lajes \\
\hline EESC & Escola de Engenharia de São Carlos \\
\hline ESI & Estágio Íntegro \\
\hline ESID & Estágio Inicial de Dano \\
\hline ESPD & Estágio de Propagação de Dano \\
\hline ESCP & Estágio de Colapso Progressivo \\
\hline EUA & Estados Unidos da América \\
\hline FIB & Fédération Internationale du Béton \\
\hline FORM & First Order Second Moment \\
\hline GSA & General Services Adminstration \\
\hline ISMC & Importance Sampling Monte Carlo \\
\hline MCA & Método dos Caminhos Alternativos \\
\hline MRLE & Método da Resistência Local Específica \\
\hline NBR & Norma Brasileira Regulamentadora \\
\hline NISTIR & National Institute of Standard and Technology \\
\hline NLC & Não Linearidade de Contato \\
\hline
\end{tabular}




$\begin{array}{ll}\text { NLF } & \text { Não Linearidade Física } \\ \text { NLG } & \text { Não Linearidade Geométrica } \\ \text { NP } & \text { Norma Portuguesa } \\ \text { R } & \text { Robustez } \\ \text { RAPC } & \text { Risk Analysis of the Progressive Collapse } \\ \text { SMC } & \text { Simulação de Monte Carlos } \\ \text { StRAnD } & \text { Structural Risk Analysis and Design } \\ \text { USP } & \text { Universidade de São Paulo } \\ \text { TCP } & \text { Teoria de Charneiras Plásticas } \\ \text { V } & \text { Vulnerabilidade }\end{array}$




\section{Lista de símbolos}

\begin{tabular}{|c|c|}
\hline$A_{k}$ & ação excepcional pré-definida \\
\hline$A_{s}$ & $\begin{array}{l}\text { área das armaduras na face inferior da laje que atravessam a seção do } \\
\text { pilar }\end{array}$ \\
\hline$A_{s, c c p}$ & $\begin{array}{l}\text { somatório de todas as áreas das barras inferiores que cruzam cada uma } \\
\text { das faces do pilar }\end{array}$ \\
\hline$f_{y d}$ & valor de cálculo da tensão do aço \\
\hline$F_{g}$ & ações permanentes \\
\hline$F_{q}$ & ações variáveis \\
\hline$F_{S d}$ & força transmitida ao pilar \\
\hline$G_{L D}$ & incremento das cargas devido aos deslocamentos \\
\hline$G_{L F}$ & incremento das cargas devido aos esforços \\
\hline $\mathrm{g}(\mathbf{X})$ & equação de estado limite do vetor $\mathbf{X}$ \\
\hline$Q_{U D, L i m}$ & esforço no elemento estrutural \\
\hline$Q_{C E}$ & capacidade máxima resistente esperada em serviço do elemento \\
\hline$m$ & momento de plastificação positivo \\
\hline$m^{\prime}$ & momento de plastificação negativo \\
\hline$n_{s}$ & número de andares da edificação \\
\hline$P_{f}$ & probabilidade de falha \\
\hline$P_{l}$ & carga linear na borda livre da laje \\
\hline$P(x)$ & probabilidade de um evento $\mathrm{x}$ \\
\hline$P\left(\mathbf{F}_{j} \mid \mathbf{F}_{i}\right)$ & probabilidade condicional do evento $j$ dado a ocorrência do evento $i$ \\
\hline$P\left(\mathbf{F}_{k} \mid \mathbf{F}_{i, j}\right)$ & $\begin{array}{l}\text { probabilidade condicional dupla do evento } k \text { dado a ocorrência do evento } \\
i \text { e } j \text {. }\end{array}$ \\
\hline$R_{n}$ & resistência de amarração nominal \\
\hline$R_{u}$ & resistência de amarração requerida \\
\hline
\end{tabular}




\begin{tabular}{|c|c|}
\hline$T_{i}$ & resistência da armadura interna \\
\hline$T_{p}$ & resistência da armadura periférica \\
\hline$T_{v}$ & resistência da armadura vertical \\
\hline$\Omega_{L D}$ & fator de aumento das ações devido aos deslocamentos \\
\hline$\Omega_{L F}$ & fator de aumento das ações devido aos esforços \\
\hline$\mu$ & média ou valor esperado \\
\hline$\sigma$ & desvio padrão \\
\hline$\beta$ & índice de confiabilidade \\
\hline$\varphi$ & fator de redução da resistência \\
\hline$\Phi(y)$ & função de distribuição cumulativa de probabilidade \\
\hline$\Omega_{f}$ & domínio de falha \\
\hline$\Omega_{s}$ & domínio de sobrevivência \\
\hline$\alpha$ & vetor de cossenos diretores \\
\hline$\cup$ & união de eventos \\
\hline$\cap$ & intersecção do evento \\
\hline$\kappa$ & índice de ortotropia \\
\hline$\phi$ & grau de engastamento \\
\hline$\phi(y)$ & função de densidade de probabilidade \\
\hline
\end{tabular}




\section{Sumário}

INTRODUÇÃo $\ldots \ldots \ldots \ldots \ldots \ldots \ldots \ldots \ldots$

I PREPARAÇÃO DA PESQUISA

OBJETIVOS E JUSTIFICATIVA . . . . . . . . . . . . . . 29

Objetivo geral .

DANOS ACIDENTAIS E COLAPSO PROGRESSIVO . . . . . . 35

4.2 Requisitos fundamentais para à prevenção contra o colapso progressivo . . . . . . . . . . . . . . . . . . . . 39

4.3 Introdução aos métodos de prevenção contra o colapso progressivo 44

$4.3 .1 \quad$ Projeto indireto . . . . . . . . . . . . . . . . . . 46

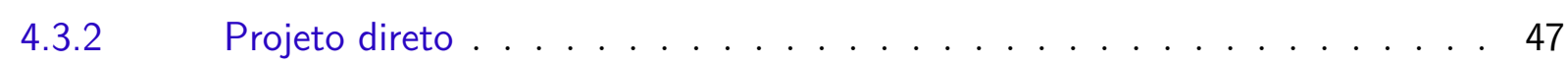

4.3.2.1 Método da resistência local específica . . . . . . . . . . . . . . . . . . . . . . . 48

4.3.2.2 Método dos caminhos alternativos . . . . . . . . . . . . . . . . . . . . . . . . . 48

$4.4 \quad$ Normas e recomendações . . . . . . . . . . . . . 51

5 CONFIABILIDADE ESTRUTURAL $\ldots \ldots \ldots \ldots \ldots$

$5.1 \quad$ Estados limites . . . . . . . . . . . . . . . . . . 55

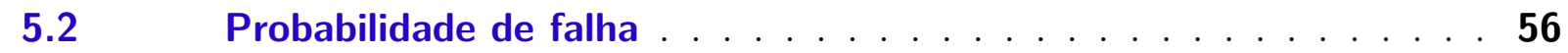

$5.3 \quad$ Índice de confiabilidade . . . . . . . . . . . . . . . 57

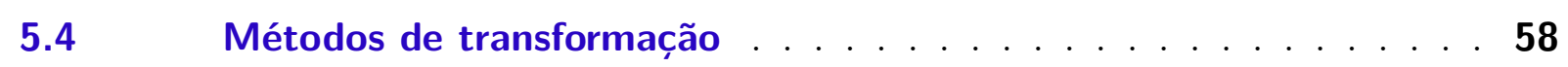

5.4.1 Transformações de variáveis . . . . . . . . . . . . . . . . . 59

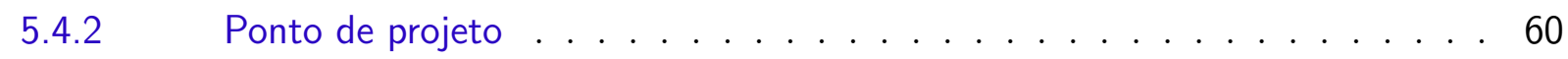

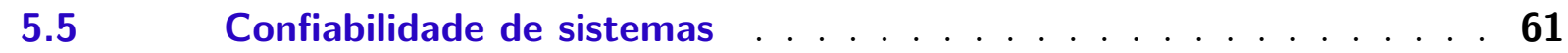

5.5 .1 Idealização em série . . . . . . . . . . . . . . . . 63

5.5.2 Idealização em paralelo . . . . . . . . . . . . . . . . 63

$5.6 \quad$ Simulação de Monte Carlo . . . . . . . . . . . . . . 65 


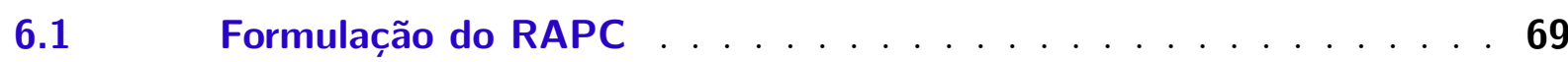

6.2 Coeficiente de importância, coeficiente de vulnerabilidade e elemento chave . . . . . . . . . . . . . . . 74

6.3 Múltiplos riscos ou múltiplos eventos de carregamento . . . . . . 78

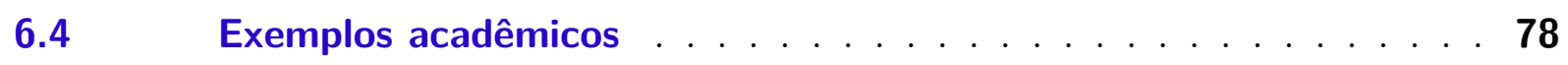

6.4 .1 Sistema de Daniels . . . . . . . . . . . . . . . . . . . 78

6.4 .2 Treliça hiperestática . . . . . . . . . . . . . . . 80

7 EQUAÇÃO DE ESTAdO LIMITE DAS PAREDES . . . . . . . 85

7.1 Equação de Estado Limite das Paredes . . . . . . . . . . . . 85

7.2 Sensibilidade da probabilidade de falha . . . . . . . . . 87

$7.3 \quad$ Exemplo de aplicação: edifício de alvenaria . . . . . . . . . 88

8 DETERMINAÇÃO DOS ESFORÇOS NAS LAJES . . . . . . . 95

$8.1 \quad$ Noções sobre o cálculo elástico . . . . . . . . . . . . . . 95

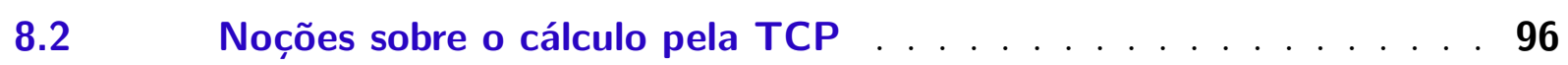

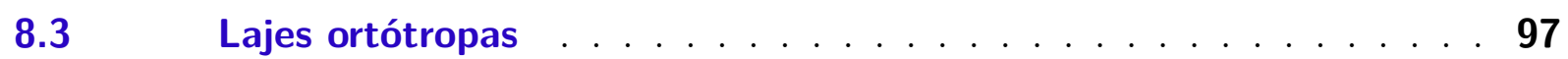

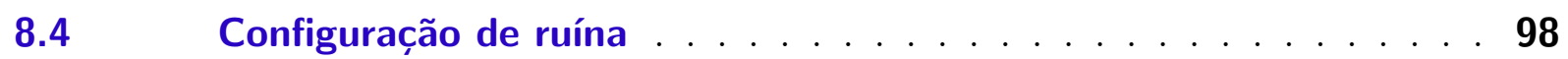

8.5 Marcha de cálculo: lajes simplesmente apoiadas . . . . . . . . 99

$8.5 .1 \quad$ Dados . . . . . . . . . . . . . . . . . . . . 99

8.5.2 Valores de $\phi$ e de $\kappa \ldots \ldots \ldots \ldots . \ldots \ldots 9 . \ldots \ldots$

8.5.3 Direção da charneira central . . . . . . . . . . . . . . . 99

8.5 .4 Momento de plastificação . . . . . . . . . . . . . 100

8.5.5 Configuração de ruína . . . . . . . . . . . . . . . . . . 100

8.5.6 Reações de apoio . . . . . . . . . . . . . . . . . . . . . . . . 101

8.6 Marcha de cálculo: lajes simplesmente apoiadas com uma borda livre101

$8.6 .1 \quad$ Dados . . . . . . . . . . . . . . . . . . . . . . . 101

8.6.2 Valores de $\phi$ e de $\kappa \ldots \ldots . \ldots . \ldots . \ldots . \ldots 2$

8.6.3 Momento de plastificação . . . . . . . . . . . . . . . . 103

8.6 .4 Reações de apoios . . . . . . . . . . . . . . . . . . 103

$8.7 \quad$ Rotina DIM-TCP . . . . . . . . . . . . . . . . . . . . . . . 104

8.7.1 Exemplo 1: laje simplesmente apoiada . . . . . . . . . . . . . . . . 104

8.7.2 Exemplo 2: laje simplesmente apoiada com uma borda livre . . . . . . . 105

9 EQUAÇÃO DE ESTADO LIMITE PARA LAJES . . . . . . . . 107

9.1 Cálculo do momento resistente da seção . . . . . . . . . . 107

9.2 Equações de estado limite . . . . . . . . . . . . . . . 108

$9.2 .1 \quad$ Laje simplesmente apoiada . . . . . . . . . . . . . . . . 108 
9.2.2 Laje simplesmente apoiada com uma borda livre . . . . . . . . . . . . 109

9.3 Rotina EEL-TCP . . . . . . . . . . . . . . . . . . . . 109

9.4 Metodologia do RAPC . . . . . . . . . . . 111

$\begin{array}{lll}\text { IV } & \text { RESULTADOS } & 113\end{array}$

10 AVALIAÇÃO DA CONFIABILIDADE DAS LAJES . . . . . . . . 115

$10.1 \quad$ Avaliação da probabilidade de falha das lajes . . . . . . . . . 117

11 VALIDAÇÃO DA METODOLOGIA DO RAPC: MODELO NUMÉRICO . . . . . . . . . . . . . . . . . 119

11.1 Modelo de pórtico tridimensional . . . . . . . . . . . . 119

$11.2 \quad$ Simulação numérica . . . . . . . . . . . . . . . . . . 121

11.2.1 Propriedades gerais do modelo numérico . . . . . . . . . . . . . . . . 121

11.2.1.1 Propriedades dos elementos estruturais . . . . . . . . . . . . . . . . . . . . 121

11.2.1.2 Propriedades dos materiais . . . . . . . . . . . . . . . . . . 122

11.2.1.3 Malha e elementos finitos . . . . . . . . . . . . . . . . . . 122

11.2.1.4 Carregamentos e condições de contorno . . . . . . . . . . . . . . . . . . . 122

11.3 Validação da metodologia do RAPC: análise estática linear . . . . 123

11.3.1 Dimensionamento do edifício . . . . . . . . . . . . . . . . . . . . . 124

11.3.2 Análise dos resultados . . . . . . . . . . . . . . . . . 126

11.4 Validação da metodologia do RAPC: análise estática não linear . . . 134

12 CONSIDERAÇÕES FINAIS E RECOMENDAÇÕES PARA TRABALHOS FUTUROS . . . . . . . . . . . . . . . . . . . . 137

$12.1 \quad$ Considerações finais . . . . . . . . . . . . . . . 137

12.2 Recomendações para trabalhos futuros . . . . . . . . . . . . . 139

REFERÊNCIAS . . . . . . . . . . . . . . . 141 



\section{Introdução}

As incertezas que um engenheiro estrutural encontra ao projetar a estrutura de uma edificação estão presentes na aleatoriedade natural do processo envolvido, tendo em vista que, tanto as ações consideradas como as resistências dos materiais são variáveis aleatórias. Da mesma forma, os modelos de engenharia adotados para representar o problema físico são aproximados.

O engenheiro projetista pode avaliar a segurança da estrutura pelo método probabilístico, levando em consideração as incertezas das variáveis de projeto e as distribuições de probabilidades ou utilizar o método semi-probabilístico em que as incertezas são atreladas indiretamente aos coeficientes parciais de segurança. Entretanto, a utilização do método semi-probabilístico não fornece uma medida exata de quanto é segura uma estrutura (BECK, 2015).

Segundo a norma de ações e segurança nas estruturas, ABNT NBR 8681 (2004), existem três tipos de ações com relação à sua variação no tempo: permanentes, variáveis e excepcionais. As ações permanentes são aquelas que ocorrem com valores constantes ou com baixa variação ao longo da vida útil da edificação, por exemplo, o peso próprio dos elementos estruturais. As ações variáveis, são aquelas que ocorrem com variabilidade ao longo da vida útil da construção, como por exemplo, o peso de móveis e pessoas. Por fim, as ações excepcionais, que são aquelas com uma duração curta e com baixa probabilidade de ocorrência ao longo da vida da estrutura, tais como o impacto de veículos, explosões de gás, ataques terroristas, cujo dano tem efeito catastrófico na estrutura.

Em se tratando das ações excepcionais, normalmente as mesmas não são consideradas nas combinações de projetos devido à sua baixa probabilidade de ocorrência. Entretanto, na eventualidade destas acontecerem, graves problemas nas construções, como o colapso progressivo, podem ocorrer.

O acidente do edifício Ronan Point em 1968 na cidade de Londres, despertou o interesse no estudo das previsões das ações excepcionais e colapso progressivo nas estruturas, cuja casualidade resultou na atualização das normas regulamentadoras da época.

Os casos de colapso progressivo usualmente citados são presentes em estruturas de concreto, em especial, estruturas de concreto pré-moldado, pois dada à ausência ou deficiência de continuidade no sistema estrutural estes estão mais susceptíveis ao colapso. Em relação aos edifícios de alvenaria estrutural, seu comportamento frágil e heterogêneo aumenta a probabilidade de colapso progressivo na ocorrência de uma ação excepcional. 
Em se tratando da alvenaria estrutural, a remoção de paredes para aumentar ambientes ou a retirada de paredes por ignorância dos usuários sem a autorização do responsável técnico pelo projeto, aumenta a probabilidade de ocorrência de danos acidentais com graves consequências para a estrutura do edifício. Portanto, surge uma grande preocupação a respeito da ocorrência deste problema, a qual envolve riscos à vida humana, assim como danos financeiros à sociedade.

A identificação de possíveis danos acidentais em estruturas de alvenaria devido a falha de uma parede estrutural com a ocorrência do colapso progressivo não é plenamente compreendido no meio técnico nacional. As próprias normas de alvenaria estrutural, ABNT NBR 15812-1 (2010) e ABNT NBR 15961-1 (2011), em seus anexos mencionam em caráter informativo sobre dano acidental e colapso progressivo, mas não torna claro ao leitor como proceder para minimizar a probabilidade de ocorrência dos mesmos.

Vale ressaltar que dimensionar uma estrutura de alvenaria estrutural avaliando a possibilidade de danos acidentais com o objetivo de redução na probabilidade de ocorrência de colapso progressivo requer do projetista uma visão diferenciada, tendo em vista, que as combinações de ações descritas nas normas brasileiras não levam em consideração estes efeitos nas estruturas. 


\section{Parte I}

\section{Preparação da pesquisa}





\section{Objetivos e Justificativa}

\subsection{Objetivo geral}

Desenvolver uma metodologia para prever a ocorrência do colapso progressivo em estruturas através de uma abordagem que utiliza a teoria da confiabilidade de sistemas e aplicar em edifícios de alvenaria estrutural.

\subsection{Objetivos específicos}

a) determinar as probabilidades de falha dos elementos estruturais isolados do edifício: paredes e lajes;

b) determinar as probabilidades de falha condicionais dada a falha de um elemento e as probabilidades de falha condicionais duplas dadas a falha de dois elementos do edifício;

c) deduzir uma expressão que caracterize o colapso progressivo com base em confiabilidade de sistemas;

d) definir uma expressão que caracterize o coeficiente de importância, coeficiente de vulnerabilidade e o elemento chave para a estrutura do edifício.

\subsection{Justificativa}

Este trabalho inicia-se por uma descrição do estado da arte sobre o tema proposto. O colapso progressivo começou a ser estudado, principalmente, após o acidente do Edifício Ronan Point, em 1968, na cidade de Londres.

Outros acidentes ocorreram nas últimas décadas, tais como: o colapso do edifício Skyline Plaza, em 1973, com 14 vítimas; os ataques terroristas no edifício do World Trade Center, em 1993, com 6 vítimas; no edifício Alfred P. Murrah Federal Building, em 1995, com 168 vítimas; os atentados de 11 de setembro de 2001, com 2996 vítimas, ambos nos EUA, e recentemente, o colapso do Edifício Liberdade no Rio de Janeiro em 2012, com 22 vítimas.

Esses acidentes fizeram o meio técnico rever as considerações prescritas nas normas regulamentadoras, com vista a adicionar recomendações que visam minimizar os danos causados quando uma estrutura está submetida a um dano acidental. 
Entretanto, as recomendações descritas atualmente nas normas técnicas para a prevenção do colapso progressivo, não realizam a análise do risco da estrutura colapsar. Essas abordagens também não conseguem analisar medidas de robustez e vulnerabilidade, nem determinam quais são os elementos chave para a estrutura.

Sendo assim, partindo destes questionamentos, o presente trabalho pretende desenvolver uma nova metodologia nomeada aqui de Risk Analysis of the Progressive Collapse (RAPC). Este procedimento fornece uma medida mais precisa dos riscos, através de uma abordagem que utiliza a Teoria da Confiabilidade Estrutural. Portanto, o engenheiro ao projetar uma estrutura utilizando o RAPC pode determinar a sua probabilidade de falha na ocorrência de um dano acidental.

Essa metodologia consiste em verificar o colapso progressivo baseando-se em análise de confiabilidade de sistemas sem a necessidade do projetista se preocupar com a causa que gerou o colapso, mas sim com a consequência da falha do edifício. Assim, a estrutura é idealizada em subsistemas com componentes formados em série e em paralelo. Dessa forma, os eventos que correspondem a uma sequência de falha estão associados em paralelo, enquanto que as diferentes sequências de falha formam eventos em série. Então, a ocorrência do colapso progressivo é caracterizada quando a falha de um subsistema levar a falha do sistema (estrutura do edifício), ou seja, a probabilidade de colapso do sistema é dada pelo somatório das probabilidades de colapso dos subsistemas individuais. 


\section{Metodologia}

Inicialmente é efetuada uma investigação do estado da arte do tema em estudo. Em seguida, uma expressão para considerar a probabilidade de ocorrência do colapso progressivo é deduzida com base em confiabilidade de sistemas. Depois são definidos o coeficiente de vulnerabilidade $(C V)$, o coeficiente de importância para a progressão do dano $(C I D)$, o coeficiente de importância para o colapso estrutural $(C I C)$, o coeficiente de vulnerabilidade para o colapso progressivo $(C V C)$ e o elemento chave $(E C)$.

Na sequência são deduzidos e implementados os modos de falhas para as paredes estruturais e lajes. Em se tratando das paredes estruturais, é considerado o modo de falha por compressão axial. Em relação às lajes, é adotado o modo de falha por formação de charneiras plásticas. Para este modo de falha, sua respectiva equação de estado limite é definida através da Teoria de Charneiras Plásticas (TCP).

As análises de confiabilidade são realizadas via FORM (First Order Reliability Method) e ISMC (Importance Sampling Monte Carlo). Para tal, esta pesquisa utiliza como ferramenta o software StRAnD (Structural Risk Analysis Design), desenvolvido por Beck (2007).

Na análise numérica é adotado o modelo estrutural de pórtico tridimensional no qual se considera a hipótese do comportamento de diafragma rígido das lajes. O mesmo é modelado no software comercial DIANA ${ }^{\circledR}$ aplicando as etapas da metodologia do Risk Analysis of the Progressive Collapse (RAPC).

A consideração da análise não linear é realizada, assumindo-se as seguintes estratégias: na determinação dos esforços no modelo estrutural é realizada considerando a não linearidade geométrica (NLG), a não linearidade física (NLF) é avaliada de forma simplificada penalizando o módulo de elasticidade dos elementos de acordo com ABNT NBR 15961-1 (2011). Ademais, a NLF também é analisada nas equações de estado limite que são deduzidas para os modos de falhas das paredes estruturais e lajes.

Por fim, as formulações desenvolvidas na metodologia do RAPC são implementadas em Fortran. Para isso, a modelagem do pórtico tridimensional é feita utilizando o software DIANA ${ }^{\circledR}$, no qual os esforços solicitantes são obtidos e utilizados como dados de entrada na análise de confiabilidade. Valores de probabilidades de falha individual por parede, condicional e condicional dupla são calculados com auxílio do programa StRAnD. Um algoritmo em Fortran é implementado para acoplamento do DIANA ${ }^{\circledR}$ e StRAnD, além de mapear a probabilidade de falha das paredes. Na Figura 1 é apresentado um esquema da metodologia aplicada para a determinação da probabilidade do colapso progressivo no modelo estrutural baseado no RAPC. 
Figura 1 - Esquema da abordagem do RAPC.

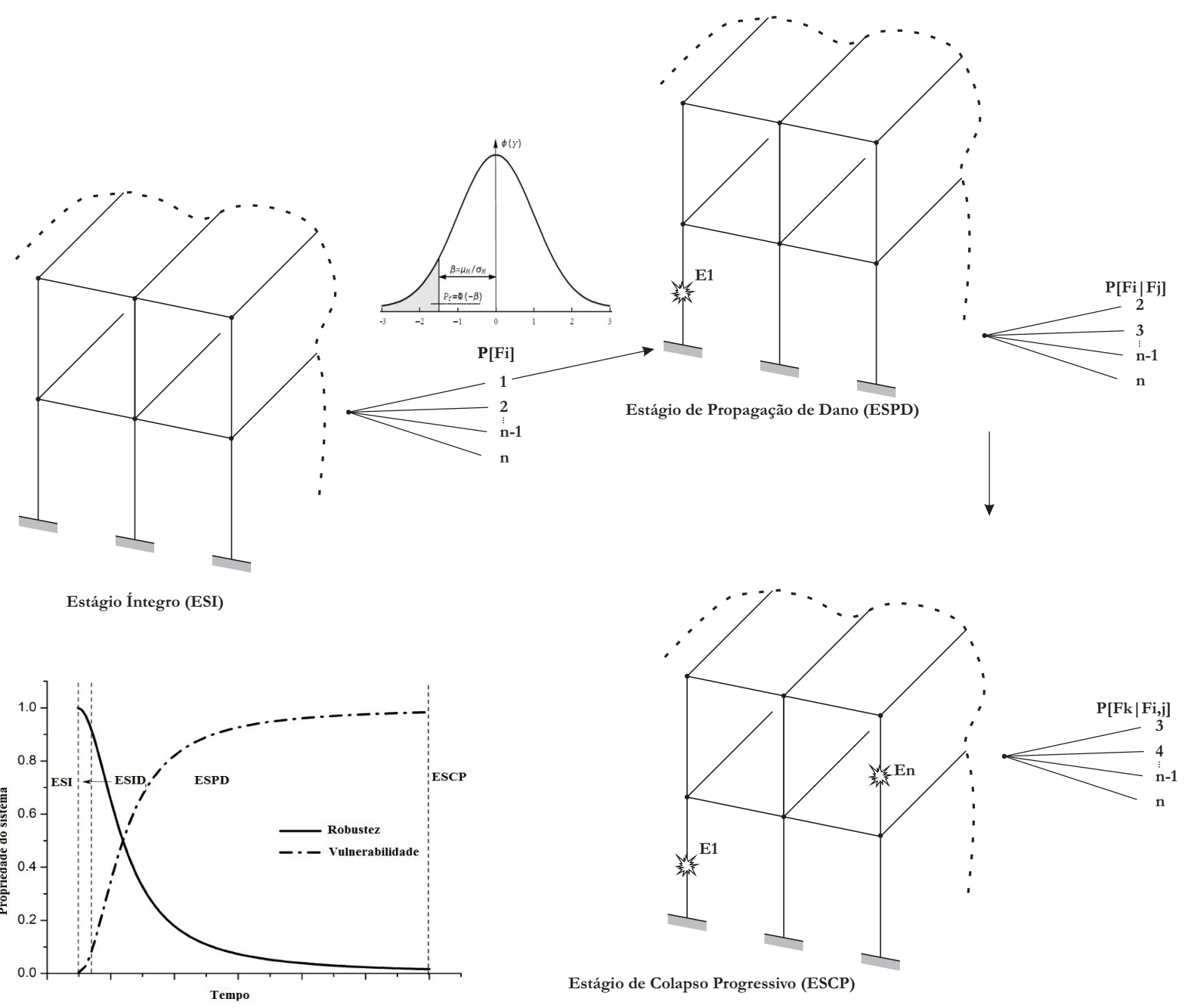

Fonte: Autoria própria. 
Parte II

Referencial teórico 



\section{Danos Acidentais e Colapso Progressivo}

A falha ou a ruptura de uma estrutura submetida a um dano acidental está associada à grandes implicações econômicas e graves repercussões sociais. Embora os danos acidentais e/ou colapso progressivo sejam eventos com baixa probabilidade de ocorrência, as consequências dos seus acontecimentos têm um impacto profundo na sociedade, devido as perdas de vidas humanas.

Diversos autores citam que eventos que incluem ações excepcionais geralmente não são considerados em projetos estruturais de edificações, o que implica na possibilidade da perda da integridade estrutural por ocorrência de um dano acidental (VASILIEVA, 2013; NISTIR 7396, 2007; ELLINGWOOD et al., 1982). Além disso, tais danos podem provocar o colapso parcial ou total das edificações e a perda de um número elevado de vidas humanas (HAACH, 2015; KOZLOVA, 2013; STAROSSEK; HABERLAND, 2010).

O NISTIR 7396 (2007), Ellingwood (2007) e o Eurocode 1 (2003) recomendam que os danos acidentais ocorridos na edificação após uma ação excepcional não excedam $15 \%$ da área em planta, mas não maior que $100 \mathrm{~m}^{2}$, e, na direção vertical, não maior que dois andares adjacentes a localização do dano, conforme a Figura 2. Contudo, o Eurocode 1 (2003) enfatiza que danos localizados em um elemento estrutural podem ser aceitáveis se a edificação mantiver sua integridade estrutural por um período suficiente até ser completamente evacuada.

Figura 2 - Limites recomendados de danos admissíveis.

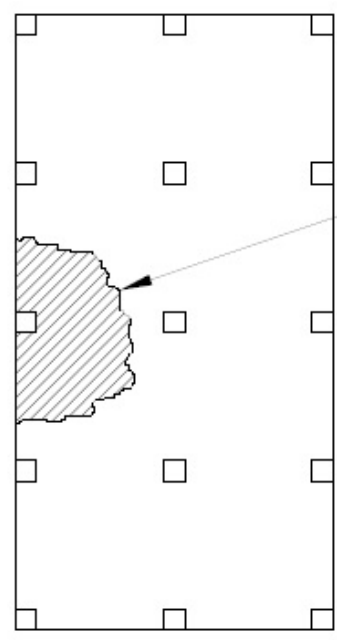

PLANTA

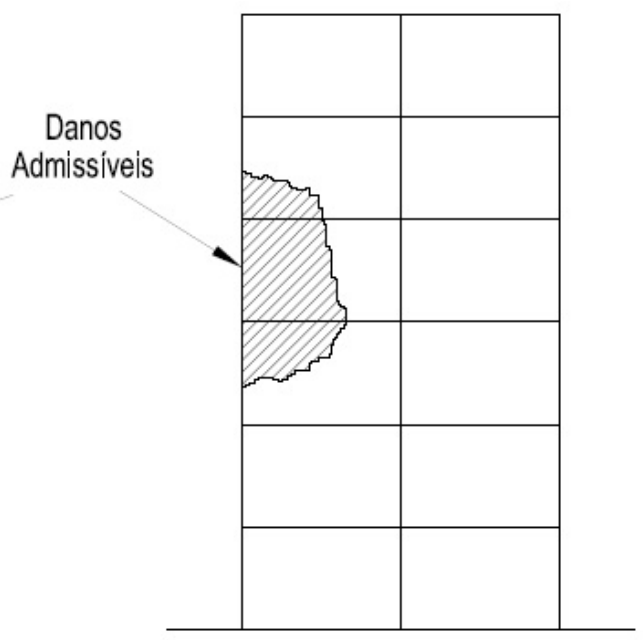

PERFIL VERTICAL

Fonte: Eurocode 1 (2003). 
Os pesquisadores Kousgaard e Erdogmus (2015), Dat, Hai e Jun (2015) e Stevens et al. (2011) citam que atualmente o documento que mais detalha o colapso progressivo é a UFC 4-023-03 (2009). Entretanto, esse documento é mais adequado para estruturas aporticadas, em que a perda de um pilar instantaneamente em um eventual dano acidental é o principal fator da ocorrência de um colapso.

Em se tratando do colapso progressivo, o mesmo é definido como a propagação de uma falha localizada que leva ao colapso total ou parcial de uma estrutura. Segundo os autores Starossek e Haberland (2008), Ellingwood (2005) e ASCE 7 (2005) o colapso progressivo é um tipo de ruptura incremental, no qual o dano total é desproporcional à causa inicial, isto porque o estado final da ruptura é desproporcionalmente maior do que a severidade do evento inicial. Para os pesquisadores Haberland e Starossek (2009) o colapso progressivo é a destruição consecutiva da estrutura, devido um dano inicial de um elemento que leva à ruína da estrutura ou parte dela. O mesmo pode ocorrer por erros de projeto, erros de construção e ações excepcionais.

Ellingwood e Dusenberry (2005) e Dusenberry e Juneja (2002) afirmam que projetos específicos que garantam segurança a danos acidentais não foram padronizados nos Estados Unidos e nem em outro lugar do mundo. Contudo, os códigos e as normas que tratam sobre colapso progressivo abordam de forma qualitativa ${ }^{1}$ este assunto.

Em se tratando do colapso progressivo em edifícios de alvenaria estrutural, há uma insuficiência de informações, pois os trabalhos que tratam sobre o tema não mostram os procedimentos necessários para minimizar a sua ocorrência. Essas insuficiências de informações se devem à dificuldade de avaliação do comportamento frágil, heterogêneo e anisotrópico da alvenaria (KOUSGAARD; ERDOGMUS, 2015).

Um dos primeiros trabalhos a tratar sobre o colapso progressivo em estruturas de alvenaria foi o de McGuire (1974), no qual, através da norma inglesa da época, foi realizado um estudo de caso sobre o colapso progressivo em um edifício de alvenaria na prevenção de danos acidentais. O referido autor recomenda que a estrutura seja analisada através do método dos caminhos alternativos e do método da resistência local especifica ${ }^{2}$. Breen (1976) enfatiza que estruturas de alvenarias são mais susceptíveis na ocorrência de um dano acidental. Isto devido à falta de continuidade e ductilidade desse sistema estrutural, além da falta de estabilidade na perda de duas paredes. O mesmo recomenda o fortalecimento do efeito de membrana como uma medida para diminuir o risco de colapso progressivo. Contudo, é necessário a introdução de tirantes ancorados entre os elementos estruturais nas direções vertical, horizontal e periférica.

Hendry (1981) fez um estudo das concepções estruturais dos edifícios de alvenaria da época quanto aos danos acidentais, tendo verificado três casos básicos de detalhes de

1 Recomendações para aumentar a robustez da estrutura.

2 Estes métodos serão abordados na seção 4.3. 
construção, conforme mostrado na Figura 3, que necessitam de uma atenção especial por parte do projetista estrutural: a) parede externa sem flanges, b) parede interna sem flanges e c) uma grande concentração de tensão em uma pequena área de outras paredes quando da remoção de uma parede.

Figura 3 - Detalhes de construção que necessitam de uma atenção especial em edifícios de alvenaria estrutural em relação a danos acidentais.

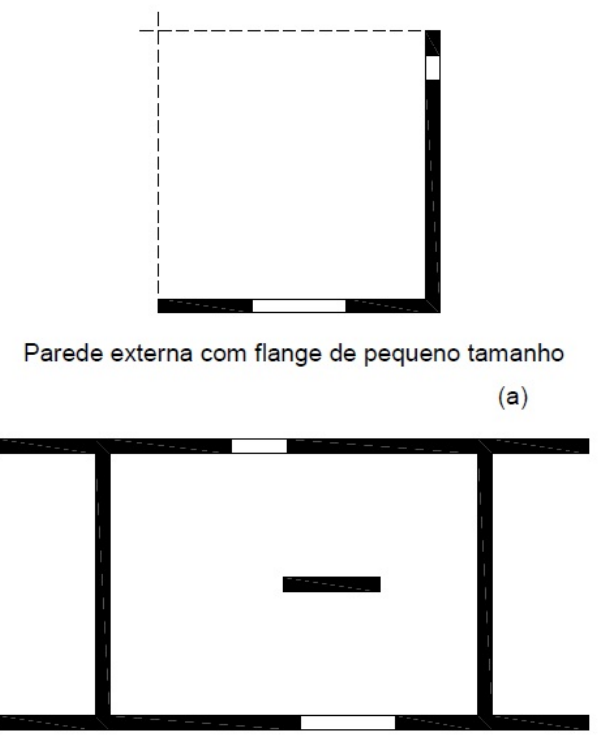

(b)
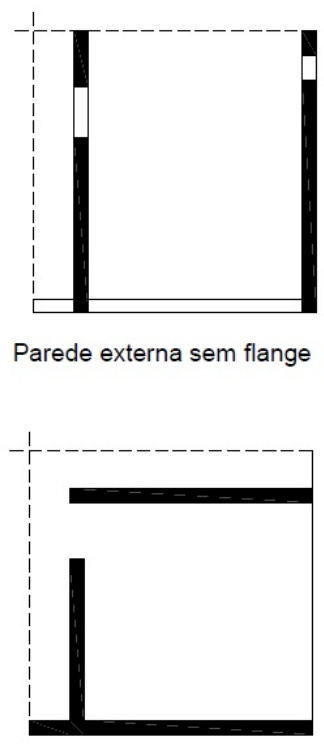

(c)

Fonte: Adaptado de Hendry (1981).

Ellingwood, Leyendecker e Yao (1983) e Ellingwood, Leyendecker e Yao (1984) através de uma análise de confiabilidade estrutural, realizaram um estudo de caso para um edifício de oito pavimentos de alvenaria de bloco cerâmico quando o mesmo é submetido a uma explosão de um botijão de gás no oitavo pavimento. Os referidos autores calcularam a probabilidade de falha da estrutura considerando o modo de falha das paredes estruturais por flexo-compressão. Os mesmos concluíram que a falta de continuidade e ductilidade das estruturas de alvenaria tornam as mesmas susceptíveis ao colapso progressivo.

Com as preocupações relativas a ataques terroristas nas edificações vários pesquisadores (SMITH; P; GOODE, 2010; WU; HAO, 2007; LUCCIONE; AMBROSINI; F, 2004; CORLEY et al., 1998; LONGINOW; MNISZEWSKI, 1996; YOKEL; WRIGHT; STONE, 1989) começaram a estudar o comportamento das estruturas quando submetidas a explosões. Esses estudos em geral, restringem-se a estruturas de concreto e estruturas metálicas.

Em relação a estruturas de alvenaria, em 2013 um grupo de pesquisa da Universidade de McMaster, Canadá, realizou ensaios experimentais em três paredes armadas de alvenaria para identificar sua resposta quando submetida a uma explosão. Estas paredes foram 
comparadas com paredes convencionais submetidas às mesmas cargas de explosão. O nível de deformação permanente foi significativamente menor nas paredes armadas, indicando a sua capacidade de prevenção de colapso progressivo (EL-DAKHAKHNI et al., 2013).

Para o melhor entendimento sobre o colapso progressivo em edifícios, os tópicos a seguir mostram de forma sucinta os seus pontos principais.

\title{
4.1 Tipos de colapso progressivo
}

No dimensionamento de uma edificação, o projetista estrutural deve levar em consideração todas as possíveis combinações de ações descritas na ABNT NBR 8681 (2004). Entretanto, a referida norma não traz os coeficientes de ponderação de ações que levem em considerações os danos acidentais ou colapso progressivo na estrutura. Isto implica, que em um eventual incremento de carga devido aos danos acidentais nas envoltórias de ações da estrutura, aumente a probabilidade de ocorrência de colapso local e/ou global da edificação.

Conforme (DIMAS, 2014, p.5):

\begin{abstract}
A capacidade de uma estrutura não colapsar, de uma forma catastrófica, quando solicitada por uma carga acidental, depende de vários fatores: o tipo de ação, a localização da ação acidental na estrutura em relação aos seus elementos estruturais, o tipo de sistema estrutural e a tecnologia de construção.
\end{abstract}

O colapso progressivo pode ser classificado em quatro tipos, são eles: dominó, seção, instabilidade e misto. Entretanto, Johan (2010) e Starossek (2009), subdividem o colapso do tipo dominó em pancake e zipper.

Em se tratanto do colapso tipo dominó, este é baseado no efeito dominó, em que o colapso da estrutura tem origem numa reação em cadeia com a falha sequencial devida à separação dos elementos estruturais (DIMAS, 2014; STAROSSEK, 2009).

O aumento das tensões em algumas seções de elementos estruturais nas edificações que estão sujeitos a esforço cortante pode levar à ruptura de uma parte da seção transversal do elemento, podendo ocorrer a propagação por toda a seção transversal, este tipo de colapso é denominado seção (DIMAS, 2014; STAROSSEK, 2009).

Imperfeições em elementos estruturais podem gerar instabilidade na estrutura de uma edificação que podem dar início a um colapso progressivo, denominado colapso tipo instabilidade. Este tipo de catástrofe, com falhas dos elementos estruturais e consequentemente ruptura da estrutura, com uma grande probabilidade de perdas humanas e onerosos danos financeiros à sociedade, mostra claramente que se precisa de uma melhor modelagem das edificações para representar a real resposta da estrutura diante dos carregamentos impostos (DIMAS, 2014; OLIVEIRA, 2002). 
Em se tratando da instabilidade da estrutura, pode-se de modo simplista definir que é caracterizada por pequenas imperfeições que acarretam grandes deformações ou mesmo o colapso da edificação. Essa pode ser classificada em dois tipos: global e local. A instabilidade global é aquela que é verificada na estrutura como um todo. Já a instabilidade local, é verificada para um elemento isolado da estrutura.

Um aspecto importante nos problemas gerados pelo colapso progressivo é o comportamento não linear das estruturas, pois quando essas estão sujeitas a esse evento sofrem grandes deformações e grandes rotações, fazendo com que uma análise linear não mostre o real comportamento das mesmas.

O comportamento não linear de uma edificação é influenciado pelas não linearidades que a estrutura está submetida, são elas: a não-linearidade física e a não-linearidade geométrica. A não-linearidade física (NLF) está relacionada com o comportamento não linear dos materiais, ou seja, as propriedades dos materiais envolvidos em projetos de edificações têm uma resposta não linear, como por exemplo, o aço e o concreto. Já nãolinearidade geométrica (NLG) está relacionada com o comportamento da estrutura como um todo, pois consiste na necessidade de se formular a condição de equilíbrio considerandose a sua posição deformada (PROENÇA, 2016). Como essas não-linearidades influenciam diretamente na determinação da rigidez da estrutura, a análise do comportamento de instabilidade e do colapso progressivo requerem a consideração de uma análise não linear.

Finalmente o colapso tipo misto, na qual é atribuído à estrutura, onde um ou mais modos de ruptura podem estar associados a diferentes tipos de colapso, ou seja, envolvem combinações de diferentes colapsos citados anteriormente (DIMAS, 2014; STAROSSEK, 2009).

\subsection{Requisitos fundamentais para à prevenção contra o colapso progressivo}

No projeto de uma edificação, o projetista estrutural deve considerar a atuação das cargas permanentes, variáveis e excepcionais nas combinações de ações majoradas pelos coeficientes parciais de segurança descritos por norma.

Nas combinações de ações que considerem a ocorrência das ações excepcionais, como por exemplo, projetos para ação de sismos, a variabilidade nos coeficientes de segurança adotados para majorar os esforços solicitantes, já oferece uma margem de segurança contra pequenos danos acidentais. Contudo, o projetista estrutural, na concepção da estrutura, deve garantir que esta possua redundância, resistência e ductilidade suficiente para evitar o fenômeno do colapso progressivo.

Apesar de tal fenômeno ter baixa probabilidade de ocorrências nas edificações, este 
pode envolver uma quantidade elevada de vidas humanas e grande danos físicos. Por isso, a filosofia de prevenção contra esse efeito é realizada com o propósito fundamental de salvar vidas ao projetar estruturas que tenha robustez para reduzir a extensão dos danos, evitando o colapso progressivo do edifício, pelo menos até que as pessoas tenham sido evacuadas (BITTARELLO, 2013).

Devido à baixa probabilidade de ocorrência de uma ação excepcional na estrutura de uma edificação, por razões econômicas, os projetistas estruturais abordam medidas de proteção passiva ${ }^{3}$ em vez da consideração desta ação nas envoltórias de esforços da estrutura.

Na literatura o termo robustez aparece com frequência em publicações e debates como uma forma de minimizar os danos causados pelo colapso progressivo. Entretanto, Chen et al. (2016), Brett e Lu (2013) afirmam que ainda não há nenhum acordo geral sobre o significado preciso deste termo. Isto devido às incertezas nos danos acidentais e na verificação da capacidade da estrutura resistir a um dano local.

Robustez refere-se a capacidade de uma edificação não reagir desproporcionalmente a um dano acidental ou inicial. É definida como a insensibilidade da estrutura na ocorrência da perda de um elemento estrutural, propriedade que depende da estrutura e da quantidade de dano inicial. O evento complementar da robustez é a vulnerabilidade, sendo definido como a sensibilidade da estrutura a um dano local (CHEN et al., 2016; BRETT; LU, 2013). Conforme Lind (1995), vulnerabilidade é a falta de tolerância de dano, que é definida como a tolerância de danos imprevistos ou não considerados no projeto. Uma estrutura é vulnerável se pequenos danos levam a desproporcionalidades grandes.

O colapso progressivo, portanto, está intimamente associado com o evento (dano acidental), com a vulnerabilidade e robustez da estrutura, sendo uma forma de entender o problema fisicamente.

Conforme mostrado na Figura 4, esse evento pode ser dividido em quatro estágios, são eles: estágio inicial (ESI), estágio inicial de dano (ESID), estágio de propagação de dano (ESPD) e estágio de colapso progressivo (ESCP) (CHEN et al., 2016).

Cada estágio tem uma característica particular. No ESI a estrutura está íntegra. No ESID a ocorrência do dano é praticamente instantânea, ou seja, a perda de um elemento estrutural neste estágio não provoca deslocamentos excessivos na estrutura.

3 Medidas que aumentem a continuidade e dutilidade local da estrutura por introdução de tirantes ancorados ao longo de alguns elementos estruturais pré-definidos (UFC 4-023-03, 2009; NISTIR 7396, 2007; ASCE 7, 2005; BS 5628-1, 1992). 
Figura 4 - Estágios da ocorrência do colapso progressivo.

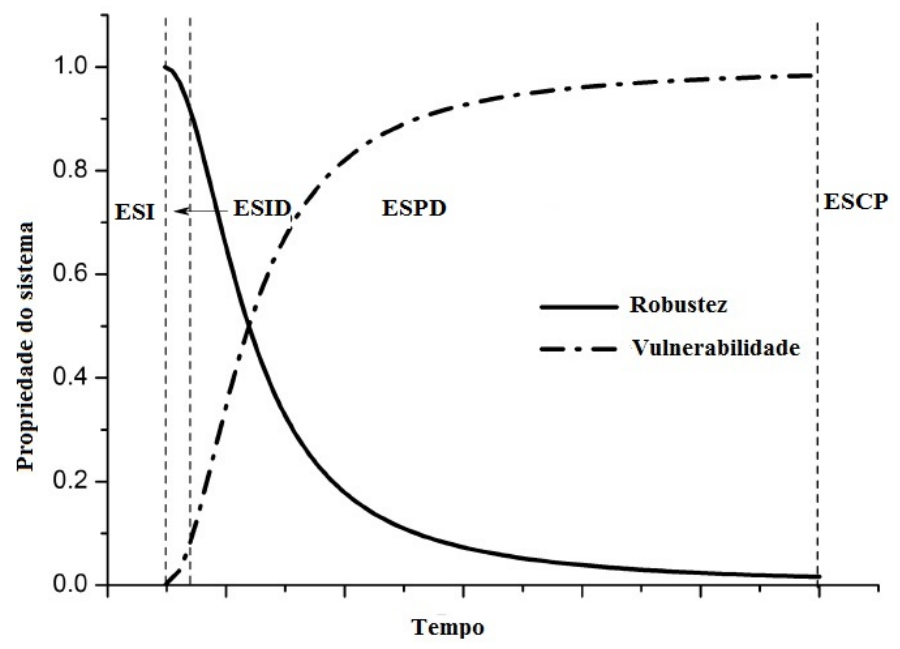

Fonte: Adaptado de Chen et al. (2016).

No ESPD a estrutura vai redistribuir os esforços e procurar uma nova posição de equilíbrio. Neste caso, a vulnerabilidade e robustez têm um papel fundamental na maximização ou minimização do ESCP, respectivamente. A vulnerabilidade está associada com as consequências diretas (danos locais), enquanto que a robustez está associada com as consequências indiretas (danos globais). A Figura 5 mostra um esquema sucinto das etapas que forma o ESCP.

Figura 5 - Esquema com as etapas do ESCP.

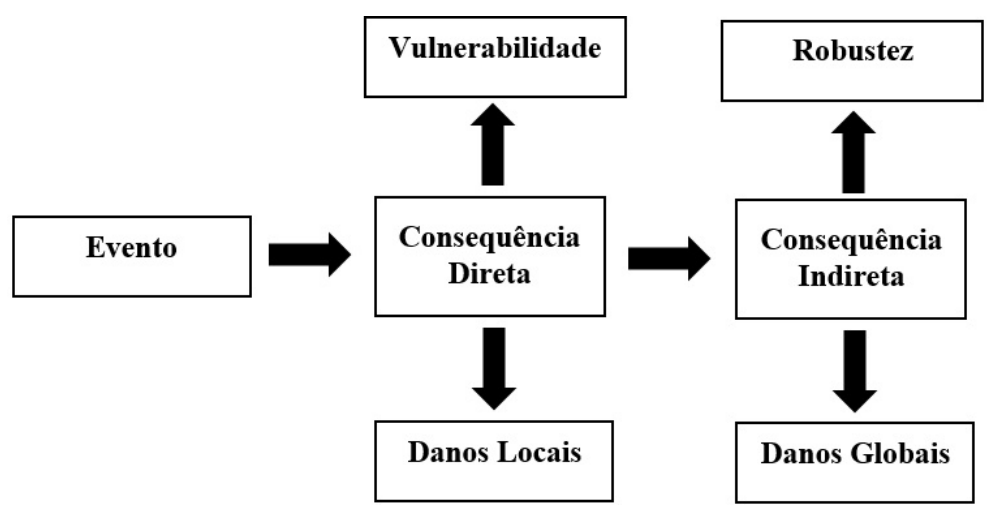

Fonte: Autoria própria.

Como é praticamente impossível eliminar todos os danos acidentais que possa vir a ocorrer durante a vida útil da edificação. Muitos pesquisadores começaram a estudar formas de definir critérios através da definição de coeficientes de vulnerabilidade e coeficientes de robustez (CHEN et al., 2016; BRETT; LU, 2013; STAROSSEK et al., 2011; STAROSSEK; 
HABERLAND, 2010; BAKER; SCHUBERT; FABER, 2008; BIONDINI; FRANGOPOL; RESTELLI, 2008; STAROSSEK; HABERLAND, 2008; DUTUIT; RAUZY, 2001; FU; FRANGOPOL, 1990; FRANGOPOL; CURLEY, 1987). Contudo, os critérios ainda não estão bem definidos. Isso porque, existem incertezas atreladas aos danos acidentais e à capacidade da estrutura resistir a um colapso.

Na literatura uma expressão teórica para a probabilidade do risco do colapso progressivo é dado pela Equação 4.2 (STAROSSEK et al., 2011; ELLINGWOOD, 2009; ELLINGWOOD et al., 2009; STAROSSEK; HABERLAND, 2008; NISTIR 7396, 2007). Esta expressão pode ser deduzida a partir da definição de risco. O risco associado a um determinado evento é definido como o produto direto da probabilidade de ocorrência do evento $(P[E])$, pelas suas consequências $(C[E])$, sendo expresso pela seguinte equação:

$$
\operatorname{risco}[E]=P[E] \cdot C[E]
$$

A consequência do colapso progressivo vai depender da vulnerabilidade da estrutura $(P[D \mid E])$, bem como da sua robustez $(P[$ colapso $\mid D E])$. Logo, a Equação 4.1 pode ser escrita como:

$$
P[\text { colapso }]=\underbrace{P[\text { colapso } \mid D, E]}_{\text {Robustez }} \cdot \underbrace{P[D \mid E]}_{\text {Vulnerabilidade }} \cdot \underbrace{P[E]}_{\text {Evento }}
$$

em que, $D$ é um evento severo que causa dano a estrutura e $E$ é a frequência da ocorrência anual deste evento definida pela função hazard.

A Equação 4.2 só pode ser utilizada para um evento pré-definido. Como também a determinação do termo $P[$ colapso $\mid D, E]$ não é trivial. Na prática, a literatura adota para essa um valor $P[$ colapso $]=10^{-7} /$ ano (NISTIR 7396, 2007; PATE-CORNELL, 1994).

Um aspecto importante no projeto de um edifício que traz uma relevante contribuição à prevenção do colapso progressivo é a forma da edificação. Uma forma regular, modular, com disposição uniforme dos pilares tem efeito favorável na prevenção deste fenômeno (LARANJEIRAS, 2011). Isso porque, a regularização e a modulação no projeto estrutural contribuem para a redundância e continuidade da estrutura.

No caso das estruturas de alvenaria, sua modulação e rigidez contribuem na prevenção do colapso progressivo, pois, em geral são estruturas de baixa deslocabilidade e apresentam um efeito favorável conhecido como efeito arco que confere à alvenaria a capacidade de redistribuição de esforços (HAACH, 2015).

O documento NISTIR 7396 (2007) prescreve que os atributos fundamentais para garantir robustez a um sistema estrutural são: redundância, continuidade, ductilidade e capacidade para resistir à inversão de esforços.

A redundância é caracterizada pela possibilidade de redistribuição de esforços por caminhos de cargas alternativos quando um elemento estrutural sofre um colapso. Um 
exemplo de uma estrutura redundante localizada em nosso território é a ponte estaiada sobre o Rio Pinheiros em São Paulo (Figura 6), na qual a perda da capacidade de um dos estais oferece alternativas para a redistribuição de esforços. Uma outra estrutura redundante, com uma grande quantidade de alternativas de redistribuição de esforços, no caso da ruptura de um de seus elementos estruturais, é a estrutura da pista do aeroporto da Ilha da Madeira, conforme mostrado na Figura 7, (LARANJEIRAS, 2011).

Figura 6 - Ponte sobre o Rio Pinheiros em São Paulo.

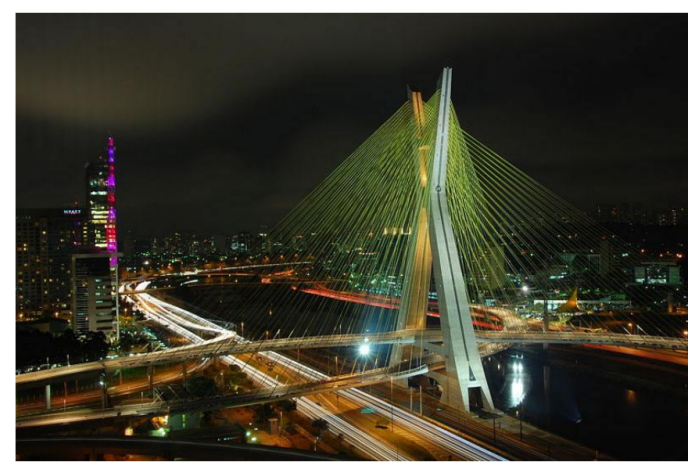

Fonte: Laranjeiras (2011).

Figura 7 - Estrutura do aeroporto da Ilha da Madeira.

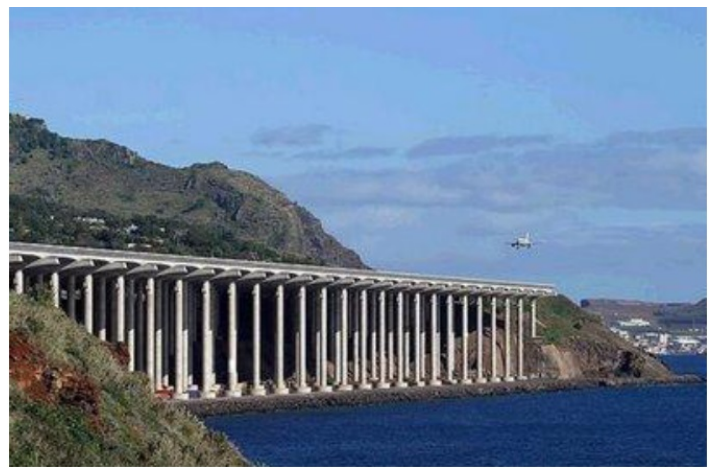

Fonte: Laranjeiras (2011).

A continuidade é o mecanismo que proporciona a redistribuição de esforços entre as ligações dos elementos estruturais após um colapso. Assim, a continuidade se relaciona com o monolitismo e com a hiperestaticidade da estrutura, ou seja, com a conectividade entre os seus elementos (LARANJEIRAS, 2011). Estes atributos garantem a interconexão entre lajes, pilares e vigas com uma melhor redistribuição de esforços no caso de um colapso localizado.

Entretanto, Dimas (2014) e Nair (2007) advertem que um sistema estrutural só será eficiente se houver uma combinação entre as características de redundância e conti- 
nuidade. Isso porque, mesmo uma estrutura com uma grande redundância de apoios não é suficientemente eficaz se não garantir uma completa continuidade ao mesmo tempo, visto que, em caso de danos acidentais ou colapso progressivo não possibilitará a redistribuição de esforços. Um exemplo são as estruturas pré-moldadas, em que a falta de continuidade das ligações as tornam susceptíveis ao colapso progressivo.

Quando uma edificação perde um elemento estrutural, espera-se que haja uma transferência de cargas para os outros elementos mantendo-se integridade da estrutura, mesmo que seja acompanhada de grandes deformações. A capacidade de uma estrutura suportar grandes deformações antes de colapsar é definida como ductilidade (LARANJEIRAS, 2011).

Pode-se citar como exemplo, o confinamento do concreto dos pilares, que garante uma elevada ductilidade próximo às emendas e conexões entre os elementos estruturais, transformando o comportamento do concreto de frágil, na ruptura, em dúctil (LARANJEIRAS, 2011). Outro aspecto importante é a utilização de pilares cintados, pois sua alta ductilidade favorece na prevenção do colapso progressivo. A NP EN 1992-1-1 (2010) no item 9.10.1 prescreve que as edificações que não são dimensionadas para resistir a danos acidentais devem ser dotadas de sistema de cintagem adequada para possibilitar as trajetórias de caminhos alternativos de cargas.

\subsection{Introdução aos métodos de prevenção contra o colapso pro- gressivo}

O projeto de uma estrutura envolve uma série de incertezas relacionadas com as resistências dos materiais utilizados, como também com ações adotadas pelo projetista. Assim, o engenheiro ao projetar uma edificação assume riscos. Tais riscos devem ser minimizados, pois são eventos potencialmente perigosos e sua prevenção tem como objetivo fundamental salvar vidas.

O NISTIR 7396 (2007) menciona que a probabilidade de ocorrência de uma ação excepcional ou do colapso progressivo em uma estrutura não deve ser um parâmetro eficaz na tomada de decisão por parte do projetista estrutural. Isso porque a baixa probabilidade de ocorrência de tais eventos não reflete os graves riscos de perdas humanas e ao impacto na sociedade quando ocorre uma ação excepcional ou colapso progressivo. Entretanto, projetar uma estrutura com a consideração de risco nulo, torna-se inviável do ponto de vista econômico e técnico, pois, como citado anteriormente neste trabalho, é impossível quantificar e prevenir todas as ações excepcionais a que uma estrutura possa estar submetida.

$\mathrm{Na}$ ocorrência de um acidente de grandes proporções, como por exemplo, no que 
ocorreu no Edifício Liberdade, na cidade do Rio de Janeiro em 2012, o projetista estrutural deve garantir que a estrutura possua uma probabilidade de falha aceitável para não atingir rapidamente a ruína, pelo menos até que todos os ocupantes tenham sido evacuados.

Entretanto, qual a probabilidade de falha aceitável? Segundo o NISTIR 7396 (2007), Ellingwood (2006) e Pate-Cornell (1994) uma probabilidade de falha alvo de $10^{-7}$, considerando a ocorrência anual do colapso da estrutura, é suficiente.

NISTIR 7396 (2007) e Corrêa e Ramalho (2004) destacam três procedimentos empregados para reduzir a probabilidade de ocorrência do colapso progressivo podendo haver combinação entre eles.

a) reduzir o risco da ocorrência de ações excepcionais. Esse procedimento deve ser sempre realizado pelos projetistas estruturais, contudo, seu alcance é limitado, visto que, não se consegue eliminar a possibilidade de ocorrência de tais ações;

b) projetar a estrutura para suportar as ações excepcionais. Esse procedimento não é normalmente utilizado, pois quantificar e prevenir as ações excepcionais é de difícil realização, além do mais, ficaria praticamente impossível dimensionar uma estrutura submetida a todas as ações excepcionais e extremamente oneroso;

c) prevenir a propagação de uma possível ruína localizada. Neste procedimento, o mais empregado em normas regulamentadoras de projeto, e o que é mais usual pelo meio técnico, parte-se das abordagens do projeto indireto e/ou projeto direto, garantindo maior integridade ao sistema estrutural.

As estratégias de prevenção do colapso progressivo dependem das suas consequências. Neste sentido, as edificações podem ser classificadas em classes de consequência (UFC 4-023-03, 2009):

a) classe I - consequências limitadas, edificações até 4 andares: sem requisitos específicos;

b) classe II - consequência média, edificações até 5 andares: método da força de amarração;

c) classe III - consequência alta, edificações até 15 andares: estratégia do projeto direto;

d) classe $\mathrm{V}$ - consequência muito alta, edificações acima de 15 andares: abordagem do projeto direto e método da força de amarração.

Os documentos, UFC 4-023-03 (2009), STO (2009), NISTIR 7396 (2007), ASCE 7 (2005) e GSA (2003), que tratam sobre o colapso progressivo, prescrevem duas abordagens para projetar estruturas de edifícios: Projeto indireto e o Projeto direto. A seguir são discutidas estas abordagens. 


\subsubsection{Projeto indireto}

O projeto indireto consiste em prever requisitos mínimos de redundância, continuidade, ductilidade e resistência à inversão de esforços. Quando um projetista utiliza uma norma técnica considerando todas as suas especificações e produz um projeto com disposição uniforme dos elementos estruturais, indiretamente, o mesmo está contribuindo na redundância, continuidade e ductilidade da estrutura. Contudo, as recomendações do projeto indireto não garantem por si só a integridade estrutural no eventual colapso progressivo da estrutura. Dentro do projeto indireto o projetista ainda pode utilizar o Método da Força de Amarração, que estabelece que os elementos estruturais devam estar interligados entre si através de tirantes, aumentando a capacidade de redistribuição de esforços.

Para mobilizar os caminhos alternativos de transferência das cargas no caso de uma ruptura localizada de um elemento estrutural, o projetista deve utilizar armaduras adicionais ancoradas nos elementos estruturais, não prevista no dimensionamento usual da estrutura (EL-DEBS, 2000). O documento UFC 4-023-03 (2009) descreve que as amarrações em uma estrutura podem ser divididas em: longitudinal, transversal, periférica e vertical, conforme a disposição dada na Figura 8.

Figura 8 - Tipos de amarrações incorporadas à estrutura para prover a integridade estrutural.

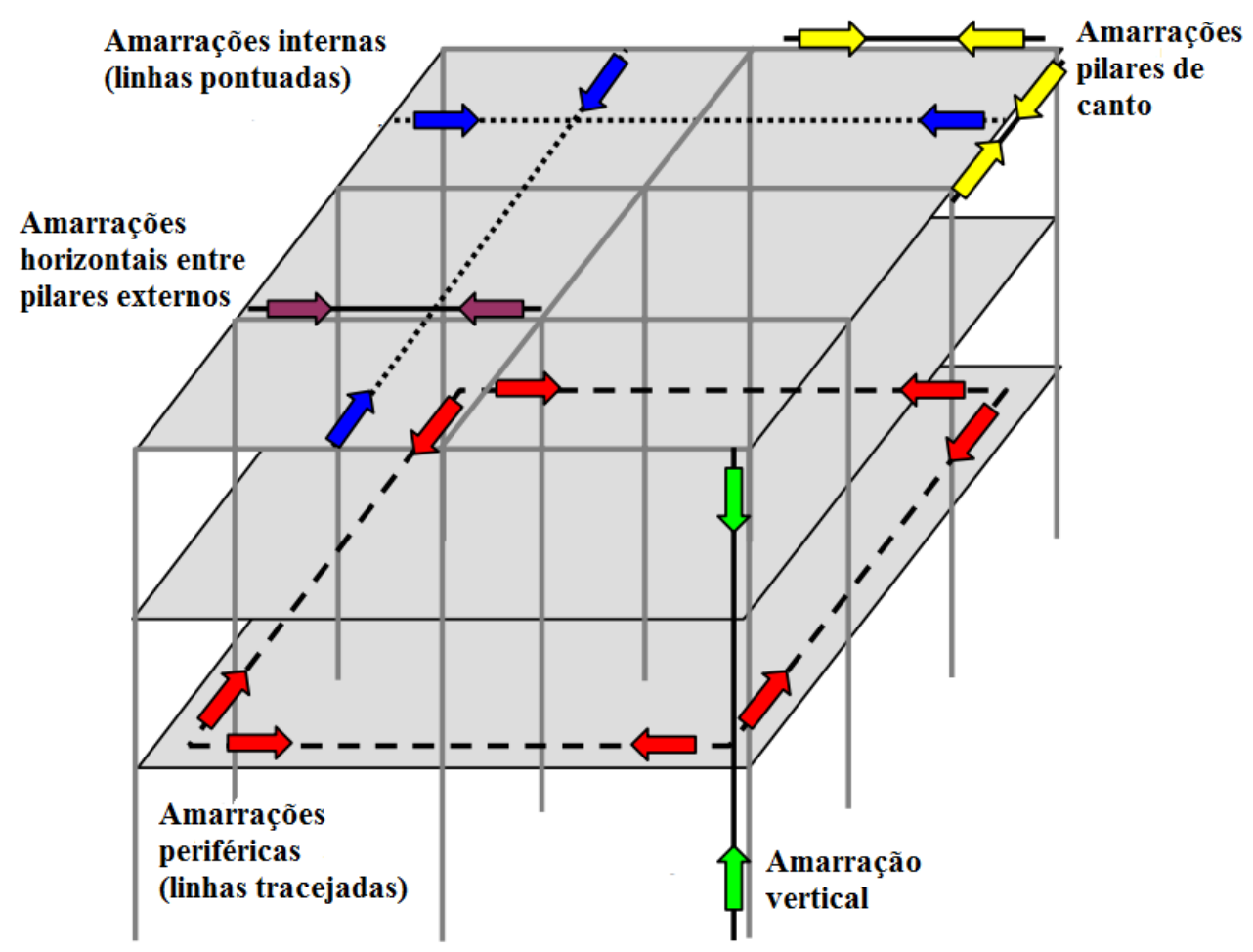

Fonte: UFC 4-023-03 (2009). 
Para utilizar este método o projetista estrutural deve fazer a seguinte verificação de estado limite último:

$$
\varphi \cdot R_{n} \geq R_{u}
$$

em que: $\varphi$ é o fator de redução da resistência, $R_{n}$ é a resistência de amarração nominal, calculada a partir das recomendações dos capítulos 5 a 8 da norma ASCE 41 (2006) e $R_{u}$ é a resistência de amarração requerida.

Para um carregamento uniforme por andar, a resistência de amarração requerida em $\left(k N / m^{2}\right)$ é determinada pela seguinte combinação de ações:

$$
w=1,2 \cdot F_{g}+0,5 \cdot F_{q}
$$

sendo, $w$ a carga por andar em $\left(k N / m^{2}\right), F_{g}$ o carregamento permanente em $\left(k N / m^{2}\right)$ e $F_{q}$ o carregamento variável em $\left(k N / m^{2}\right)$. Partindo da laje mostrada na Figura 9 , pode-se deduzir uma expressão para o cálculo da resistência de amarração requerida na situação limite, considerando a posição deformada da laje após a perda do apoio no ponto B, ver Figura 10.

Figura 9 - Perda do apoio B.

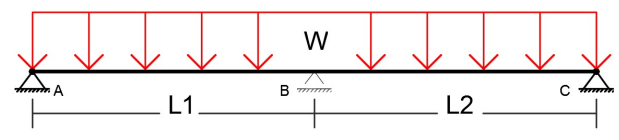

Fonte: Autoria própria.
Figura 10 - Posição da deformada após a perda do apoio B.

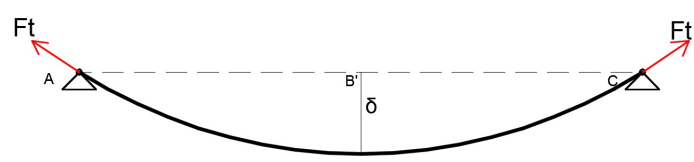

Fonte: Autoria própria.

Fazendo o equilíbrio dos momentos no ponto B' (Figura 10), obtém-se:

$$
F_{t}=\frac{w \cdot\left(L_{1}+L_{2}\right)^{2}}{8 \cdot \delta}=R_{u}
$$

A armadura necessária para garantir continuidade pelos apoios é calculada pela seguinte expressão:

$$
A_{s}=\frac{F_{t}}{f_{y d}}
$$

\subsubsection{Projeto direto}

O projeto direto consiste em dimensionar elementos estruturais principais para resistir ao aumento da capacidade de cargas e a transferência de esforços quando estão sujeitos a um dano acidental. Neste caso, necessita-se realizar uma análise da estrutura na perda instantânea de um elemento estrutural pré-definido. Esta visa determinar o comportamento da estrutura quando submetida a um dano acidental, buscando determinar as deformações e tensões resultantes nos elementos estruturais. 
A aplicação do projeto direto pode ser resumida em duas hipóteses, são elas: aumentar a resistência de alguns elementos estruturais para suportar as solicitações de um dano acidental, essa hipótese se enquadra no Método da Resistência Local Específica (MRLE), e dimensionar a estrutura considerando caminhos de cargas no caso de um colapso localizado, neste caso, tem-se o Método dos Caminhos Alternativos (MCA).

\subsubsection{Método da resistência local específica}

O método da resistência local específica é indicado na verificação do colapso progressivo para uma causa pré-definida. Nesse caso, o projetista realiza os cálculos dos esforços dos elementos estruturais considerando nas combinações de ações os seus respectivos efeitos, como por exemplo, ataques terroristas, explosões, incêndios e terremotos.

Segundo Leyendecker e Ellingwood (1977) uma forma de implementar esse método é simplesmente aumentar os coeficientes parciais de segurança sobre as cargas usuais de projeto. Entretanto, o aumento dos coeficientes parciais de segurança pode não ser uma solução adequada. Isto porque quando a estrutura está submetida a um colapso, os modos de falha podem ser diferentes daqueles considerados inicialmente para calibrar os coeficientes, ou seja, torna-se irrelevante o seu aumento para o modo de falha atual.

Conforme o documento NISTIR 7396 (2007), no dimensionamento de uma estrutura baseado neste método é necessário recorrer a uma análise não linear dinâmica. Por esse motivo, um projeto utilizando o MRLE é normalmente pouco prático, sendo uma solução mais viável para estruturas que no seu dimensionamento considerem as ações devidas a ataques terroristas.

\subsubsection{Método dos caminhos alternativos}

O método dos caminhos alternativos centra-se na avaliação da redistribuição de esforços depois que um elemento estrutural previamente escolhido é retirado da estrutura. A sua retirada visa analisar o comportamento da estrutura de forma integral. O MCA é um método de cálculo eficiente ao assegurar redundância ao sistema estrutural.

O colapso localizado que é utilizado para projetar a estrutura por esse método, consiste na retirada de um elemento de apoio de forma a estabelecer caminhos alternativos de cargas. A retirada deste elemento independe da ação excepcional atuante na estrutura. Entretanto, o documento UFC 4-023-03 (2009) enfatiza que a aplicação deste método deve ser analisada através de um modelo tridimensional da estrutura.

El-Debs (2000) descreve dois exemplos que ocorrem em estruturas pré-moldadas que se encaixam no MCA: o primeiro é a ação de balanço em viga e o segundo é a ação de membrana.

Em se tratando da ação de balanço, essa ocorre, por exemplo, quando um pilar de 
canto venha a ruir ou quando o painel pré-moldado não apresente mais função estrutural, conforme apresentado na Figura 11. Ao ocorrer esses eventos, a viga da estrutura localizada na parte superior inverte o sentido dos esforços, ou seja, o esforço que antes seria resistido pela armadura positiva é agora suportado pela armadura negativa, alterando com isso o caminho das cargas na viga.

Figura 11 - Ação de balanço em uma edificação pré-moldada.

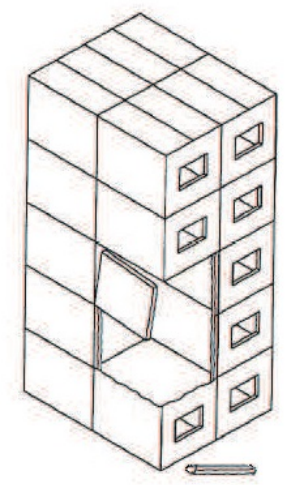

Fonte: El-Debs (2000).
Figura 12 - Ação de membrana em uma edificação pré-moldada.

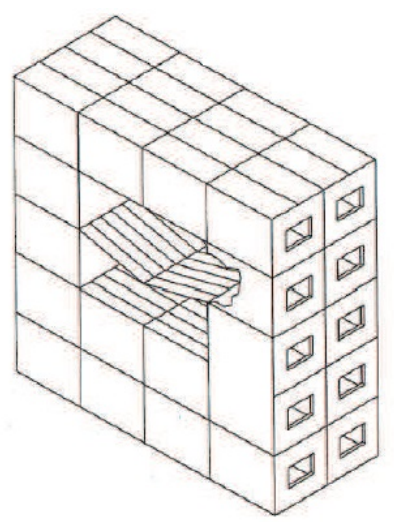

Fonte: El-Debs (2000).

No caso da ruína de um pilar central ou de um pilar intermediário, a ação de membrana seria um mecanismo responsável por minimizar o colapso progressivo das lajes ou vigas internas que perderiam estes apoios, conforme a Figura 12. Contudo, o projetista precisa calcular através da Equação 4.6, a armadura necessária de continuidade nos apoios com vista a evitar o colapso de elementos adjacentes.

Conforme os documentos UFC 4-023-03 (2009) e GSA (2003) três procedimentos de análises podem ser empregados para avaliação do MCA, são eles: análise estática linear, análise estática não linear e análise não linear dinâmica. Independente da análise considerada, é necessário avaliar o critério de aceitação das referidas normas. Essa avaliação é realizada pela relação demanda-capacidade (Demand-Capacity Ratios - DCR), que consiste em determinar um valor adimensional entre a relação do esforço atuante no elemento pela capacidade resistente máxima do elemento, definida pela seguinte equação:

$$
D C R=\frac{Q_{U D, \text { Lim }}}{Q_{C E}}
$$

sendo, $Q_{U D, \text { Lim }}$ as ações resultantes (esforços internos) nos elementos estruturais após aplicar o MCA e $Q_{C E}$ a resistência esperada dos elementos estruturais. De acordo com GSA (2003), os limites desta relação são os seguintes: $D C R \leq 2,0$ para configuração estrutural típica; $D C R \leq 1,5$ para configuração estrutural atípica. 
O valor do DCR deve estar no intervalo limitado entre 1,0 e 2,0. Portanto, os elementos que estiverem fora desses limites têm uma alta probabilidade de ocorrência de colapso progressivo.

Para avaliar a Equação 4.7 o projetista deve realizar separadamente uma verificação no controle da deformação e uma verificação no controle dos esforços. Estas verificações são determinadas a partir de duas combinações de ações, a primeira na região de influência da aplicação do MCA e a segunda no restante da estrutura. A região de influência é dada pela região dos elementos adjacentes ao elemento removido em todos os andares acima desse elemento, como ilustrado na Figura 13.

Figura 13 - Região de influência para as combinações de ações.

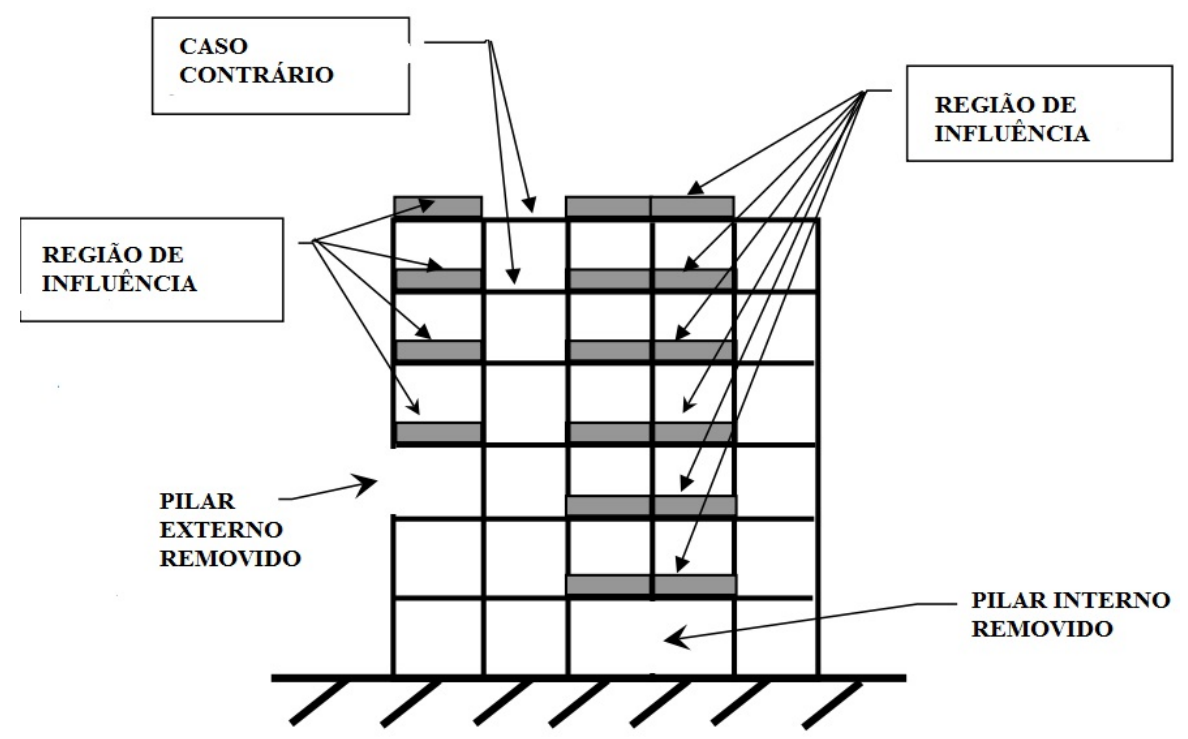

Fonte: UFC 4-023-03 (2009).

No caso da verificação do controle da deformação, o documento UFC 4-023-03 (2009) prescreve as seguintes combinações de ações:

$$
\begin{array}{ll}
G_{L D}=\Omega_{L D} \cdot\left[1,2 \cdot F_{g}+0,5 \cdot F_{q}\right] & (\text { região de influência }) \\
G=1,2 \cdot F_{g}+0,5 \cdot F_{q} & (\text { caso contrário })
\end{array}
$$

Já no caso da verificação do controle dos esforços, o documento UFC 4-023-03 (2009) recomenda as seguintes combinações de ações:

$$
\begin{array}{ll}
G_{L F}=\Omega_{L F} \cdot\left[1,2 \cdot F_{g}+0,5 \cdot F_{q}\right] & (\text { região de influência }) \\
G=1,2 \cdot F_{g}+0,5 \cdot F_{q} & (\text { caso contrário })
\end{array}
$$

em que, $G_{L D}$ é o incremento das cargas devido ao controle da deformação na análise estática linear, $G_{L F}$ é o incremento das cargas devido ao controle dos esforços na análise 
estática linear, $\Omega_{L D}$ e $\Omega_{L F}$ são fatores de aumento das ações, respectivamente, devido ao controle da deformação e ao controle dos esforços, definidos na Tabela 3.4 do documento UFC 4-023-03 (2009).

Para edificações acima de 10 pavimentos ou instalações com configuração atípicas, GSA (2003) enfatiza que o projetista deve ter uma atenção especial, pois nestes casos é necessário fazer uma análise não linear estática e dinâmica para capturar a não linearidade geométrica e a não linearidade física. Dessa forma, levando em consideração de forma simplificada o efeito dinâmico na estrutura devido à remoção instantânea de um pilar, a referida norma propõe uma combinação de carga que deve ser aplicada na estrutura.

$$
F_{d}=2 \cdot F_{g}+0,5 \cdot F_{q}
$$

\subsection{Normas e recomendações}

Atualmente a consideração de danos acidentais e do colapso progressivo nos projetos de novos edifícios tem sido incorporado nos principais documentos normativos. Pode-se citar como exemplo, os documentos norte-americanos UFC 4-023-03 (2009), NISTIR 7396 (2007), ASCE 7 (2005) e GSA (2003) e a norma russa STO (2009), as quais estabelecem recomendações para prevenção do colapso progressivo de estruturas aporticadas.

Em se tratando das estruturas de alvenaria, o documento UFC 4-023-03 (2009) no capítulo 6, prescreve que os edifícios de alvenaria estrutural sejam analisados pelo método da força de amarração e pelo método dos caminhos alternativos descrito, respectivamente, nos itens 3.1 e 3.2 do referido documento.

O documento NISTIR 7396 (2007) no item 4.2.2 prescreve que as estruturas de alvenaria devem possuir armações horizontais periféricas ao longo de todo o perímetro dentro de uma distância nominal na borda da laje ancorada em paredes reentrantes em todos os andares do edifício.

Ainda o referido documento no item 5.2.4 traz as seguintes considerações de projeto que devem ser utilizadas para aumentar a robustez dos edifícios de alvenaria, são elas: amarrações nas paredes para forças fora do plano e armaduras contínuas adicionais em ambas as direções das paredes estruturais. Deve-se ainda fortalecer o comportamento de membrana da laje se possível. E fornecer pelo menos uma barra horizontal ao longo de cada fiada e uma barra vertical em cada célula para que a parede tenha potencial para suportar um eventual dano acidental. Nota-se que este item, em termos econômicos, torna-se impraticável para os edifícios de alvenaria estrutural.

Para a consideração dos danos acidentais o documento ASCE 7 (2005) prescreve as seguintes combinações de ações que devem ser utilizadas para fornecer robustez à estrutura, 
são elas:

$$
\begin{aligned}
& F_{d}=\left(\begin{array}{lll}
0,90 & a & 1,2
\end{array}\right) \cdot F_{g}+0,5 \cdot F_{q} \\
& F_{d}=\left(\begin{array}{lll}
0,90 & a & 1.2
\end{array}\right) \cdot F_{g}+A_{k}+0,5 \cdot F_{q}
\end{aligned}
$$

sendo, $A_{k}$ um dano específico, como por exemplo, explosão ou impacto de veículos.

Os documentos GSA (2003) e STO (2009) concentram suas recomendações em estruturas de concreto, não possuindo nenhum comentário sobre danos acidentais e colapso progressivo em edifícios de alvenaria estrutural.

Uma norma que merece um destaque especial nas recomendações dos danos acidentais e colapso progressivo para estruturas de alvenaria é a norma britânica BS 5628-1 (1992). Esta norma se diferencia de outras por trazer as primeiras especificações para minimizar a ocorrência de danos acidentais. A referida norma na seção 37 prescreve recomendações através do método da força de amarração que devem ser consideradas em projetos para prevenção do colapso progressivo.

Na Tabela 13 da BS 5628-1 (1992) são definidas as resistências necessárias que as armaduras periféricas $\left(T_{p}\right)$ e internas $\left(T_{i}\right)$ das lajes devem resistir, conforme as equações a seguir:

$$
\begin{gathered}
T_{p}(k N) \leq\left\{\begin{array}{l}
60 \\
20+4 \cdot n_{s}
\end{array}\right. \\
T_{i}(k N) \geq\left\{\begin{array}{l}
F_{t} \\
F_{t} \cdot\left(\frac{F_{g}+F_{q}}{7,5}\right) \cdot \frac{z}{5}
\end{array}\right. \\
F_{t}(k N) \leq\left\{\begin{array}{l}
60 \\
20+4 \cdot n_{s}
\end{array}\right.
\end{gathered}
$$

sendo $n_{s}$ o número de andares da edificação, $z$ é o menor valor entre a maior distância entre apoios da laje medida em metros na direção das armaduras ou 5 vezes a altura livre do andar $(\mathrm{H})$. A referida norma ainda recomenda que seja adotada uma armadura horizontal distribuída nas paredes externas. A mesma deve resistir uma força de tração dada pela seguinte equação:

$$
T_{p e}(k N) \leq\left\{\begin{array}{l}
F_{t} \\
\left(\frac{H}{2,5}\right) \cdot F_{t}
\end{array}\right.
$$

Entretanto, a BS 5628-1 (1992) não especifica as recomendações do projeto direto como solução para aumentar a integridade estrutural dos edifícios de alvenaria. 
O Eurocode 1 (2003) descreve que as armaduras verticais nos edifícios de alvenaria, serão consideradas efetivas, se respeitar os seguintes critérios:

a) a espessura das paredes devem ter no mínimo $15 \mathrm{~cm}$ e apresentam resistência à compressão de no mínimo $5 \mathrm{MPa}$;

b) a altura livre da parede $(\mathrm{H})$ deve ser menor que 20 vezes sua espessura (t);

c) armaduras verticais devem ter espaçamento máximo de $5 m$ e não mais que 2,5 $m$ de um extremidade de parede sem restrição;

d) as armaduras verticais devem resistir a uma força de tração dada pela seguinte equação:

$$
T_{v}(k N) \geq\left\{\begin{array}{l}
100 \\
\frac{34 \cdot A}{8} \cdot\left(\frac{H}{t}\right)^{2}
\end{array}\right.
$$

em que, $A$ é a área da parede em planta.

No Brasil, a norma de concreto armado ABNT NBR 6118 (2014) no item 19.5.4 prescreve que além da armadura de punção é necessária uma armadura adicional para garantir ductilidade local e consequentemente uma proteção contra colapso progressivo, ver Figura 14. Essa armadura é determinada pela seguinte expressão:

$$
f_{y d} \cdot A_{s, c c p} \geq 1,5 \cdot F_{S d}
$$

em que, $A_{s, c c p}$ é o somatório de todas as áreas das barras inferiores que cruzam cada uma das faces do pilar, e $F_{S d}$ pode ser calculado com $\gamma_{f}$ igual a 1,2.

Figura 14 - Armadura adicional contra o colapso progressivo.

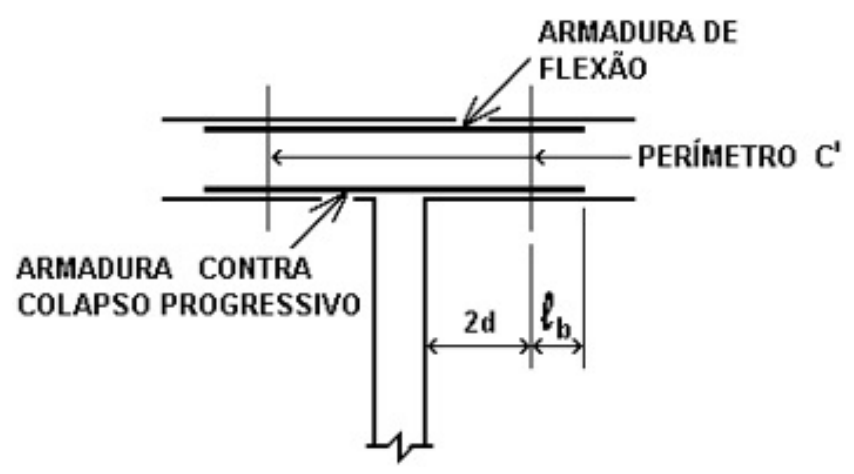

Fonte: ABNT NBR 6118 (2014).

A norma de concreto pré-moldado ABNT NBR 9062 (2006) no item 5.1.1.4 enfatiza que o projetista estrutural deve ter cuidados especiais no detalhamento da estrutura para minimizar a ocorrência de colapso progressivo. Por outro lado, a norma de paredes de 
concreto ABNT NBR 16055 (2012) não comenta nada sobre colapso progressivo. Notase que as normativas brasileiras ainda não adotam um método de prevenção contra o colapso progressivo, contudo, nosso país tem histórico de estruturas que sofreram colapso progressivo, como por exemplo, o Edifício Liberdade no Rio de Janeiro em 2012 que vitimou 22 pessoas. 


\section{Confiabilidade Estrutural}

Neste capítulo é realizada uma sucinta revisão teórica sobre a confiabilidade estrutural de processos independente do tempo. Esta revisão é importante para introduzir os conceitos fundamentais que são aplicados para formular a metodologia do Risk Analysis of the Progressive Collapse (RAPC). Maiores detalhes sobre confiabilidade estrutural podem ser encontrados nos trabalhos de Beck (2015), Ang e Tang (2007), Ditlevsen e Madsen (2007), Melchers (1999) e Ang e Tang (1984).

A confiabilidade estrutural é o ramo da engenharia de estruturas que permite considerar as incertezas das variáveis de projeto através das distribuições de probabilidade, resultando na medida da probabilidade de sobrevivência (confiabilidade) e na probabilidade de falha, com o objetivo de avaliar a segurança da estrutura (SAGRILO, 1994). A confiabilidade é definida como grau de confiança da estrutura não falhar durante a sua vida útil. Já a probabilidade de falha, evento complementar da confiabilidade, é definida como a probabilidade de que a estrutura não atenda as especificações de projeto (BECK, 2015). A seguir, são apresentados os conceitos fundamentais para a formulação da teoria da confiabilidade.

\subsection{Estados limites}

Conforme a ABNT NBR 8681 (2004) os estados limites podem ser definidos, como os estados a partir dos quais a estrutura apresenta desempenho inadequado às finalidades da construção. Generalizando esta definição para se adequar a teoria da confiabilidade, pode-se dizer que um estado limite é a fronteira entre o estado desejado (domínio de sobrevivência) e o indesejado (domínio de falha) para uma estrutura. Assim, cada distinta forma que leve a um estado indesejável é denominada modo de falha.

Os estados limites podem ser estados limites últimos ou estados limites de serviço. Os estados limites últimos correspondem aos requisitos de segurança, que pela sua simples ocorrência, determinam a paralisação total ou parcial de uma construção. Já os estados limites de serviço correspondem aos requisitos de desempenho, que por sua ocorrência causam efeitos estruturais que não respeitam as condições especificadas para o uso normal da construção, ou ainda que são indícios de comprometimento da durabilidade da estrutura (ABNT NBR 8681, 2004).

A avaliação da probabilidade de falha é baseada na descrição das equações de estado limite, $g(\boldsymbol{X})$, em que $\boldsymbol{X}$ é um vetor que inclui todas a variáveis consideradas na análise. Essas variáveis podem ser classificadas como aleatórias e/ou determinísticas. As 
variáveis aleatórias são especificadas através das suas distribuições de probabilidades e de seus parâmetros associados (média, desvio-padrão e variância). Enquanto que as variáveis determinísticas são especificadas com seus valores algébricos. Assim, a equação de estado limite é escrita como função dessas duas variáveis, conforme segue:

$$
g(\boldsymbol{X})=f\left(X_{1}, X_{2}, \ldots, X_{n}\right)=0 .
$$

Para cada modo de falha da estrutura, uma equação de estado limite deve ser escrita. Essas equações são definidas de forma que, para valores negativos de $g(\boldsymbol{X})$ (domínio de falha $\Omega_{f}$ ) tem-se a falha da estrutura e para valores positivos de $g(\boldsymbol{X})$ (domínio de sobrevivência $\Omega_{s}$ ) tem-se a sobrevivência da estrutura (BECK, 2015).

$$
\begin{aligned}
& \Omega_{f}=\{\boldsymbol{X} \mid g(\boldsymbol{X}) \leq 0\} \\
& \Omega_{s}=\{\boldsymbol{X} \mid g(\boldsymbol{X})>0\}
\end{aligned}
$$

Figura 15 - Representação do domínio de falha e sobrevivência.

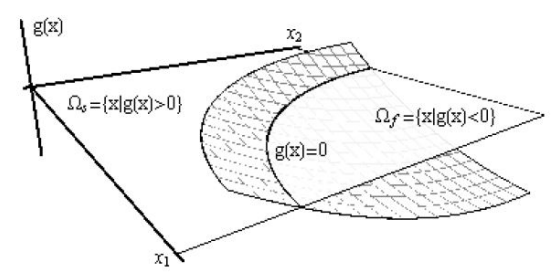

Fonte: Beck (2015).

\subsection{Probabilidade de falha}

A probabilidade de falha é uma medida da violação de um estado limite. Para um problema envolvendo duas variáveis aleatórias $R$ (resistência) e $S$ (solicitação), a equação de estado limite é definida por $g(r, s)=R-S$. A avaliação da probabilidade de falha $\left(P_{f}\right)$ para esta equação é conhecida na literatura como Problema Fundamental de Confiabilidade, o que resulta:

$$
P_{f}=P[\{R \leq S\}]=P[\{R-S \leq 0\}]
$$

Conforme a Figura 15, pode-se definir o domínio de falha como o conjunto dos pontos do espaço amostral de $\boldsymbol{X}$ que levam a falha da estrutura, e o domínio de sobrevivência o conjunto complementar a este. Logo, na avaliação da segurança de uma estrutura, a probabilidade de falha é o somatório de todos os valores associados a ocorrência dos eventos que estão dentro do domínio de falha, ou seja:

$$
P_{f}=P\left[(r, s) \in \Omega_{f}\right]=\iint_{\Omega_{f}} f_{R S}(r, s) d r d s=\int_{-\infty}^{+\infty} \int_{-\infty}^{s} f_{R S}(r, s) d r d s
$$


sendo, $f_{R S}(r, s)$ a função conjunta de densidade de probabilidade das variáveis aleatórias $R$ e $S ; r$ e $s$ são os valores assumidos pelas variáveis aleatórias $R$ e $S$. Se essas variáveis forem estatisticamente independentes, a função conjunta de densidade de probabilidade pode ser substituída pelo produto direto das funções marginais de densidade de probabilidade de cada variável. Então, a probabilidade de falha torna-se:

$$
P_{f}=\int_{-\infty}^{+\infty} \int_{-\infty}^{s} f_{R}(r) f_{S}(s) d r d s
$$

Os problemas de engenharia envolvem equações de estado limites com mais de duas variáveis, logo, a Equação 5.5 pode ser generalizada para um número qualquer de variáveis aleatórias, reescrevendo a mesma em termos de um vetor $\boldsymbol{X}$, o que resulta:

$$
P_{f}=P[g(\boldsymbol{X}) \leq 0]=\int_{\Omega_{f}} f_{\boldsymbol{x}}(\boldsymbol{x}) d \boldsymbol{x} .
$$

Contudo, a avaliação da Equação 5.7 não é trivial, uma vez que a mesma envolve a análise de uma integral multidimensional. Para fugir deste problema, pode-se utilizar os Métodos de Transformação e/ou a Simulação de Monte Carlo.

\section{3 Índice de confiabilidade}

A definição de índice de confiabilidade foi proposta por Cornell (1969), sendo um parâmetro importante para calcular a probabilidade de falha. Pode-se definir o índice de confiabilidade $\beta$, como a medida geométrica da probabilidade de falha, correspondendo a menor distância entre a equação de estado limite a origem do espaço normal padrão $\boldsymbol{Y}$. $\mathrm{O}$ ponto sobre a equação de estado limite que define essa mínima distância é chamado de ponto de projeto $\boldsymbol{y}^{*}$.

No caso particular de haverem duas variáveis aleatórias, $R$ e $S$, independentes entre si, com distribuições normais e a equação de estado limite linear, o índice de confiabilidade é definido por:

$$
\beta=\frac{\mu_{R}-\mu_{S}}{\sqrt{\sigma_{R}^{2}+\sigma_{S}^{2}}}=\frac{\mu_{M}}{\sigma_{M}}
$$

em que: $\mu_{R}$ e $\mu_{S}$ são respectivamente as médias da resistência e da solicitação; $\sigma_{R}$ e $\sigma_{S}$ são os respectivos desvios padrão.

O índice de confiabilidade é definido no espaço normal-padrão. Logo, é necessário uma transformação do espaço de projeto ${ }^{1}$ para o espaço normal padrão. Para variáveis normais e estatisticamente independentes, a transformação isoprobabilística ${ }^{2}$ para o espaço

1 Também chamado de espaço físico, pois corresponde aos valores que as variáveis de projeto pode assumir.

2 Garante o mesmo conteúdo de probabilidades no espaço de projeto e espaço normal padrão. 
normalizado pode ser obtido pela equação proposta por Hassofer e Lind (1974), expressa por:

$$
\boldsymbol{Y}=\frac{\boldsymbol{M}-\mu_{M}}{\sigma_{M}}
$$

A Equação 5.9 transforma um vetor de variáveis gaussianas $\boldsymbol{M}$ com média e desvio padrão quaisquer, em um valor $\boldsymbol{Y}$ com média zero e desvio padrão unitário. Essa permite determinar probabilidades associadas à variável $\boldsymbol{M}$ por meio da função de distribuição cumulativa normal padrão, $\Phi()$. Neste caso, a probabilidade de falha resulta:

$$
P_{f}=P[\{\boldsymbol{M} \leq 0\}]=P\left[\left\{\boldsymbol{Y} \leq-\frac{\mu_{M}}{\sigma_{M}}\right\}\right]=\Phi\left(-\frac{\mu_{M}}{\sigma_{M}}\right)=\Phi(-\beta) .
$$

Figura 16 - Probabilidade de falha em termo da variável normal padrão $\boldsymbol{Y}$.

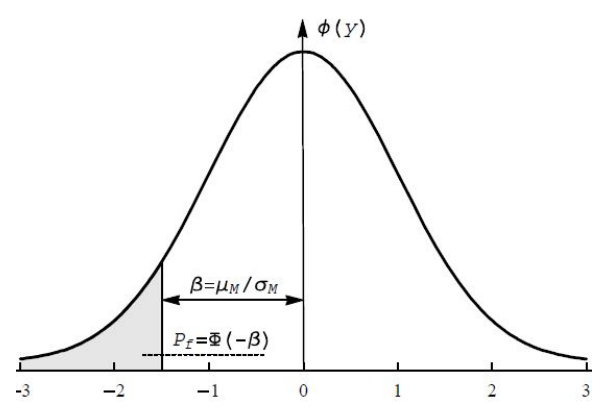

Fonte: Beck (2015).

\subsection{Métodos de transformação}

De acordo com a transformação de Hassofer-Lind, Equação 5.9, no espaço normal padrão reduzido $\boldsymbol{Y}$ com variáveis aleatórias estatisticamente independentes e com a equação de estado limite linear, o índice de confiabilidade pode ser determinado através da distância da equação a origem de $\boldsymbol{Y}$.

Os métodos de transformação estão baseados nesta ideia de Hassofer-Lind fazendo um mapeamento do vetor $\boldsymbol{X}$ (espaço de projeto), descrito por qualquer distribuição de probabilidade, em um vetor $\boldsymbol{Y}$, com distribuição normal padrão (BECK, 2015; MELCHERS, 1999; BREITUNG, 1984).

Os métodos de transformação são classificados em FORM e SORM. No FORM (First Order Reliability Method), a superfície de falha é aproximada por uma superfície linear (hiperplano) no ponto de projeto. No SORM (Second Order Reliability Method), a superfície de falha é aproximada por uma superfície parabólica no ponto de projeto. Nota-se que ambos os métodos necessitam da localização do ponto de projeto para construir a 
superfície de falha e da transformação das variáveis em normais reduzidas (SAGRILO, 1994).

Figura 17 - Métodos de transformação: FORM e SORM.

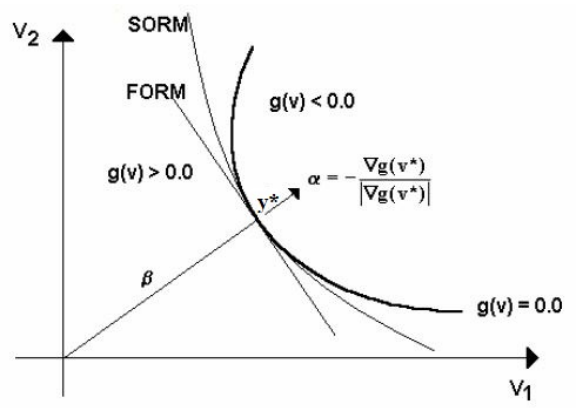

Fonte: Sagrilo (1994).

\subsubsection{Transformações de variáveis}

A transformação de variáveis aleatórias do espaço $\boldsymbol{X}$ para o espaço $\boldsymbol{Y}$ (normal padrão) se faz necessário, pois a busca pelo ponto de projeto é realizada em $\boldsymbol{Y}$. Na maioria dos casos dos problemas de engenharia, as variáveis não são guassianas, nestes casos, então, é necessária uma transformação em normal equivalente para poder utilizar a Equação 5.9. Esta transformação é realizada através do Princípio da Aproximação Normal ${ }^{3}$, o qual consiste em determinar, para um ponto $x_{i}^{*}$, uma distribuição normal equivalente que atenda as seguintes equações:

$$
\begin{gathered}
F_{x_{i}}^{n e q}\left(x_{i}^{*}\right)=F_{x_{i}}\left(x_{i}^{*}\right) \\
f_{x_{i}}^{n e q}\left(x_{i}^{*}\right)=f_{x_{i}}\left(x_{i}^{*}\right)
\end{gathered}
$$

sendo, $F_{x}$ e $f_{x}$, respectivamente, a função acumulada de probabilidade e a função de densidade de probabilidade; o índice (neq) representa normal equivalente.

O princípio da aproximação normal não considera os casos em que as variáveis são correlacionadas. No entanto, se os coeficientes de correlações entre as variáveis originais forem corrigidos para os coeficientes de correlações entre as normais equivalentes, o mesmo ainda pode ser utilizado (SAGRILO, 1994).

Uma outra forma de resolver o problema de variáveis correlacionadas é a aplicação da Transformação de Rosenblatt ou da Transformação Composta Utilizando o Modelo de Nataf.

3 Também é conhecido na literatura como o procedimento de aproximar a cauda da distribuição original pela cauda de uma distribuição normal equivalente (BECK, 2015). 
A transformação de Rosenblatt permite esse mapeamento através da utilização das distribuições de probabilidade condicionais de $\boldsymbol{X}$. Contudo, como a transformação de Rosenblatt envolve distribuições de probabilidades condicionais multidimensionais, a mesma é mais teórica do que prática devido a dificuldade na sua solução (BECK, 2015).

Uma saída para esse problema, é através da transformação composta utilizando o modelo de Nataf, o qual envolve a transformação de variáveis normais correlacionadas em variáveis normais estatisticamente independentes, através da aproximação da função conjunta de densidade de probabilidade $f_{x}(x)$ pelo produto direto da distribuição normal padrão multi-variada e da matriz de correlação das variáveis $R_{z}$ (BECK, 2015; MELCHERS, 1999; KIUREGHIAN; LIU, 1986).

$$
f_{x}(x)=\phi_{n}\left(z, R_{z}\right) \cdot \frac{f_{x_{1}}\left(x_{1}\right) \cdot f_{x_{2}}\left(x_{2}\right) \cdots f_{x_{n}}\left(x_{n}\right)}{\phi\left(z_{1}\right) \cdot \phi\left(z_{2}\right) \cdots \phi\left(z_{n}\right)}
$$

A Figura 18 exemplifica a passagem da variável aleatória $\boldsymbol{X}$, para o espaço da variável normal equivalente com correlação $\boldsymbol{Z}$, através da eliminação da correlação ${ }^{4}$ entre as variáveis, chega-se ao espaço da normal padrão $\boldsymbol{Y}$.

Figura 18 - Ilustração da transformação composta $\boldsymbol{X} \rightarrow \boldsymbol{Z} \rightarrow \boldsymbol{Y}$.
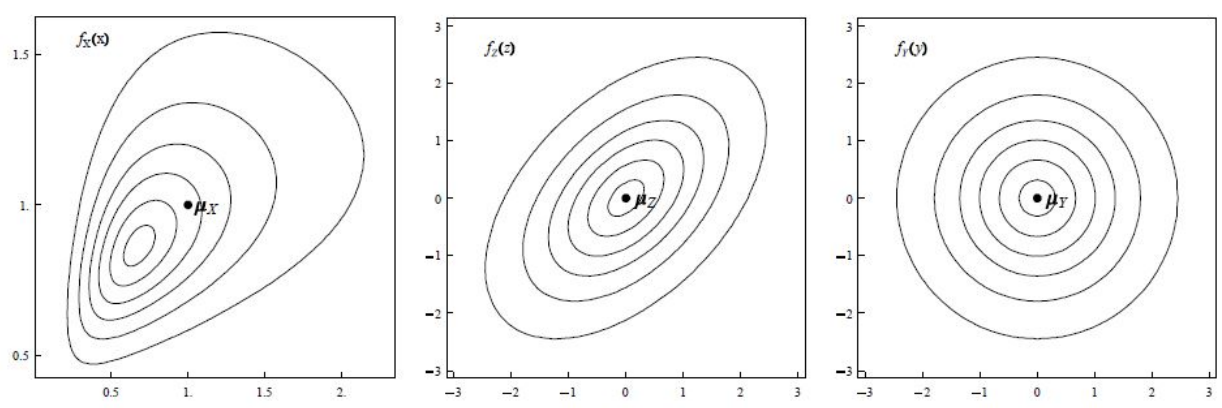

Fonte: Beck (2015).

\subsubsection{Ponto de projeto}

A fase fundamental para a determinação da probabilidade de falha pelos métodos de transformação é encontrar o ponto de projeto $\left(\boldsymbol{y}^{*}\right)$. Assim, define-se, o ponto de projeto como o ponto sobre a equação de estado limite mais próximo à origem. Conforme Beck (2015) e Melchers (1999), o ponto de projeto é a moda do domínio de falha, ou seja, o ponto com a maior probabilidade de ocorrência, sendo o local ideal para a linearização da equação de estado limite. Logo, a determinação de $\boldsymbol{y}^{*}$ pode ser formulada como um problema de otimização com restrição, dado por:

encontrar o ponto: $\boldsymbol{y}^{*}$

4 Nesse caso, aplica-se, a decomposição ortogonal ou fatoração de Cholesky. 


$$
\begin{gathered}
\text { que minimiza: } \quad d=|\boldsymbol{y}|=\sqrt{\boldsymbol{y}^{T} \cdot \boldsymbol{y}} \\
\text { sujeito } a: \quad g(\boldsymbol{y})=0
\end{gathered}
$$

em que, $d$ é a distância entre um dado $\boldsymbol{y}$ e a origem. Assim, o índice de confiabilidade de Hassofer e Lind (1974) é o valor mínimo de $d$, em que resulta:

$$
\beta=\left|\boldsymbol{y}^{*}\right|=\sqrt{\boldsymbol{y}^{* T} \cdot \boldsymbol{y}^{*}}
$$

A solução do problema de otimização apresentado anteriormente pode ser determinado a partir de algoritmos de otimização. Na literatura, o algoritmo mais popular é o HLRF (Hassofer-Lind-Racwitz-Fiessler), devido sua simplicidade é muito empregado para solução de problemas de confiabilidade estrutural (HASSOFER; LIND, 1974; RACWITS; FIESSLER, 1978). Esse algoritmo procura aproximar de maneira perpendicular o ponto $\boldsymbol{y}$ à superfície de $g(\boldsymbol{y})=0$, conforme ilustrado na Figura 19. Sua fórmula recursiva é dada por:

$$
\boldsymbol{y}_{k+1}=\frac{\nabla g\left(\boldsymbol{y}_{k}\right)^{T} \cdot \boldsymbol{y}_{k}-g\left(\boldsymbol{y}_{k}\right)}{\left|\nabla g\left(\boldsymbol{y}_{k}\right)\right|^{2}} \cdot \nabla g\left(\boldsymbol{y}_{k}\right)=\beta_{k} \cdot \boldsymbol{\alpha}_{k}
$$

Figura 19 - Ilustração do processo iterativo de busca do ponto de projeto.

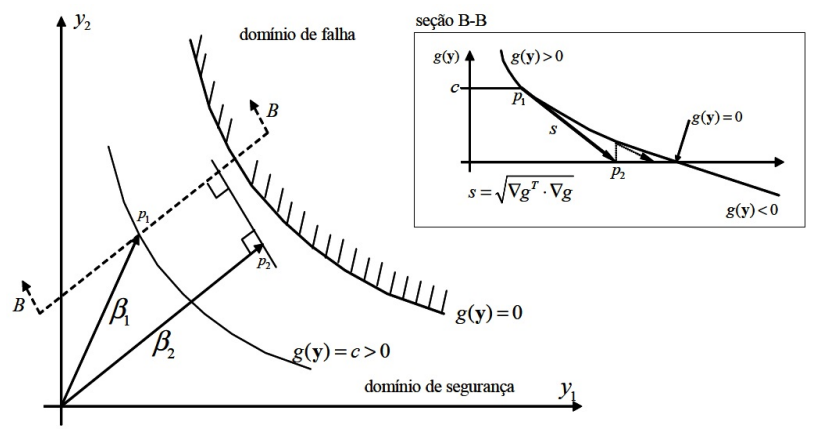

Fonte: Beck (2015).

Entretanto, a Equação 5.15 em algumas situações ${ }^{5}$ não garante há convergência ao ponto de projeto ou o ponto encontrado não seja o ponto de mínimo da função (Equação 5.14). Para contornar este problema, o algoritmo HLRF pode ser melhorado com um ajuste do passo inicial, esse novo algoritmo é chamado na literatura de iHLRF (improved HLRF) (BREITUNG, 2015).

\subsection{Confiabilidade de sistemas}

Até o momento foram descritos os processos que envolvem somente uma equação de estado limite. Nesta seção são abordados de forma sucinta os procedimentos para a

\footnotetext{
5 Situações em que as equações de estado limite sejam extremamente não lineares.
} 
aplicação dos métodos analíticos FORM e SORM na análise de sistemas estruturais com múltiplos modos de falhas. Para maiores informações e aprimoramentos sobre confiabilidade de sistemas o autor recomenda os trabalhos de Beck (2015), Fiondella e Xing (2015), Ditlevsen e Madsen (2007), Melchers (1999) e Madsen, Krenk e Lind (1986).

As estruturas usuais na engenharia civil são formadas por muitos elementos estruturais. Em geral, a falha de um elemento não implica necessariamente a falha da estrutura. Isto é devido as reservas de resistência que a mesma possui, proporcionando a redistribuição de esforços para os outros elementos estruturais (NOGUEIRA, 2010).

Nesse momento vale ressaltar a importância da redundância para uma estrutura. Como já citado no Capítulo 4 deste trabalho, a redundância é caracterizada pela possibilidade de redistribuição de esforços por caminhos de cargas alternativos quando um elemento estrutural sofre um colapso. No caso de estruturas isostáticas (sistema em série), a inexistência de redundância reflete que a falha de um componente implica na falha da estrutura. Já as estruturas hiperestáticas (sistema em paralelo) a falha da estrutura só acontece se o número de componentes dado pelo grau de hiperestaticidade $\left(g_{h}\right)$ mais um falharem.

Os sistemas estruturais na análise de confiabilidade podem ser idealizados em subsistemas associados em série e subsistemas associados em paralelo. Um subsistema é descrito em série quando a falha de um dos seus componentes leva à falha do sistema; por sua vez, um subsistema é classificado em paralelo quando a falha só ocorre se todos os componentes do sistema falharem (BECK, 2015).

Devido à complexidade da Teoria de Confiabilidade de Sistemas, a literatura estabelece limites para a determinação da probabilidade de falha das estruturas idealizadas em série ou paralelo. Isto porque soluções exatas não podem ser obtidas ou são extremamente complexas. Além disso, não existem fórmulas teóricas que verifiquem a probabilidade de falha de sistemas estruturais gerais. Logo, são utilizados procedimentos com árvore de falhas e árvore de eventos. De forma simplista estes procedimentos consistem em decompor um evento de interesse em uniões e interseções de sub-eventos básicos, em que é possível determinar a sua probabilidade de falha.

Uma outra forma para analisar a confiabilidade de sistemas é através da Programação Linear (PL). A PL consiste na solução de problema de minimização (ou maximização) de uma função linear, cujas variáveis estão sujeitas a restrições lineares de igualdade ou desigualdade. Entretanto, essa abordagem só é realizada para problemas em que a equação de estado limite é linear. Maiores detalhes da PL o autor recomenda o trabalho de Song e Kiureghian (2003). 


\subsubsection{Idealização em série}

Como a falha de um elemento num sistema em série conduz a falha da estrutura, observa-se, que a probabilidade de sobrevivência na idealização em série é medida pela confiabilidade do elemento mais frágil (NOGUEIRA, 2010). Por isso, sistemas em série são conhecidos na literatura como sistemas de correntes, ou seja, a falha ocorre no elo mais fraco (weakest link system), conforme a Figura 20.

Figura 20 - Idealização de subsistemas em série

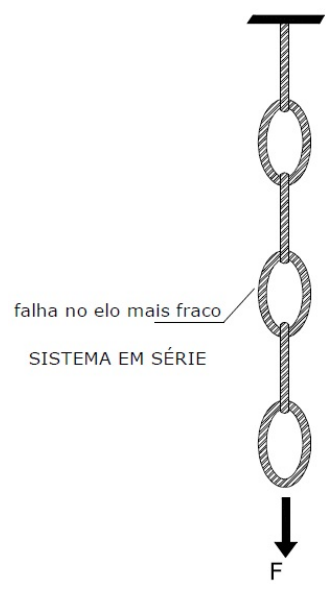

Fonte: Nogueira (2010).
Figura 21 - Idealização de subsistemas em paralelo

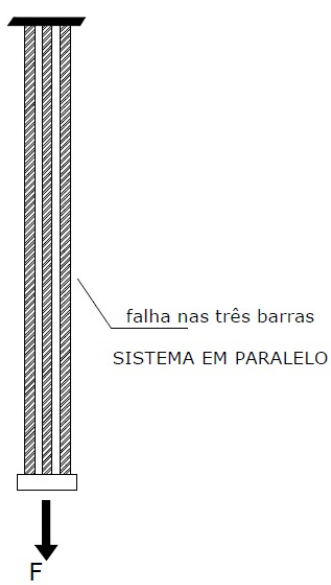

Fonte: Nogueira (2010).

Seja um evento $E_{i}$ correspondente à falha do $i$ - ésimo elemento, o evento falha do sistema $(F)$ em uma associação em série é dada pela união dos eventos $E_{i}$, logo, obtém-se:

$$
F=\left(E_{1} \cup E_{2} \cup \cdots \cup E_{n}\right)=\bigcup_{i=1}^{n} E_{i}
$$

A probabilidade de falha para sistemas em série é definida pela união das probabilidades de falhas individuais de seus elementos, sendo expressa pela seguinte equação:

$$
P_{f}=P[F]=P\left[\bigcup_{i=1}^{n} E_{i}\right]
$$

\subsubsection{Idealização em paralelo}

Na idealização em paralelo a resistência do sistema é definida pela resistência de todos os seus elementos, ou seja, se um dos elementos não falha, o sistema também não falha (NOGUEIRA, 2010). A analogia da idealização em paralelo pode ser dada por uma estrutura formada por três barras tracionadas, conforme apresentado na Figura 21, onde a falha de uma barra não implica na falha do sistema. A barra com a maior confiabilidade controla a falha do sistema. 
Para um sistema em paralelo, a falha do sistema é definida pela interseção dos eventos $E_{i}$, o que resulta:

$$
F=\left(E_{1} \cap E_{2} \cap \cdots \cap E_{n}\right)=\bigcap_{i=1}^{n} E_{i}
$$

Assim, a probabilidade de falha do sistema é definida pela interseção entre os eventos de falha individuais de seus elementos, sendo determinada pela seguinte equação:

$$
P_{f}=P[F]=P\left[\bigcap_{i=1}^{n} E_{i}\right] .
$$

Sistemas em paralelo são chamados de redundantes. Esta redundância pode ser classificada em ativa ou passiva. Na redundância ativa todos os elementos contribuem ao mesmo tempo na realização de uma mesma tarefa. Na redundância passiva, alguns elementos só passam a contribuir no desempenho da estrutura após a falha de um elemento.

Em se tratando da redundância passiva, Beck (2015, p. 137) afirma:

\begin{abstract}
A avaliação da probabilidade de falha do sistema requer a análise de probabilidades condicionais, através de árvores de falhas ${ }^{6}$. Esta é construída estabelecendo-se a probabilidade de ocorrência de cada uma das possíveis sequência de falha, que são determinadas por eventos condicionais.
\end{abstract}

A avaliação da probabilidade de falha do sistema, torna-se bastante complexa, pois, depende das interseções dos vários eventos que causam a falha do sistema. Assim, faz-se necessário estabelecer limites para a mesma. Estes limites são classificados em: limites uni-modais e limites bi-modais. Tais limites só são usados para sistemas idealizados em série.

Os limites uni-modais são obtidos desconsiderando os termos que envolvem interseções entre os modos de falhas, ou seja, a probabilidade de falha do sistema é calculada somente para os modos de falhas individuais $P\left[F_{i}\right]$. No entanto, os limites uni-modais têm baixa eficiência para situações que não há modo de falha dominante no sistema (BECK, 2015). Esses limites são obtidos pela seguinte inequação:

$$
\max _{i}\left[P\left(F_{i}\right)\right] \leq P_{f} \leq \min \left[1, \sum_{i=1}^{n} P\left(F_{i}\right)\right] .
$$

Os limites bi-modais da probabilidade de falha são determinados incluindo além dos termos de probabilidade individual $P\left[F_{i}\right]$, os termos de interseção entre dois modos de falha $P\left[F_{i} \cap F_{j}\right]$. Portanto, os limites bi-modais da probabilidade de falha são dados por:

$$
P\left(F_{1}\right)+\sum_{i=2}^{n} \max _{i}\left[0, P\left(F_{i}\right)-\sum_{j=1}^{i-1} P\left(F_{i} \cap F_{j}\right)\right] \leq P_{f} \leq \sum_{i=1}^{n} P\left(F_{i}\right)-\sum_{i=2}^{n} \max _{i>j}\left[P\left(F_{i} \cap F_{j}\right)\right] .
$$

6 Consiste em desmenbrar um evento principal em partes elementares que levam a ocorrência do evento principal. Ela permite identificar as sequências críticas (caminhos críticos) de eventos que mais provavelmente levam à falha do sistema. 
Partindo da Equação 5.21, nota-se que a sua solução não é trivial. Contudo, através de uma aproximação de primeira ordem das equações de estado limite que definem o problema, os limites bi-modais podem ser calculados. As demonstrações para obtenção desses limites podem ser vistas em Beck (2015).

Em se tratando de limites para idealização de sistemas em paralelo, Song e Kiureghian (2003 apud BOOLE, 1854) deduziram a seguinte inequação:

$$
\max \left[0, \sum_{i=1}^{n} P\left(F_{i}\right)-(n-1)\right] \leq P_{f} \leq \min _{i} P\left(F_{i}\right)
$$

\subsection{Simulação de Monte Carlo}

A simulação pode ser definida como uma forma de experimentação numérica de um problema físico. No caso da análise estrutural, a simulação pode ser utilizada na modelagem de problemas em que ensaios experimentais são de difíceis realizações ou têm um custo muito elevado.

Uma técnica amplamente utilizada nos softwares para simulação de problemas de confiabilidade estrutural, é a simulação de Monte Carlo. Tal método está fundamentado na geração de números aleatórios mediante a função conjunta de densidade de probabilidade. Para cada número gerado, a função de estado limite é avaliada e se $g(\boldsymbol{X}) \leq 0$, uma falha é contada.

Essa avaliação é dada através de uma função indicadora $I[\boldsymbol{X}]$. Se $I[\boldsymbol{X}]=1$ a realização pertence ao domínio de falha. Para $I[\boldsymbol{X}]=0$ a realização pertence ao domínio de sobrevivência. Portanto, a probabilidade de falha é dada pelo conjunto dos números pertencentes ao domínio de falha. De posse da Equação 5.7, obtém-se:

$$
P_{f}=\int_{\Omega} I[\boldsymbol{X}] f_{\boldsymbol{x}}(\boldsymbol{x}) d \boldsymbol{x} .
$$

Partindo da definição de valor esperado, nota-se que a Equação 5.23 é o valor esperado (média) da função indicadora $I[\boldsymbol{X}]$, ou seja, $P_{f}=E[I[\boldsymbol{X}]]$. Quando utiliza-se uma quantidade finita de números aleatórios $n_{s i}$, uma estimativa da probabilidade de falha, torna-se:

$$
\hat{P}_{f}=\frac{1}{n_{s i}} \sum_{i=1}^{n_{s i}} I\left[x_{i}\right]=\frac{n_{f}}{n_{s i}}
$$

em que, $n_{f}$ é o número de pontos pertencentes ao domínio de falha.

Como esta estimativa se baseia em uma amostra de tamanho finito, a mesma está submetida a um erro estatístico que corresponde à mensuração da variância de $I[\boldsymbol{X}]$. Partindo da definição de variância, obtém-se:

$$
\operatorname{Var}\left[\hat{P}_{f}\right]=\frac{1}{\left(n_{s i}-1\right)} \sum_{i=1}^{n_{s i}}\left(I\left[x_{i}\right]-\hat{P}_{f}\right)^{2} .
$$


Observa-se da Equação 5.25 que a incerteza diminui à medida que o tamanho da amostra aumenta, sendo zero quando o tamanho da amostra tende ao infinito. Logo, conclui-se que o número de simulações necessárias para alcançar determinados pontos no domínio de falha é extremamente grande.

A maneira como foi formulado o método de Monte Carlo anteriormente é conhecido na literatura como método de Monte Carlo bruto, por não utilizar ferramentas de redução da variância em vista a diminuir a quantidade de números a serem simulados (BECK, 2015; KIUREGHIAN; LIU, 1989).

Para contornar este problema, foram desenvolvidos técnicas de redução de variância, tais como: variáveis antitéticas, amostragem por importância, amostragem por hiper-cubo latino, amostragem assintótica e amostragem por sub-conjunto. Mais detalhes sobre essas técnicas de redução de variância podem ser encontradas em Beck (2015) e Melchers (1999).

Como citado no Capítulo 3 é empregado neste trabalho a técnica Importance Sampling Monte Carlo (ISMC). Esta consiste em deslocar os pontos simulados para regiões importantes do domínio de falha, reduzindo-se o número de simulações. Esses pontos são gerados através de uma função de amostragem $h_{\boldsymbol{x}}(\boldsymbol{x})$. Multiplicando e dividindo a Equação 5.23 por $h_{\boldsymbol{x}}(\boldsymbol{x})$, a probabilidade de falha, resulta:

$$
P_{f}=\int_{\Omega} I[\boldsymbol{x}] \frac{f_{\boldsymbol{x}}(\boldsymbol{x})}{h_{\boldsymbol{x}}(\boldsymbol{x})} h_{\boldsymbol{x}}(\boldsymbol{x}) d \boldsymbol{x} .
$$

A Equação 5.26 é o valor esperado da função $I[\boldsymbol{x}] \frac{f \boldsymbol{x}(\boldsymbol{x})}{h \boldsymbol{x}(\boldsymbol{x})}$, em relação a $h_{\boldsymbol{x}}(\boldsymbol{x})$. Tal valor pode ser aferido por uma amostra de tamanho finito $\left(n_{s i}\right)$, o que resulta:

$$
\bar{P}_{f}=\frac{1}{n_{s i}} \sum_{i=1}^{n_{s i}} I\left[\boldsymbol{x}_{i}\right] \frac{f_{\boldsymbol{x}}(\boldsymbol{x})}{h_{\boldsymbol{x}}(\boldsymbol{x})} .
$$

Da Equação 5.27, torna-se evidente que cada ponto de amostragem ficará associado à um peso de simulação $\left(w_{i}\right)$, dado por:

$$
w_{i}=\frac{f_{\boldsymbol{x}}(\boldsymbol{x})}{h_{\boldsymbol{x}}(\boldsymbol{x})}<1
$$

Portanto, o sucesso do ISMC está na escolha da $h \boldsymbol{x}(\boldsymbol{x})$. No caso de um modo de falha, essa técnica centraliza a $h_{\boldsymbol{x}}(\boldsymbol{x})$ no ponto de projeto. Já no caso de múltiplos modos de falha, a $h \boldsymbol{x}(\boldsymbol{x})$ é estabelecida de forma a possuir uma saliência sobre cada ponto de projeto. As deduções para determinar a função de amostragem pode ser encontradas em Beck (2015) e Melchers (1999). 
Parte III

Formulação 



\section{Risk Analysis of the Progressive Collapse}

Neste ponto já pode-se introduzir a metodologia do Risk Analysis of the Progressive Collapse (RAPC). Assim, primeiramente, é deduzido uma expressão para considerar a probabilidade de ocorrência do colapso progressivo para um subsistema formado por 4 elementos, depois esta expressão é generalizada para uma estrutura. Por fim, são definidos os coeficientes de importância, de vulnerabilidade e o elemento chave.

\subsection{Formulação do RAPC}

A formulação do RAPC é baseada na Teoria de Confiabilidade de Sistemas e no Estágio de Propagação de Dano (ESPD). Uma estrutura complexa pode ser idealizada como subsistemas formados em série ou em paralelo. Assim, uma estrutura complexa que seria muito difícil de ser analisada, pode ser desmembrada em subsistemas mais simples. Recordando que a ocorrência do colapso progressivo, é dada por uma reação em cadeia devido à falha de um conjunto de elementos estruturais (subsistema) ou por um único elemento estrutural.

Quando o colapso progressivo ocorre devido à falha de um único elemento estrutural, tem-se, basicamente, de forma simplista a definição de elemento chave. Neste caso, observase que este fenômeno é caracterizado por um sistema formado em série. Isso porque, a falha de um elemento caracteriza a falha da estrutura.

O elemento chave $(E C)$ possui a característica de ser vulnerável e ao mesmo tempo importante. O conceito de $E C$ ainda não é plenamente compreendido pela literatura. Isto porque, para a sua determinação são necessários os conceitos de coeficiente de vulnerabilidade $(C V)$ e coeficiente de importância $(C I)$. Partindo do diagrama de Venn, conforme apresentado na Figura 22, observa-se que $E C$ é a interseção entre o $C V$ e o $C I$ (CHEN et al., 2016). Na seção 6.2 deste trabalho estes coeficientes são definidos.

O RAPC é fundamentado nas seguintes hipóteses:

a) a estrutura é analisada no ESPD. Isto implica que já ocorreu a falha de um elemento estrutural, logo, probabilidade de falha é considerada aproximadamente igual a 1. Portanto, o projetista ao utilizar o RAPC não precisa especificar qual foi o evento que provocou a falha do elemento. Isso porque, no ESPD os modos de falhas atuantes são independentes do evento que levou à falha do elemento.

b) a estrutura do edifício é desmembrada em subsistemas em paralelo;

c) cada subsistema em paralelo contribui na redundância da estrutura. Estes 
subsistemas estão interligados formando um sistema em série;

d) o colapso progressivo da estrutura será caracterizado pela falha progressiva de cada subsistema individual;

e) o elemento chave ou elementos chave são identificados para um determinado cenário de carregamento. Portanto, é totalmente compatível com as diretrizes de projeto, promovendo a continuidade, a ductilidade e a redundância na concepção dos edifícios.

Figura 22 - Representação do diagrama de Venn para a determinação do $E C$.

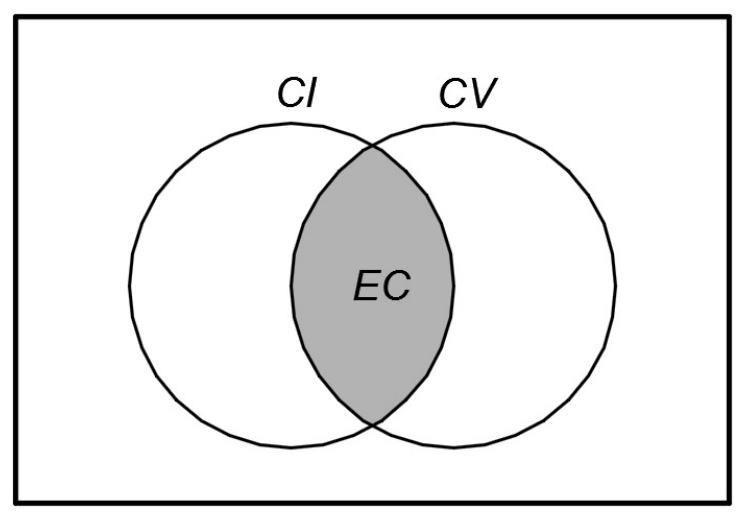

Fonte: Autoria própria.

Seja, $P\left[\boldsymbol{F}_{i}\right]$ a probabilidade de falha de um elemento estrutural $E_{i}$ dado os diferentes modos de falha e $\boldsymbol{F}$ um vetor que engloba os múltiplos modos de falha da estrutura. Aplicando o processo das áreas (charneiras plásticas), tem-se o seguinte esquema de distribuição de esforços para cada elemento estrutural (Figura 23-a). Ordenando as probabilidades de falha dos elementos isolados, retira-se o elemento estrutural mais vulnerável e mais importante, e distribui os esforços (Figura 23-b). Neste caso, tem-se, as probabilidades de falha condicionais de um segundo elemento estrutural falhar dado a falha do primeiro $P\left[\boldsymbol{F}_{j} \mid \boldsymbol{F}_{i}\right]$, utilizando as mesmas equações de estado limite, mas considerando a redistribuição de esforços.

Na Figura 23-c, verifica-se que a falha de um segundo elemento estrutural caracteriza o colapso progressivo do subsistema, devido a laje não ter suporte e, consequentemente, os outros elementos apoiados sobre a mesma entrariam em uma reação em cadeia. As probabilidades de falha, neste caso, dos outros elementos estruturais, são calculados pelas probabilidades condicionais duplas $P\left[\boldsymbol{F}_{k} \mid \boldsymbol{F}_{i, j}\right]$ de um terceiro elemento estrutural falhar dados que o primeiro e o segundo falhem. 
Figura 23 - Esquema de colapso progressivo para a laje suportada por quatro paredes: a) estrutura íntegra; b) falha do primeiro elemento e redistribuição de esforços; c) falha do segundo elemento e colapso total (sem possibilidade de redistribuição de esforços).

a)

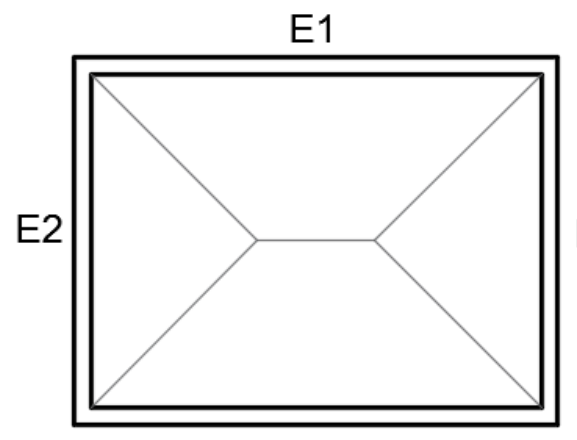

E4 b)

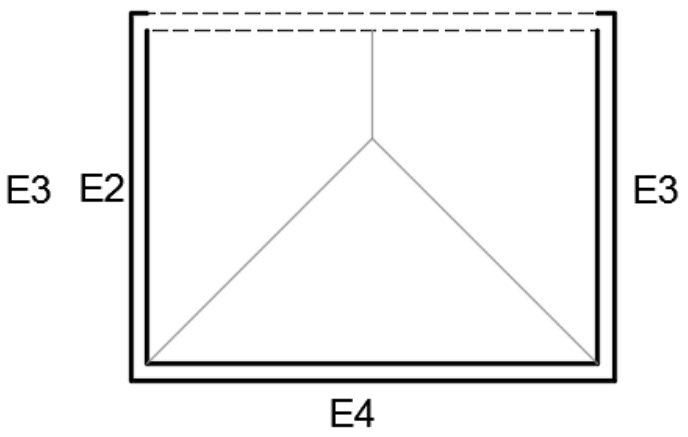

c)

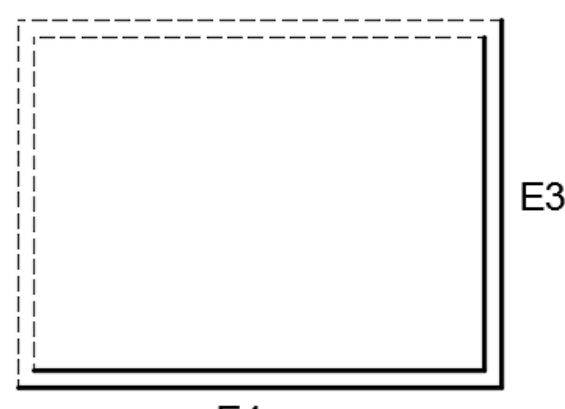

E4

Fonte: Autoria própria.

Então, a probabilidade da ocorrência de colapso progressivo para este subsistema, considerando, um caminho de falha iniciado pelo elemento $E_{i}$, é dado por:

$$
P\left[c_{i}\right]=\sum_{\substack{j=1 \\ j \neq i}}^{n} P\left[\boldsymbol{F}_{i}\right] \cdot P\left[\boldsymbol{F}_{j} \mid \boldsymbol{F}_{i}\right] \cdot P\left[\bigcup_{\substack{k=1 \\ k \neq i \\ k \neq j}}^{n}\left(\boldsymbol{F}_{k} \mid \boldsymbol{F}_{i, j}\right)\right] .
$$

A probabilidade de colapso do sistema é dada pela somatória das probabilidades de colapso dos subsistemas individuais. Cada sequência de falha é formada pela falha de $g_{h}+1$ elementos estruturais, sendo $g_{h}$ o grau de hiperestaticidade do subsistema. Assim, todas as sequências de falha devem ser consideradas.

Os eventos que correspondem a uma sequência de falha são mutuamente exclusivos. Então, a probabilidade de falha é dada pela interseção entre os diferentes modos de falha. Sendo verificado através das probabilidades de falha condicionais. Recordando da Teoria de Probabilidade, a interseção entre os modos de falha devido à falha do elemento $E_{i}$, é 
dado por:

$$
P\left[\boldsymbol{F}_{j} \mid \boldsymbol{F}_{i}\right]=\frac{P\left[\boldsymbol{F}_{j} \cap \boldsymbol{F}_{i}\right]}{P\left[\boldsymbol{F}_{i}\right]} \quad \rightarrow \quad P\left[\boldsymbol{F}_{j} \cap \boldsymbol{F}_{i}\right]=P\left[\boldsymbol{F}_{j} \mid \boldsymbol{F}_{i}\right] \cdot P\left[\boldsymbol{F}_{i}\right]
$$

A interseção entre os modos de falha devido à falha do segundo elemento, torna-se:

$$
\begin{gathered}
P\left[\bigcup_{\substack{k=1 \\
k \neq i \\
k \neq j}}^{n}\left(\boldsymbol{F}_{k} \mid \boldsymbol{F}_{i, j}\right)\right]=\frac{P\left[\boldsymbol{F}_{k} \cap \boldsymbol{F}_{j} \cap \boldsymbol{F}_{i}\right]}{P\left[\boldsymbol{F}_{j} \cap \boldsymbol{F}_{i}\right]} \\
P\left[\boldsymbol{F}_{k} \cap \boldsymbol{F}_{j} \cap \boldsymbol{F}_{i}\right]=P\left[\bigcup_{\substack{k=1 \\
k \neq i \\
k \neq j}}^{n}\left(\boldsymbol{F}_{k} \mid \boldsymbol{F}_{i, j}\right)\right] \cdot P\left[\boldsymbol{F}_{j} \cap \boldsymbol{F}_{i}\right]
\end{gathered}
$$

Combinando a Equação 6.2 e Equação 6.4, obtém-se:

$$
P\left[\bigcup_{\substack{k=1 \\ k \neq i \\ k \neq j}}^{n}\left(\boldsymbol{F}_{k} \mid \boldsymbol{F}_{i, j}\right)\right] \cdot P\left[\boldsymbol{F}_{j} \cap \boldsymbol{F}_{i}\right]=P\left[\bigcup_{\substack{k=1 \\ k \neq i \\ k \neq j}}^{n}\left(\boldsymbol{F}_{k} \mid \boldsymbol{F}_{i, j}\right)\right] \cdot P\left[\boldsymbol{F}_{j} \mid \boldsymbol{F}_{i}\right] \cdot P\left[\boldsymbol{F}_{i}\right] .
$$

As diferentes sequências de falha no ESPD resultam no colapso progressivo do subsistema. Então, sua probabilidade de ocorrência é dada pela seguinte equação:

$$
P[\text { colapso }]=P\left[c_{1}\right]+P\left[c_{2}\right]+\cdots+P\left[c_{n-1}\right]+P\left[c_{n}\right] .
$$

Combinando a (Equação 6.1) e (Equação 6.6), pode-se generalizar esta expressão, determinando a probabilidade de ocorrência do colapso progressivo para uma estrutura, o que resulta:

$$
P[\text { colapso }]=\sum_{i=1}^{n} P\left[c_{i}\right]=\sum_{i=1}^{n} \sum_{\substack{j=1 \\ j \neq i}}^{n} P\left[\boldsymbol{F}_{i}\right] \cdot P\left[\boldsymbol{F}_{j} \mid \boldsymbol{F}_{i}\right] \cdot P\left[\bigcup_{\substack{k=1 \\ k \neq i \\ k \neq j}}^{n}\left(\boldsymbol{F}_{k} \mid \boldsymbol{F}_{i, j}\right)\right] .
$$

Recordando da Teoria de Probabilidade, sabe-se que a probabilidade de falha da união de eventos, resulta:

$$
\begin{aligned}
P\left[\bigcup_{\substack{k=1 \\
k \neq i \\
k \neq j}}^{n}\left(\boldsymbol{F}_{k} \mid \boldsymbol{F}_{i, j}\right)\right]= & P\left[\boldsymbol{F}_{1} \mid \boldsymbol{F}_{(i, j)}\right]+\cdots+P\left[\boldsymbol{F}_{n} \mid \boldsymbol{F}_{(i, j)}\right]+\cdots-P\left[\boldsymbol{F}_{n}\left|\boldsymbol{F}_{(i, j)} \bigcap \boldsymbol{F}_{n-1}\right| \boldsymbol{F}_{(i, j)}\right]+ \\
& +\cdots+P\left[\boldsymbol{F}_{n}\left|\boldsymbol{F}_{(i, j)} \bigcap \boldsymbol{F}_{n-1}\right| \boldsymbol{F}_{(i, j)} \bigcap \boldsymbol{F}_{n-2} \mid \boldsymbol{F}_{(i, j)}\right]+\cdots
\end{aligned}
$$


fazendo:

$$
\overline{\boldsymbol{F}}_{k}=\boldsymbol{F}_{k}\left|\boldsymbol{F}_{(i, j)} ; \quad \overline{\boldsymbol{F}}_{m}=\boldsymbol{F}_{m}\right| \boldsymbol{F}_{(i, j)} \quad e \quad \overline{\boldsymbol{F}}_{n}=\boldsymbol{F}_{n} \mid \boldsymbol{F}_{(i, j)}
$$

resulta:

$$
P\left[\bigcup_{\substack{k=1 \\ k \neq i \\ k \neq j}}^{n}\left(\boldsymbol{F}_{k} \mid \boldsymbol{F}_{i, j}\right)\right]=P\left[\overline{\boldsymbol{F}}_{k}\right]-P\left[\overline{\boldsymbol{F}}_{m} \bigcap \overline{\boldsymbol{F}}_{k}\right]+P\left[\overline{\boldsymbol{F}}_{n} \bigcap \overline{\boldsymbol{F}}_{m} \bigcap \overline{\boldsymbol{F}}_{k}\right]+\cdots
$$

Da Equação 6.9, constata-se que a medida que interseções entre eventos são incorporadas, os sinais daquelas parcelas alternam-se entre positivo e negativo. Neste caso, como já citado no Capítulo 5, os limites uni-modais são obtidos com os termos de probabilidades individuais da Equação 6.9, enquanto que os limites bi-modais são calculados truncando a Equação 6.9 nos termos de interseção entre dois modos de falha.

Como, normalmente, as probabilidades de falha dos elementos estruturais são baixas, na análise de confiabilidade de estruturas, da ordem de $10^{-5}$ JCSS Probabilistic Model Code (2001), os termos de ordem superior (interseção múltipla) podem ser desprezados ${ }^{1}$. Logo, generalizado a Equação 6.9, tem-se:

$$
P\left[\bigcup_{\substack{k=1 \\ k \neq i \\ k \neq j}}^{n}\left(\boldsymbol{F}_{k} \mid \boldsymbol{F}_{i, j}\right)\right]=\sum_{\substack{m=1 \\ m \neq i \\ m \neq j}}^{n} P\left[\overline{\boldsymbol{F}}_{m}\right]-\sum_{\substack{m=2 \\ m \neq i \\ m \neq i \\ m \neq j}}^{n} \sum_{\substack{k \neq 1 \\ k \neq j \\ k<m}}^{m-1} P\left[\overline{\boldsymbol{F}}_{m} \bigcap \overline{\boldsymbol{F}}_{k}\right]
$$

Da Equação 6.2, pode-se reescrever a Equação 6.10, o que resulta:

$$
P\left[\bigcup_{\substack{k=1 \\ k \neq i \\ k \neq j}}^{n}\left(\boldsymbol{F}_{k} \mid \boldsymbol{F}_{i, j}\right)\right]=\sum_{\substack{m=1 \\ m \neq i \\ m \neq j}}^{n} P\left[\overline{\boldsymbol{F}}_{m}\right]-\sum_{\substack{m=2 \\ m \neq i \\ m \neq i \\ m \neq 1 \\ k \neq j \\ k \neq j \\ k<m}}^{n} \sum_{\substack{k=1 \\ m-1}}^{m-1}\left[\overline{\boldsymbol{F}}_{m} \mid \overline{\boldsymbol{F}}_{k}\right] \cdot P\left[\overline{\boldsymbol{F}}_{k}\right]
$$

Substituindo a Equação 6.11 na Equação 6.7, obtém-se:

$$
P[\text { colapso }]=\sum_{i=1}^{n} \sum_{\substack{j=1 \\ j \neq i}}^{n} P\left[\boldsymbol{F}_{i}\right] \cdot P\left[\boldsymbol{F}_{j} \mid \boldsymbol{F}_{i}\right] \cdot\left(\sum_{\substack{m=1 \\ m \neq i \\ m \neq j}}^{n} P\left[\overline{\boldsymbol{F}}_{m}\right]-\sum_{\substack{m=2 \\ m \neq i \\ m \neq j}}^{n} \sum_{\substack{k=1 \\ k \neq j \\ k \neq j \\ k<m}}^{m-1} P\left[\overline{\boldsymbol{F}}_{m} \mid \overline{\boldsymbol{F}}_{k}\right] \cdot P\left[\overline{\boldsymbol{F}}_{k}\right]\right) .
$$

A Equação 6.12, pode ser aplicada para avaliar a probabilidade de falha da estrutura independente da causa. Sendo uma expressão mais geral na avaliação do risco do colapso 
progressivo por englobar termos de primeira e segunda ordem das probabilidades de falhas condicionais. Outro ponto importante, é que as incertezas nos danos e na resistência da estrutura, agora podem ser avaliadas. A resistência ao colapso progressivo determinada pela Equação 6.12, será dada pela contribuição da redundância que cada subsistema vai proporcionar na redistribuição de esforços.

\subsection{Coeficiente de importância, coeficiente de vulnerabilidade e ele- mento chave}

Uma aplicação do RAPC é a determinação do coeficiente de vulnerabilidade $(C V)$, o coeficiente de importância para a progressão do dano $(C I D)$, o coeficiente de importância para o colapso estrutural $(C I C)$, o coeficiente de vulnerabilidade para o colapso progressivo $(C V C)$ e o elemento chave $(E C)$. Estes são definidos a partir das propriedades do sistema no estágio inicial (ESI), estágio de propagação de dano (ESPD) e estágio de colapso progressivo (ESCP).

Definição 6.1. O coeficiente de vulnerabilidade $C V$ de um elemento $E_{i}$ é dado pela relação entre a probabilidade de falha deste elemento $\left(P\left[\boldsymbol{F}_{i}\right]\right)$ pela soma das probabilidades de falha de todos os elementos no subsistema, analisado no ESI. Assim, o $C V$ fica expresso pela seguinte equação:

$$
C V_{i}=\frac{P\left[\boldsymbol{F}_{i}\right]}{\sum_{i=1}^{n} P\left[\boldsymbol{F}_{i}\right]}=\frac{\Phi\left(-\beta_{i}\right)}{\sum_{i=1}^{n} \Phi\left(-\beta_{i}\right)}
$$

sendo, $\Phi()$ a função de distribuição cumulativa normal padrão, e $\beta_{i}$ é o índice de confiabilidade do elemento $E_{i}$.

Definição 6.2. O coeficiente de importância para a propagação de dano (ou desproporcionalidade) $C I D$, de um elemento $E_{i}$, é definido como a razão entre a probabilidade de falha de progressão $\left(P\left[\boldsymbol{F}_{j} \mid \boldsymbol{F}_{i}\right]\right)$, pela máxima probabilidade de propagação de dano, avaliado no ESPD.

O $C I D_{i}$ é analisado considerando a falha do elemento $E_{i}$. Para cada elemento que falha, retira-se o mesmo do sistema, e redistribui-se os fatores de cargas para os outros elementos. Então, a probabilidade de falha do sistema é dada pela interseção entre os diferentes modos de falha. Sendo verificado através das probabilidades de falha condicionais. Como as sequências de falha $\left(P\left[\boldsymbol{F}_{j} \mid \boldsymbol{F}_{i}\right]\right)$ apresentadas na Figura 24 são eventos mutuamente exclusivos, a probabilidade de falha resulta:

$$
P\left[\boldsymbol{F}_{i}^{P}\right]=\sum_{\substack{j=1 \\ j \neq i}}^{n} P\left[\boldsymbol{F}_{j} \cap \boldsymbol{F}_{i}\right]=\sum_{\substack{j=1 \\ j \neq i}}^{n} P\left[\boldsymbol{F}_{j} \mid \boldsymbol{F}_{i}\right] \cdot P\left[\boldsymbol{F}_{i}\right] .
$$


Figura 24 - Representação da árvore de falha para à determinação do CID.

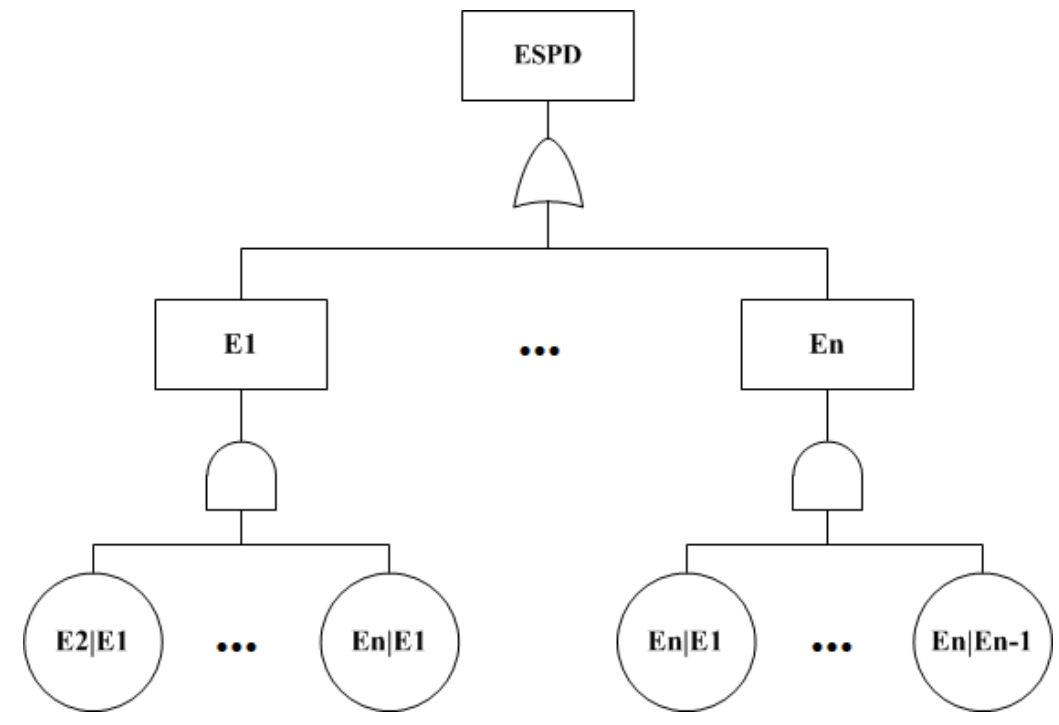

Fonte: Autoria própria.

Logo, o índice de confiabilidade do sistema dada a falha do elemento $E_{i}, \beta_{i}^{P}$, torna-se:

$$
\beta_{i}^{P}=-\Phi^{-1}\left(P\left[\boldsymbol{F}_{i}^{P}\right]\right)
$$

Assim, o $C I D_{i}$, resulta:

$$
C I D_{i}=\frac{P\left[\boldsymbol{F}_{i}^{P}\right]}{\max _{i}\left[P\left[\boldsymbol{F}_{i}^{P}\right]\right]}=\frac{\Phi\left(-\beta_{i}^{P}\right)}{\max _{i}\left[\Phi\left(-\beta_{i}^{P}\right)\right]} .
$$

Definição 6.3. O coeficiente de importância para o colapso progressivo (ou desproporcionalidade) $C I C$, de um elemento $E_{i}$, é definido como a relação entre a probabilidade de ocorrência do caminho de falha $c_{i}$, iniciado pela falha do $E_{i}$, pela probabilidade de falha do máximo caminho, conforme ilustrado na Figura 25, analisado no ESCP:

$$
C I C_{i}=\frac{P\left[c_{i}\right]}{\max _{i}\left[P\left[c_{i}\right]\right]}
$$

sendo, $P\left[c_{i}\right]$ determinado pela Equação 6.1.

Definição 6.4. O coeficiente de vulnerabilidade para a propagação do dano $C V D$, de um elemento $E_{i}$, é definido como à interseção entre os eventos "elevado $C V$ " e "elevado CID". Assumindo a independência entre estes eventos, o $C V D$ é expresso por:

$$
C V D_{i}=C V_{i} \cdot C I D_{i}
$$


Figura 25 - Representação da árvore de falha para à determinação do $C I C$.

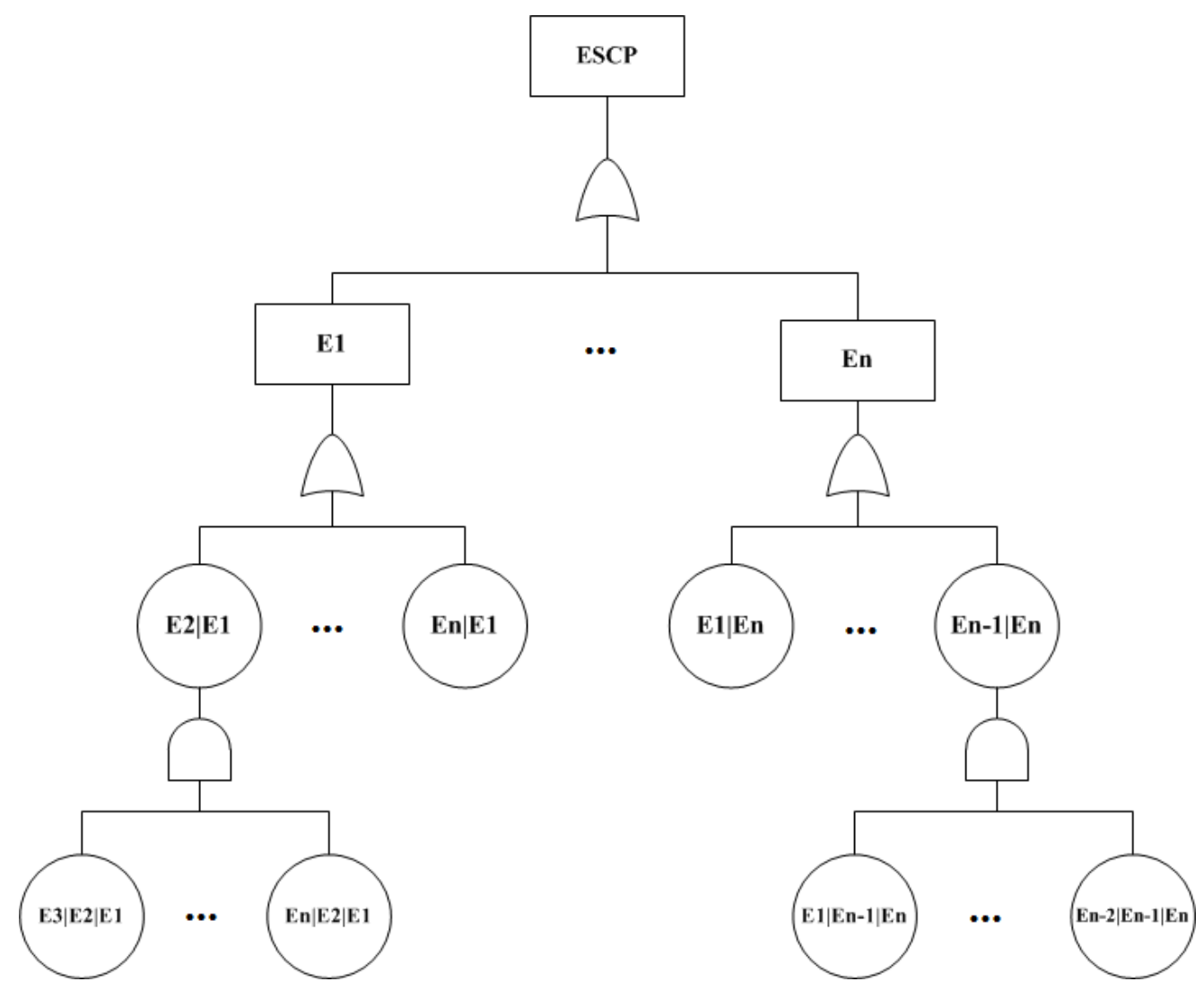

Fonte: Autoria própria.

Definição 6.5. O coeficiente de vulnerabilidade para o colapso estrutural $C V C$, de um elemento $E_{i}$, é definido como à interseção entre os eventos "elevado $C V$ " e "elevado $C I C$ ". Admitindo a independência de tais eventos, o $C V C$, torna-se:

$$
C V C_{i}=C V_{i} \cdot C I C_{i}
$$

Para estruturas convencionais ou arranjos estruturais convencionais, espera-se que os coeficientes $C V D$ e $C V C$, de um elemento em particular, sejam semelhantes. No entanto, para estruturas equipadas com fuso estrutural (elemento de sacrifício), assumido que a falha do fuso é parte da propagação do dano, o $C V D$ seria geralmente maior do que o $C V C$. Especificamente, um elemento $E_{i}$, cuja falha ativa um fuso estrutural, este teria menor $C V C$ do que um elemento cuja falha não ativa o fuso, mas maior $C V D$. A probabilidade condicional de falha de um elemento fuso deve ser grande, mas se sua progressão de falha cessa, esta pode ser considerada uma falha de serviço. Portanto, a distinção entre progressão de dano e colapso estrutural, nos coeficientes $C V D$ e $C V C$, permite ao projetista estrutural concentrar sua atenção em cada um desses termos separadamente. 
Claramente, os elementos estruturais em um edifício podem ser ordenados de acordo com seus valores de $C V D$ e $C V C$. Quando o projetista estrutural está direcionando a progressão de dano, ele deve concentrar sua atenção nos elementos com maior $C V D$. Se o mesmo quiser atingir o colapso progressivo, seu foco deve ser em elementos com maior CVC.

Definição 6.6. O elemento chave $E C$ é definido como o elemento $E_{i}$ que tem a maior vulnerabilidade para o colapso estrutural, isto é:

$$
E C=\max _{i}\left(C V C_{i}\right)=\max _{i}\left(C V_{i} \cdot C I C_{i}\right)
$$

Melhorias no projeto estrutural para aumentar a robustez devem centrar-se no(s) elemento(s) chave. Contudo, mudanças relevantes no projeto ou a consideração de novos eventos de carregamentos mudarão potencialmente os coeficientes definidos acima. Neste caso, o projetista deve ter uma atenção especial para descrever os novos modos de falha que podem surgir. Portanto, eles devem ser recalculados após mudanças significativas no projeto estrutural.

A identificação do elemento chave, ou a ordenação dos elementos estruturais num edifício em termos de $C V D$ ou $C V C$, permite simplificar as soluções do problema. Ressaltase que as sequências de falhas que começam com os elementos estruturais mais importantes dominam as probabilidades de colapso na Equação 6.12. Sendo assim, se o $C V C_{e c}$ do elemento chave for significativamente maior que os $C V C_{i}$ para outros elementos estruturais em um edifício, a Equação 6.12 pode ser simplificada para:

$P[$ colapso $] \approx P\left[c_{e c}\right]=P\left[\boldsymbol{F}_{e c}\right] \cdot \sum_{\substack{j=1 \\ j \neq e c}}^{n} P\left[\boldsymbol{F}_{j} \mid \boldsymbol{F}_{e c}\right] \cdot\left(\sum_{\substack{m=1 \\ m \neq e c \\ m \neq j}}^{n} P\left[\overline{\boldsymbol{F}}_{m}\right]-\sum_{\substack{m=2 \\ m \neq e c \\ m \neq j}}^{n} \sum_{\substack{k=1 \\ k \neq j \\ k \neq j}}^{m-1} P\left[\overline{\boldsymbol{F}}_{m} \mid \overline{\boldsymbol{F}}_{k}\right] \cdot P\left[\overline{\boldsymbol{F}}_{k}\right]\right)$.

Assumindo que a importância dos elementos estruturais é consistente entre os diferentes níveis de análises, por hipótese, o projetista pode calcular os coeficientes definidos anteriormente por meio de uma análise estática linear. Identificado o(s) elemento(s) chave, o projetista pode retira-lo e processar novamente o seu modelo estrutural empregando uma análise mais refinada (análise não linear ${ }^{2}$ ). Logo, a avaliação da probabilidade de colapso da estrutura, considerando uma análise não linear é realizada por meio da Equação 6.21.

$\overline{2}$ Neste caso, o projetista pode utilizar uma análise estática não linear ou dinâmica não linear. Contudo, dada à complexidade de uma análise dinâmica não linear, recomenda-se que esta seja realizada quando o projetista especifica um dado evento que gere efeitos dinâmicos na estrutura, como por exemplo, explosões. Neste caso, a determinação da probabilidade de colapso deve ser realizada com Equação 6.23. 
Portanto, constata-se que a Equação 6.21 reduz o número de análise dos caminhos de falha evitando análises de confiabilidade excessivas.

\subsection{Múltiplos riscos ou múltiplos eventos de carregamento}

Os coeficientes definidos na seção 6.2 quantificam a importância relativa de cada elemento estrutural no estágio íntegro, estágio de propagação de dano e estágio de colapso progressivo. Se o projetista estrutural pretende dimensionar uma estrutura para uma dada ameaça específica ou evento de carregamento $\left(E_{v}\right)$, a Equação 6.12 é generalizada, o que resulta:

$$
P[\text { colapso }]=\sum_{v=1}^{m} P\left[\text { colapso } \mid \boldsymbol{E}_{v}\right]=\sum_{v=1}^{m} \sum_{i=1}^{n} \sum_{\substack{j=1 \\ j \neq i}}^{n} P\left[\boldsymbol{E}_{v}\right] \cdot P\left[\boldsymbol{F}_{i}\right] \cdot P\left[\boldsymbol{F}_{j} \mid \boldsymbol{F}_{i}\right] \cdot P\left[\bigcup_{\substack{k=1 \\ k \neq 1 \\ k \neq j}}^{n}\left(\boldsymbol{F}_{k} \mid \boldsymbol{F}_{i, j}\right)\right] .
$$

onde $m$ é o número de eventos de carregamento significativos, que podem surgir do mesmo ou de diferentes riscos. Para a Equação 6.21, uma versão simplificada da Equação 6.22, é dada por:

$$
P[\text { colapso }] \approx \sum_{v=1}^{m} P\left[\boldsymbol{E}_{v}\right] \cdot P\left[\boldsymbol{F}_{(e c, v)}\right] \cdot \sum_{\substack{j=1 \\ j \neq(e c, v)}}^{n} P\left[\boldsymbol{F}_{j} \mid \boldsymbol{F}_{(e c, v)}\right] \cdot P\left\{\bigcup_{\substack{k=1 \\ k \neq(e c, v) \\ k \neq j}}^{n}\left[\boldsymbol{F}_{k} \mid \boldsymbol{F}_{(e c, v), j}\right]\right\} .
$$

em que, o índice $(e c, v)$ é um lembrete de que o elemento chave é provável que seja diferente para diferentes eventos de carregamento. Na Equação 6.22 e Equação 6.23, os termos de probabilidade interna $P\left[\boldsymbol{F}_{i}\right]$ devem ser interpretados como condicionais à ocorrência do evento de carga $\left(E_{v}\right)$, conforme indicado na Equação 4.2 e Equação 6.7.

\subsection{Exemplos acadêmicos}

\subsubsection{Sistema de Daniels}

Neste exemplo é abordado uma estrutura clássica da confiabilidade de sistema, conhecida como Sistema de Daniels (GOLLWITZER; RACKWITZ, 1990). Esta é composta por $n$ barras paralelas que compartilham uma carga $S$, conforme ilustrado na Figura 26. O objetivo principal deste exemplo é ilustrar o comportamento dos coeficientes propostos na seção 6.2, a medida que o número de elementos no subsistema em paralelo aumenta. Todos os membros do sistema têm a mesma resistência $\left(R_{i}\right)$, que é suposto seguir uma distribuição lognormal, com coeficiente de variação (c.o.v.) igual a 0,07 (JCSS PROBABILISTIC MODEL CODE, 2001). A média da resistência de cada componente é avaliada de tal 
forma que, independentemente do número de barras $n$, as probabilidades individuais de falha são constantes e iguais a 0,001 (BAKER; SCHUBERT; FABER, 2008). As barras são assumidas de material frágil. Portanto, falham completamente se sua resistência é excedida. As forças nas $n$ barras assumem-se independentes. A carga $S$ segue uma distribuição lognormal com média unitária e c.o.v. $=0,3$. Neste caso, a resistência do sistema $\left(R_{n}\right)$, resulta:

$$
R_{n}=\max _{i}^{n}\left[(n-i+1) \cdot \bar{R}_{i}\right]
$$

em que, $\bar{R}_{i}$ são os valores ordenados da resistência de cada membro $\left(R_{i}\right)$, tal que: $\bar{R}_{1} \leq$ $\bar{R}_{2} \leq \cdots \leq \bar{R}_{n}$. Logo, a probabilidade de falha do Sistema de Daniels, fica determinada por:

$$
P_{f}=P\left[R_{n} \leq S\right]=P\left\{\bigcap_{i=1}^{n}\left[(n-i+1) \cdot \bar{R}_{i}-S \leq 0\right]\right\}
$$

Figura 26 - Sistema de Daniels formado de $n$ barras paralelas de material frágil.

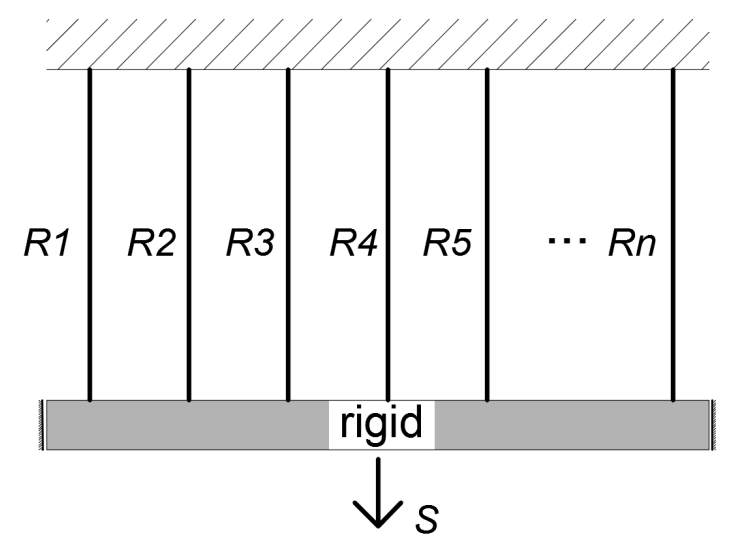

Fonte: Autoria própria.

As análises de confiabilidade foram realizadas via ISMC com auxílio do software StRAnD (BECK, 2007). Os coeficientes de vulnerabilidade e importância resultantes são mostrados na Figura 27. Pode-se observar na Figura 27 que, à medida que mais elementos são adicionados, a vulnerabilidade do sistema com relação ao colapso progressivo é reduzido $(C V C)$. Para um sistema de dois elementos, os coeficientes $C I D$ e $C I C$ são os mesmos. No entanto, a partir de três barras em diante, $C I D$ diminui em uma taxa menor do que $C I C$. Para um sistema tão simples, formado por barras idênticas, não se espera que as diferenças entre $C I D$ e $C I C$ sejam expressivas. Entretanto, para sistemas complexos formados de membros não idênticos e apresentando caminhos de carga alterantes, fusos estruturais, etc., essas diferenças devem se tornar significativas. 
Figura 27 - Coeficiente de vulnerabilidade e importância para o Sistema de Daniels formado por $n$ barras paralelas de material frágil.

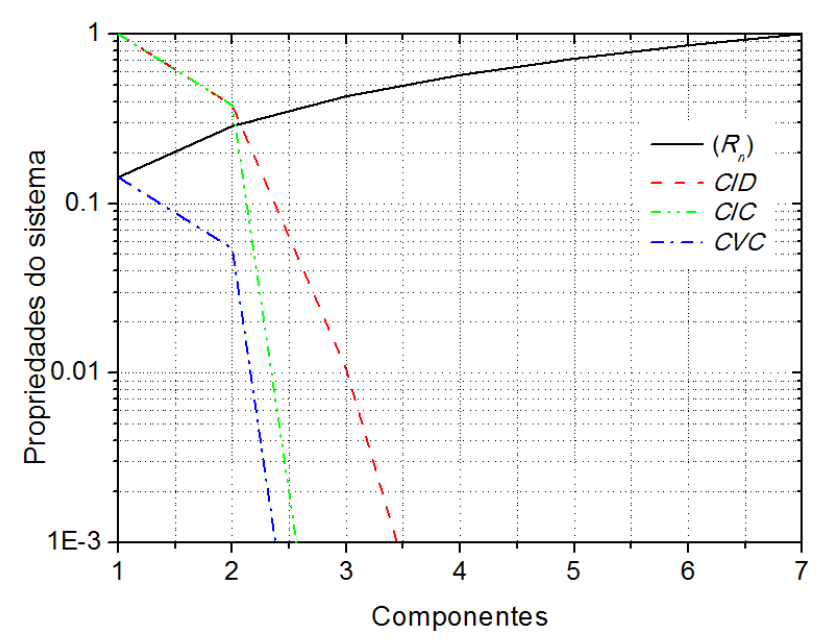

Fonte: Autoria própria.

\subsubsection{Treliça hiperestática}

Este problema consiste em uma treliça hiperestática formada por 11 barras, como ilustrado na Figura 28. As secções transversais de todos os membros foram dimensionados com o mesmo índice de confiabilidade igual a $3,7\left(P_{f} \approx 10^{-4}\right)$ (JCSS PROBABILISTIC MODEL CODE, 2001). Um único evento de carregamento $\left(E_{v}\right)$ é considerado, conforme apresentado na Figura 28. Pretende mostrar o comportamento dos coeficientes definidos na seção 6.2 quando assume-se todos os componentes do sistema com a mesma confiabilidade. Além disso, avaliar os elementos mais importantes para o colapso progressivo, admitindo um reforço nestes elementos.

Figura 28 - Treliça hiperestática formada por 11 membros.

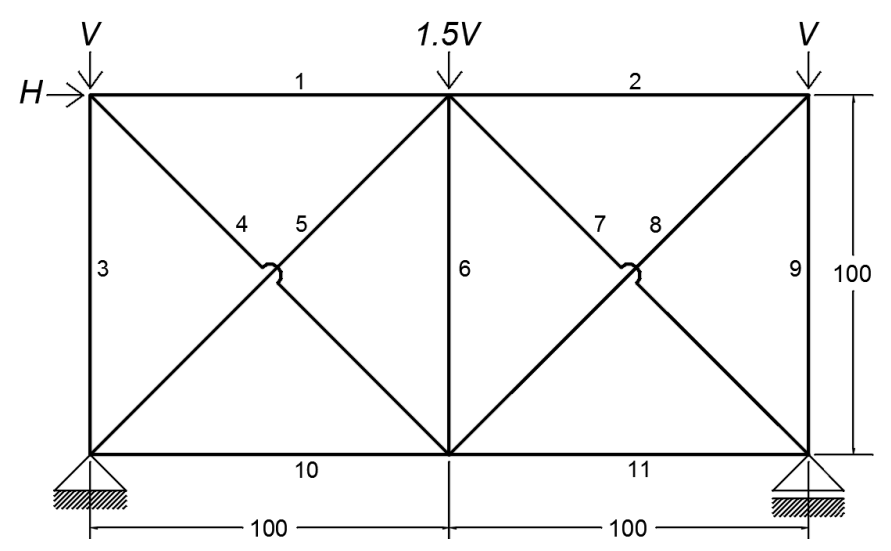

Fonte: Autoria própria. 
Duas equações de estado limite são escritas para as onze barras. Como as forças $H$ e $V$ são estritamente positivas (com valores apresentados na Tabela 1), as barras 1, 2, 3, 4, 5, 6, 7 e 9 estão comprimidas, enquanto as barras 8, 10 e 11 estão tracionadas. A falha dos elementos comprimidos é dada pela carga de flambagem de Euler e a falha das barras tracionadas é determinada pelo escoamento da seção bruta:

$$
\begin{gathered}
g_{i}\left(E_{i}, V, H\right)=\frac{\pi^{2} \cdot E_{i} \cdot I_{i}}{L_{i}^{2}}-\left(a_{i} \cdot V+b_{i} \cdot H\right), \quad \text { com } \quad i=\{1,2,3,4,5,6,7,9\} ; \\
g_{i}\left(f_{y_{i}}, V, H\right)=A_{i} \cdot f_{y_{i}}-\left(a_{i} \cdot V+b_{i} \cdot H\right), \quad \text { com } \quad i=\{8,10,11\} ;
\end{gathered}
$$

sendo $E_{i}$ o módulo de elasticidade, $I_{i}$ o momento de inércia, $L_{i}$ o comprimento da barra, $A_{i}$ a área da seção transversal, $f_{y_{i}}$ a tensão de escoamento do aço, $V$ a carga vertical, $H$ a carga horizontal, $a_{i}$ o fator de distribuição de carga vertical, $b_{i}$ o fator de distribuição de carga horizontal, respectivamente da barra $i$. Adotou-se uma correlação de 0,10 entre as cargas $V$ e $H$ (SANTOS; BECK, 2015). O módulo de elasticidade, a tensão de escoamento do aço e as cargas são variáveis aleatórias, como mostrado na Tabela 1 (VERZENHASSI, 2008).

Tabela 1 - Estatísticas para o problema em estudo.

\begin{tabular}{ccccc}
\hline Variável aleatória & Distribuição & Média & Coeficiente de variação & Unidades \\
\hline \hline$E_{i}$ & Lognormal & 20500 & 0,05 & $\left(\mathrm{kN} / \mathrm{cm}^{2}\right)$ \\
\hline$f_{y_{i}}$ & Lognormal & 25 & 0,05 & $\left(\mathrm{kN} / \mathrm{cm}^{2}\right)$ \\
\hline$V$ & Lognormal & 10 & 0,20 & $(k N)$ \\
\hline$H$ & Lognormal & 10 & 0,30 & $(k N)$ \\
\hline
\end{tabular}

Fonte: Verzenhassi (2008).

Definidas as equações de estado limite, os fatores de carga $a_{i}$ e $b_{i}$ são avaliados para cargas unitárias $H$ e $V$ via o Método dos Elementos Finitos Posicional, disponível no software AcadFrame (CODA; PACCOLA, 2006). Esses fatores de carga são recalculados para as estruturas isostáticas resultantes de falhas de membros supostos. As análises de confiabilidade são realizadas via FORM, utilizando o software StRAnD (BECK, 2007).

Assim, são determinadas as probabilidades de falha $\left(P\left[\boldsymbol{F}_{i}\right]\right)$ para a estrutura no estágio íntegro (ESI). Aplicando a Equação 6.13, têm-se os resultados apresentados na Tabela 2. Para a fase de propagação de danos, as probabilidades de falha do sistema $\left(P\left[\boldsymbol{F}_{i}^{P}\right]\right)$ (Equação 6.14), condicionadas à falha da barra $i$, e os valores dos coeficientes $C V, C I D$ e $C V D$ são também mostrados na Tabela 2.

Aplicando a Equação 6.20, o Elemento Chave $(E C)$ é a barra de número 7, como esperado. Uma sequência de falha iniciada na barra 7 tem a maior probabilidade de 
ocorrência, entre todos os caminhos de falha alternativos, com $P\left[c_{7}\right]=7,05 \cdot 10^{-5}$. Para validar a metodologia proposta neste trabalho, as probabilidades associadas aos outros dez possíveis caminhos de falha (iniciando por falhas das barras 1, 2, 3, 4, 5, 6, 8, 9, 10 ou 11) também são avaliadas, conforme apresentado na Tabela 3.

Tabela 2 - Coeficientes $C V, C I D$ e $C V D$ para a treliça em estudo.

\begin{tabular}{cccccc}
\hline Barra & $P\left[\boldsymbol{F}_{i}\right]$ & $C V$ & $P\left[\boldsymbol{F}_{i}^{P}\right]$ & $C I D$ & $C V D$ \\
\hline \hline 1 & $1,00 \cdot 10^{-4}$ & $9,09 \cdot 10^{-2}$ & $2,20 \cdot 10^{-4}$ & $9,95 \cdot 10^{-1}$ & $9,04 \cdot 10^{-2}$ \\
\hline 2 & $1,00 \cdot 10^{-4}$ & $9,09 \cdot 10^{-2}$ & $1,31 \cdot 10^{-5}$ & $5,93 \cdot 10^{-2}$ & $5,39 \cdot 10^{-3}$ \\
\hline 3 & $1,00 \cdot 10^{-4}$ & $9,09 \cdot 10^{-2}$ & $2,15 \cdot 10^{-4}$ & $9,73 \cdot 10^{-1}$ & $8,84 \cdot 10^{-2}$ \\
\hline 4 & $1,00 \cdot 10^{-4}$ & $9,09 \cdot 10^{-2}$ & $2,59 \cdot 10^{-7}$ & $1,17 \cdot 10^{-3}$ & $1,06 \cdot 10^{-4}$ \\
\hline 5 & $1,00 \cdot 10^{-4}$ & $9,09 \cdot 10^{-2}$ & $1,67 \cdot 10^{-6}$ & $7,56 \cdot 10^{-3}$ & $6,87 \cdot 10^{-4}$ \\
\hline 6 & $1,00 \cdot 10^{-4}$ & $9,09 \cdot 10^{-2}$ & $2,31 \cdot 10^{-6}$ & $1,05 \cdot 10^{-2}$ & $9,54 \cdot 10^{-4}$ \\
\hline $\mathbf{7}$ & $\mathbf{1 , 0 0 \cdot \mathbf { 1 0 } ^ { - 4 }}$ & $\mathbf{9 , 0 9 \cdot 1 0 ^ { - 2 }}$ & $\mathbf{2 , 2 1} \cdot \mathbf{1 0}-\mathbf{4}$ & $\mathbf{1 , 0 0}$ & $\mathbf{9 , 0 9 \cdot 1 0 ^ { - 2 }}$ \\
\hline 8 & $1,00 \cdot 10^{-4}$ & $9,09 \cdot 10^{-2}$ & $1,22 \cdot 10^{-5}$ & $5,52 \cdot 10^{-2}$ & $5,02 \cdot 10^{-3}$ \\
\hline 9 & $1,00 \cdot 10^{-4}$ & $9,09 \cdot 10^{-2}$ & $2,05 \cdot 10^{-4}$ & $9,28 \cdot 10^{-1}$ & $8,44 \cdot 10^{-2}$ \\
\hline 10 & $1,00 \cdot 10^{-4}$ & $9,09 \cdot 10^{-2}$ & $8,27 \cdot 10^{-5}$ & $3,74 \cdot 10^{-1}$ & $3,40 \cdot 10^{-2}$ \\
\hline 11 & $1,00 \cdot 10^{-4}$ & $9,09 \cdot 10^{-2}$ & $1,94 \cdot 10^{-4}$ & $8,78 \cdot 10^{-1}$ & $7,98 \cdot 10^{-2}$ \\
\hline soma & $1,10 \cdot 10^{-3}$ & $\mathbf{m a x}$ & $2,21 \cdot 10^{-4}$ & & \\
\hline
\end{tabular}

Fonte: Autoria própria.

Tabela 3 - Coeficientes $C I C$ e $C V C$ para a treliça em estudo.

\begin{tabular}{|c|c|c|c|c|c|}
\hline Barra & $P\left[\boldsymbol{F}_{i}\right]$ & $C V$ & $P\left[c_{i}\right]$ & $C I C$ & $C V C$ \\
\hline 1 & $1,00 \cdot 10^{-4}$ & $9,09 \cdot 10^{-2}$ & $7,32 \cdot 10^{-6}$ & $1,04 \cdot 10^{-1}$ & $9,45 \cdot 10^{-3}$ \\
\hline 2 & $1,00 \cdot 10^{-4}$ & $9,09 \cdot 10^{-2}$ & $4,23 \cdot 10^{-6}$ & $6,00 \cdot 10^{-2}$ & $5,45 \cdot 10^{-3}$ \\
\hline 3 & $1,00 \cdot 10^{-4}$ & $9,09 \cdot 10^{-2}$ & $6,99 \cdot 10^{-6}$ & $9,91 \cdot 10^{-2}$ & $9,01 \cdot 10^{-3}$ \\
\hline 4 & $1,00 \cdot 10^{-4}$ & $9,09 \cdot 10^{-2}$ & $8,33 \cdot 10^{-8}$ & $1,18 \cdot 10^{-3}$ & $1,07 \cdot 10^{-4}$ \\
\hline 5 & $1,00 \cdot 10^{-4}$ & $9,09 \cdot 10^{-2}$ & $1,22 \cdot 10^{-7}$ & $1,73 \cdot 10^{-3}$ & $1,57 \cdot 10^{-4}$ \\
\hline 6 & $1,00 \cdot 10^{-4}$ & $9,09 \cdot 10^{-2}$ & $4,34 \cdot 10^{-6}$ & $6,16 \cdot 10^{-2}$ & $5,60 \cdot 10^{-3}$ \\
\hline 7 & $1,00 \cdot 10^{-4}$ & $9,09 \cdot 10^{-2}$ & $7,05 \cdot 10^{-5}$ & 1,00 & $9,09 \cdot 10^{-2}$ \\
\hline 8 & $1,00 \cdot 10^{-4}$ & $9,09 \cdot 10^{-2}$ & $5,61 \cdot 10^{-7}$ & $7,96 \cdot 10^{-3}$ & $7,24 \cdot 10^{-4}$ \\
\hline 9 & $1,00 \cdot 10^{-4}$ & $9,09 \cdot 10^{-2}$ & $2,31 \cdot 10^{-5}$ & $3,28 \cdot 10^{-1}$ & $2,98 \cdot 10^{-2}$ \\
\hline 10 & $1,00 \cdot 10^{-4}$ & $9,09 \cdot 10^{-2}$ & $1,79 \cdot 10^{-6}$ & $2,54 \cdot 10^{-2}$ & $2,31 \cdot 10^{-3}$ \\
\hline 11 & $1,00 \cdot 10^{-4}$ & $9,09 \cdot 10^{-2}$ & $5,30 \cdot 10^{-6}$ & $7,52 \cdot 10^{-2}$ & $6,84 \cdot 10^{-3}$ \\
\hline soma & $1,10 \cdot 10^{-3}$ & $\max$ & $7,05 \cdot 10^{-5}$ & & \\
\hline
\end{tabular}

Fonte: Autoria própria.

Na Tabela 3, verifica-se que o elemento mais importante é a barra número 7 , pois 
apresenta o maior valor de $C V C$, seguida pelas barras 9, 1, 3, 11, 6, 2 e 10. Os coeficientes $C V C$ para as barras 4, 5 e 8 são aproximadamente zero. Isto mostra que uma falha primária dessas barras leva a uma baixa desproporcionalidade nos esforços e deslocamentos para a estrutura. Portanto, a treliça na perda desses elementos busca uma nova posição de equilíbrio, sem a ocorrência do colapso progressivo.

Comparando o valor da soma das probabilidades dos caminhos das barras 1, 2, 3, $4,5,6,8,9,10$ e $11\left(5,35 \cdot 10^{-5}\right)$ com o valor da sequência de falha do $E C\left(7,05 \cdot 10^{-5}\right)$, observa-se que o valor determinado por este é ainda maior do que o verificado para a soma de todos os outros caminhos. Além disso, a probabilidade de colapso total é encontrada como $P[$ colapso $]=1,24 \cdot 10^{-4}$, com $56,9 \%$ deste valor associado à sequência de falha do $E C$. Como o $E C$ gera a maior $P\left[c_{i}\right]$, sua determinação implica na diminuição das análises das outras sequências de falha que sempre terão valores de $P\left[c_{i}\right]$ menores. Desta forma, observa-se que a metodologia identifica adequadamente o(s) elemento(s) chave, servindo de guia para projetos estruturais que visem minimizar à ocorrência do colapso progressivo.

O projetista estrutural pode se concentrar em medidas que aumentem a resistência dos elementos com maiores valores de $C V C$ para minimizar à ocorrência do ESPD. Por exemplo, pode-se aumentar a taxa de armadura ou realizar reforços para prover ductilidade nesses elementos. Dessa forma, analisa-se novamente a treliça hiperestática assumindo um reforço nas barras 7 e 9, dimensionada com um índice de confiabilidade igual a 4,7 $\left(P_{f} \approx 10^{-6}\right)$, conforme a JCSS Probabilistic Model Code (2001), e mantendo as outras barras com suas propriedades iniciais. Na Tabela 4 e Tabela 5, são apresentados os coeficientes de vulnerabilidade e importância para essa nova análise.

Da Tabela 4, nota-se que o elemento mais importante para iniciar o estágio de propagação de dano é a barra 1, seguida da 3 e 10. Todavia, o elemento mais importante passa a ser a barra 3 na avaliação do estágio de colapso progressivo (Tabela 5). As outras barras da treliça hiperestática têm valores de $C V C$ aproximadamente iguais a zero, consequentemente a falha desses elementos dificilmente provoca o colapso dessa estrutura.

É evidente que a introdução do reforço nas barras 7 e 9 diminuem as probabilidades das sequências de falhas condicionais de todos os membros $\left(P\left[c_{i}\right]\right)$, conforme a Tabela 5 . Verifica-se que as $P\left[c_{i}\right]$ (exceto a $P\left[c_{3}\right]$ e $P\left[c_{1}\right]$ ) estão com o valor de risco aceitável, dado um evento que acarrete à falha desses membros de acordo com (NISTIR 7396, 2007; ELLINGWOOD, 2006; PATE-CORNELL, 1994).

Portanto, a identificação dos elementos estruturais mais importantes, particularmente o(s) elemento(s) chave, é um requisito básico para projetos estruturais que visem minimizar à ocorrência do colapso progressivo. Conhecido esses elementos, o engenheiro pode reforçá-los, aumentando a robustez da estrutura contra eventuais danos. 
Tabela 4 - Coeficientes $C V, C I D$ e $C V D$ para a nova análise da treliça em estudo.

\begin{tabular}{|c|c|c|c|c|c|}
\hline Barra & $P\left[\boldsymbol{F}_{i}\right]$ & $C V$ & $P\left[\boldsymbol{F}_{i}^{P}\right]$ & $C I D$ & $C V D$ \\
\hline 1 & $1,00 \cdot 10^{-4}$ & $1,10 \cdot 10^{-1}$ & $2,46 \cdot 10^{-5}$ & 1,00 & $1,10 \cdot 10^{-1}$ \\
\hline 2 & $1,00 \cdot 10^{-4}$ & $1,10 \cdot 10^{-1}$ & $8,54 \cdot 10^{-9}$ & $3,47 \cdot 10^{-4}$ & $3,82 \cdot 10^{-5}$ \\
\hline 3 & $1,00 \cdot 10^{-4}$ & $1,10 \cdot 10^{-1}$ & $2,35 \cdot 10^{-5}$ & $9,55 \cdot 10^{-1}$ & $1,05 \cdot 10^{-1}$ \\
\hline 4 & $1,00 \cdot 10^{-4}$ & $1,10 \cdot 10^{-1}$ & $1,42 \cdot 10^{-7}$ & $5,77 \cdot 10^{-3}$ & $6,35 \cdot 10^{-4}$ \\
\hline 5 & $1,00 \cdot 10^{-4}$ & $1,10 \cdot 10^{-1}$ & $1,34 \cdot 10^{-6}$ & $5,45 \cdot 10^{-2}$ & $6,00 \cdot 10^{-3}$ \\
\hline 6 & $1,00 \cdot 10^{-4}$ & $1,10 \cdot 10^{-1}$ & $2,29 \cdot 10^{-8}$ & $9,31 \cdot 10^{-4}$ & $1,02 \cdot 10^{-4}$ \\
\hline 7 & $1,00 \cdot 10^{-6}$ & $1,10 \cdot 10^{-3}$ & $3,26 \cdot 10^{-7}$ & $1,33 \cdot 10^{-2}$ & $1,46 \cdot 10^{-5}$ \\
\hline 8 & $1,00 \cdot 10^{-4}$ & $1,10 \cdot 10^{-1}$ & $7,81 \cdot 10^{-9}$ & $3,17 \cdot 10^{-4}$ & $3,49 \cdot 10^{-5}$ \\
\hline 9 & $1,00 \cdot 10^{-6}$ & $1,10 \cdot 10^{-3}$ & $5,84 \cdot 10^{-7}$ & $2,37 \cdot 10^{-2}$ & $2,61 \cdot 10^{-5}$ \\
\hline 10 & $1,00 \cdot 10^{-4}$ & $1,10 \cdot 10^{-1}$ & $7,30 \cdot 10^{-6}$ & $2,97 \cdot 10^{-1}$ & $3,27 \cdot 10^{-2}$ \\
\hline 11 & $1,00 \cdot 10^{-4}$ & $1,10 \cdot 10^{-1}$ & $1,51 \cdot 10^{-6}$ & $6,14 \cdot 10^{-2}$ & $6,75 \cdot 10^{-3}$ \\
\hline soma & $9,02 \cdot 10^{-4}$ & $\max$ & $2,46 \cdot 10^{-5}$ & & \\
\hline
\end{tabular}

Fonte: Autoria própria.

Tabela 5 - Coeficientes $C I C$ e $C V C$ para a nova análise da treliça em estudo.

\begin{tabular}{cccccc}
\hline Barra & $P\left[\boldsymbol{F}_{i}\right]$ & $C V$ & $P\left[c_{i}\right]$ & $C I C$ & $C V C$ \\
\hline \hline 1 & $1,00 \cdot 10^{-4}$ & $1,10 \cdot 10^{-1}$ & $6,55 \cdot 10^{-7}$ & $9,21 \cdot 10^{-1}$ & $1,01 \cdot 10^{-1}$ \\
\hline 2 & $1,00 \cdot 10^{-4}$ & $1,10 \cdot 10^{-1}$ & $1,51 \cdot 10^{-10}$ & $2,12 \cdot 10^{-4}$ & $2,33 \cdot 10^{-5}$ \\
\hline $\mathbf{3}$ & $\mathbf{1 , 0 0} \cdot \mathbf{1 0}^{-\mathbf{4}}$ & $\mathbf{1 , 1 0} \cdot \mathbf{1 0}-\mathbf{1}$ & $\mathbf{7 , 1 1} \cdot \mathbf{1 0}^{-\mathbf{7}}$ & $\mathbf{1 , 0 0}$ & $\mathbf{1 , 1 0 \cdot 1 0 ^ { - \mathbf { 1 } }}$ \\
\hline 4 & $1,00 \cdot 10^{-4}$ & $1,10 \cdot 10^{-1}$ & $6,82 \cdot 10^{-9}$ & $9,59 \cdot 10^{-3}$ & $1,05 \cdot 10^{-3}$ \\
\hline 5 & $1,00 \cdot 10^{-4}$ & $1,10 \cdot 10^{-1}$ & $2,18 \cdot 10^{-9}$ & $3,07 \cdot 10^{-3}$ & $3,38 \cdot 10^{-4}$ \\
\hline 6 & $1,00 \cdot 10^{-4}$ & $1,10 \cdot 10^{-1}$ & $1,97 \cdot 10^{-9}$ & $2,77 \cdot 10^{-3}$ & $3,05 \cdot 10^{-4}$ \\
\hline 7 & $1,00 \cdot 10^{-6}$ & $1,10 \cdot 10^{-3}$ & $1,93 \cdot 10^{-8}$ & $2,71 \cdot 10^{-2}$ & $2,98 \cdot 10^{-5}$ \\
\hline 8 & $1,00 \cdot 10^{-4}$ & $1,10 \cdot 10^{-1}$ & $6,18 \cdot 10^{-11}$ & $8,69 \cdot 10^{-5}$ & $9,56 \cdot 10^{-6}$ \\
\hline 9 & $1,00 \cdot 10^{-6}$ & $1,10 \cdot 10^{-3}$ & $7,02 \cdot 10^{-9}$ & $9,87 \cdot 10^{-3}$ & $1,09 \cdot 10^{-5}$ \\
\hline 10 & $1,00 \cdot 10^{-4}$ & $1,10 \cdot 10^{-1}$ & $8,92 \cdot 10^{-8}$ & $1,25 \cdot 10^{-1}$ & $1,38 \cdot 10^{-2}$ \\
\hline 11 & $1,00 \cdot 10^{-4}$ & $1,10 \cdot 10^{-1}$ & $7,55 \cdot 10^{-8}$ & $1,06 \cdot 10^{-1}$ & $1,17 \cdot 10^{-2}$ \\
\hline soma & $9,02 \cdot 10^{-4}$ & $\mathbf{m a x}$ & $7,11 \cdot 10^{-7}$ & & \\
\hline
\end{tabular}

Fonte: Autoria própria. 


\section{Equação de Estado Limite das Paredes}

Neste capítulo é apresentado a formulação da equação de estado limite à compressão axial das paredes estruturais. Ademais, ao final do capítulo é realizado um estudo de caso em um edifício de alvenaria, aplicando a equação deduzida e as definições apresentadas no Capítulo 6.

\subsection{Equação de Estado Limite das Paredes}

A resistência à compressão, certamente, é a propriedade mais importante e comum em edifícios de alvenaria, pois as paredes estruturais estão sujeitas predominantemente ao esforço de compressão (PARSEKIAN; HAMID; DRYSDALE, 2013; CORRÊA; RAMALHO, 2004).

No dimensionamento de um elemento submetido à compressão, um dos fatores importantes a ser levando em consideração, é a instabilidade que possa ocorrer nesse elemento. As normativas brasileira de alvenaria estrutural, ABNT NBR 15961-1 (2011) e ABNT NBR 15812-1 (2010), adotam o conceito de esbeltez simplificada para levar em consideração os efeitos de instabilidade nas paredes. Neste caso, a resistência à compressão da alvenaria é penalizada através de um coeficiente $R$, definido por:

$$
R=\left[1-\left(\frac{\lambda}{40}\right)^{3}\right]
$$

sendo, $\lambda$ a esbeltez simplificada definida:

$$
\lambda=\frac{h_{e f}}{t_{\text {ef }}} \leq\left\{\begin{array}{lll}
24 & \text { alvenaria } & \text { não armada } \\
30 & \text { alvenaria } & \text { armada }
\end{array}\right.
$$

em que, $h_{e f}$ e $t_{e f}$ são a altura efetiva e a espessura efetiva determinadas pelas recomendações da ABNT NBR 15961-1 (2011) e ABNT NBR 15812-1 (2010).

Ressalta-se que a Equação 7.1 tem sua origem em documentos normativos que abordavam o dimensionamento das paredes estruturais pelo método das tensões admissíveis (Método Determinístico). Entretanto, a Equação 7.1 ainda continua sendo utilizada na ABNT NBR 15961-1 (2011) e ABNT NBR 15812-1 (2010), o que provoca uma contradição, visto que as referidas normas adotam os conceitos de estados limites (Método Semiprobabilístico) para o dimensionamento dos elementos estruturais.

Neste trabalho, é adotado o coeficiente de redução prescrito no ACI 530 (2013). Este foi obtido com base em estudos de pesquisadores americanos através de aproximação 
de ensaios experimentais (LOPES, 2014). Logo, $R$ resulta:

$$
R=\left[1-\left(\frac{\lambda}{140}\right)^{2}\right]
$$

sendo, $\lambda$ definido a partir da Teoria da Mecânica dos Sólidos, isto é:

$$
\lambda=\frac{h_{e f}}{r} \rightarrow r=\sqrt{\frac{I}{A}}
$$

onde, $A, I$ e $r$ são, respectivamente, a área, a inércia e o raio de giração da seção transversal da parede. No caso, de elementos retangulares, tem-se:

$$
\lambda=\frac{h_{e f} \cdot \sqrt{12}}{t_{e f}}
$$

Figura 29 - Análise do coeficiente de redução $R$.

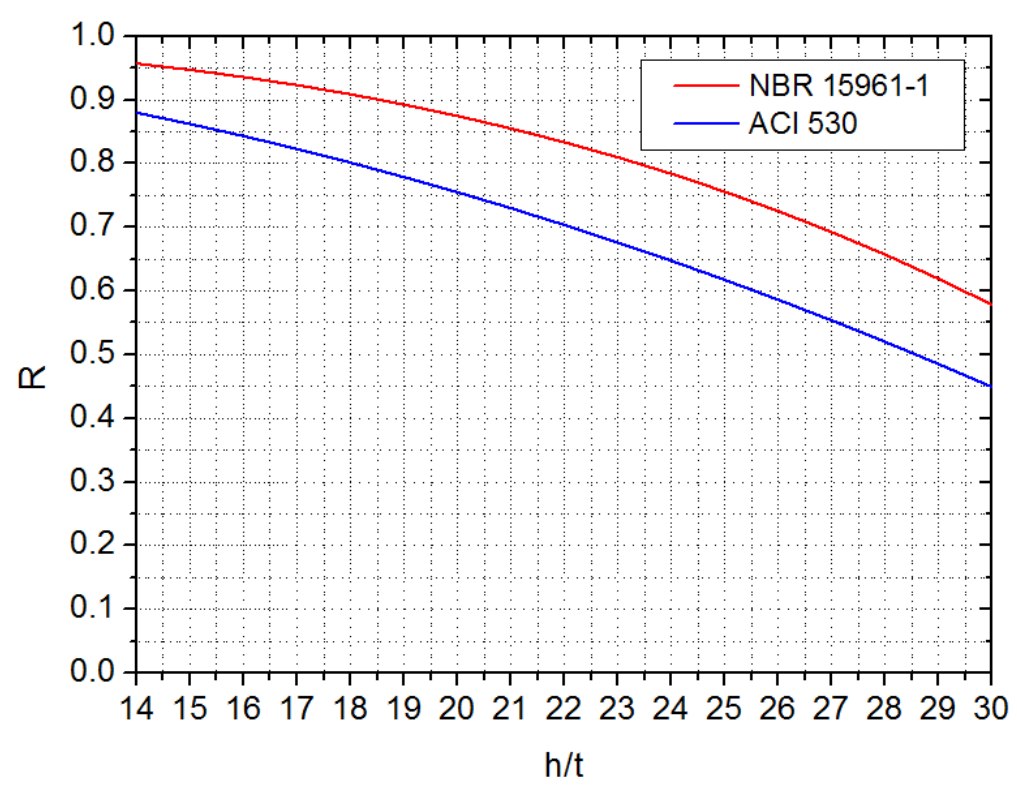

Fonte: Autoria própria.

Constata-se na Figura 29 que o coeficiente $R$ determinado pela Equação 7.1 gera uma dispersão nos resultados se comparados com o calculado via Equação 7.3. Como o $R$ é o coeficiente de penalização da resistência à compressão, verifica-se que para a mesma resistência à compressão, a Equação 7.3 resulta em um valor menor que a Equação 7.1, ou seja, aquela é a favor da segurança em comparação com esta.

Conhecido o valor do coeficiente $R$ e a área da seção transversal $\left(A=t_{e f} \cdot L\right)$, a capacidade (força) resistente da parede $\left(F_{R}\right)$, é determinada pelo produto direto destas constantes com a resistência à compressão da alvenaria $\left(f_{a}\right)$. A força solicitante $\left(F_{S}\right)$ é 
obtida por meio da integração das tensões atuantes na seção transversal do elemento analisado. Assim, a equação de estado limite das paredes estruturais sujeitas à compressão axial, torna-se:

$$
g(r, s)=F_{R}-F_{S}=f_{a} \cdot A \cdot R-F_{S}
$$

Combinando a Equação 7.3, Equação 7.4 e Equação 7.6, tem-se:

$$
g\left(f_{a}, t, h, L, g, q\right)=f_{a} \cdot t_{e f} \cdot L \cdot\left[1-\left(\frac{h_{e f} \cdot \sqrt{12}}{140 \cdot t_{e f}}\right)^{2}\right]-\left(F_{S, g}+F_{S, q}\right)
$$

onde, $L$ é o comprimento da parede analisada, enquanto que $F_{S, g}$ e $F_{S, q}$ são as forças solicitantes permanentes e variáveis, respectivamente.

\subsection{Sensibilidade da probabilidade de falha}

A medida da sensibilidade da probabilidade de falha $\left(\boldsymbol{S}\left[P_{f}\right]\right)$ é muito importante para os problemas de confiabilidade estrutural, pois permite reduzir a dimensão do problema por meio da eliminação de variáveis aleatórias sem relevância.

Para determinar a $\boldsymbol{S}\left[P_{f}\right]$, toma-se a derivada da probabilidade de falha, em relação às variáveis aleatórias que compõem o problema no ponto de projeto $\left(\boldsymbol{y}^{*}\right)$. Assim, obtém-se informações sobre a parcela de cada variável aleatória na composição da probabilidade de falha $\left(P_{f}\right)$, o que resulta:

$$
\boldsymbol{S}\left[P_{f}\right]=\left.\frac{\partial P_{f}}{\partial \boldsymbol{y}}\right|_{\boldsymbol{y}=\boldsymbol{y}^{*}}=\left.\frac{\partial[\Phi(-\beta)]}{\partial \boldsymbol{y}}\right|_{\boldsymbol{y}=\boldsymbol{y}^{*}}=\left.\frac{\partial \Phi(-\beta)}{\partial \boldsymbol{y}} \cdot \frac{\partial \beta}{\partial \boldsymbol{y}}\right|_{\boldsymbol{y}=\boldsymbol{y}^{*}}
$$

Recordando da Teoria de Probabilidade, obtém-se:

$$
f_{x}(x)=\frac{\partial F_{x}(x)}{\partial x} \quad \longrightarrow \quad \phi(-\beta)=\frac{\partial \Phi(-\beta)}{\partial \boldsymbol{y}}
$$

em que, $f_{x}(x), F_{x}(x), \phi(y)$ e $\Phi(y)$ são as funções de densidades de probabilidade e as funções de distribuição cumulativa de probabilidade, respectivamente, no espaço de projeto e no espaço normal padrão. A segunda parcela da derivada na Equação 7.8 é determinada a partir da definição do ponto de projeto. Neste caso, o gradiente da equação de estado limite se projeta sobre a origem, de forma que:

$$
\boldsymbol{y}^{*}=-\boldsymbol{\alpha}\left(\boldsymbol{y}^{*}\right) \cdot \beta \quad \Longleftrightarrow \quad \beta=\left\|\boldsymbol{y}^{*}\right\|
$$

sendo, $\boldsymbol{\alpha}$ o vetor de cossenos diretores da equação de estado limite avaliado em $\boldsymbol{y}^{*}$. Logo, substituindo a Equação 7.10 na segunda parcela da derivada na Equação 7.8, resulta:

$$
\left.\frac{\partial \beta}{\partial \boldsymbol{y}}\right|_{\boldsymbol{y}=\boldsymbol{y}^{*}}=-\frac{\nabla g\left(\boldsymbol{y}^{*}\right)}{\left\|\nabla g\left(\boldsymbol{y}^{*}\right)\right\|}=-\boldsymbol{\alpha}\left(\boldsymbol{y}^{*}\right)
$$


Combinando a Equação 7.11, Equação 7.9 e Equação 7.8, obtém-se:

$$
\boldsymbol{S}\left[P_{f}\right]=\left.\frac{\partial P_{f}}{\partial \boldsymbol{y}}\right|_{\boldsymbol{y}=\boldsymbol{y}^{*}}=-\boldsymbol{\alpha}\left(\boldsymbol{y}^{*}\right) \cdot \phi(-\beta) .
$$

Como o termo $\phi(-\beta)$ é um valor constante, e lembrando da álgebra linear que $\sum \alpha_{i}^{2}=1$, constata-se que os $\alpha_{i}^{2}$ indicam a contribuição relativa de $\boldsymbol{y}_{i}{ }^{1}$ na composição da $P_{f}$. Sendo assim, se $\alpha_{i}^{2} \approx 0, \boldsymbol{y}_{i}$ tem pouca contribuição na $P_{f}$, podendo ser substituída pelo seu valor determinístico (BECK, 2015). Deste modo, realizando uma análise de sensibilidade na Equação 7.7, verifica-se que $L$ e $h_{e f}$ podem ser consideradas como variáveis determinísticas, pois seus valores de $\alpha_{i}^{2}$ são aproximadamente iguais a zero.

\subsection{Exemplo de aplicação: edifício de alvenaria}

Para a validação das definições apresentadas no Capítulo 6, é realizado um estudo de caso em um edifício de alvenaria estrutural não armado de bloco de concreto com seis pavimentos, conforme ilustrado na Figura 30. O colapso potencial do edifício é configurado, supondo que uma parede estrutural é perdida, assumindo que a probabilidade de falha dessa ocorrência é igual a unidade ${ }^{2}$.

Figura 30 - Planta baixa do edifício em estudo (dimensões em $\mathrm{cm}$ ).

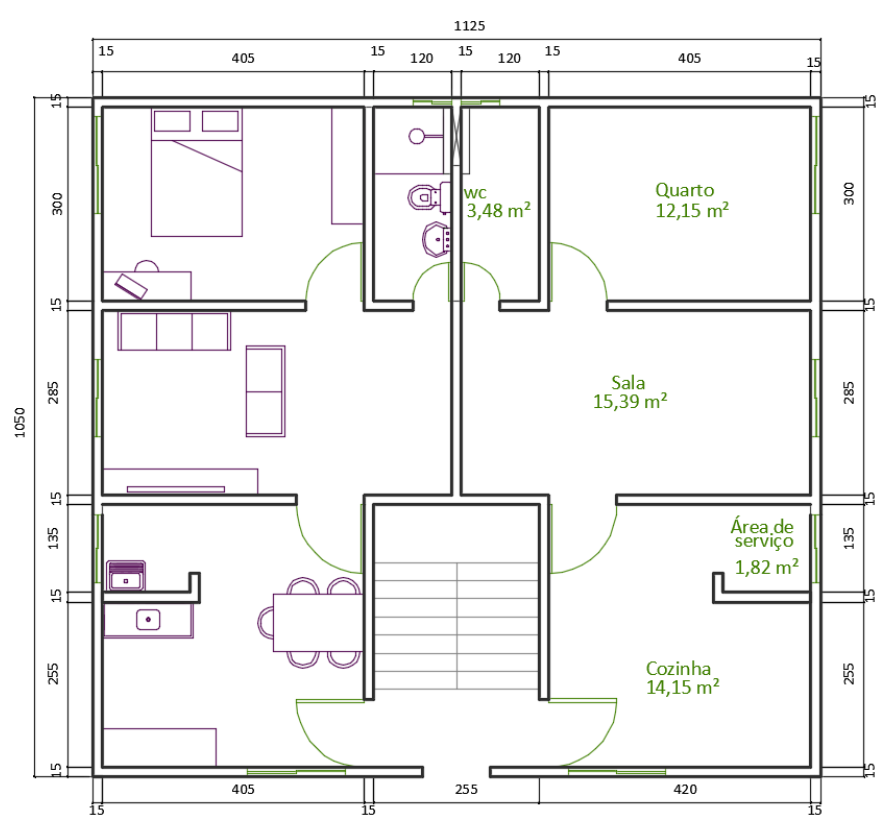

Fonte: AltoQi (2015).

As seguintes hipóteses simplificadoras são adotadas na solução deste problema:

1 Portanto, também o valor da variável aleatória no espaço de projeto $\boldsymbol{x}_{\boldsymbol{i}}$.

2 A metodologia do RAPC é independente de qual evento $E_{v}$ produz o dano inicial (falha do elemento estrutural), de acordo com a hipótese Item a) da seção 6.1. 
a) desconsidera-se as aberturas de portas e janelas;

b) o modo de falha considerado é somente o de compressão axial;

c) as probabilidades de falha são determinadas somente para o pavimento térreo;

d) considera-se as lajes infinitamente rígidas.

As lajes do edifício são do tipo maciça com espessura de $10 \mathrm{~cm}$, as paredes têm espessura de $14 \mathrm{~cm}$ e altura de $280 \mathrm{~cm}$. De acordo com a ABNT NBR 6120 (1980), em edificações residenciais, a carga mínima para dormitórios, sala, copa, cozinha e banheiro é de $1,5 \mathrm{kN} / \mathrm{m}^{2}$, e para despensa, área de serviço e lavanderia é de $2,0 \mathrm{kN} / \mathrm{m}^{2}$. Assim, adota-se para o edifício como um todo, uma carga variável igual a $q=2,0 \mathrm{kN} / \mathrm{m}^{2}$.

A carga permanente nas lajes é dada pelo produto da espessura $(h=10 \mathrm{~cm})$ pelo peso específico do concreto armado $\left(\gamma_{c}=25 \mathrm{kN} / \mathrm{m}^{3}\right)$, mais uma parcela de carga devido a um contra-piso e um revestimento cerâmico de $1,0 \mathrm{kN} / \mathrm{m}^{2}$, logo, a carga permanente é igual a $g=3,5 \mathrm{kN} / \mathrm{m}^{2}$. O vão efetivo das lajes e das paredes são determinados das distâncias eixo a eixo de cada elemento.

Figura 31 - Esquema de numeração das paredes e posição da $q_{i}$.

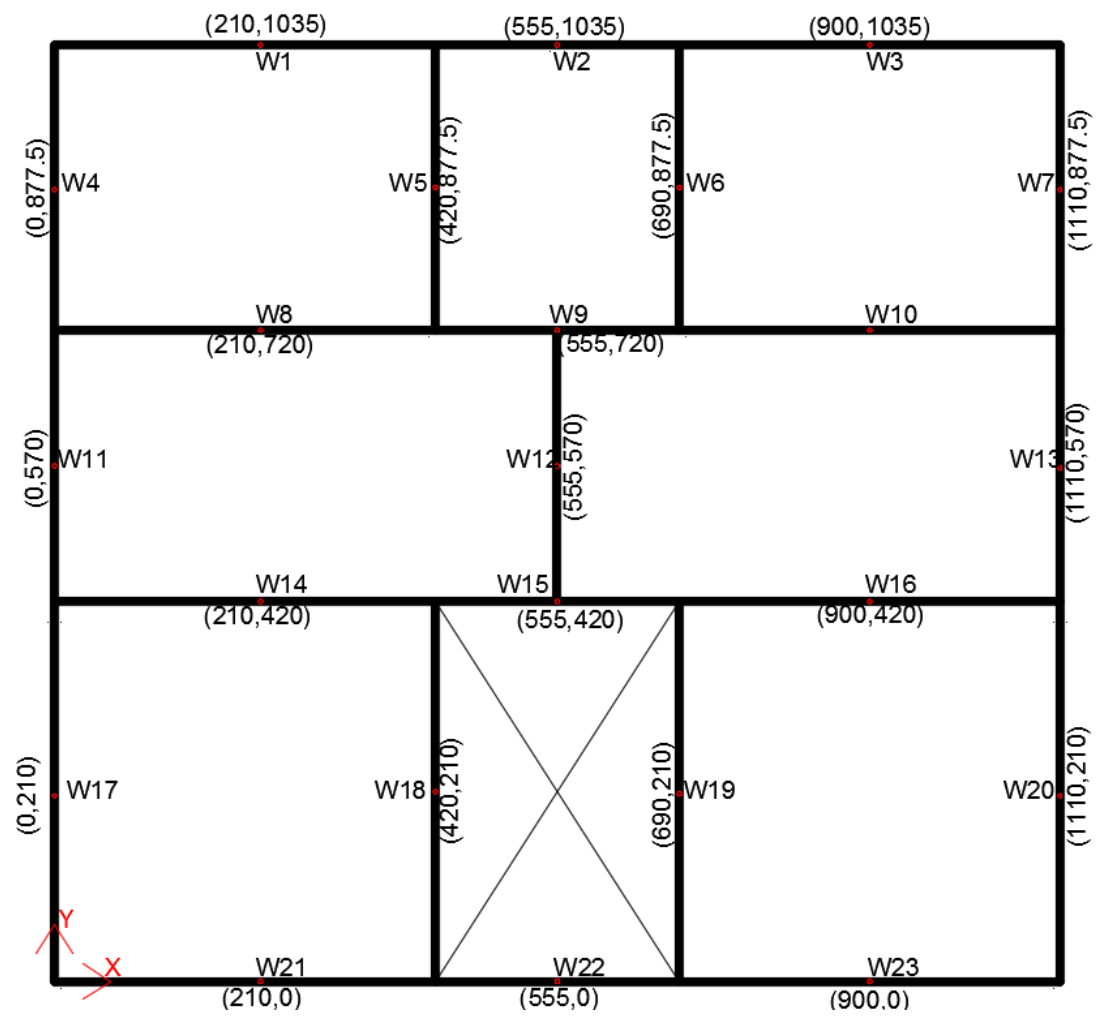

Fonte: Autoria própria.

O levantamento dos quinhões de cargas $\left(q_{i}\right)$ para cada elemento estrutural é 
realizado através da seguinte equação:

$$
q_{i}=Q \cdot\left(\frac{A_{i}}{\sum_{i=1}^{n} A_{i}}+\frac{e_{x} \cdot A_{i} \cdot X_{i}}{\sum_{i=1}^{n} A_{i} \cdot X_{i}^{2}}+\frac{e_{y} \cdot A_{i} \cdot Y_{i}}{\sum_{i=1}^{n} A_{i} \cdot Y_{i}^{2}}\right) .
$$

sendo, $Q, A_{i}, X_{i}, e_{x}, Y_{i}$ e $e_{y}$, respectivamente, o carregamento, a área da seção transversal do elemento $E_{i}$, a posição de aplicação da carga $q_{i}$ no elemento $E_{i}$ na direção $x$, a excentricidade em relação ao centro elástico na direção $x$, a posição de aplicação da carga $q_{i}$ no elemento $E_{i}$ na direção $y$ e a excentricidade em relação ao centro elástico na direção y. A Figura 31 mostra o esquema de numeração de todas as paredes, bem como a posição da aplicação da carga $q_{i}$.

O dimensionamento do edifício é realizado a partir das recomendações da ABNT NBR 15961-1 (2011) e Eurocode 6 (2005). Para tal, adota-se para o pavimento em análise (pavimento térreo) bloco de concreto com $f_{b}=4,5 \mathrm{MPa}$ ( $50 \%$ de furação), argamassa com resistência de $f_{\text {arg }}=3,6 \mathrm{MPa}$. Dessa forma, a resistência à compressão característica da alvenaria é calculada pela Equação 7.14, onde $k$ é uma constante que depende do tipo do material do bloco conforme apresentado na Tabela 3.3 do Eurocode 6 (2005). Para blocos de concreto incluído no grupo $2, k=0,45$, o que resulta:

$$
f_{k}=k \cdot f_{b}^{0,7} \cdot f_{\text {arg }}^{0,3} \cong 1,90 M P a .
$$

Figura 32 - Tensão solicitante de cálculo em MPa.

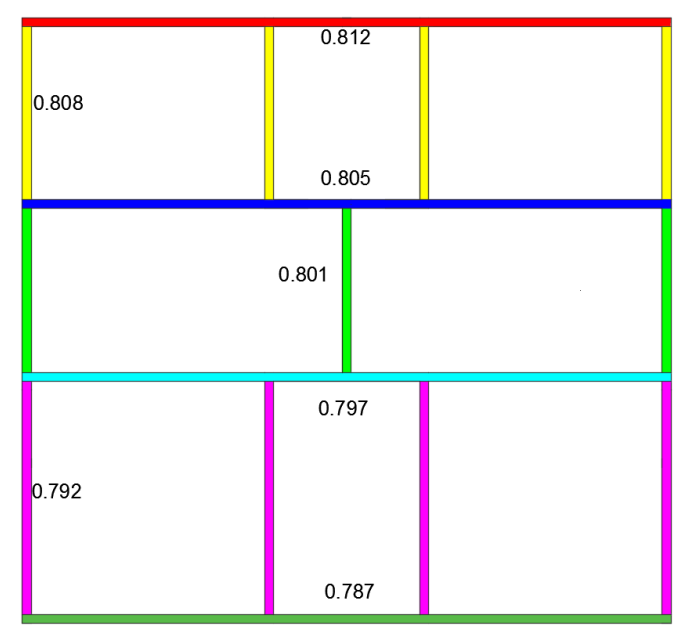

Fonte: Autoria própria.

Então, a resistência à compressão de cálculo da alvenaria, resulta: $f_{d}=f_{k} / \gamma_{m}=$ 0,950 MPa, onde $\gamma_{m}=2$ (ABNT NBR 15961-1, 2011). Como a máxima tensão de 
compressão solicitante de cálculo da alvenaria é igual a $\sigma_{S d}=0,812 M P a$, conforme ilustrado na Figura 32, verifica-se que o dimensionamento é atendido.

O modo de falha considerado para avaliação da estrutura é a compressão axial. Logo, a equação de estado limite para este modo de falha é dado por:

$$
g_{i}\left(f_{a_{i}}, t_{i}, g_{i}, q_{i}\right)=f_{a_{i}} \cdot L_{i} \cdot t_{i} \cdot\left[1-\left(\frac{H_{i} \cdot \sqrt{12}}{140 \cdot t_{i}}\right)^{2}\right]-g_{i}-q_{i}
$$

em que, $f_{a_{i}}$ é a resistência à compressão da alvenaria, $L_{i}$ é o comprimento da parede, $t_{i}$ é a espessura do bloco, $H_{i}$ é a altura da parede, $g_{i}$ é a carga permanente e $q_{i}$ é a carga variável, respectivamente da parede $i$. Para as análises de confiabilidade a resistência à compressão da alvenaria é calculada pelo seu valor médio, na qual vai depender da sua distribuição de probabilidade e de seus parâmetros associados (média, desvio-padrão e variância). Admitindo-se uma distribuição normal, e sendo cov = coeficiente de variação, tem-se:

$$
f_{m}=\frac{f_{k}}{1-1,645 \cdot \operatorname{cov}}
$$

As estatísticas são utilizadas da norma AS 3700 (2001) para o coeficiente de variação da resistência à compressão da alvenaria, Ellingwood e Galambos (1983) para as cargas permanentes e variáveis, a espessura do bloco da ABNT NBR 6136 (2014), sendo apresentadas na Tabela 6. As análises de confiabilidade são realizadas via FORM e ISMC com o auxílio do software StRAnD (BECK, 2007).

Tabela 6 - Estatísticas das variáveis aleatórias.

\begin{tabular}{ccccc}
\hline Estatística & $f_{a i}\left(k N / \mathrm{cm}^{2}\right)$ & $t_{i}(\mathrm{~cm})$ & $g_{i}(k N)$ & $q_{i}(k N)$ \\
\hline \hline Média & 0,252 & 14,000 & $1,050 \cdot g_{n}$ & $1,000 \cdot q_{n}$ \\
\hline cov & 0,150 & 0,012 & 0,100 & 0,250 \\
\hline Distribuição & Normal & Uniforme & Normal & Gumbel max. \\
\hline
\end{tabular}

Fonte: ABNT NBR 6136 (2014), AS 3700 (2001) e Ellingwood e Galambos (1983).

Nota: $g_{n}$ e $q_{n}$ são os valores nominais, respectivamente, das cargas permanentes e variáveis.

Depois de determinar o quinhão de carga para cada parede (Equação 7.13), e usando a Equação 7.15, são determinadas as probabilidades de falha individuais das paredes. $\mathrm{O}$ $C V$ para cada parede é determinado usando a Equação 6.13. Estes valores de $C V$ são mostrados na Figura 33. As paredes número 1, 2 e 3 são as mais vulneráveis, nesta ordem, com $C V_{W 1}=0,053, C V_{W 2}=0,052$ e $C V_{W 3}=0,053$.

Para determinar os coeficientes de importância (ou desproporcionalidade) $C I D_{i}$, para a propagação de dano, o elemento $E_{i}$ é removido da estrutura. Os fatores de carga 
para as paredes restantes são avaliados pela Equação 7.13. As probabilidades condicionais de falha, dada a falha do elemento $E_{i}$, são então avaliadas.

Este procedimento é repetido para as 23 paredes, sempre colocando de volta a parede retirada na análise anterior. Dessa forma, avaliam-se as confiabilidades condicionais $\beta_{i}^{P}$ (Equação 6.15) e os coeficientes de desproporcionalidade $C I D_{i}$ (Equação 6.16), como ilustrado na Figura 34. Os resultados mostram que os maiores coeficientes de desproporcionalidade são obtidos para as paredes 17, 21 e 14, que também são as paredes mais importantes para o colapso progressivo, conforme apresentado na Figura 35. No entanto, por definição, um $C V$ baixo não significa necessariamente $C I D$ baixo. Como exemplo, parede $W 17$ tem menor vulnerabilidade do que a maioria das paredes neste pavimento, mas tem o maior $C I D$.

Figura 33 - Valores de $C V$.

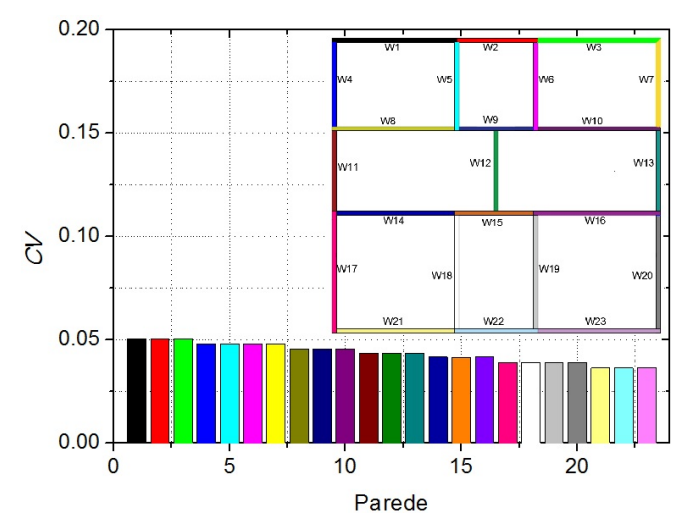

Fonte: Autoria própria.

Figura 35 - Valores de $C I C$.

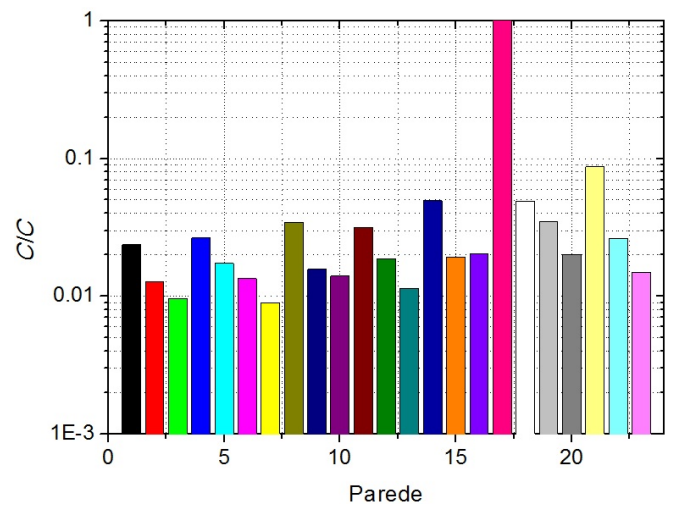

Fonte: Autoria própria.
Figura 34 - Valores de CID.

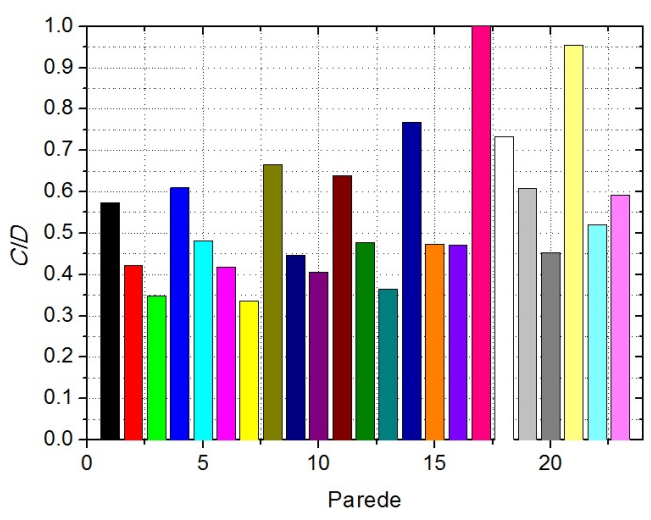

Fonte: Autoria própria.

Figura 36 - Valores de $C V C$.

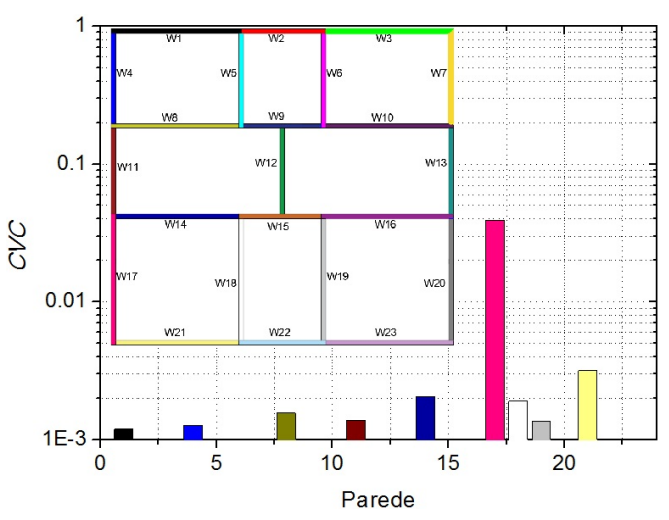

Fonte: Autoria própria.

A Figura 36 mostra os coeficientes de vulnerabilidade ao colapso estrutural $(C V C)$ para todas as paredes estruturais do edifício de alvenaria. A imagem contém um gráfico de barras com valores de $C V C$ e um mapa de risco do pavimento, que identifica os elementos críticos para o colapso progressivo. Valores não visíveis no gráfico de barra, ou 
não aparecendo no mapa de risco do pavimento, são muito próximos de zero. Torna-se claro que as paredes 17 e 21 são as mais vulneráveis neste edifício.

Por meio da Definição 6.6, o elemento chave $(E C)$ é a parede 17. A perda do elemento chave inicia o caminho mais provável para o colapso progressivo. A partir da metodologia RAPC proposta (seção 9.4), um critério de parada para a análise do caminho de falha é dado por uma probabilidade de falha condicional $P\left[c_{i}\right] \leq 10^{-7} /$ ano, que é o risco aceitável de colapso, dado o dano conforme (NISTIR 7396, 2007; ELLINGWOOD, 2006; PATE-CORNELL, 1994). Para a construção de alvenaria em estudo, a falha do elemento chave resulta em $P\left[c_{17}\right]=1,68 \cdot 10^{-9}$, que é a probabilidade de colapso condicional para a estrutura, dada a falha da parede 17. Essa probabilidade é muito alta, especialmente porque apenas a falha por compressão axial é considerada. Repetindo-se os mesmos procedimentos descritos anteriormente, contudo, para uma análise via ISMC, tem-se: $P\left[c_{17}\right]=1,80 \cdot 10^{-9}$.

Tabela 7 - Determinação da $P\left[c_{i}\right]$ via FORM e ISMC.

\begin{tabular}{|c|c|c|c|c|c|}
\hline Parede & $P\left[c_{i}\right]$ FORM & $P\left[c_{i}\right] \mathrm{ISMC}$ & Parede & $P\left[c_{i}\right]$ FORM & $P\left[c_{i}\right] \mathrm{ISMC}$ \\
\hline 1 & $3,99 \cdot 10^{-11}$ & $4,67 \cdot 10^{-11}$ & 13 & $1,92 \cdot 10^{-11}$ & $2,28 \cdot 10^{-11}$ \\
\hline 2 & $2,15 \cdot 10^{-11}$ & $2,54 \cdot 10^{-11}$ & 14 & $8,32 \cdot 10^{-11}$ & $9,70 \cdot 10^{-11}$ \\
\hline 3 & $1,62 \cdot 10^{-11}$ & $1,91 \cdot 10^{-11}$ & 15 & $3,23 \cdot 10^{-11}$ & $3,80 \cdot 10^{-11}$ \\
\hline 4 & $4,47 \cdot 10^{-11}$ & $5,24 \cdot 10^{-11}$ & 16 & $3,42 \cdot 10^{-11}$ & $4,01 \cdot 10^{-11}$ \\
\hline 5 & $2,92 \cdot 10^{-11}$ & $3,44 \cdot 10^{-11}$ & 17 & $1,68 \cdot 10^{-9}$ & $1,80 \cdot 10^{-9}$ \\
\hline 6 & $2,26 \cdot 10^{-11}$ & $2,67 \cdot 10^{-11}$ & 18 & $8,26 \cdot 10^{-11}$ & $9,64 \cdot 10^{-11}$ \\
\hline 7 & $1,52 \cdot 10^{-11}$ & $1,80 \cdot 10^{-11}$ & 19 & $5,86 \cdot 10^{-11}$ & $6,85 \cdot 10^{-11}$ \\
\hline 8 & $5,79 \cdot 10^{-11}$ & $6,77 \cdot 10^{-11}$ & 20 & $3,38 \cdot 10^{-11}$ & $3,97 \cdot 10^{-11}$ \\
\hline 9 & $2,64 \cdot 10^{-11}$ & $3,11 \cdot 10^{-11}$ & 21 & $1,47 \cdot 10^{-10}$ & $1,71 \cdot 10^{-10}$ \\
\hline 10 & $2,37 \cdot 10^{-11}$ & $2,80 \cdot 10^{-11}$ & 22 & $4,44 \cdot 10^{-11}$ & $5,19 \cdot 10^{-11}$ \\
\hline 11 & $5,35 \cdot 10^{-11}$ & $6,27 \cdot 10^{-11}$ & 23 & $2,51 \cdot 10^{-11}$ & $2,94 \cdot 10^{-11}$ \\
\hline 12 & $3,17 \cdot 10^{-11}$ & $3,74 \cdot 10^{-11}$ & $P[$ colapso $]$ & $2,63 \cdot 10^{-9}$ & $2,90 \cdot 10^{-9}$ \\
\hline
\end{tabular}

Fonte: Autoria própria.

A Tabela 7 mostra as probabilidades de falha condicional para todos os possíveis caminhos de falha, para a construção de alvenaria em estudo. Observa-se que todas as paredes identificadas no mapa de risco do pavimento (Figura 36) têm $P\left[c_{i}\right]<10^{-7}$. No entanto, a validação da Equação 6.21, observa-se que considerando o caminho de falha iniciado apenas pelo elemento chave, o mesmo contribui com $63,9 \%$ da probabilidade de colapso para esse edifício.

Os elementos com coeficiente de vulnerabilidade próximo a zero (não mostrado no mapa de risco da Figura 36) têm pequenas consequências de falha para a estrutura. 
Comparando os caminhos de falha iniciados por falhas de uma parede interna (W12), a uma parede periférica $(W 13)$ a uma parede de canto $(W 21)$ as probabilidades de colapso condicional são obtidas como: $P\left[c_{12}\right]=3,17 \cdot 10^{-11}, P\left[c_{13}\right]=1,92 \cdot 10^{-11} \mathrm{e}$ $P\left[c_{21}\right]=1,47 \cdot 10^{-10}$. Assim, a parede de canto é claramente observada como mais crítica do que uma parede interna.

A $P[$ colapso $]$ calculada somente para o modo de falha de compressão axial já leva a estrutura ter um alto risco de colapsar. Contudo, a probabilidade real da estrutura quando submetida ao colapso progressivo depende também dos modos de falha para as lajes. Assim, ao considerar os modos de falha para as lajes, a $P[$ colapso] teria um aumento significativo. Entretanto, como o processo de determinação dos esforços foi manual, é praticamente impossível escrever as equações de estado limite para as lajes sem recorrer aos métodos numéricos ou a Teoria de Charneiras Plásticas. Outro ponto importante é o comportamento não linear da estrutura que neste exemplo não foi estudado. Sendo assim, partindo dos resultados do Capítulo 9, as equações de estado limite para as lajes são aplicadas no pavimento tipo do edifício em estudo no Capítulo 10, bem como no modelo numérico apresentado no Capítulo 11. Para esse modelo numérico a influência das lajes e da análise não linear são analisadas. 


\section{Determinação dos Esforços nas Lajes}

Neste capítulo é apresentado uma sucinta revisão teórica sobre a Teoria das Charneiras Plásticas (TCP). Esta revisão é importante para introduzir as equações de estado limite das lajes na formulação da metodologia do Risk Analysis of the Progressive Collapse. A TCP consiste de uma aplicação às placas do Teorema do Limite Superior da Teoria da Plasticidade. Maiores detalhes sobre a TCP podem ser encontrados nos trabalhos de (GONZALEZ, 1997; AMED, 1995; RIOS, 1991; PINHEIRO, 1988; LANGENDONCK, 1975; LANGENDONCK, 1970; JOHANSEN, 1932; INGERSLEV, 1923).

Nos exemplos apresentados nos capítulos posteriores deste trabalho é considerado o pavimento do edifício formado por lajes simplesmente apoiadas nas quatro bordas. Este procedimento é usual nos escritórios de cálculo estrutural para edifício de alvenaria. Isso porque, os vãos das lajes são pequenos o que implica em baixos momentos solicitantes nas suas bordas. Além disso, as fissuras que surgem nas bordas das mesmas ficam sob as paredes estruturais.

Entretanto, ressalta-se que a falha de um elemento estrutural de apoio modifica as condições de contorno das lajes. No caso em estudo, edifícios de alvenaria estrutural, na ocorrência da falha de uma parede, a condição de contorno da laje fica com três bordas apoiadas e uma borda livre. Sendo assim, para cada iteração da metodologia do RAPC, faz-se necessário a determinação dos esforços, pois as análises de confiabilidade dependem dos esforços atuantes para a configuração atual da laje.

Nas seções à seguir, são deduzidas as equações da TCP para lajes retangulares simplesmente apoiada e apoiada com uma borda livre. No equacionamento é utilizado o processo das forças nodais. É realizado a automatização dos cálculos, utilizando-se tanto o cálculo elástico quanto o cálculo plástico. O carregamento adotado é o uniformemente distribuído. No caso da laje com uma borda livre, também carga linear ao longo desta borda. Estes cálculos são implementados em linguagem Fortran, e acoplado com o programa RAPC-ACADEMIC.

\subsection{Noç̃ões sobre o cálculo elástico}

Conforme Pinheiro (1988), o método plástico é o mais apropriado para o dimensionamento das lajes de concreto armado no estado limite último. Entretanto, o cálculo elástico é indispensável. Isso porque, nas condições de serviços, a laje comporta-se elasticamente, ou seja, as verificações de estado limite de serviço devem ser realizadas em regime elástico. Bem como no pré-dimensionamento para o cálculo plástico: determinação 
do índice de ortotropia $(\kappa)$ e o grau de engastamento $(\phi)$. O cálculo elástico é baseado na equação diferencial das placas. Para um maior aprofundamento o autor recomenda o trabalho de Timoshenko e Woinosky-Krieger (1940).

Como a solução do problema de valor de contorno para uma dada laje não é trivial, recorre-se a soluções aproximadas. Neste caso, pode-se adotar o cálculo por diferenças finitas, o método dos elementos finitos e a analogia de grelha. O cálculo por diferenças finitas, para lajes com formas e carregamentos usuais, é preferivelmente aplicado na elaboração de tabelas, como por exemplo, as de Melges (1993), Pinheiro (1988) e Bares (1972). Nos casos de lajes com forma e carregamentos complexos, condições de apoios variados e aberturas, o método dos elementos finitos e analogia de grelha são mais adequados.

Portanto, para prosseguir no estudo da TCP, o cálculo elástico das lajes simplesmente apoiadas é realizado através de funções aproximadas descritas no trabalho de Pinheiro (1988). Em que, considera-se $l_{x}=$ menor vão e $l_{y}=$ maior vão. Para as lajes simplesmente apoiadas com uma borda livre, adota-se as funções aproximadas apresentadas em Amed (1995), considerando $l_{x}$ paralelo e $l_{y}$ perpendicular à borda livre. Em ambos os casos, o erro máximo das funções aproximadas é da ordem de 3\% (AMED, 1995; PINHEIRO, 1988).

\subsection{Noções sobre o cálculo pela TCP}

Ingerslev (1923) iniciou os estudos da TCP para as lajes. Partindo do equilíbrio de cada região, delimitada por linhas de plastificação, o referido autor assumiu a hipótese que os momentos atuavam somente ao longo destas linhas. A ruína da laje ocorre com a formação de linhas de plastificação, chamadas de charneiras plásticas. Portanto, a finalidade da TCP é a determinação dos momentos de plastificação.

Johansen (1932) introduziu novas correções na teoria, estabelecendo o conceito de forças nodais. Estas substituem os efeitos das forças cortantes e momentos de torção que atuam nas interseções das charneiras. Devidas suas contribuições no desenvolvimento da TCP, foram creditados ao referido autor os méritos de criador desta teoria.

A TCP é fundamentada nas seguintes hipóteses: as lajes devem ser subarmadas; não deverá ocorrer ruína prematura por cisalhamento ou por punção; o material é considerado rígido-plástico; os momentos ao longo das charneiras são admitidos constantes; desprezamse os efeitos de membrana da laje (PINHEIRO, 1988; LANGENDONCK, 1975).

Existem dois processos de cálculo. O primeiro o processo do equilíbrio ou processo das forças nodais. Este foi usado no trabalho original de Johansen (1932), e ainda continua sendo utilizado. O segundo, o processo da energia, baseado no Princípio dos Trabalhos Virtuais (PTV), o qual permite que o problema de valor de contorno seja escrito em forma 
fraca, o que implica num cálculo mais conciso.

No caso de lajes isótropas, o momento de plastificação, é constante ao longo de cada charneira, bem como é igual para qualquer direção. Isto implica que lajes isótropas apresentem a mesma resistência à flexão em qualquer direção. Não havendo igualdade de resistência em ambas as direções, a laje é denominada anisótropa. Se as armaduras são dispostas em direções ortogonais em uma laje anisótropa, de modo que os momentos de plastificação positivos guardem entre si uma relação igual à relação entre os momentos de plastificação negativos correspondentes, a laje será ortótropa (LANGENDONCK, 1975). O índice de ortotropia é definido como:

$$
\kappa=\frac{m_{y}}{m_{x}}=\frac{m_{y}^{\prime}}{m_{x}^{\prime}}
$$

em que, $m_{x}$ e $m_{y}, m_{x}^{\prime}$ e $m_{y}^{\prime}$ são, respectivamente os momentos de plastificação positivo e negativo nas direções $x$ e $y$. A razão entre o momento de plastificação negativo $\left(m^{\prime}\right)$ e o momento de plastificação positivo $(m)$ é definido como grau de engastamento. Sendo dado pela equação abaixo:

$$
\phi=\frac{m^{\prime}}{m}
$$

As lajes ortótropas podem ser calculadas como se fossem isótropas, fazendo-se uma modificação nas suas dimensões. A transformação de lajes ortótropas em isótropas foi proposto por Johansen (1932). Consiste basicamente da multiplicação das dimensões da laje nas direções de $m$ e $m^{\prime}$ por um coeficiente adimensional $\xi$, sem modificar o valor do carregamento uniformemente distribuído atuante na laje. Este coeficiente é definido pela seguinte expressão:

$$
\xi=\frac{1}{\sqrt{\kappa}}
$$

\subsection{Lajes ortótropas}

As lajes usualmente são ortótropas. Assim, no seu equacionamento, esta ortotropia deve ser considerada. No caso particular, $\kappa=1$, as lajes são tratadas como isótropas.

Quando um projetista vai realizar um dimensionamento de uma laje, de antemão, são conhecidos os vãos, as cargas e as condições de vinculações. O $\kappa$ e o $\phi$ são adotados ou estimados com base em um pré-dimensionamento em regime elástico ou por um critério econômico (PINHEIRO, 1988).

Como já citado anteriormente, o $\kappa$ e o $\phi$ são determinados por um pré-dimensionamento em regime elástico. As lajes ortótropas são calculadas considerando a sua transformação em isótropas afins, para a configuração comum e configuração eventual. 


\subsection{Configuração de ruína}

A configuração de ruína é aquela associada ao maior valor de momento de plastificação (PINHEIRO, 1988; LANGENDONCK, 1975). Nas lajes retangulares, a configuração de ruína mais frequente apresenta-se com à charneira central paralela a maior dimensão, conforme mostrado na Figura 37. Esta é chamada de configuração comum. No caso, em que a relação entre o maior e menor vão da laje é pequeno, e a charneira central seja paralela ao menor vão, esta é denominada de configuração eventual, de acordo com a Figura 38 (PINHEIRO, 1988).

Figura 37 - Notação para configuração comum.
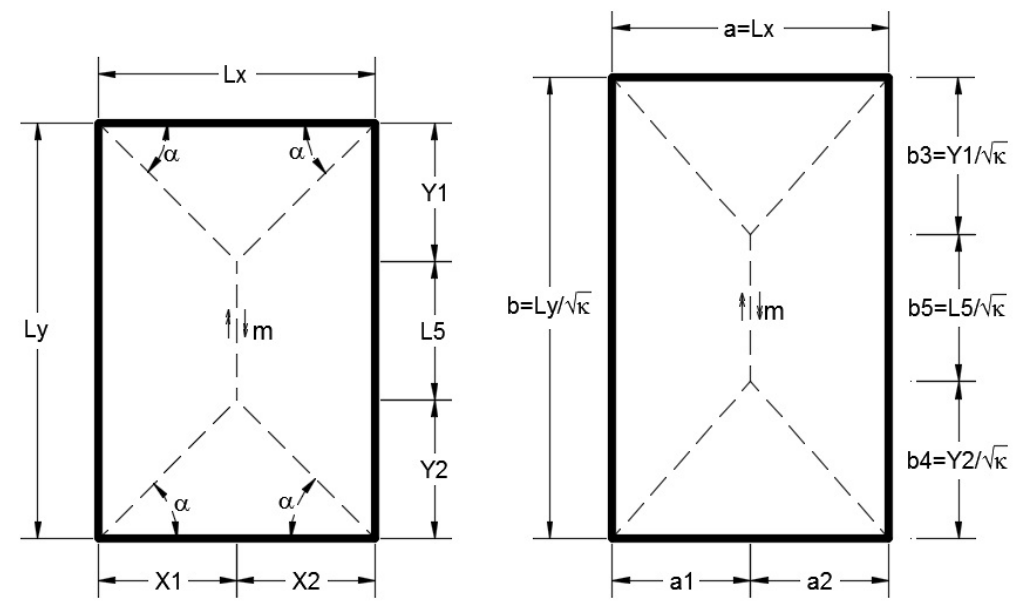

Fonte: Autoria própria.

Figura 38 - Notação para configuração eventual.
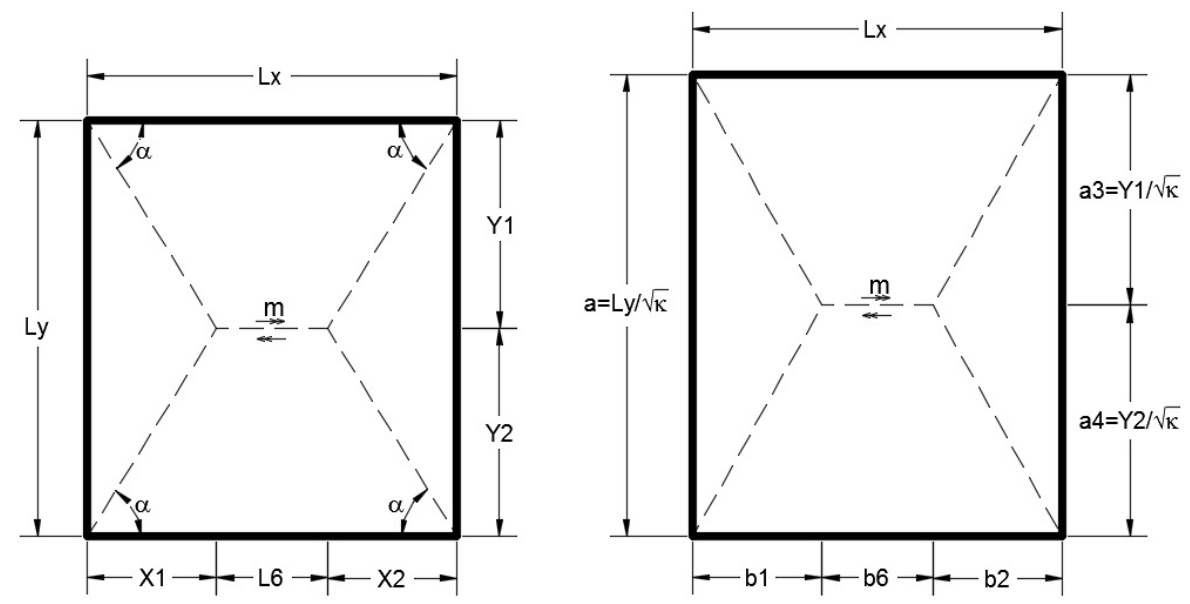

Fonte: Autoria própria. 


\subsection{Marcha de cálculo: lajes simplesmente apoiadas}

Nesta seção é apresentada a marcha de cálculo desde os dados iniciais da laje até o cálculo dos momentos de plastificação, bem como, a configuração de ruína e as reações de apoio. De antemão, considera-se conhecidos os carregamentos uniformemente distribuidos e a espessura da laje.

A dedução minuciosa das equações apresentadas abaixo não faz parte dos objetivos deste trabalho. Apresentam-se, resumidamente, as equações fundamentais e noções sobre o processo de cálculo. Para maiores detalhes, recomenda-se a leitura das referências citadas ao longo deste capítulo.

\subsubsection{Dados}

De início são conhecidos: $l_{x}=$ menor vão, $l_{y}=$ maior vão, $\lambda=l_{y} / l_{x}=$ razão $\operatorname{dos}$ vãos e $F_{d}=$ carga total uniformemente distribuída.

\subsubsection{Valores de $\phi$ e de $\kappa$}

Para lajes com bordas simplesmemente apoiadas, $\phi=0$. Com relação aos valores de $\kappa$, realiza-se um pré-dimensionamento em regime elástico, utilizando-se as funções aproximadas dadas na Tabela 8.

$$
\begin{aligned}
\text { Tabela } 8 \text { - } & \text { Cálculo dos momentos adimensio- } \\
& \text { nais no regime elástico para lajes } \\
& \text { simplesmente apoiadas. }
\end{aligned}
$$

\begin{tabular}{ccc}
\hline$\mu$ & $\lambda=l_{y} / l_{x}$ & $\mu=f(\lambda)$ \\
\hline \hline$\mu_{x}$ & $1,0 \leq \lambda \leq 2,5$ & $-2,46 \cdot \lambda^{2}+13,07 \cdot \lambda-6,20$ \\
\hline$\mu_{x}$ & $2,5<\lambda \leq 4,0$ & $0,93 \cdot \lambda+8,78$ \\
\hline$\mu_{x}$ & $\lambda>4,0$ & 12,50 \\
\hline \hline$\mu_{y}$ & $\lambda \geq 1,0$ & 4,40 \\
\hline
\end{tabular}

Fonte: Pinheiro (1988).

Então, o índice de ortotropia é determinado fazendo:

$$
\kappa=\frac{\mu_{y}}{\mu_{x}} .
$$

\subsubsection{Direção da charneira central}

Inicialmente, supõe-se que a configuração da charneira central seja paralela à maior dimensão (Figura 37). Neste caso, tem-se:

$$
a=l_{x} \quad b=\frac{l_{y}}{\sqrt{\kappa}} .
$$


Se $a \leq b$, a hipótese inicial é correta e, de fato, ocorre a configuração comum. Como $a$ e $b$ são as dimensões de uma laje isótropa afim apoiada nos quatro lados, portanto, $a$ é sempre perpendicular a charneira central, logo, $a$ não pode ser maior que $b$. Caso contrário, $a>b$, ocorre a configuração eventual, em que a charneira central é paralela à menor dimensão (Figura 38). Logo, $a$ e $b$ assumem os seguintes valores.

$$
a=\frac{l_{y}}{\sqrt{\kappa}} \quad b=l_{x}
$$

\subsubsection{Momento de plastificação}

Determinados os valores de $a$ e $b$, calcula-se o momento de plastificação, $m$, fazendose:

$$
m=m_{x}=\frac{F_{d} \cdot c^{2}}{6}
$$

em que,

$$
c=\frac{a}{2} \cdot\left\{\left[\left(\frac{a}{b}\right)^{2}+3\right]^{1 / 2}-\frac{a}{b}\right\} .
$$

O momento na direção y é dado pela Equação 8.1.

$$
m_{y}=\kappa \cdot m_{x}=\kappa \cdot m
$$

\subsubsection{Configuração de ruína}

A configuração de ruína será definida a partir dos valores de $x_{1}, x_{2}, y_{1}$ e $y_{2}$, dos quais $l_{5}$ ou $l_{6}$ são decorrentes. No caso da configuração comum, estes valores são determinados pelas seguintes equações:

$$
\begin{gathered}
x_{1}=x_{2}=\frac{a}{2} \\
y_{1}=y_{2}=c \sqrt{\kappa} \\
l_{5}=l_{y}-\left(y_{1}+y_{2}\right) \\
b_{5}=\frac{l_{y}}{\sqrt{\kappa}}-2 c=\frac{l_{5}}{\sqrt{\kappa}} .
\end{gathered}
$$

As inclinações das charneiras, medidas em relação aos lados menores, resultam:

$$
\alpha=\arctan \left(\frac{2 \cdot c \cdot \sqrt{\kappa}}{a}\right) .
$$

Para a configuração eventual, utilizam-se as seguintes equações:

$$
x_{1}=x_{2}=c
$$




$$
\begin{gathered}
y_{1}=y_{2}=\frac{a}{2} \sqrt{\kappa} \\
l_{6}=l_{x}-\left(x_{1}+x_{2}\right) \\
b_{6}=l_{x}-2 c \\
\alpha=\arctan \left(\frac{a \cdot \sqrt{\kappa}}{2 \cdot c}\right) .
\end{gathered}
$$

\subsubsection{Reações de apoio}

As reações de apoio médias são obtidas, somando-se as parcelas das forças nodais junto aos cantos com as parcelas das reações ao longo das bordas.

Para a configuração comum as reações médias, $r_{x}$ e $r_{y}$, respectivamente, nas direções de $l_{x}$ e $l_{y}$, resultam:

$$
\begin{gathered}
r_{x}=\frac{2 \cdot c \cdot F_{d} \cdot \sqrt{\kappa}}{3}-\frac{2 \cdot m \cdot \kappa}{l_{x} \cdot \tan \alpha} \\
r_{y}=\frac{a \cdot F_{d}}{6} \cdot\left[2+2 \cdot \sqrt{\kappa} \cdot\left(\frac{b_{5}}{l_{y}}\right)-\kappa \cdot\left(\frac{b_{5}}{l_{y}}\right)^{2}\right]-\frac{2 \cdot m \cdot \tan \alpha}{l_{y}}
\end{gathered}
$$

em que, $\alpha$ é calculado pela Equação 8.12.

No caso da configuração eventual, tem-se:

$$
\begin{gathered}
r_{x}=\frac{a \cdot F_{d} \cdot \sqrt{\kappa}}{6} \cdot\left[2+2 \cdot\left(\frac{b_{6}}{l_{x}}\right)-\left(\frac{b_{6}}{l_{x}}\right)^{2}\right]-\frac{2 \cdot m \cdot \kappa}{l_{x} \cdot \tan \alpha} \\
r_{y}=\frac{2 \cdot c \cdot F_{d}}{3}-\frac{2 \cdot m \cdot \tan \alpha}{l_{y}}
\end{gathered}
$$

sendo, $\alpha$ calculado pela Equação 8.17.

\subsection{Marcha de cálculo: lajes simplesmente apoiadas com uma borda livre}

\subsubsection{Dados}

De início são conhecidos: $a=$ dimensão perpendicular à borda livre, $b=$ dimensão paralela à borda livre, $\lambda=a / b=$ razão dos vãos, $F_{d}=$ carga total uniformemente distribuída e $P_{l}=$ carga linear ao longo da borda livre.

A Figura 39 apresenta a notação utilizada nesta seção. Em que, $m_{a}$ é o momento que determina a armadura perpendicular à borda livre, $m_{b}$ corresponde o momento na direção paralela à mesma. 
Figura 39 - Laje retangular com uma borda livre: a) configuração comum e b) configuração eventual.
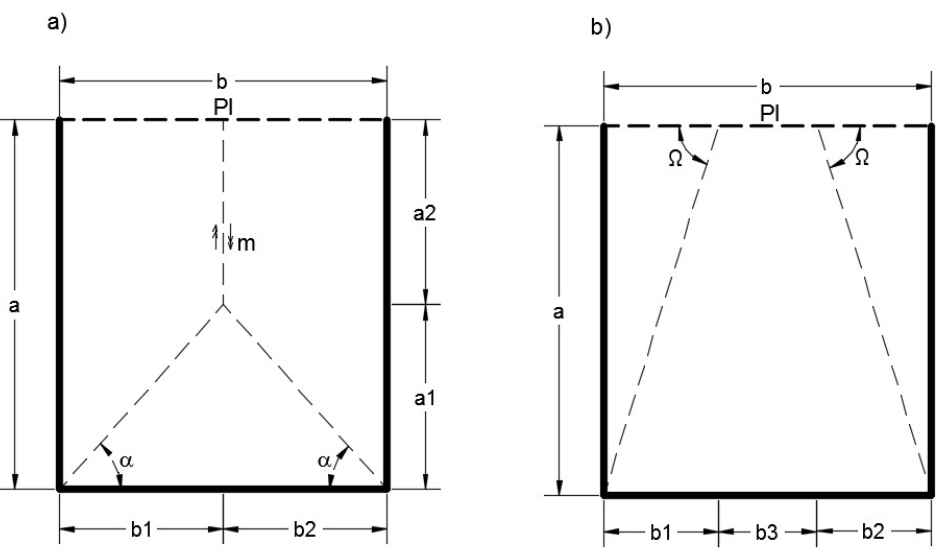

Fonte: Autoria própria.

\subsubsection{Valores de $\phi$ e de $\kappa$}

Para lajes com bordas simplesmemente apoiadas e uma borda livre, $\phi=0$. Com relação aos valores de $\kappa$, realiza-se um pré-dimensionamento em regime elástico, utilizandose as funções aproximadas dadas na Tabela 9. Da Figura 39, tem-se: $m_{a}=m$ e $m_{b}=\kappa m$.

Tabela 9 - Cálculo dos momentos adimensionais no regime elástico para lajes simplesmente apoiadas com uma borda livre.

\begin{tabular}{ccc}
\hline$\mu$ & $\lambda=a / b$ & $\mu=f(\lambda)$ \\
\hline \hline$\mu_{a}$ & $0,2 \leq \lambda \leq 0,5$ & $5,69 \cdot \lambda^{2}+5,57 \cdot \lambda-0,67$ \\
\hline$\mu_{a}$ & $0,5<\lambda \leq 1,0$ & $-4,80 \cdot \lambda^{2}+15,35 \cdot \lambda-2,95$ \\
\hline$\mu_{a}$ & $1,0<\lambda \leq 2,0$ & $-2,29 \cdot \lambda^{2}+10,34 \cdot \lambda-0,40$ \\
\hline$\mu_{a}$ & $2,0<\lambda \leq 3,0$ & $-0,62 \cdot \lambda^{2}+4,08 \cdot \lambda+5,47$ \\
\hline$\mu_{a}$ & $\lambda>3,0$ & 12,50 \\
\hline \hline$\mu_{b}$ & $0,2 \leq \lambda \leq 0,5$ & $-0,62 \cdot \lambda^{2}+6,13 \cdot \lambda-0,71$ \\
\hline$\mu_{b}$ & $0,5<\lambda \leq 1,0$ & $-4,54 \cdot \lambda^{2}+9,36 \cdot \lambda-1,37$ \\
\hline$\mu_{b}$ & $1,0<\lambda \leq 1,4$ & $-0,34 \cdot \lambda^{2}+0,73 \cdot \lambda+3,06$ \\
\hline$\mu_{b}$ & $1,4<\lambda \leq 4,0$ & $0,10 \cdot \lambda^{2}-0,85 \cdot \lambda+4,43$ \\
\hline$\mu_{b}$ & $\lambda>4,0$ & 2,52 \\
\hline
\end{tabular}

Fonte: Amed (1995). 


\subsubsection{Momento de plastificação}

Inicialmente, supõe-se, que a configuração de ruína é a apresentada na Figura 39a. Assim, fazendo-se o equilíbrio de momentos para cada região, em torno das bordas adjacentes, e combinando-se as equações obtidas, têm-se:

$$
m=\frac{b^{2}}{24 \cdot a \cdot \kappa} \cdot\left[F_{d} \cdot\left(3 \cdot a-2 \cdot a_{1}\right)+3 \cdot P_{l}\right]
$$

em que,

$$
a_{1}=\frac{b^{2}}{4 \cdot a \cdot \kappa} \cdot\left[-1+\sqrt{1+\frac{12 \cdot a \cdot \kappa \cdot\left(F_{d} \cdot a+P_{l}\right)}{F_{d} \cdot b^{2}}}\right] .
$$

Para verificar a hipótese inicial, é indispensável que $a_{1} \leq a$. Caso contrário, a configuração de ruína é aquela mostrada na Figura 39-b. Neste caso, faz-se o equilíbrio de momentos para cada região novamente, obtendo-se a seguinte equação:

$$
m=\frac{b_{2}^{2}}{6 \cdot a \cdot\left[\kappa-\left(\frac{b_{2}}{a}\right)^{2}\right]} \cdot\left(F_{d} \cdot a+3 \cdot P_{l}\right)
$$

em que,

$$
\begin{gathered}
b_{2}=\frac{a^{2} \cdot \kappa}{b} \cdot\left(\frac{\sqrt{c_{3}}-2 \cdot c_{1}}{3 \cdot c_{2}}\right) \\
c_{1}=F_{d} \cdot a+3 \cdot P_{l} \\
c_{2}=F_{d} \cdot a+2 \cdot P_{l} \\
c_{3}=4 \cdot c_{1}^{2}+\frac{9 \cdot b^{2} \cdot c_{2}^{2}}{a^{2} \cdot \kappa} .
\end{gathered}
$$

\subsubsection{Reações de apoios}

Para a configuração dada pela Figura 39- $a$ as reações médias, $r_{a}$ e $r_{b}$, respectivamente, nas direções de $a$ e $b$, resultam:

$$
\begin{gathered}
r_{a}=\frac{P_{l} \cdot b}{2 \cdot a}+\frac{F_{d} \cdot b}{4 \cdot a} \cdot\left(2 \cdot a-a_{1}\right) \\
r_{b}=\frac{F_{d} \cdot a_{1}}{2} .
\end{gathered}
$$

Para a configuração dada pela Figura 39-b, tem-se:

$$
\begin{gathered}
r_{a}=\frac{P_{l} \cdot b_{2}}{a}+\frac{F_{d} \cdot b_{2}}{2} \\
r_{b}=\frac{P_{l} \cdot\left(b-2 \cdot b_{2}\right)}{b}+\frac{F_{d} \cdot a}{b} \cdot\left(b-b_{2}\right) .
\end{gathered}
$$




\subsection{Rotina DIM-TCP}

Para auxiliar a determinação dos esforços nas lajes em cada iteração da metodologia do RAPC é implementado em linguagem Fortran as marchas de cálculo da seção 8.5 e seção 8.6. Esta rotina é denominada de DIM-TCP.

Recordando que uma das hipóteses da TCP é a consideração que as lajes devem ser subarmadas. Assim, partindo das recomendações da ABNT NBR 6118 (2014), é implementado uma rotina para o dimensionamento a flexão das lajes em estudo. Esta é acoplada com a DIM-TCP. A seguir apresenta-se algumas aplicações.

\subsubsection{Exemplo 1: laje simplesmente apoiada}

Na rotina DIM-TCP, faz-se necessário que o usuário entre com os dados iniciais no arquivo LAJE-INPUT, conforme mostrado na Figura 40. O usuário tem a opção de fazer dois tipos de análise. A primeira a DIM-TCP realiza a determinação dos esforços e dimensionamento para o caso de lajes simplesmente apoiadas, enquanto que na segunda, lajes simplesmente apoiadas com uma borda livre. É possível também realizar simultaneamente várias análises. Basta o usuário colocar a quantidade de lajes que serão analisadas, no campo número de lajes. Entretanto, o usuário deve fornecer os dados iniciais de cada laje.

Figura 40 - Arquivo de entrada da rotina DIM-TCP.

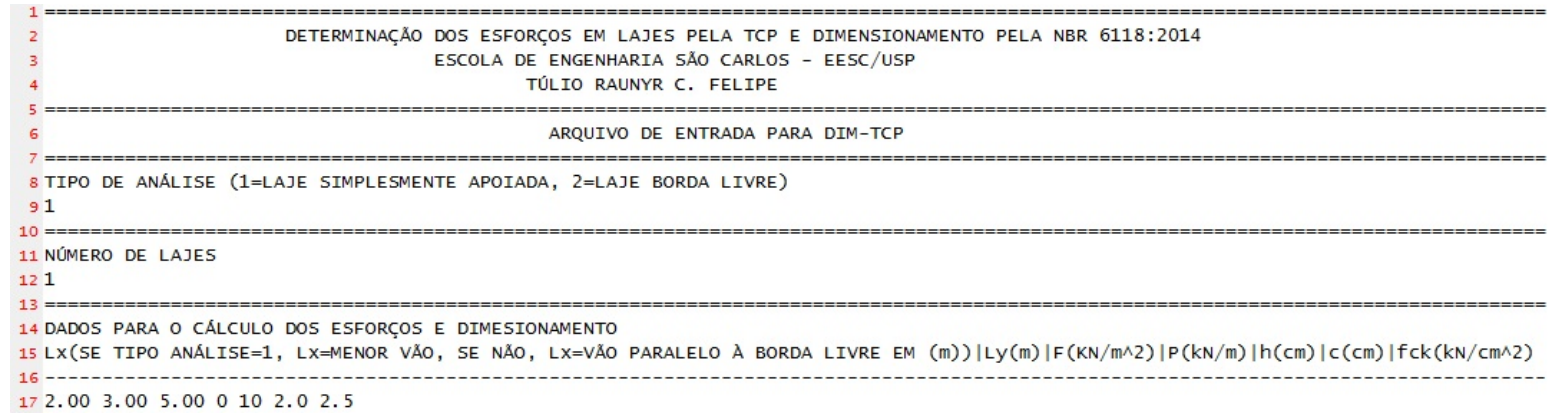

Fonte: Autoria própria.

No campo, dados para o cálculo dos esforços e dimensionamento, o usuário deve ter atenção para fornecer a sequência e unidades corretas dos valores dos dados iniciais. Sendo, $l_{x}(m), l_{y}(m), F_{d}\left(k N / m^{2}\right), P_{l}(k N / m), h=$ altura da laje em centímetro, $c=$ cobrimento da armadura em centímetro e $f_{c k}\left(k N / \mathrm{cm}^{2}\right)$. Se a análise for do tipo $1, l_{x}=$ ao menor vão, caso contrário, $l_{x}=$ ao vão paralelo à borda livre.

Com os dados iniciais apresentados na Figura 41, considerando-se uma laje de espessura de $10 \mathrm{~cm}$, cobrimento de $2,0 \mathrm{~cm}$ e um $f_{c k}=2,5 \mathrm{kN} / \mathrm{cm}^{2}$. A rotina realiza os 
cálculos e o dimensionamento, fornecendo um arquivo de saída LAJE-OUTPUT, com todos os resultados, apresentados na Figura 42.

Figura 41 - Exemplo de laje retangular simplesmente apoiada.

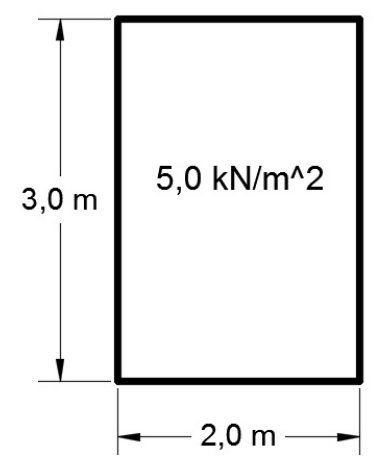

Fonte: Autoria própria.

Figura 42 - Arquivo de saída da rotina DIM-TCP.

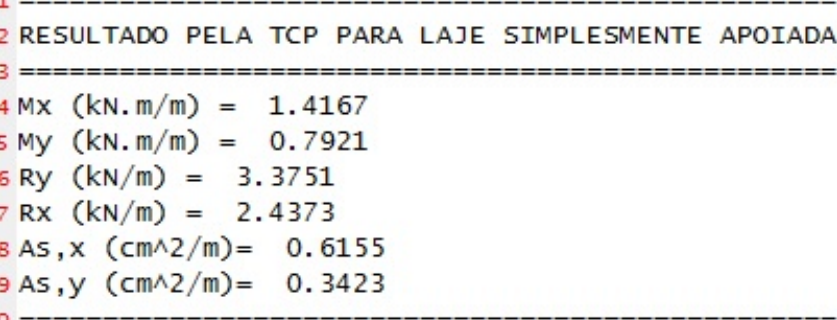

Fonte: Autoria própria.

No arquivo de saída, Figura $42, A_{s, x}$ e $A_{s, y}$, são respectivamente, as armaduras por metro na direção $x$ e $y$. Ressalta-se que a DIM-TCP também faz a verificação de armadura mínima, de acordo com as recomendações da ABNT NBR 6118 (2014).

\subsubsection{Exemplo 2: laje simplesmente apoiada com uma borda livre}

Com os mesmos dados do exemplo anterior, agora considerando a laje com uma borda livre, Figura 43, têm-se os resultados apresentados na Figura 45.

Na Figura $45, M_{x}, R_{x}, A_{s, x}$ e $M_{y}, R_{y}, A_{s, y}$, são respectivamente, o momento fletor, a reação de apoio, a armadura por metro na direção paralela e perpendicular à borda livre. Verifica-se que a configuração de ruína para uma laje simplesmente apoiada com uma borda livre, impõe, um aumento significativo no momento solicitante da laje e, consequentemente, um aumento nas suas armaduras e reações de apoios. 
Figura 43 - Exemplo de laje retangular com uma borda livre.

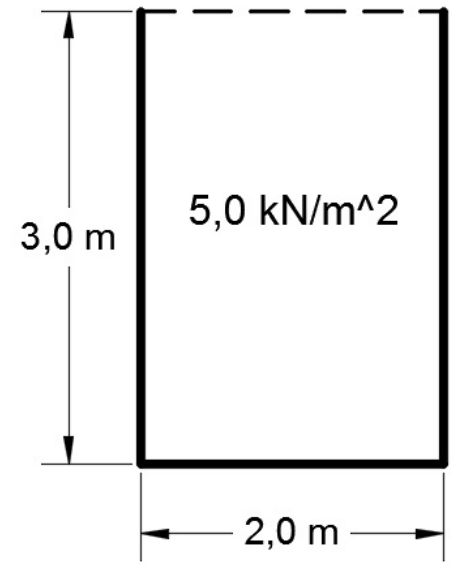

Fonte: Autoria própria.

Figura 44 - Arquivo de entrada da rotina DIM-TCP.

DETERMINAÇAO DOS ESFORÇOS EM LAJES PELA TCP E DIMENSIONAMENTO PELA NBR 6118:2014

ESCOLA DE ENGENHARIA SÃO CARLOS - EESC/USP

TÚLIO RAUNYR C. FELIPE

ARQUIVO DE ENTRADA PARA DIM-TCP

8 TIPO DE ANÁLISE (1=LAJE SIMPLESMENTE APOIADA, 2=LAJE BORDA LIVRE)

92

$10==============+1$
11 NÚMERO DE LAJES

121

14 DADOS PARA O CÁLCULO DOS ESFORCYOS E DIMESIONAMENTO

15 LX(SE TIPO ANÁLISE $=1$, LX=MENOR VÃO, SE NÅO, LX=VÅO PARALELO A BORDA LIVRE EM $(\mathrm{m}))|\mathrm{Ly}(\mathrm{m})| \mathrm{F}(\mathrm{KN} / \mathrm{m} \wedge 2)|\mathrm{P}(\mathrm{kN} / \mathrm{m})| \mathrm{h}(\mathrm{cm})|\mathrm{c}(\mathrm{cm})| \mathrm{fck}(\mathrm{kN} / \mathrm{cm} \wedge 2)$

172.003 .005 .000102 .02 .5

Fonte: Autoria própria.

Figura 45 - Arquivo de saída da rotina DIM-TCP.

RESULTADO PELA TCP PARA LAJE COM UMA BORDA LIVRE

$2===================1$
$3 \mathrm{MX}(\mathrm{kN}, \mathrm{m} / \mathrm{m})=3.8480$

$4 \mathrm{My}(\mathrm{kN} . \mathrm{m} / \mathrm{m})=1.3062$

$5 \mathrm{RX}(\mathrm{kN} / \mathrm{m})=5.3722$

6 RY $(\mathrm{kN} / \mathrm{m})=3.2093$

7 As, $x(\mathrm{~cm} \wedge 2 / \mathrm{m})=1.7078$

8 As, $y(\mathrm{~cm} \wedge 2 / \mathrm{m})=0.5669$

Fonte: Autoria própria. 


\section{Equação de Estado Limite para Lajes}

Neste capítulo, partindo dos resultados obtidos no Capítulo 8, são definidas as equações de estado limite para as lajes em estudo. Estas equações tornam-se fundamentais para a realização das análises de confiabilidade.

Primeiramente, é determinado o momento resistente para uma seção de concreto armado. Em seguida, é implementado uma rotina em linguagem Fortran, denominada EEL-TCP, acoplada ao StRAnD. Esta realiza as análises de confiabilidade das lajes para cada iteração da metodologia do RAPC. A seguir, apresenta-se os procedimentos adotados.

\subsection{Cálculo do momento resistente da seção}

A rotina DIM-TCP fornece as armaduras longitudinais $\left(A_{s}\right)$ para os esforços calculados pela TCP. Recordando que a DIM-TCP dimensiona a estrutura com as recomendações da ABNT NBR 6118 (2014). Logo, como os valores de $A_{s}$ são conhecidos, basta calcular o máximo momento resistente da seção para tais valores.

Para a formulação das equações de estado limite, os valores das propriedades dos materiais que compõe o valor do máximo momento resistente da seção devem ser avaliados com seus valores nominais.

Figura 46 - Seção transversal retangular solicitada por momento fletor.

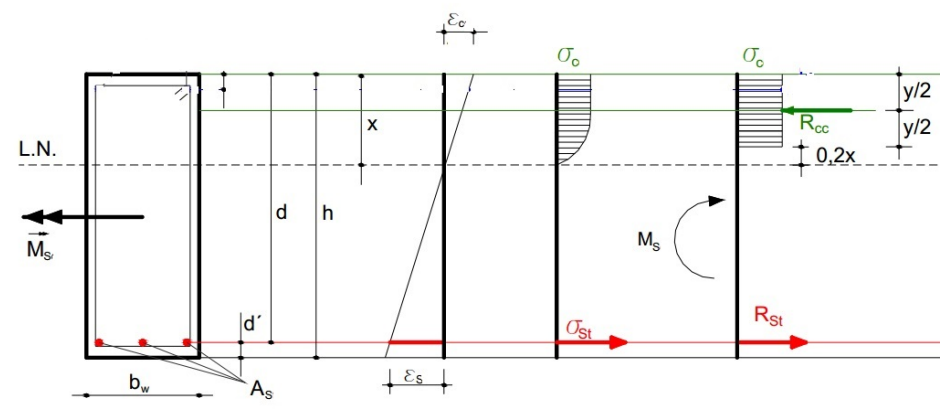

Fonte: Giongo (2015).

A solução do problema pode ser realizada, fazendo-se o equilíbrio dos esforços atuantes na seção transversal (Figura 46). Recorde que uma das hipóteses da TCP, é a consideração da seção subarmada. Assim, a seção trabalha no domínio 3, em que, o aço tracionado estará escoando. Logo, conhecendo-se $A_{s}$, a força atuante na armadura $\left(R_{S t}\right)$ é 
dada por:

$$
R_{S t}=A_{s} \cdot f_{y}
$$

Partindo das recomendações da ABNT NBR 6118 (2014), considerando-se o diagrama retangular para a distribuição de tensões de compressão no concreto, tem-se:

$$
R_{c c}=\left(0,85 \cdot f_{c}\right) \cdot\left(b_{w}\right) \cdot(0,8 \cdot x)
$$

em que, $f_{y}=$ tensão de escoamento do aço, $f_{c}=$ resistência à compressão do concreto, $b_{w}=$ largura da seção transversal, no caso de laje $b_{w}=100 \mathrm{~cm}$ e $x=$ posição da linha neutra.

Por equilíbrio dos esforços normais, tem-se que $R_{S t}=R_{c c}$, o que resulta:

$$
x=\frac{A_{s} \cdot f_{y}}{0,68 \cdot f_{c} \cdot b_{w}} .
$$

O máximo momento resistido $\left(M_{R}\right)$ é obtido pelo produto direto da força na armadura, ou concreto, pelo braço de alavanca $(d-0,4 \cdot x)$, em que $d=$ altura útil, o que resulta:

$$
M_{R}=R_{S t} \cdot(d-0,4 \cdot x)=A_{s} \cdot f_{y} \cdot\left(d-\frac{A_{s} \cdot f_{y}}{170 \cdot f_{c}}\right) .
$$

\subsection{Equações de estado limite}

Na avaliação da confiabilidade de uma estrutura é fundamental a determinação das Equações de Estado Limite (EEL) para cada modo de falha. No caso das lajes em estudo, o modo de falha considerado é a formação das charneiras plásticas. Esta transforma o comportamento da laje em um mecanismo, provocando o seu colapso.

A determinação dos momentos de plastificação depende da configuração de ruína da laje. Dessa forma, verifica-se que para cada configuração, uma respectiva EEL deve ser avaliada. A seguir apresenta-se as EEL's para essas lajes.

\subsubsection{Laje simplesmente apoiada}

A EEL para a configuração comum e configuração eventual é dada por:

$$
\begin{aligned}
g\left(f_{c}, f_{y}, g, q\right) & =A_{s} \cdot f_{y} \cdot\left(d-\frac{A_{s} \cdot f_{y}}{170 \cdot f_{c}}\right)- \\
& +\frac{(g+q)}{6} \cdot\left\{\frac{a}{2}\left\{\left[\left(\frac{a}{b}\right)^{2}+3\right]^{1 / 2}-\frac{a}{b}\right\}\right\}^{2}
\end{aligned}
$$

sendo, $g$ e $q$, respectivamente, a carga permanente e a carga acidental atuante na laje. Recorde que na configuração comum os valores de $a$ e $b$ são dado pela Equação 8.5, enquanto que na configuração eventual, os valores de $a$ e $b$ são determinados pela Equação 8.4. 


\subsubsection{Laje simplesmente apoiada com uma borda livre}

Para o caso apresentado na Figura 39-a:

$$
\begin{aligned}
g\left(f_{c}, f_{y}, g, q, P_{l, g}, P_{l, q}\right) & =A_{s} \cdot f_{y} \cdot\left(d-\frac{A_{s} \cdot f_{y}}{170 \cdot f_{c}}\right)- \\
& +\frac{b^{2}}{24 \cdot a \cdot \kappa} \cdot\left[(g+q) \cdot\left(3 \cdot a-2 \cdot a_{1}\right)+3 \cdot\left(P_{l, g}+P_{l, q}\right)\right]
\end{aligned}
$$

em que,

$$
a_{1}=\frac{b^{2}}{4 \cdot a \cdot \kappa} \cdot\left\{-1+\sqrt{1+\frac{12 \cdot a \cdot \kappa\left[a \cdot(g+q)+\left(P_{l, g}+P_{l, q}\right)\right]}{(g+q) \cdot b^{2}}}\right\}
$$

No caso da Figura 39-b:

$$
\begin{aligned}
g\left(f_{c}, f_{y}, g, q, P_{l, g}, P_{l, q}\right) & =A_{s} \cdot f_{y} \cdot\left(d-\frac{A_{s} \cdot f_{y}}{170 \cdot f_{c}}\right)- \\
& +\frac{b_{2}^{2}}{6 \cdot a \cdot\left[\kappa-\left(\frac{b_{2}}{a}\right)^{2}\right]} \cdot\left[a \cdot(g+q)+3 \cdot\left(P_{l, g}+P_{l, q}\right)\right]
\end{aligned}
$$

em que,

$$
\begin{array}{r}
b_{2}=\frac{a^{2} \cdot \kappa}{b} \cdot\left(\frac{\sqrt{c_{3}}-2 \cdot c_{1}}{3 \cdot c_{2}}\right) \\
c_{1}=a \cdot(g+q)+3 \cdot\left(P_{l, g}+P_{l, q}\right) \\
c_{2}=a \cdot(g+q)+2 \cdot\left(P_{l, g}+P_{l, q}\right) \\
c_{3}=4 \cdot c_{1}^{2}+\frac{9 \cdot b^{2} \cdot c_{2}^{2}}{a^{2} \cdot \kappa} .
\end{array}
$$

\subsection{Rotina EEL-TCP}

Para auxiliar as análises de confiabilidade das lajes é implementado em linguagem Fortran a rotina EEL-TCP. Esta é acoplada com StRAnD. Para realizar as análises o usuário deve entrar no arquivo de texto EEL-TCP-INPUT, com os resultados fornecidos pela DIM-TCP.

Em relação aos resultados fornecidos pela DIM-TCP, inicialmente, deve-se dimensionar as lajes com as cargas atuantes, e no arquivo EEL-TCP-INPUT, anota-se os valores de $A_{s, x}$ e $A_{s, y}$, correspondentes a estas cargas. Recorde que as equações de estado limite, Equação 9.5, Equação 9.6 e Equação 9.7, dependem dos valores de $A_{s}$.

Em seguida, na rotina DIM-TCP, fornece um valor unitário para $F_{d}$, e calcula-se os fatores de distribuição de momento de plastificação, $m_{x}$ e $m_{y}$, respectivamente, nas direções $x$ e $y$. Anota-se os referidos valores no arquivo EEL-TCP-INPUT. 
O momento solicitante nas lajes, Equação 8.6, Equação 8.22 e Equação 8.24, depende das propriedades geométricas, da configuração de ruína e das cargas atuantes $\left(F_{d}, P_{l}\right)$. As cargas atuantes são divididas em duas parcelas: permanente $(g)$ e variável $(q)$. Isso porque para realizar as análises de confiabilidade, $g$ e $q$ possuem estatísticas diferentes.

Com as estatísticas apresentadas na Tabela 10, realiza-se a determinação da probabilidade de falha $\left(P_{f}\right)$ para a laje apresentada na Figura 47. Para tal, utiliza-se as armaduras dimensionadas pela DIM-TCP.

Figura 47 - Laje no estado íntegro.

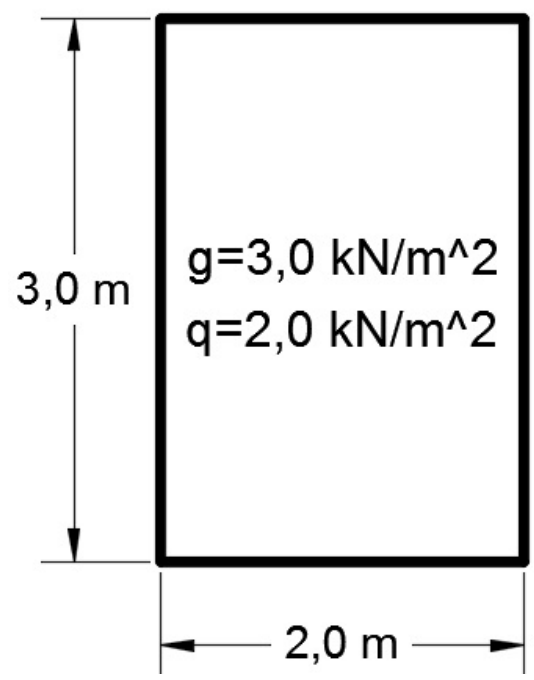

Fonte: Autoria própria.

Tabela 10 - Estatísticas das variáveis aleatórias.

\begin{tabular}{ccccc}
\hline Estatística & $f_{y}\left(k N / \mathrm{cm}^{2}\right)$ & $f_{c}\left(k N / \mathrm{cm}^{2}\right)$ & $g\left(k N / m^{2}\right)$ & $q\left(\mathrm{kN} / \mathrm{m}^{2}\right)$ \\
\hline \hline Média & 54,50 & 3,00 & $1,05 \cdot g_{n}$ & $q_{n}$ \\
\hline Coeficiente de variação & 0,05 & 0,10 & 0,10 & 0,25 \\
\hline Distribuição & Normal & Normal & Normal & Gumbel max. \\
\hline
\end{tabular}

Fonte: Autoria própria.

Nota: $f_{y}$ e $f_{c}$ são os valores médios, respectivamente, da resistência de escoamento do aço e resistência à compressão do concreto, determinados pela Equação 7.16, com as estatísticas do trabalho de Nogueira (2010) .

Nota: $g_{n}$ e $q_{n}$ são os valores nominais, respectivamente, das cargas permanentes e variáveis, com as estatísticas do trabalho de Ellingwood e Galambos (1983).

Primeiramente, calcula-se a $P_{f}$ considerando o estado íntegro (ESI), ou seja, para a laje simplesmente apoiada. Assim, $P_{f}$ determinada para essa laje é igual a $1,17 \cdot 10^{-4} \mathrm{e}$ $1,21 \cdot 10^{-4}$, respectivamente na direção $x$ e $y$ via FORM. Em seguida, realiza-se a análise 
no estágio de propagação de dano (ESPD). Neste caso, a configuração de ruína da laje (borda livre), vai depender da posição do elemento de apoio que falhou. Assim, para a falha do elemento de apoio sob o vão menor da laje a probabilidade de falha via FORM é igual a 1,00 e $3,39 \cdot 10^{-1}$, respectivamente na direção $x$ e $y$. Já no caso da falha do elemento de apoio sob o vão maior da laje a probabilidade de falha via FORM é igual a 1,00 em ambas as direções. Constata-se que a configuração de ruína da laje com uma borda livre impõe um aumento considerável no momento solicitante o que leva ao colapso da mesma. Para essa laje o aumento é em média igual 2,35 vezes o momento solicitante no ESI.

\subsection{Metodologia do RAPC}

O algoritmo seguinte detalha as etapas necessárias para aplicar a metodologia RAPC:

a) identificar os riscos relevantes aos quais o edifício é susceptível de estar exposto e os casos de carga resultantes. Se $P\left[E_{v}\right] \leq 10^{-7} /$ ano, o cenário de carregamento pode ser desconsiderado, seguindo (NISTIR 7396, 2007; ELLINGWOOD, 2006; PATE-CORNELL, 1994);

b) para um cenário de carregamento específico, descreva as equações de estado limite para todos os modos de falha relevantes de todos os elementos estruturais, avaliando as probabilidades de falha individuais $P\left[\boldsymbol{F}_{i}\right]$;

c) avaliar os coeficientes de vulnerabilidade $(C V)$ através da Equação 6.13;

d) remover o elemento $E_{i}$ da estrutura, avaliar as probabilidades de falha condicional $P\left[\boldsymbol{F}_{j} \mid \boldsymbol{F}_{i}\right]$; calcular o coeficiente de importância para a propagação de danos $(C I D)$;

e) calcular as probabilidades de falha das lajes $P\left[\boldsymbol{L}_{j} \mid \boldsymbol{F}_{i}\right]$ devido à falha do elemento $E_{i}$, utilizando a Equação 9.5, Equação 9.6 e Equação 9.7;

f) se a estrutura ainda estiver em equilíbrio, remova os elementos $E_{j}$ da estrutura, um de cada vez; calcule as probabilidades de falha condicional $P\left[\boldsymbol{F}_{k} \mid \boldsymbol{F}_{i, j}\right]$; determine as probabilidades de ocorrência do caminho de falha $c_{i}$ (Equação 6.1), e avalie o coeficiente de importância para o colapso $(C I C)$;

g) classificar os elementos em ordem de importância com relação a vulnerabilidade ao colapso estrutural $(C V C)$, por meio da Equação 6.19, e identificar o elemento chave $(E C)$ para o caso do evento $E_{v}$ de acordo com a Equação 6.20;

h) volte ao passo b) e repita para outros casos de carga e riscos relevantes;

Na Figura 48 é mostrado o esquema com os passos para a utilização da metodologia do RAPC, estes passos são implementados no código RAPC-ACADEMIC. Dessa forma, 
conclui-se que, os questionamentos que a literatura até o momento não conseguiu responder podem ser verificados a partir da metodologia do RAPC.

Figura 48 - Algoritmo da metodologia do RAPC.

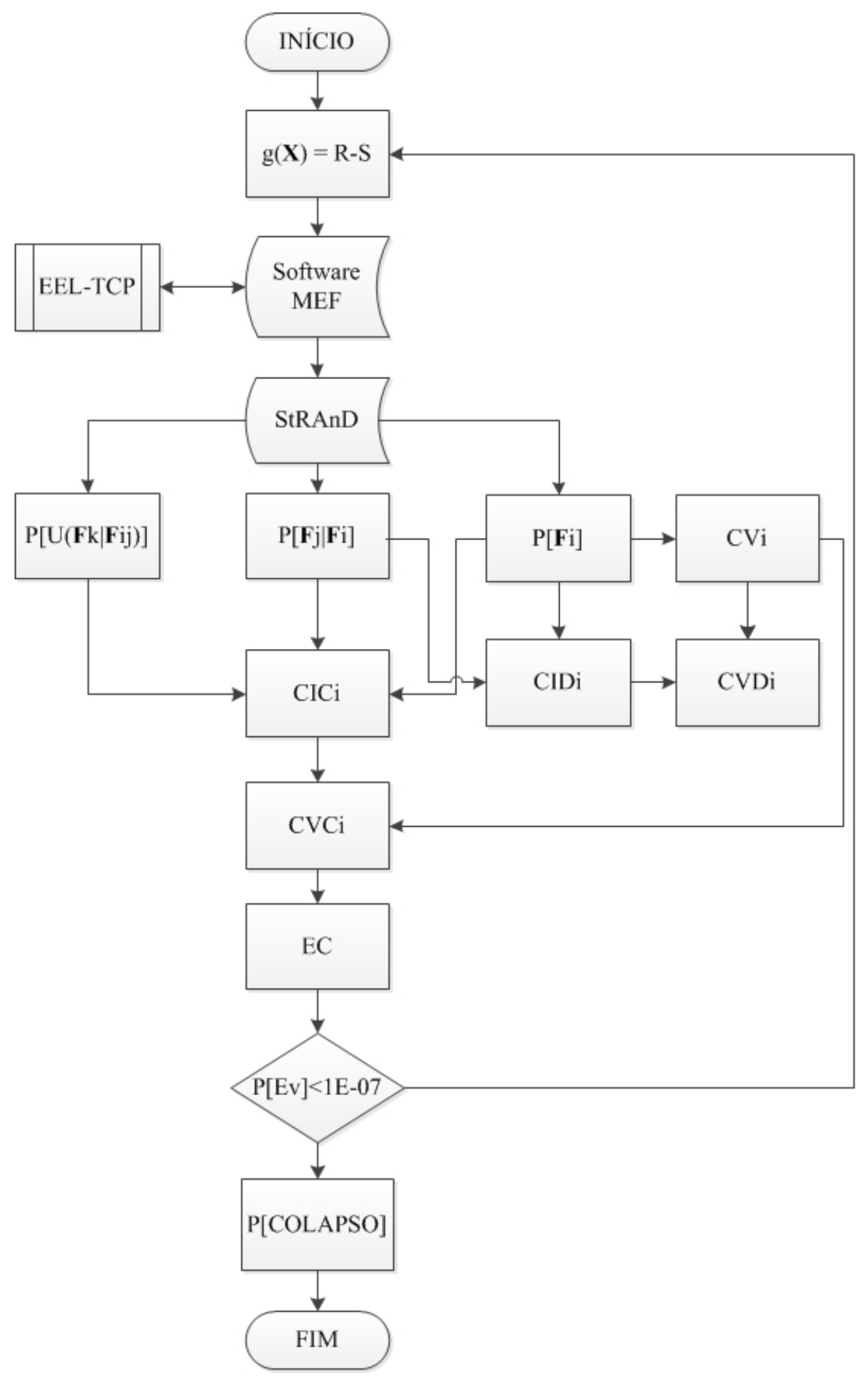

Fonte: Autoria própria. 


\section{Parte IV}

Resultados 



\section{Avaliação da confiabilidade das lajes}

A Figura 30 apresenta o pavimento tipo do edifício de alvenaria estrutural em estudo. Para a determinação dos esforços e dimensionamento das lajes deste pavimento, utiliza-se a rotina DIM-TCP. A Figura 49 mostra a numeração das lajes.

Figura 49 - Numeração das lajes do pavimento tipo.

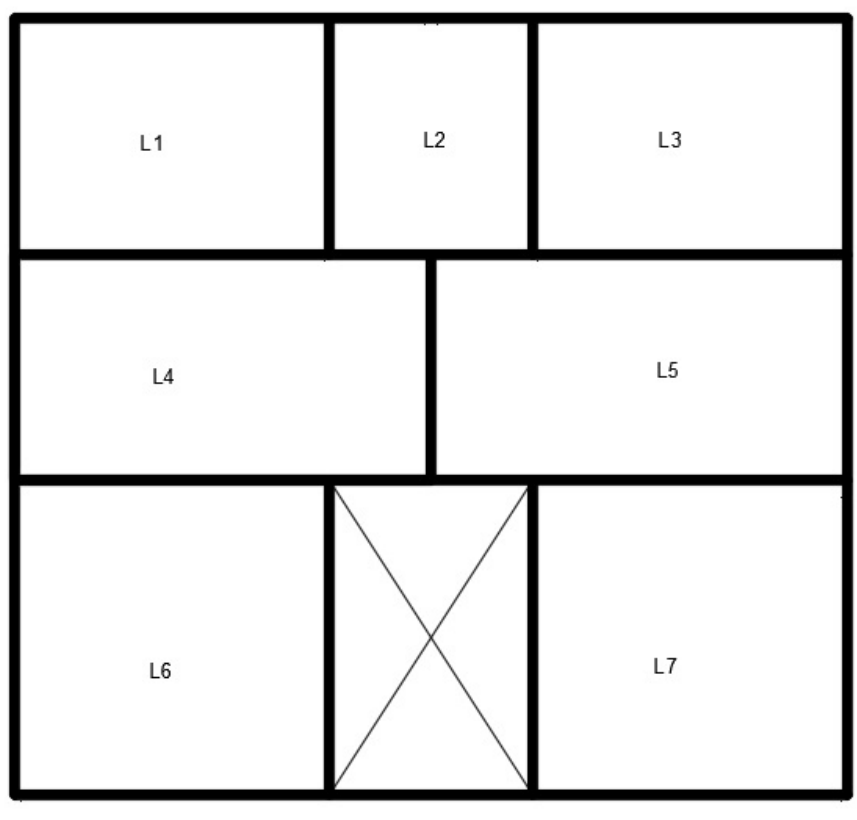

Fonte: Autoria própria.

Tabela 11 - Dimensões das lajes em $\mathrm{cm}$.

\begin{tabular}{cccccccc}
\hline Vão & L1 & L2 & L3 & L4 & L5 & L6 & L7 \\
\hline \hline$l_{x}$ & 315 & 270 & 315 & 300 & 300 & 420 & 420 \\
\hline$l_{y}$ & 420 & 315 & 420 & 555 & 555 & 420 & 420 \\
\hline
\end{tabular}

Fonte: Autoria própria.

As lajes do edifício são do tipo maciça com espessura $h=10 \mathrm{~cm}$, a carga permanente $g=3,5 \mathrm{kN} / \mathrm{m}^{2}$ e a carga acidental $q=2,0 \mathrm{kN} / \mathrm{m}^{2}$. Para as combinações de ação, adotamse os coeficientes de ponderações das ações: $\gamma_{g}=1,4$ e $\gamma_{q}=1$, 4. Além disso, considera-se um cobrimento nominal $c=2,5 \mathrm{~cm}$ (classe de agressividade ambiental II ABNT NBR 6118 (2014)), concreto C25 e aço CA-50. A resistência do concreto e do aço são minoradas pelos respectivos coeficientes de ponderações das resistências: $\gamma_{c}=1,4$ e $\gamma_{s}=1,15$. O 
vão efetivo das lajes é determinado das distâncias eixo a eixo de cada elemento, conforme apresentado na Tabela 11.

Figura 50 - Arquivo de entrada de dados para a DIM-TCP.

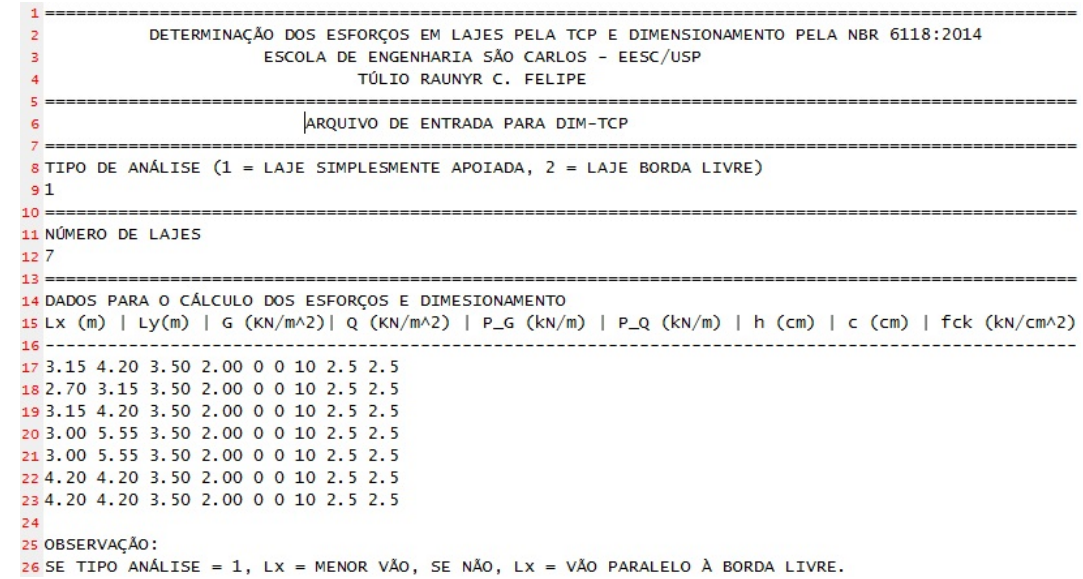

Fonte: Autoria própria.

Figura 51 - Dimensionamento do pavimento tipo pela DIM-TCP.

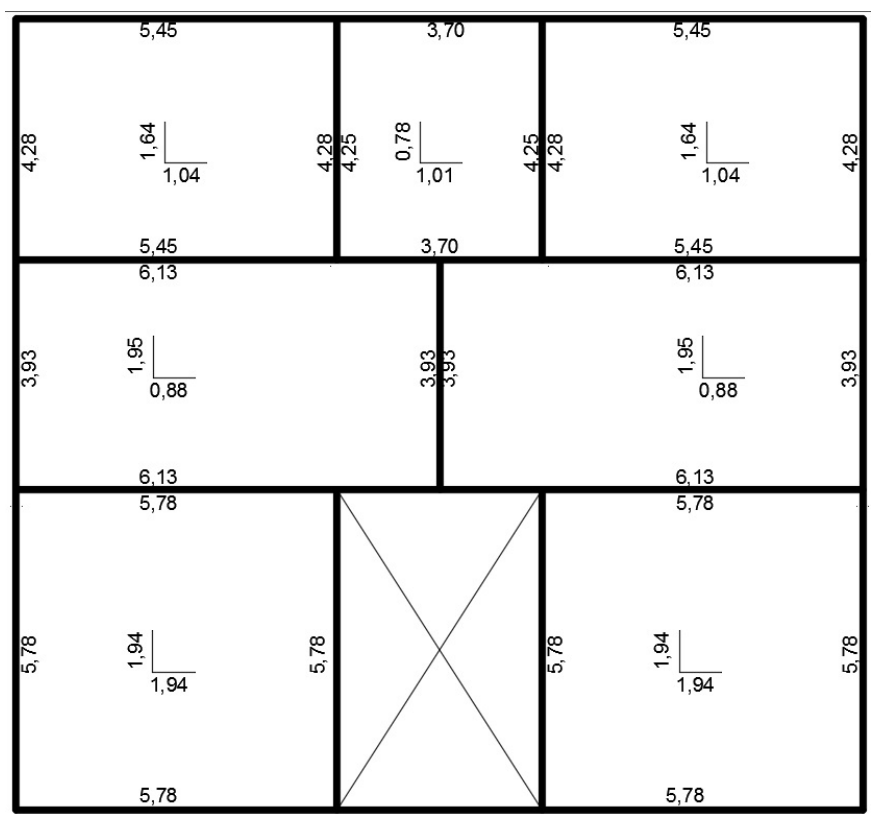

Fonte: Autoria própria.

Com estes dados obteve-se os resultados apresentados na Figura 51. Em que os valores das armaduras $\left(\mathrm{cm}^{2} / \mathrm{m}\right)$ e reações de apoios $(k N / m)$ são mostrados, respectivamente, no centro e na borda de cada laje. Na seção 10.1, partindo das equações definidas 
na seção 8.5 e seção 8.6, e com os valores ilustrados na Figura 51, são realizadas as análises de confiabilidade para esse pavimento tipo.

\subsection{Avaliação da probabilidade de falha das lajes}

Partindo das estatísticas apresentadas na Tabela 10, realiza-se a determinação da probabilidade de falha $\left(P_{f}\right)$ para o pavimento tipo em estudo. Primeiramente, calcula-se as $P_{f}$ considerando o estado íntegro (ESI), ou seja, para as lajes simplesmente apoiadas.

Como os valores das armaduras $\left(A_{s}\right)$ são determinadas para cada direção $(x, y)$, a análise de confiabilidade deve ser realizada considerando a equação de estado limite correspondente a cada direção. Assim, a $P_{f}$ é dada pela soma da sequência de falha referente a $A_{s, x}$ e $A_{s, y}$, assumindo que tais eventos são mutuamente exclusivos. As análises são realizadas via FORM e ISMC com auxílio da rotina EEL-TCP, conforme mostrado na Tabela 12.

Tabela 12 - Análise das lajes no estado íntegro.

\begin{tabular}{ccccccc}
\hline Laje & $P_{f, x}(\mathrm{FORM})$ & $P_{f, y}(\mathrm{FORM})$ & $P_{f, x}(\mathrm{ISMC})$ & $P_{f, y}(\mathrm{ISMC})$ & $P_{f}(\mathrm{FORM})$ & $P_{f}(\mathrm{ISMC})$ \\
\hline \hline $\mathrm{L} 1$ & $5,13 \cdot 10^{-5}$ & $5,60 \cdot 10^{-5}$ & $5,25 \cdot 10^{-5}$ & $5,58 \cdot 10^{-5}$ & $1,07 \cdot 10^{-4}$ & $1,08 \cdot 10^{-4}$ \\
\hline L2 & $5,62 \cdot 10^{-5}$ & $5,82 \cdot 10^{-5}$ & $6,05 \cdot 10^{-5}$ & $5,64 \cdot 10^{-5}$ & $1,14 \cdot 10^{-4}$ & $1,17 \cdot 10^{-4}$ \\
\hline L3 & $5,13 \cdot 10^{-5}$ & $5,60 \cdot 10^{-5}$ & $5,25 \cdot 10^{-5}$ & $5,58 \cdot 10^{-5}$ & $1,07 \cdot 10^{-4}$ & $1,08 \cdot 10^{-4}$ \\
\hline L4 & $4,90 \cdot 10^{-5}$ & $5,74 \cdot 10^{-5}$ & $5,17 \cdot 10^{-5}$ & $5,53 \cdot 10^{-5}$ & $1,07 \cdot 10^{-4}$ & $1,07 \cdot 10^{-4}$ \\
\hline L5 & $4,90 \cdot 10^{-5}$ & $5,74 \cdot 10^{-5}$ & $5,17 \cdot 10^{-5}$ & $5,53 \cdot 10^{-5}$ & $1,07 \cdot 10^{-4}$ & $1,07 \cdot 10^{-4}$ \\
\hline L6 & $4,91 \cdot 10^{-5}$ & $4,91 \cdot 10^{-5}$ & $5,09 \cdot 10^{-5}$ & $5,09 \cdot 10^{-5}$ & $9,82 \cdot 10^{-5}$ & $1,02 \cdot 10^{-4}$ \\
\hline L7 & $4,91 \cdot 10^{-5}$ & $4,91 \cdot 10^{-5}$ & $5,09 \cdot 10^{-5}$ & $5,09 \cdot 10^{-5}$ & $9,82 \cdot 10^{-5}$ & $1,02 \cdot 10^{-4}$ \\
\hline
\end{tabular}

Fonte: Autoria própria.

Como já citado no Capítulo 8, a TCP é baseada no teorema do limite superior. Este teorema estabelece que toda configuração de ruína cinematicamente admissível é maior ou igual à carga que provoca a ruína da peça. Portanto, verifica-se que a carga determinada por este teorema é o limite superior para a carga efetiva de ruína.

Comparando os valores de $P_{f}$ apresentados na Tabela 12, com a probabilidade de falha aceitável proposta pelo JCSS Probabilistic Model Code (2001), Tabela 13, observa-se que todas as lajes estão com um alto risco de falha. O que comprova que a TCP subestima a carga de ruína das lajes, sendo a favor da segurança.

De acordo com Pinheiro (1988), resultados experimentais comprovam que a carga de ruína é geralmente maior que a determinada pela TCP. Isso porque o efeito de membrana e arqueamento oferece uma reserva de resistência. Contudo, tal reserva pode não haver para todos os tipos de lajes. 
Tabela 13 - Valores de $P_{f}$ alvo para elementos estruturais no ELU.

\begin{tabular}{cccc}
\hline $\begin{array}{c}\text { Medida relativa do } \\
\text { custo de segurança }\end{array}$ & $\begin{array}{c}\text { Conseq. de falha } \\
\text { leves }\end{array}$ & $\begin{array}{c}\text { Conseq. de falha } \\
\text { moderadas }\end{array}$ & $\begin{array}{c}\text { Conseq. de falha } \\
\text { graves }\end{array}$ \\
\hline \hline Grande & $1 \cdot 10^{-3}$ & $5 \cdot 10^{-4}$ & $1 \cdot 10^{-4}$ \\
\hline Normal & $1 \cdot 10^{-4}$ & $1 \cdot 10^{-5}$ & $5 \cdot 10^{-6}$ \\
\hline Pequeno & $1 \cdot 10^{-5}$ & $5 \cdot 10^{-6}$ & $1 \cdot 10^{-6}$ \\
\hline
\end{tabular}

Fonte: JCSS Probabilistic Model Code (2001).

Nota: Conseq. $=$ consequências e ELU $=$ estado limite último.

Nota: As consequências leves, o risco de vida e danos econômicos são pequenos ou negligenciáveis. Já as consequências moderadas, o risco de vida e danos econômicos são consideráveis. Enquanto que as consequências graves, o risco de vida e os danos econômicos são altos (JCSS PROBABILISTIC MODEL CODE, 2001).

Realizando novamente as análises de confiabilidade, agora para a estrutura no estágio de propagação de dano (ESPD), falha de um elemento de apoio $\left(E_{i}\right)$, determinam-se as probabilidades de falha condicionais $\left(P\left[\boldsymbol{L}_{j} \mid \boldsymbol{F}_{i}\right]\right)$, falha da laje $L_{j}$ dada à ocorrência de falha do elemento $E_{i}$. Para tal, inicialmente, calcula-se as cargas nas bordas das lajes $P_{g}$ e $P_{q}$, respectivamente, para as cargas $g$ e $q$ em $(k N / m)$.

Com os valores de cargas nas bordas, mais a parcela devido ao peso próprio das paredes de alvenaria, são calculadas as $P\left[\boldsymbol{L}_{j} \mid \boldsymbol{F}_{i}\right]$ para o pavimento térreo. Recordando do Capítulo 7 que o edifício em estudo é formado por 6 pavimentos. As estatísticas são as mesmas da Tabela 10.

Neste caso todas as lajes falharam. Isso porque, a probabilidade de falha das mesmas é igual a 1. A configuração de ruína da laje devido à falha de um elemento de apoio, aumenta drasticamente o momento solicitante. Como o dimensionamento do pavimento tipo foi realizado para uma configuração que gera um momento razoavelmente baixo, as armaduras calculadas por este momento não são suficientes para suportar o aumento do momento para a configuração de ruína atual. Portanto, conclui-se que uma possível solução de projeto para minimizar os efeitos do colapso das lajes é a consideração das mesmas com vinculação engastada. Uma vez que, a configuração de ruína de uma laje engastada redistribui melhor os momentos solicitantes transferindo parte desses momentos para as bordas engastadas. Além disso, suas bordas possuem taxas de armaduras dadas pelo seu dimensionamento que contribuíram no momento resistente da seção. 


\section{Validação da Metodologia do RAPC: Mo- delo Numérico}

O presente capítulo apresenta a influência das lajes e da análise não linear na avaliação do colapso progressivo. Assim, a simulação de um edifício de alvenaria estrutural com quatro pavimentos é realizada no software comercial DIANA ${ }^{\circledR}$. Para tal, é adotado o pavimento tipo estudado no Capítulo 7, conforme ilustrado na Figura 30.

Inicialmente, a avaliação do colapso progressivo no modelo numérico é efetuada através de análises geometricamente lineares (seção 11.3). Em seguida, a verificação do colapso progressivo é realizada considerando análise não linear geométrica (seção 11.4). Em ambos os casos, a não linearidade física é assumida de forma aproximada, penalizando o módulo de elasticidade, conforme a ABNT NBR 15961-1 (2011).

O modelo estrutural adotado é o do pórtico tridimensional, em que, considera-se a hipótese do comportamento de diafragma rígido das lajes. Neste caso, a análise das lajes é feita de forma desacoplada do modelo de pórtico e são verificadas através das rotinas DIM-TCP e EEL-TCP.

Por fim, os resultados dos esforços solicitantes obtidos no DIANA ${ }^{\circledR}$ em cada etapa da metodologia do RAPC, é analisado pelo RAPC-ACADEMIC. Na primeira etapa são determinados os coeficientes de vulnerabilidade $\left(C V^{\prime} s\right)$. Na segunda os coeficientes de importância $\left(C I D^{\prime} s\right.$ e $\left.C I C^{\prime} s\right)$, e com tais valores de $C V^{\prime} s$ e $C I C^{\prime} s$, define-se o(s) elemento(s) chave. Por fim, na terceira etapa, a $P[$ colapso $]$ é calculada. A seguir, apresentamse os procedimentos adotados.

\subsection{Modelo de pórtico tridimensional}

O modelo de pórtico tridimensional foi proposto por Yagui (1978) para simular núcleos de concreto. Nascimento (1999) através deste modelo simulou e analisou edifícios de alvenaria estrutural.

No caso de edifícios de alvenaria estrutural, esse modelo consiste na discretização das paredes estruturais por elementos de barra tridimensional. Os elementos de barras devem ter as mesmas características geométricas das paredes correspondentes. Também devem ser dispostos no centro de gravidade (CG) da seção da parede (NASCIMENTO, 1999). Conforme Nascimento (1999), nestas seções não considera-se a composição da existência de abas ou flanges, isso porque a contribuição desta composição está incorporada ao modelo. 
As paredes adjacentes são interligadas por barras horizontais rígidas, conforme apresentado na Figura 52. Estas visam simular a interação que efetivamente se desenvolve nas paredes. As suas extremidades comuns são consideradas rotuladas, admitindo somente a transferência de tensão de cisalhamento. Também é possível a inclusão de lintéis. Estes são incorporados ao modelo através de barras horizontais flexíveis, com suas extremidades engastadas nas barras rígidas (NASCIMENTO, 1999).

Figura 52 - Modelagem das paredes de alvenaria estrutural.

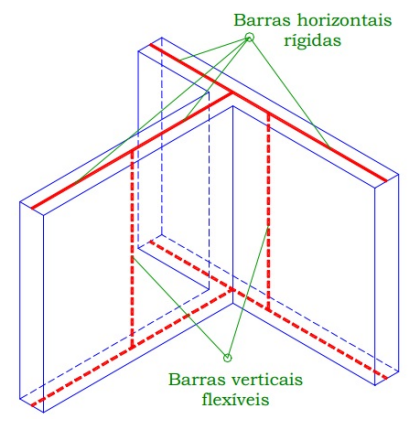

Fonte: Nascimento (1999).

Figura 53 - Esquema da modelagem das paredes por barras rígidas.

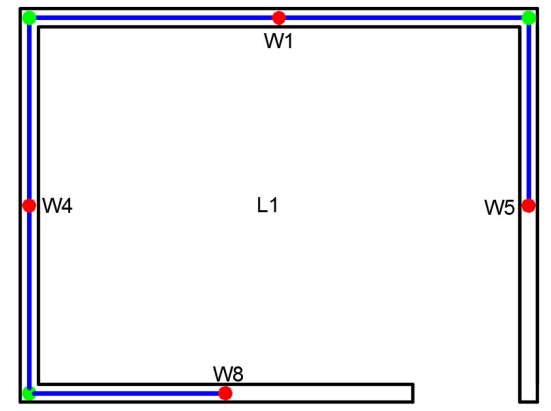

Fonte: Autoria própria.

Da Figura 53, observa-se que cada parede estrutural tem um nó no CG da seção (círculo em vermelho) mais aqueles definidos pelas rótulas entre paredes (círculo verde). A linha azul representa as barras rígidas interligando as paredes. Estas barras apresentam a característica recomendada por Corrêa (1991). Em que, utiliza-se barras com seções de espessuras igual à parede e altura do pé-direito. Segundo o referido autor o objetivo da simulação é obtido, sem perturbação na estabilidade numérica da solução. Entretanto, Braguim (2013) recomenda que a rigidez dessas barras rígidas seja multiplicada por 100.

Em se tratando da modelagem das lajes, estas são imaginadas como um diafragma rígido em seu plano. Para tal, utiliza-se o recurso do nó mestre, compatibilizando-se os 
deslocamentos ao nível de cada pavimento (CORRÊA; RAMALHO, 2004; NASCIMENTO, 1999). Os deslocamentos de cada nó são dependentes dos do nó mestre (Figura 54). Estes são definidos por duas translações no plano do pavimento e uma rotação em torno de um eixo normal a este plano (CORRÊA, 1991).

Figura 54 - Graus de liberdade dos nós com a consideração do recurso do nó mestre.

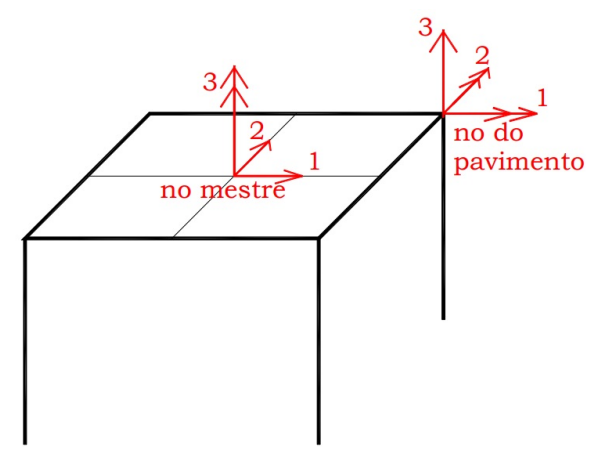

Fonte: Nascimento (1999).

\subsection{Simulação numérica}

O método amplamente utilizado nos softwares para simulação atualmente é o dos Elementos Finitos (MEF). De forma simplista, consiste em transformar um problema complexo, na soma de diversos problemas simples, diminuindo o custo computacional (FELIPE; HAACH, 2016).

Conforme Soriano (2003) e Kazda (1990), o MEF é um método que consiste em aproximar uma função contínua por um modelo discreto em um número finito de pontos pré-selecionados no seu domínio. O domínio é dividido em subdomínios ou elementos de dimensão finita interligados por meio de pontos. Estes são chamados de nós, aqueles de elementos finitos.

Na próxima seção são apresentadas as propriedades gerais adotadas no modelo numérico. Pretende-se mostrar as considerações realizadas na simulação do edifício em estudo.

\subsubsection{Propriedades gerais do modelo numérico}

\subsubsection{Propriedades dos elementos estruturais}

As lajes são maciças com espessura de $10 \mathrm{~cm}$, cobrimento de $2,5 \mathrm{~cm}, f_{c k}=25 \mathrm{MPa}$ e aço CA-50. As cargas adotadas são $g=3,5 \mathrm{kN} / \mathrm{m}^{2}$ e $q=2,0 \mathrm{kN} / \mathrm{m}^{2}$. Em relação as paredes, estas têm espessura de $14 \mathrm{~cm}$ e altura de $280 \mathrm{~cm}$, com resistência característica 
de prisma $\left(f_{p k}\right)$ igual 2,70 MPa. O vão efetivo é calculado das distâncias eixo a eixo de cada elemento.

\subsubsection{Propriedades dos materiais}

Os valores das propriedades elásticas da alvenaria são adotados de acordo com a Tabela 1 da ABNT NBR 15961-1 (2011). Neste caso, para uma resistência de prisma de 2,7 $M P a$, obtém-se: $E=2160 M P a$ e $\nu=0,20$, sendo $E^{1}$ e $\nu$, respectivamente o módulo de elasticidade e o coeficiente de Poisson.

\subsubsection{Malha e elementos finitos}

Para a simulação é utilizado o elemento de barra L12BE disponível no software DIANA ${ }^{\circledR}$. Este elemento tridimensional possui dois nós, com dois pontos de integração por elemento, conforme ilustrado na Figura 55. O mesmo é descrito por uma função de aproximação dos deslocamentos do $3^{\circ}$ grau. A sua formulação é baseada na cinemática de Euler-Bernoulli. A malha de cada parede é discretizada em 4 elementos.

Figura 55 - Elemento finito de barra L12BE.

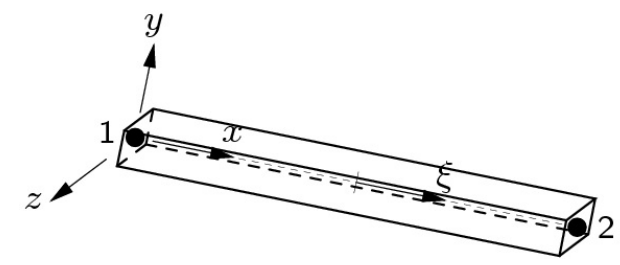

Fonte: DIANA ${ }^{\circledR}$.

\subsubsection{Carregamentos e condições de contorno}

Os carregamentos são aplicados na forma de carga concentrada no nó do CG das respectivas paredes. Esta carga é composta por duas parcelas, sendo a primeira devido ao peso próprio da parede e a segunda pelas reações que chegam da laje. Os carregamentos devido à solicitação na laje são determinados pela teoria de charneiras plásticas implementada na rotina DIM-TCP. Despreza-se as ações horizontais.

Para a estrutura íntegra, as lajes são consideradas simplesmente apoiadas nas quatro bordas. Já na fase de propagação de dano, as reações são analisadas considerando as lajes com uma borda livre. Para tal, a carga linear na borda livre das respectivas lajes é obtida pelo resultado do modelo numérico. Neste caso, para cada parede que falha, é verificado a força normal que atua no nível do pavimento superior, localizado sobre a parede que falhou.

1 Para a consideração da não linearidade física de forma aproximada, o $E$ é reduzido em $40 \%$ (ABNT NBR 15961-1, 2011). 
A carga linear na borda é obtida dividindo este esforço pela respectiva dimensão da parede. Com o valor desta carga, a análise de confiabilidade da laje é realizada via FORM e ISMC através das equações de estado limites implementadas na rotina EEL-TCP acoplada ao StRAnD. Na ocorrência de falha dessa laje, as cargas atuantes são transferidas para a laje subjacente. Com os novos carregamentos na laje subjacente a análise de confiabilidade é realizada. Repete-se este procedimento até o pavimento térreo.

As condições de contorno na base do edifício são consideradas engastadas. No nível de cada pavimento, acopla-se os deslocamentos dos nós das paredes com a do nó mestre. Adota-se a posição do nó mestre no centro geométrico do edifício.

\subsection{Validação da metodologia do RAPC: análise estática linear}

A Figura 56 apresenta o diagrama unifiliar das paredes em planta do edifício em estudo. O mesmo é modelado no software DIANA ${ }^{\circledR}$ com quatro pavimentos, adotando-se as recomendações mostradas na seção 11.1. As propriedades dos materiais, cargas e as condições de contorno são adotadas de acordo com a seção 11.2.

Figura 56 - Diagrama unifiliar das paredes em planta.

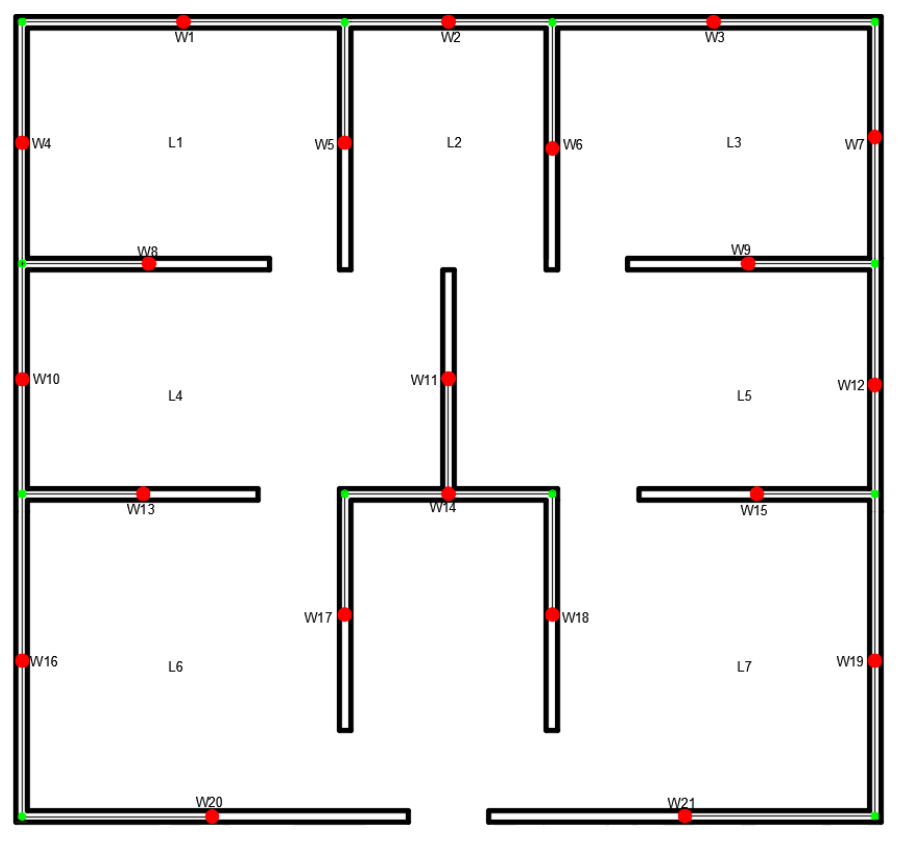

Fonte: Autoria própria.

A Figura 57 apresenta uma visão tridimensional do pavimento tipo. Observa-se que são considerados as aberturas das portas. Entretanto, não são analisados a influência dos lintéis. 
Figura 57 - Visão tridimensional do pavimento tipo.

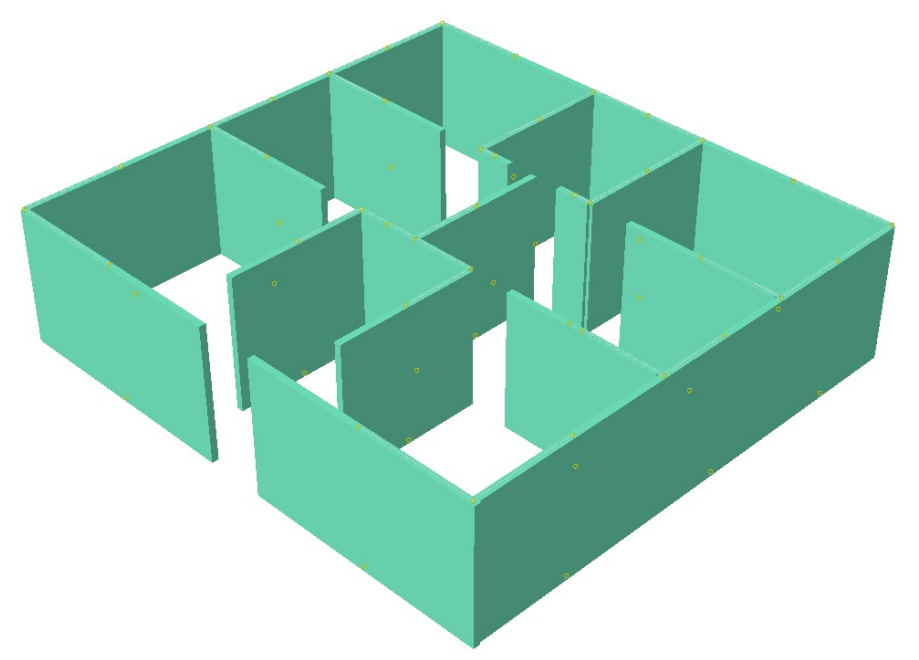

Fonte: Autoria própria.

A consideração da análise do colapso progressivo no software DIANA ${ }^{\circledR}$, é realizada adotando-se os seguintes procedimentos: na fase de lançamento da estrutura, cria-se um material com propriedades que gera uma rigidez nula. Este material é denominado de M-COLAPSO. Para cada avaliação do RAPC na fase de propagação de dano, muda-se as propriedades da parede analisada, para M-COLAPSO. Assim, são determinados os esforços nas outras paredes. Para a avaliação de uma nova parede, retorna-se com as propriedades reais da parede que falhou, e aplica-se a M-COLAPSO na nova parede. Repete-se este procedimento para todas as paredes até a determinação do elemento chave $(E C)$.

Como a rigidez das paredes com M-COLAPSO tende a zero, esse artifício simula a falha das referidas paredes. Tal artifício é importante para a otimização do modelo numérico. Isso porque, não são necessárias as retiradas das paredes (barras) do modelo, o que implicaria na renumeração dos nós em cada iteração.

\subsubsection{Dimensionamento do edifício}

Com as tensões de compressão no nível de cada pavimento obtidas do modelo numérico, em uma análise estática linear, é realizado o dimensionamento do edifício. A Tabela 14 apresenta os valores da tensões de compressão solicitantes de cálculo em cada pavimento do edifício.

O dimensionamento é efetuado a partir das recomendações da ABNT NBR 15961-1 (2011) e Eurocode 6 (2005). Para tal, adota-se bloco de concreto com 4,5 MPa (50\% de furação), argamassa com resistência de 3,6 MPa. Logo, a resistência à compressão 
característica da alvenaria é dada pela seguinte equação:

$$
f_{k}=k \cdot f_{b}^{0,7} \cdot f_{\text {arg }}^{0,3}
$$

sendo, $f_{b}$ a resistência à compressão do bloco, $f_{\text {arg }}$ a resistência à compressão da argamassa, $k$ um constante que depende do tipo do material do bloco conforme apresentado na Tabela 3.3 do Eurocode 6 (2005). Para blocos de concreto incluído no grupo $2, k=0,45$, o que resulta: $f_{k}=1,90 M P a$.

Tabela 14 - Determinação das tensões de compressão solicitantes de cálculo.

\begin{tabular}{ccccc}
\hline Elemento & Pavimento 1 & Pavimento 2 & Pavimento 3 & Pavimento 4 \\
\hline \hline Paredes simétricas & $\sigma_{S d}(M P a)$ & $\sigma_{S d}(M P a)$ & $\sigma_{S d}(M P a)$ & $\sigma_{S d}(M P a)$ \\
\hline 1 e 3 & 0,423 & 0,316 & 0,210 & 0,105 \\
\hline 2 & 0,408 & 0,309 & 0,207 & 0,103 \\
\hline 4 e 7 & 0,402 & 0,303 & 0,202 & 0,101 \\
\hline 5 e 6 & 0,554 & 0,415 & 0,277 & 0,139 \\
\hline 8 e 9 & 0,672 & 0,503 & 0,336 & 0,169 \\
\hline 10 e 12 & 0,402 & 0,304 & 0,203 & 0,100 \\
\hline 11 & 0,591 & 0,448 & 0,299 & 0,149 \\
\hline 13 e 15 & 0,686 & 0,513 & 0,342 & 0,172 \\
\hline 14 & 0,617 & 0,457 & 0,303 & 0,154 \\
\hline 16 e 19 & 0,447 & 0,335 & 0,223 & 0,111 \\
\hline 17 e 18 & 0,457 & 0,343 & 0,229 & 0,114 \\
\hline 20 e 21 & 0,407 & 0,306 & 0,204 & 0,102 \\
\hline
\end{tabular}

Fonte: Autoria própria.

Nota: $\sigma_{S d}$ é calculado para a combinação de ação no ELU com $\gamma_{g}=\gamma_{q}=1,4$.

Para a verificação do estado limite último (ELU), a ABNT NBR 15961-1 (2011) estabelece que a resistência de cálculo para combinações normais, deve ser obtida pela resistência característica, dividida pelo coeficiente de ponderação das resistências $\gamma_{m}=2,0$. Logo, a resistência à compressão de cálculo da alvenaria $\left(f_{d}\right)$, resulta: $f_{d}=0,95 M P a$. O dimensionamento dos elementos estruturais deve atender a seguinte equação de ELU:

$$
\sigma_{R, d} \geq \sigma_{S d}
$$

Neste caso, como a máxima tensão solicitante de cálculo da alvenaria $\left(\sigma_{S d}\right)$ é igual 0,686 MPa, verifica-se que o dimensionamento é atendido com uma certa folga. Ressalta-se que nas análises de confiabilidade que são realizadas neste capítulo, o valor adotado para a média da resistência da alvenaria é calculada de acordo com a Equação 7.16, o que resulta: $f_{a}=2,52 M P a$. 


\subsubsection{Análise dos resultados}

Como as cargas permanentes e variáveis possuem estatísticas diferentes são modelados dois modelos numéricos do edifício. O primeiro modelo, as ações atuantes são provenientes de cargas permanentes. O segundo modelo, as ações atuantes são originadas das cargas variáveis. Para cada etapa da metodologia do RAPC esses modelos são avaliados.

Na primeira etapa, estrutura íntegra (ESI), é considerada a análise estática geometricamente linear para a obtenção dos esforços de cada elemento estrutural. Assim, cada modelo numérico é avaliado no software DIANA ${ }^{\circledR}$ considerando essa análise. Com os resultados dos esforços fornecidos por esses modelos e as estatísticas das variáveis aleatórias apresentadas na Tabela 15, determinam-se os coeficientes de vulnerabilidade dos elementos (Equação 6.13) através do RAPC-ACADEMIC. As estatísticas são extraídas dos trabalhos Ellingwood e Galambos (1983) para as cargas permanentes e variáveis, a espessura da parede da ABNT NBR 6136 (2014) e o coeficiente de variação para a resistência da alvenaria da AS 3700 (2001). Recordando que o modo de falha considerado para avaliação da estrutura é a compressão axial, o que resulta na seguinte equação de estado limite.

$$
g_{i}\left(f_{a i}, t_{i}, g_{i}, q_{i}\right)=f_{a i} \cdot L_{i} \cdot t_{i}\left[1-\left(\frac{h_{i} \cdot \sqrt{12}}{140 \cdot t_{i}}\right)^{2}\right]-g_{i}-q_{i}
$$

em que, $f_{a i}$ é a resistência à compressão da alvenaria, $L_{i}$ é o comprimento da parede, $t_{i}$ é a espessura do bloco, $h_{i}$ é a altura da parede, $g_{i}$ é a carga permanente e $q_{i}$ é a carga variável, respectivamente da parede $i$.

Tabela 15 - Estatísticas das variáveis aleatórias do edifício de alvenaria.

\begin{tabular}{ccccc}
\hline Estatística & $f_{a i}\left(\mathrm{kN} / \mathrm{cm}^{2}\right)$ & $t_{i}(\mathrm{~cm})$ & $g_{i}(k N)$ & $q_{i}(k N)$ \\
\hline \hline Média & 0,252 & 14,000 & $1,050 \cdot g_{n}$ & $1,000 \cdot q_{n}$ \\
\hline cov & 0,150 & 0,012 & 0,100 & 0,250 \\
\hline Distribuição & Normal & Uniforme & Normal & Gumbel max. \\
\hline
\end{tabular}

Fonte: ABNT NBR 6136 (2014), AS 3700 (2001) e Ellingwood e Galambos (1983).

Nota: $g_{n}$ e $q_{n}$ são os valores nominais, respectivamente, das cargas permanentes e variáveis.

Na Figura 58 é apresentado os valores de $C V$ para análise via FORM, respectivamente, para os pavimentos 1, 2, 3 e 4. Verifica-se que as paredes mais vulneráveis são $W 13$ e W8. Com relação as análises de confiabilidade, constata-se que em média, os valores via FORM apresentam um aumento de $3 \%$ nos valores de $C V$ em relação aos valores determinados via ISMC. Na verdade, isto é esperado, pois o FORM devido a linearização da equação de estado limite no ponto de projeto, provoca um erro de aproximação na 
determinação do valor de $P\left[\boldsymbol{F}_{i}\right]$. Observa-se que devido a simetria do edifício os valores de $C V$ para os elementos simétricos são os mesmos.

Figura 58 - Coeficiente de vulnerabilidade $(C V)$ via FORM para o edifício.

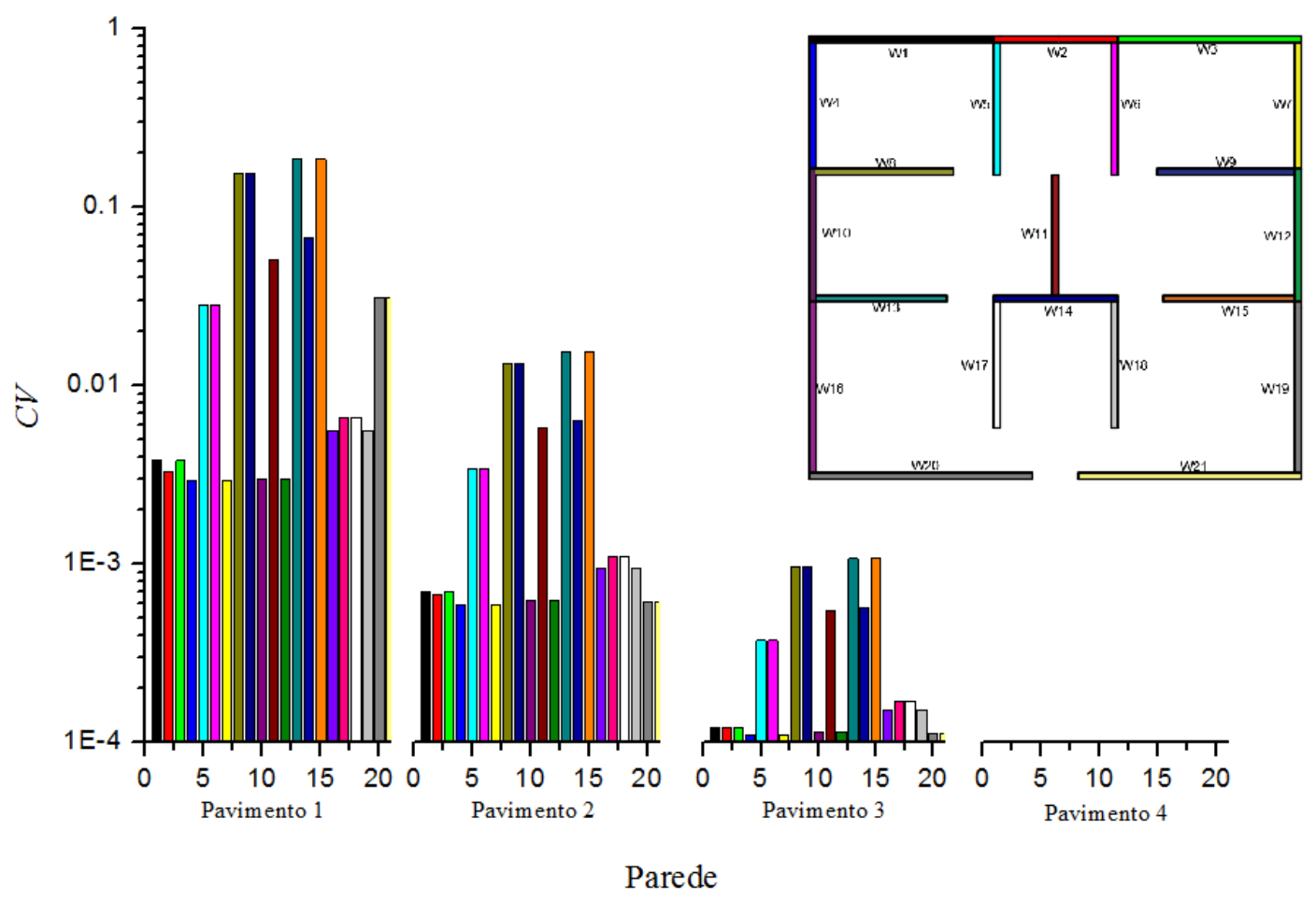

Fonte: Autoria própria.

Ressalta-se que os elementos estruturais em pavimentos superiores têm vulnerabilidade próxima de zero. Isso é esperado, pois os fatores de carga ( $g$ e $q$ ), que compõem a equação de estado limite (Equação 11.3), vão diminuindo ao longo da altura do edifício. Ademais, a resistência à compressão da alvenaria nos pavimentos 2, 3 e 4 estão com uma folga ainda maior em comparação com o pavimento 1. Isto porque, no dimensionamento do edifício assumiu-se a mesma resistência à compressão da alvenaria para todos os pavimentos.

No estágio de propagação de dano (ESPD), adota-se os procedimentos descritos na subseção 11.2.1.4 e seção 11.3. Como o edifício possui 21 paredes estruturais por pavimento, ver Figura 56, totalizado 84 paredes, primeiramente, é implementado em linguagem Fortran a rotina RAPC-MCOLAPSO. Esta consiste em um algoritmo que realiza a mudança da propriedade da parede analisada para o M-COLAPSO e criando arquivos de entrada (.dat ${ }^{2}$ ) para o DIANA ${ }^{\circledR}$ com tais propriedades modificadas.

Para o processamento dos modelos numéricos, utiliza-se o programa Command Box, disponível no pacote do software DIANA ${ }^{\circledR}$. Este é acoplado com o RAPC-ACADEMIC 2 Extensão dos arquivos de pré-processamento do DIANA ${ }^{\circledR}$. 
para realizar o processamento dos modelos numéricos. Após as análises destes modelos no Command Box, para cada parede que falhou, a carga linear na borda livre da respectiva laje é obtida. Com o valor desta carga, a análise de confiabilidade da laje é realizada através da rotina EEL-TCP.

Como já citado no Capítulo 9, a configuração de ruína para uma laje com borda livre, impõe um aumento significativo no momento solicitante. Nas lajes do pavimento tipo do edifício em estudo, em média há um aumento de 2,5 vezes do valor do momento solicitante.

Os coeficientes parciais de segurança utilizados para o dimensionamento da laje, conforme recomendado pela ABNT NBR 6118 (2014), não são suficientes para garantir um valor de momento resistente maior que o momento solicitante para a configuração atual. Isso implica que as lajes do edifício com configuração de borda livre falhem (probabilidade de falha elevada ou igual a unidade). Dessa forma, constata-se que a falha de uma parede estrutural provoca o colapso da laje. Contudo, a falha dessa laje não implica necessariamente no colapso do edifício. Neste caso, deve-se verificar o desempenho dos outros elementos estruturais, após a redistribuição dos esforços, no comportamento global da estrutura avaliando as suas probabilidades de falha através da metodologia do RAPC.

Com a ocorrência da falha da laje superior ${ }^{3}$ (pavimento 4), as cargas atuantes são transferidas para a laje subjacente (pavimento 3). Neste caso, as análises são realizadas para a configuração de laje simplesmente apoiada, considerando o dobro do carregamento da estrutura íntegra, ou seja, $g_{n}=7,0 \mathrm{kN} / \mathrm{m}^{2}$ e $q_{n}=4,0 \mathrm{kN} / \mathrm{m}^{2}$. Com estes novos valores, realiza-se novamente uma análise de confiabilidade. Na Tabela 16 são apresentados os valores de probabilidade de falha das referidas lajes via ISMC, sendo $P_{f, x}$ e $P_{f, y}$ os valores referentes as armaduras nas direções $x$ e $y$.

Da Tabela 16, verifica-se que todas as lajes falham. Isso porque a probabilidade de falha via ISMC para essas lajes é igual a unidade. Conforme comentado no Capítulo 5 o método de simulação de Monte Carlo tende ao valor exato da probabilidade de falha $\left(P_{f}\right)$, à medida que aumenta o número de simulações. Nos demais pavimentos (1 e 2) o aumento nos carregamentos das lajes subjacentes, dado a falha das lajes do pavimento 3 e pavimento 4, implica em probabilidade de falha igual a unidade, o que provoca a ruptura em cadeia desses elementos estruturais.

3 Esta falha pode ocorrer quando um elemento de apoio falha (o que configura a laje com vinculação com borda livre) ou devido ao acréscimo dos carregamentos nas outras lajes (simplesmente apoiada nos quatro lados) nos andares inferiores. Deste modo, a falha das lajes do pavimento 4 dobra as cargas das lajes do pavimento 3, que por sua vez triplica as cargas das lajes do pavimento 2, sucessivamente, tornando-se um efeito sequencial (colapso tipo dominó). Pode-se citar como exemplo, o colapso parcial do Edifício Senador com 14 andares na cidade de São Bernardo do Campos - SP em 2012. Neste caso, uma sobrecarga adicional em uma laje no último pavimento desse edifício devido ao entulho de uma reforma ocasionou a falha deste elemento estrutural (o que provocou um dano de aproximadamente $78,5 \mathrm{~m}^{2}$ da área em planta em todos os pavimentos), culminando na falha das lajes subjacentes até o subsolo, vitimando duas pessoas e outras seis ficaram feridas. 
Tabela 16 - Análise das lajes no estágio de propagação de dano via ISMC.

\begin{tabular}{ccccccccc}
\hline & Pavimento 1 & \multicolumn{2}{c}{ Pavimento 2 } & \multicolumn{3}{c}{ Pavimento 3 } & \multicolumn{3}{c}{ Pavimento 4} \\
Laje & $P_{f, x}$ & $P_{f, y}$ & $P_{f, x}$ & $P_{f, y}$ & $P_{f, x}$ & $P_{f, y}$ & $P_{f, x}$ & $P_{f, y}$ \\
\hline \hline L1 & 1,0 & 1,0 & 1,0 & 1,0 & 1,0 & 1,0 & 1,0 & 1,0 \\
\hline L2 & 1,0 & 1,0 & 1,0 & 1,0 & 1,0 & 1,0 & 1,0 & 1,0 \\
\hline L3 & 1,0 & 1,0 & 1,0 & 1,0 & 1,0 & 1,0 & 1,0 & 1,0 \\
\hline L4 & 1,0 & 1,0 & 1,0 & 1,0 & 1,0 & 1,0 & 1,0 & 1,0 \\
\hline L5 & 1,0 & 1,0 & 1,0 & 1,0 & 1,0 & 1,0 & 1,0 & 1,0 \\
\hline L6 & 1,0 & 1,0 & 1,0 & 1,0 & 1,0 & 1,0 & 1,0 & 1,0 \\
\hline L7 & 1,0 & 1,0 & 1,0 & 1,0 & 1,0 & 1,0 & 1,0 & 1,0 \\
\hline
\end{tabular}

Fonte: Autoria própria.

Figura 59 - Coeficiente de desproporcionalidade para a propagação do dano $(C I D)$, dada a falha do elemento $E_{i}$.

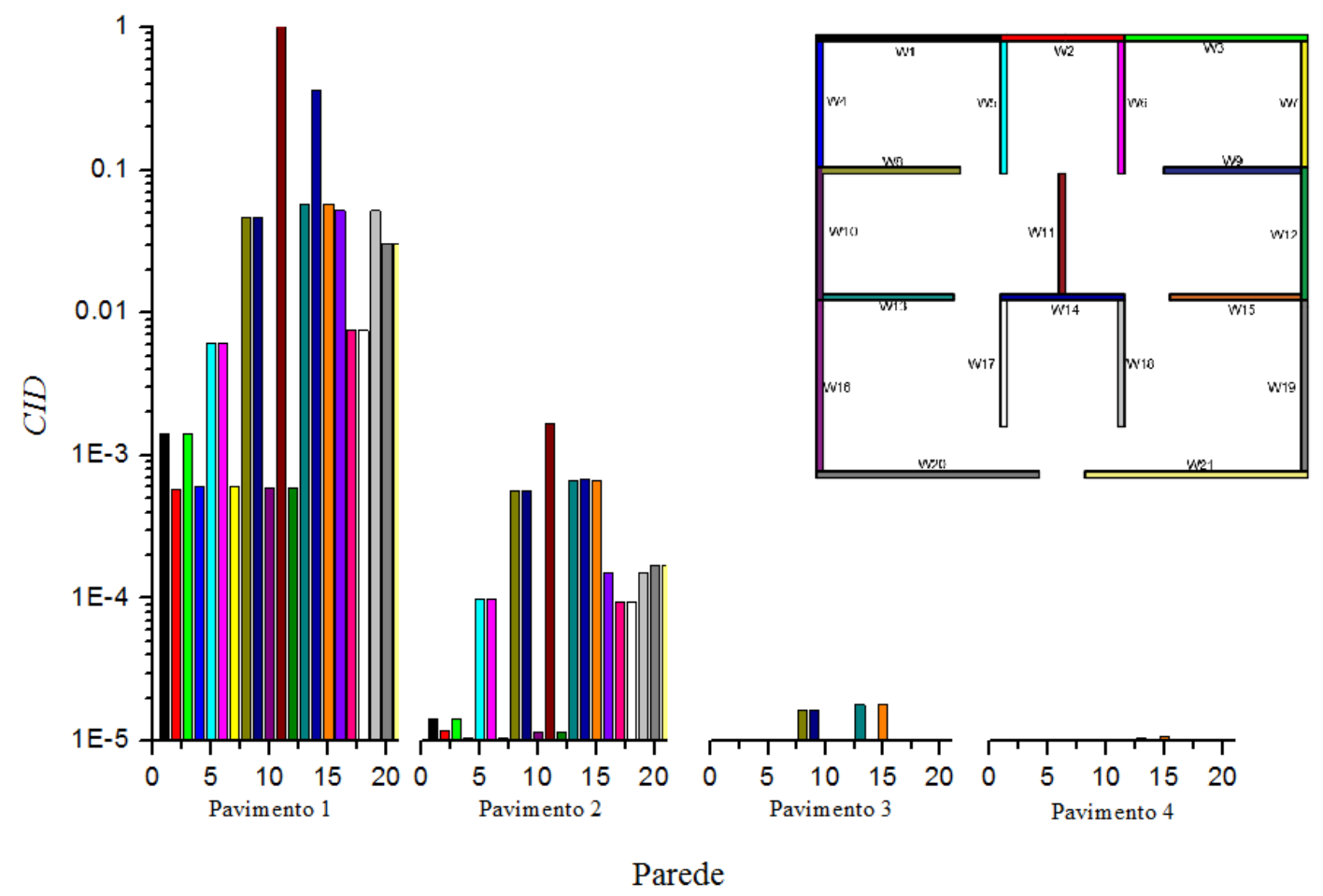

Fonte: Autoria própria.

Após o processamento no RAPC-ACADEMIC são obtidos os coeficientes de importância $\left(C I D^{\prime} s\right.$ e $\left.C I C^{\prime} s\right)$ de cada elemento estrutural. Na Figura 59 é apresentado os $C I D^{\prime} s$ via FORM. Torna-se evidente que os elementos mais importantes para a propagação de dano são $W 11$ e $W 14$.

Observa-se que a falha de um elemento $E_{i}$ com baixo $C V$ gera desproporcionalidade para a estrutura, como por exemplo a parede $W 11$, é o elemento mais importante para 
iniciar o estágio de propagação de dano. Constata-se que no pavimento 3, ocorre uma inversão nos valores dos coeficientes $C I D^{\prime} s$, o que leva as paredes de número $W 13$ (W15 simétrica) e $W 8$ (W9 simétrica) originarem $C I D^{\prime} s$ maiores que as paredes $W 11$ e $W 14$.

Figura 60 - Coeficiente de vulnerabilidade para a propagação de dano $(C I D)$ via FORM.

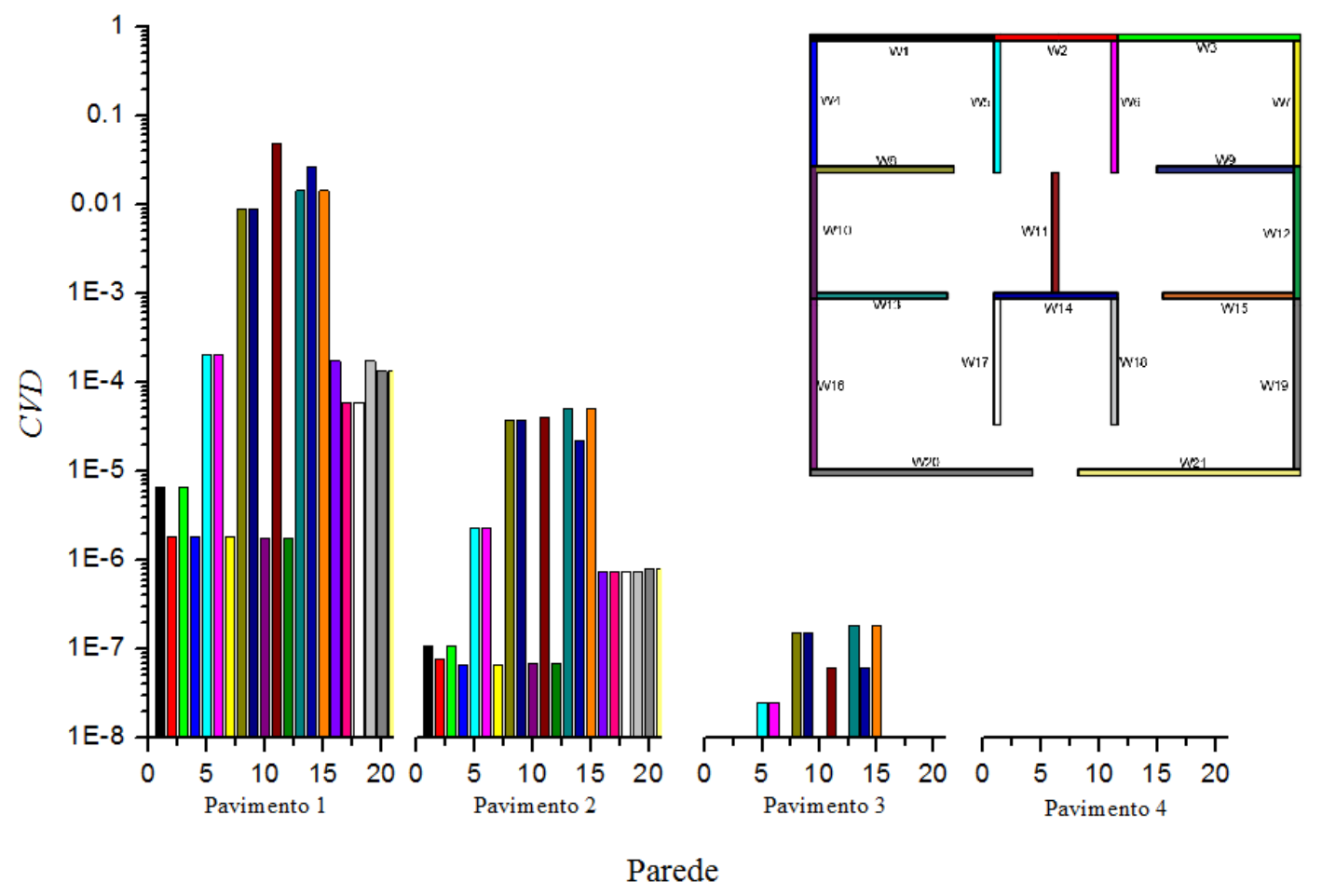

Fonte: Autoria própria.

Na Figura 60 é mostrado os valores dos coeficientes $C V D$ via FORM. Ressalta-se que os elementos que não são ilustrados nessa figura, ou com valores próximos de zero, têm baixa probabilidade para iniciar o estágio de propagação de dano (ESPD). Neste caso, o projetista estrutural para minimizar a ocorrência do ESPD, pode se concentrar em medidas que aumente a resistência dos elementos com os maiores valores de $C V D$. Como por exemplo, taxas de armaduras para prover ductilidade entre esses elementos. Tais armaduras devem ter resistências mínimas na direção horizontal e vertical, calculadas, respectivamente, pela Equação 4.15 e Equação 4.16.

Na Figura 61 é apresentado os valores dos coeficientes $C I C^{\prime} s$ via FORM. Identificase que os elementos mais importantes para iniciar o colapso estrutural são as paredes de número $W 20$ (W21 simétrica) e $W 13$ (W15 simétrica). Nota-se que no pavimento 4 (Figura 61) houve uma mudança nessa ordem, com as paredes $W 20$ e $W 21$ tendo valores de $C I C$ menores que a maioria das paredes desse pavimento. 
Figura 61 - Coeficiente de desproporcionalidade para o colapso progressivo $(C I C)$, dada a falha do elemento $E_{i}$.

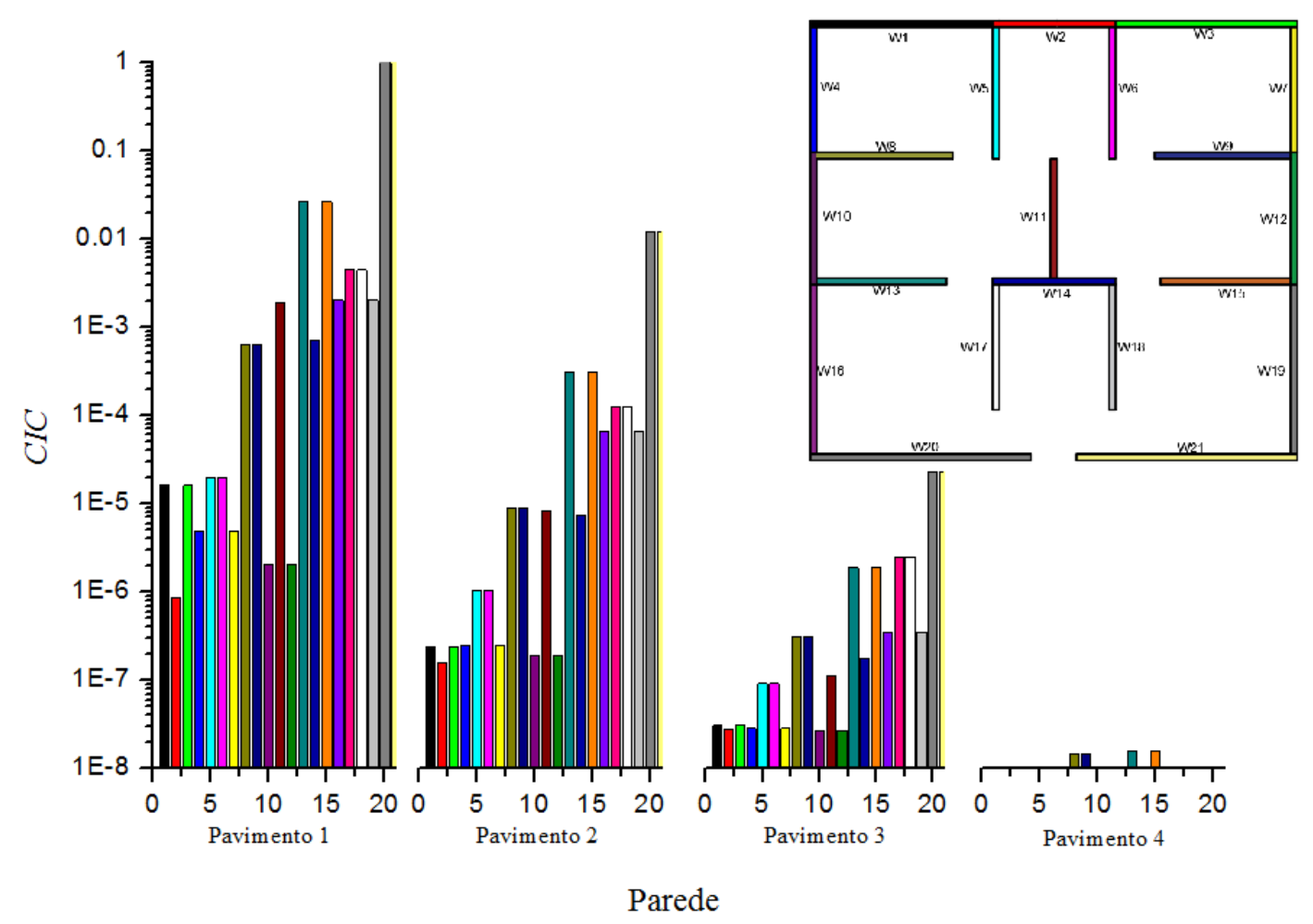

Fonte: Autoria própria.

A Figura 62 apresenta os valores dos coeficientes de vulnerabilidade para o colapso estrutural $(C V C)$. Torna-se evidente que os elementos mais vulneráveis são as paredes de número $W 20$ (W21 simétrica). Na ilustração contida na Figura 62 é exibido o mapa de risco do edifício em estudo. Os elementos que não são mostrados ou com $C V C$ próximo a zero têm pequena relevância para iniciar o estágio de colapso progressivo. Isso indica, que a falha de um desses elementos não causa o colapso do edifício. Dessa forma, a estrutura redistribui os esforços e deslocamentos de forma a permanecer em uma nova posição de equilíbrio sem a ocorrência de grandes desproporcionalidades.

Aplicando a Definição 6.6, tem-se que o elemento chave é a parede de número W20 (W21 simétrica). A falha desse elemento da início ao caminho mais provável para o colapso progressivo. Para o edifício de alvenaria estrutural em estudo, a falha do elemento chave resulta em $P\left[c_{20}\right]=P\left[c_{21}\right]=1,01 \cdot 10^{-8}$. O valor de $P\left[c_{20}\right]$ é entendido como a probabilidade de colapso condicional do edifício, dada à ocorrência da falha do elemento $W 20$. Tal valor é muito alto, sobretudo porque somente a falha por compressão axial é avaliada. Ressalta que o risco admissível de colapso, dado à ocorrência de um evento é $P\left[c_{i}\right] \leq 10^{-7} /$ ano, de acordo com NISTIR 7396 (2007), Ellingwood (2006), Pate-Cornell (1994). Dessa forma, seguindo as mesmas estratégias, contudo, para uma análise via ISMC, 
tem-se: $P\left[c_{20}\right]=P\left[c_{21}\right]=1,05 \cdot 10^{-8}$.

Figura 62 - Coeficiente de vulnerabilidade para o colapso estrutural $(C V C)$ via FORM.

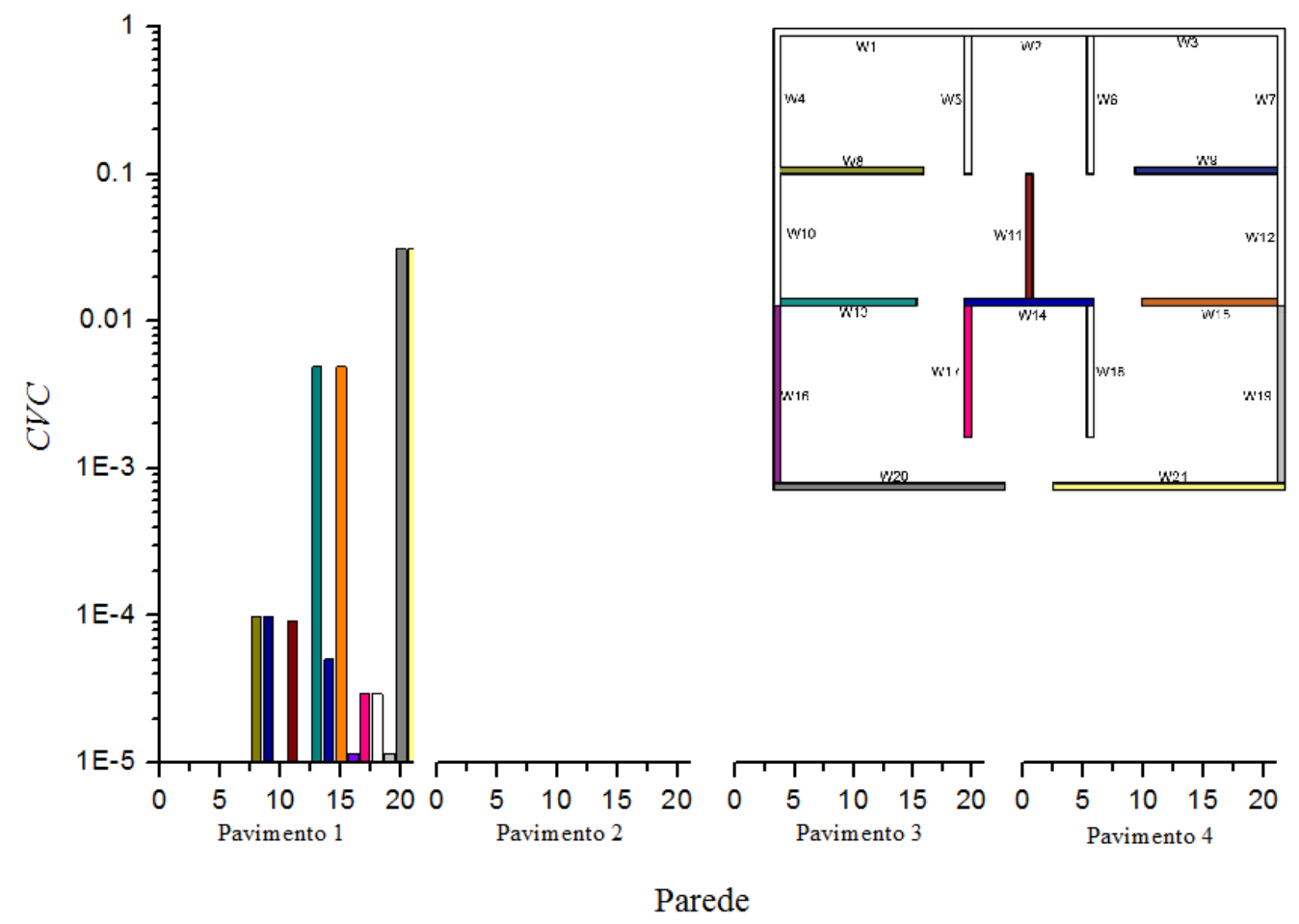

Fonte: Autoria própria.

Na Tabela 17 e Tabela 18 são apresentados todos os caminhos de falhas condicionais para o edifício. Comparando as sequências de falha dos elementos centrais, elementos periféricos e elementos de cantos, constata-se que os elementos de cantos geram maiores valores de $P[c]$ que os elementos centrais, e estes ocasionam maiores valores de $P[c]$ que os elementos periféricos. Verifica-se das referidas tabelas, que localmente (nos pavimentos 1, 2 e 3), os elementos chave são sempre os elementos $W 20$ e $W 21$. Já no pavimento 4 há uma mudança nos caminhos de falha condicionais o que causa máxima $P\left[c_{i}\right]$ na parede $W 13$ ( $W 15$ simétrica) seguida da $W 8$ (W9 simétrica). Além disso, para cada pavimento superior do edifício, em média a $P[c]$ diminui em ordem de grandeza de $10^{-2}$. Isso é esperado, visto que, elementos dos pavimentos superiores possuem baixa vulnerabilidade para o colapso progressivo. Nota-se que todos os elementos resulta $P\left[c_{i}\right]<10^{-7}$. No entanto, observa-se que a $P[c]$ determinada por aqueles elementos ainda é menor que a $P[c]$ gerada pelo elemento chave, validando mais uma vez a Definição 6.6. Ademais, avaliando a $P[c]$ iniciada exclusivamente pelo elemento chave, esta resulta na totalidade da probabilidade de colapso para este edifício. 
Tabela 17 - Probabilidades condicionais de colapso progressivo, dado a falha do elemento $W_{i}$ via FORM.

\begin{tabular}{|c|c|c|c|c|}
\hline Elemento & Pavimento 1 & Pavimento 2 & Pavimento 3 & Pavimento 4 \\
\hline Paredes simétricas & $P\left[c_{i}\right]$ & $P\left[c_{i}\right]$ & $P\left[c_{i}\right]$ & $P\left[c_{i}\right]$ \\
\hline 1 e 3 & $1,57 \cdot 10^{-13}$ & $2,33 \cdot 10^{-15}$ & $3,00 \cdot 10^{-16}$ & $4,85 \cdot 10^{-17}$ \\
\hline 2 & $8,31 \cdot 10^{-15}$ & $1,54 \cdot 10^{-15}$ & $2,77 \cdot 10^{-16}$ & $4,66 \cdot 10^{-17}$ \\
\hline 4 e 7 & $4,74 \cdot 10^{-14}$ & $2,39 \cdot 10^{-15}$ & $2,78 \cdot 10^{-16}$ & $4,57 \cdot 10^{-17}$ \\
\hline 5 e 6 & $1,93 \cdot 10^{-13}$ & $1,02 \cdot 10^{-14}$ & $9,02 \cdot 10^{-16}$ & $8,62 \cdot 10^{-17}$ \\
\hline 8 e 9 & $6,32 \cdot 10^{-12}$ & $8,81 \cdot 10^{-14}$ & $3,03 \cdot 10^{-15}$ & $1,43 \cdot 10^{-16}$ \\
\hline 10 e 12 & $2,04 \cdot 10^{-14}$ & $1,87 \cdot 10^{-15}$ & $2,62 \cdot 10^{-16}$ & $4,40 \cdot 10^{-17}$ \\
\hline 11 & $1,86 \cdot 10^{-11}$ & $8,09 \cdot 10^{-14}$ & $1,10 \cdot 10^{-15}$ & $9,19 \cdot 10^{-17}$ \\
\hline 13 e 15 & $2,59 \cdot 10^{-10}$ & $3,06 \cdot 10^{-12}$ & $1,85 \cdot 10^{-14}$ & $1,52 \cdot 10^{-16}$ \\
\hline 14 & $7,05 \cdot 10^{-12}$ & $7,18 \cdot 10^{-14}$ & $1,72 \cdot 10^{-15}$ & $3,69 \cdot 10^{-17}$ \\
\hline 16 e 19 & $2,00 \cdot 10^{-11}$ & $6,51 \cdot 10^{-13}$ & $3,43 \cdot 10^{-15}$ & $7,23 \cdot 10^{-17}$ \\
\hline 17 e 18 & $4,38 \cdot 10^{-11}$ & $1,21 \cdot 10^{-12}$ & $2,45 \cdot 10^{-14}$ & $6,15 \cdot 10^{-17}$ \\
\hline \multirow[t]{2}{*}{20 e 21} & $1,01 \cdot 10^{-8}$ & $1,17 \cdot 10^{-10}$ & $2,23 \cdot 10^{-13}$ & $4,67 \cdot 10^{-17}$ \\
\hline & & & $P[$ colapso $]$ & $2,11 \cdot 10^{-8}$ \\
\hline
\end{tabular}

Fonte: Autoria própria. 
Tabela 18 - Probabilidades condicionais de colapso progressivo, dado a falha do elemento $W_{i}$ via ISMC.

\begin{tabular}{|c|c|c|c|c|}
\hline Elemento & Pavimento 1 & Pavimento 2 & Pavimento 3 & Pavimento 4 \\
\hline Paredes simétricas & $P\left[c_{i}\right]$ & $P\left[c_{i}\right]$ & $P\left[c_{i}\right]$ & $P\left[c_{i}\right]$ \\
\hline 1 e 3 & $1,70 \cdot 10^{-13}$ & $2,55 \cdot 10^{-15}$ & $3,37 \cdot 10^{-16}$ & $5,40 \cdot 10^{-17}$ \\
\hline 2 & $9,24 \cdot 10^{-15}$ & $1,70 \cdot 10^{-15}$ & $3,11 \cdot 10^{-16}$ & $5,19 \cdot 10^{-17}$ \\
\hline 4 e 7 & $5,24 \cdot 10^{-14}$ & $2,66 \cdot 10^{-15}$ & $3,10 \cdot 10^{-16}$ & $5,10 \cdot 10^{-17}$ \\
\hline 5 e 6 & $2,18 \cdot 10^{-13}$ & $1,16 \cdot 10^{-14}$ & $1,01 \cdot 10^{-15}$ & $9,79 \cdot 10^{-17}$ \\
\hline 8 e 9 & $7,32 \cdot 10^{-12}$ & $1,02 \cdot 10^{-13}$ & $3,41 \cdot 10^{-15}$ & $1,61 \cdot 10^{-16}$ \\
\hline 10 e 12 & $2,30 \cdot 10^{-14}$ & $2,09 \cdot 10^{-15}$ & $2,92 \cdot 10^{-16}$ & $4,90 \cdot 10^{-17}$ \\
\hline 11 & $2,14 \cdot 10^{-11}$ & $9,50 \cdot 10^{-14}$ & $1,25 \cdot 10^{-15}$ & $1,04 \cdot 10^{-16}$ \\
\hline 13 e 15 & $3,01 \cdot 10^{-10}$ & $3,46 \cdot 10^{-12}$ & $2,05 \cdot 10^{-14}$ & $1,72 \cdot 10^{-16}$ \\
\hline 14 & $8,04 \cdot 10^{-14}$ & $8,40 \cdot 10^{-14}$ & $1,88 \cdot 10^{-15}$ & $4,18 \cdot 10^{-17}$ \\
\hline 16 e 19 & $2,22 \cdot 10^{-11}$ & $7,10 \cdot 10^{-13}$ & $3,84 \cdot 10^{-15}$ & $8,24 \cdot 10^{-17}$ \\
\hline 17 e 18 & $4,92 \cdot 10^{-11}$ & $1,36 \cdot 10^{-12}$ & $2,81 \cdot 10^{-14}$ & $6,95 \cdot 10^{-17}$ \\
\hline \multirow[t]{2}{*}{20 e 21} & $1,05 \cdot 10^{-8}$ & $1,23 \cdot 10^{-10}$ & $2,39 \cdot 10^{-13}$ & $5,20 \cdot 10^{-17}$ \\
\hline & & & $P[$ colapso $]$ & $2,20 \cdot 10^{-8}$ \\
\hline
\end{tabular}

Fonte: Autoria própria.

Nota: Os valores das probabilidades são calculadas com 10000 números de simulações $\left(n_{s i}\right)$.

\subsection{Validação da metodologia do RAPC: análise estática não li- near}

O meio técnico usualmente utiliza nas suas análises estruturais, as hipóteses de comportamento do material de resposta elástico-linear e regimes de pequenos deslocamentos e deformações. Entretanto, constata-se que tais hipóteses se verificam para casos particulares da real resposta da estrutura, pois o comportamento não linear dos materiais, bem como a formulação da condição de equilíbrio na configuração deslocada, impõem uma resposta não linear na trajetória de equilíbrio da estrutura (PROENÇA, 2016).

$\mathrm{Na}$ avaliação do colapso progressivo, normalmente, os documentos normativos focalizam em análise geometricamente lineares, na qual a não linearidade geométrica é abordada de forma aproximada, através de combinações de ações ponderadas por fatores de aumento das deformações (Equação 4.8), conforme discutidos na subseção 4.3.2.2. Contudo, tais fatores podem não satisfazer um nível de segurança adequado ou tornar o projeto da estrutura antieconômico. 
Devido à complexidade de avaliar integralmente uma estrutura sujeita ao colapso progressivo, os documentos normativos prescrevem através do método dos caminhos alternativos que o projetista estrutural realize análises não lineares na estrutura, dada a retirada de um elemento de apoio (UFC 4-023-03, 2009; NISTIR 7396, 2007; GSA, 2003). Porém, qual o elemento de apoio? As referidas normas ainda não têm critérios para especificar exatamente o elemento estrutural que deve ser previamente escolhido para iniciar tais análises, ficando na maioria das vezes a critério do engenheiro. Dessa forma, a metodologia do RAPC pode servir como uma ferramenta para auxiliar o método dos caminhos alternativos determinando os elementos mais vulneráveis, especialmente o(s) elemento(s) chave.

Assumindo que a importância dos elementos estruturais é consistente entre os diferentes níveis de análises, são realizadas análises geometricamente não lineares para verificar a influência destas análises no comportamento global da estrutura na ocorrência da falha do(s) elemento(s) chave. Dessa forma, a probabilidade de colapso progressivo do edifício é calculada pela Equação 6.21 considerando uma análise mais refinada.

No DIANA ${ }^{\circledR}$ as análises são efetuadas a partir da descrição Lagrangiana Total do equilíbrio. Neste caso, utiliza-se os mesmos modelos numéricos (carga permanente e carga variável). Entretanto, inicialmente, muda-se a propriedade do elemento chave para o MCOLAPSO. Deste modo, tal recurso simula a falha da referida parede estrutural. As análises das sequências de falhas das outras paredes estruturais seguem as estratégias descritas na seção 11.3. A não linearidade física, novamente, é verificada de forma aproximada penalizando a rigidez da estrutura.

A resolução do sistema de equações não lineares é feita utilizando o método iterativo de Newton-Raphson, com o número máximo de iterações limitada a 100. O incremento de carga é assumido igual a 0,01 em cem passos de carregamento. O critério de parada é adotado a partir da variação relativa da energia, com tolerância de $10^{-2}$. Esses parâmetros são dados de entrada para a análise no software DIANA ${ }^{\circledR}$.

Valores das probabilidades de falha das paredes estruturais são calculados por FORM e ISMC com auxílio do programa StRAnD. Para isso, os esforços solicitantes obtidos através do software DIANA ${ }^{\circledR}$ considerando as análises não lineares são utilizados como dados de entrada nas análises de confiabilidade.

Para o edifício de alvenaria estrutural em estudo, identifica-se dois elementos chave (W20 e W21), oferecida pela simetria dessa construção. Deste modo, a avaliação do caminho de falha condicional (Equação 6.1), pode ser realizada para um desses elementos, e depois multiplicada por dois para obter o valor da probabilidade de colapso progressivo (Equação 6.21).

Após o mapeamento de todas as sequências de falha por meio do acoplamento dos 
softwares DIANA ${ }^{\circledR}$ e StRAnD com o RAPC-ACADEMIC, a probabilidade condicional de colapso progressivo dada a falha do elemento chave (EC) é calculada, o que resulta: $P[$ colapso $\mid E C]=1,20 \cdot 10^{-7}$ e $P[$ colapso $\mid E C]=1,23 \cdot 10^{-7}$ via FORM e ISMC, respectivamente. Torna-se evidente que estes valores de probabilidades estão acima do limite mínimo aceitável para garantir a segurança da estrutura, na ocorrência de um dano que leve a perda do elemento chave, conforme as recomendações do NISTIR 7396 (2007), Ellingwood (2006) e Pate-Cornell (1994).

A $P[$ colapso $\mid E C]$ calculada por meio de análises geometricamente não lineares é aproximadamente uma ordem de grandeza maior que a determinada via análises geometricamente lineares (Tabela 17 e Tabela 18), para a construção de alvenaria estrutural em estudo. Como somente o modo de falha por compressão axial é avaliado, enfatiza-se que considerando outros modos de falhas, aquela diferença pode ser bastante superior.

Recordando que no dimensionamento do edifício em estudo é adotado a resistência da alvenaria igual para todos os elementos, ressalta-se que o valor calculado para tal resistência é maior que o valor necessário para o projeto $\left(\sigma_{d}=0,95 \mathrm{MPa}>\sigma_{S d}=0,686\right.$ $\mathrm{MPa}$. Entretanto, mesmo com o acréscimo de resistência nas paredes estruturais, a ocorrência de um dano que proporcione a falha do elemento chave pode causar o colapso do edifício.

O estudo desse edifício analisando somente o modo de falha por compressão axial para as paredes estruturais contrapõem as recomendações apresentadas nos documentos internacionais que tratam sobre o colapso progressivo. Os referidos documentos UFC 4-023-03 (2009), NISTIR 7396 (2007) e GSA (2003) não estabelecem nenhum requisito na prevenção do colapso progressivo para estrutura de até quatro pavimentos. Isso porque tais estruturas são agrupadas em classes de consequências leves, onde o risco de vida e danos econômicos são pequenos.

A metodologia do RAPC surge como uma alternativa para a determinação do risco do colapso progressivo nas estruturas de modo geral, pois as análises são realizadas independentemente da quantidade de pavimentos que tem o edifício. Dessa forma, utilizando o RAPC o engenheiro pode aferir sobre a robustez do seu projeto estrutural. Caso a probabilidade de colapso progressivo calculada para o edifício seja maior que $10^{-7}$, o mesmo deve adotar medidas para aumentar a resistência local dos elementos mais vulneráveis, sobretudo do elemento chave. Neste caso, recomenda-se que tais medidas sejam realizadas no estágio de propagação de dano. Isso porque, cessada a progressão de falha desses elementos, não há início do estágio de colapso progressivo.

Portanto, espera-se que a metodologia do RAPC possa ser utilizada para calibrar as prescrições descritas nos códigos normativos, levando em consideração a resposta da estrutura sujeita à ocorrência do colapso progressivo, conferindo robustez e integridade estrutural aos novos edifícios de alvenaria estrutural projetados. 


\section{Considerações finais e recomendações para trabalhos futuros}

\subsection{Considerações finais}

O presente trabalho apresentou uma nova metodologia para a avaliação do colapso progressivo em estruturas, denominada de Risk Analysis of the Progressive Collapse (RAPC). Os exemplos mostrados ao longo do texto foram necessários para validar as hipóteses e definições adotadas.

A partir da revisão teórica realizada sobre o tema proposto, verificou-se que ainda faltam trabalhos específicos que abordem a probabilidade de falha de estruturas de alvenaria estrutural quando considerado um dano acidental.

Na maioria dos casos, as recomendações normativas estabelecem a colocação de amarrações (tirantes) entre lajes e paredes para prover ductilidade local na estrutura. É sabido que estas amarrações aumentam a continuidade das ligações entre os elementos e consequentemente a robustez da estrutura, entretanto, pode ocorrer que o colapso local de uma parede influencie outras paredes acarretando um efeito em cadeia que culmina no colapso progressivo da estrutura. Ademais, ainda não existe um estudo na literatura que quantifique a eficiência desses tirantes na mitigação de um dano acidental.

Em se tratando das lajes, a hipótese de considerar suas vinculações rotuladas nos apoios, no caso de paredes estruturais, é contra a segurança. Isso porque, elas perdem os requisitos fundamentais mínimos de continuidade nesses apoios. Além disso, a falha de um dos seus elementos de apoio transforma a mesma em uma laje com borda livre. Tal configuração impõe um aumento significativo no momento solicitante, podendo provocar o seu colapso. Para o pavimento tipo do edifício estudado ao longo deste trabalho, em média o aumento no momento fletor solicitante foi de $250 \%$.

A formulação apresentada neste trabalho pode ser aplicada para qualquer sistema construtivo, desde que seja possível escrever as equações de estado limites para seus respectivos modos de falha. Entretanto, verifica-se que a mesma se torna complexa para ser aplicada diretamente em escritórios de projetos estruturais. Isso porque, as análises de confiabilidade requerem conhecimentos prévios específicos por parte dos projetistas. Além do mais, faz-se necessário a utilização de um software que realize tais análises.

Em relação aos coeficientes de vulnerabilidade $(C V D$ e $C V C)$, o projetista estrutural deve ter uma atenção especial, pois os procedimentos para minimizar a ocorrência do colapso progressivo têm que se concentrar nos elementos estruturais com máximos valores 
de vulnerabilidade. O elemento chave é o elemento com maior $C V C$. Quando perdido ou danificado, o elemento chave inicia o caminho de falha de colapso mais provável, para todos os possíveis caminhos de falha na estrutura. Para isso, foi demonstrado nos exemplos apresentados que a probabilidade de colapso condicional, associada à perda do elemento chave, representa a maior contribuição para a probabilidade de colapso estrutural.

A metodologia do RAPC, proposta neste trabalho mostrou-se uma ferramenta eficaz para analisar a probabilidade de colapso das estruturas. A mesma é construída em torno de uma análise de ameaça específica no estágio de propagação de dano, na qual a probabilidade de colapso deve ser avaliada para um dado evento de carregamento. Neste caso, recomenda-se a utilização da Equação 6.21, pois torna as análises de confiabilidades mais simples. Para tal, admite-se que a probabilidade da ocorrência do evento $E_{v}$ que produz o dano inicial (falha do elemento estrutural) é igual a unidade. Essa hipótese é reputada na literatura, sendo assumida na estratégia do projeto direto, de acordo com NISTIR 7396 (2007).

Dessa forma, é possível estabelecer recomendações de projeto, em vista a fortalecer o elemento chave, bem como os elementos mais vulneráveis de uma estrutura, alternativamente ao que recomendam os documentos normativos existentes, obtidos a partir de leis empíricas de natureza fenomenológica. Portanto, no que diz respeito às recomendações objetivas de projeto, é evidente que a identificação dos elementos mais vulneráveis, e do elemento chave em particular, é útil para abordagens diretas de concepção, tais como a melhoria da resistência local. Além disso, os coeficientes aqui propostos também medem os efeitos dos procedimentos de concepção que conduzem à continuidade, ductilidade e redundância. Quando essas medidas trabalham para reduzir as probabilidades de propagação de dano ou colapso, isso se reflete nas vulnerabilidades de elementos eventualmente iniciando esses caminhos de falha.

Portanto, com o RAPC pode-se avaliar as prescrições dos documentos normativos em relação à prevenção do colapso progressivo. Por exemplo, a determinação de taxas de armadura eficientes para suportar a configuração de ruína das lajes dada a falha de um elemento de apoio. Estas recomendações preventivas têm o papel fundamental de garantir que a falha dos elementos mais importantes não gere desproporcionalidade para estrutura, pois as mesmas têm a função de transferir os esforços resultantes de forma que a configuração de ruína da estrutura fique em uma nova posição de equilíbrio. Entretanto, neste trabalho não foram realizadas tais análises, sendo recomendado para trabalhos futuros.

Por fim, conclui-se que a formulação do RAPC mostrou um bom comportamento nos seus resultados, sendo uma alternativa para a determinação do risco do colapso progressivo nas estruturas. Aliás, sendo uma área pouco explorada na literatura, com poucas publicações relacionadas, espera-se que este trabalho contribua para preencher a 
lacuna existente.

\subsection{Recomendações para trabalhos futuros}

a) analisar com a metodologia do RAPC outros sistemas construtivos, tais como: estruturas de concreto armado, estruturas metálicas e estruturas de madeira;

b) equacionar outros modos de falha para as análises de confiabilidade das estruturas de alvenaria estrutural;

c) avaliar a influência das lajes com outros tipos de configuração de ruína, como, por exemplo: lajes engastadas e lajes engastadas com uma borda livre;

d) estudar a partir da metodologia do RAPC recomendações de projeto, tais como: taxas de armaduras mínimas entre os elementos estruturais, bem como, ancoragens eficientes para fornecer continuidade entre os elementos. 



\section{Referências}

ALTOQI. Curso de alvenaria estrutural para projetista. Santa Catarina: AltoQi, 2015.

AMED, P. C. Associação do cálculo elástico com a teoria das charneiras plásticas para lajes retangulares com uma borda livre. Dissertação (Dissertação de Mestrado) — Escola de Engenharia de São Carlos, Universidade de São Paulo, São Carlos, 1995.

AMERICAN CONCRETE INSTITUTE. ACI 530: Building code requirements for masonry structures. Michigan, 2013.

AMERICAN SOCIETY OF CIVIL ENGINEERS. ASCE 7: Mininum design loads for buildings and other structures. Reston, VA, 2005.

AMERICAN SOCIETY OF CIVIL ENGINEERS. ASCE 41: Seismic rehabilitation of existing buildings. Reston, VA, 2006.

ANG, A. H.-S.; TANG, W. H. Probability concepts in engineering planning and design. 2. ed. New York: John Wiley and Sons, 1984.

ANG, A. H.-S.; TANG, W. H. Probability concepts in engineering: emphasis on applications in civil e environmental. 2. ed. New York: Wiley, 2007.

ASSOCIAÇÃO BRASILEIRA DE NORMAS TÉCNICAS. NBR 6120: Cargas para o cálculo de estruturas de edificações. Rio de Janeiro, 1980.

ASSOCIAÇÃO BRASILEIRA DE NORMAS TÉCNICAS. NBR 8681: Ações e segurança nas estruturas. Rio de Janeiro, 2004.

ASSOCIAÇÃO BRASILEIRA DE NORMAS TÉCNICAS. NBR 9062: Projeto e execuc c ao de estruturas de concreto pré-moldado. Rio de Janeiro, 2006.

ASSOCIAÇÃO BRASILEIRA DE NORMAS TÉCNICAS. NBR 15812: Alvenaria estrutural — blocos cerâmicos parte 1: Projeto. Rio de Janeiro, 2010.

ASSOCIAÇÃO BRASILEIRA DE NORMAS TÉCNICAS. NBR 15961: Alvenaria estrutural - blocos de concreto parte 1: Projeto. Rio de Janeiro, 2011.

ASSOCIAÇÃO BRASILEIRA DE NORMAS TÉCNICAS. NBR 16055: Parede de concreto moldada no local para a construc c ao de edificac c oes - requisitos e procendimentos. Rio de Janeiro, 2012.

ASSOCIAÇÃO BRASILEIRA DE NORMAS TÉCNICAS. NBR 6118: Projeto e execução de obras de concreto armado — procedimentos. Rio de Janeiro, 2014.

ASSOCIAÇÃO BRASILEIRA DE NORMAS TÉCNICAS. NBR 6136: Blocos vazados de concreto simples para alvenaria - requisitos. Rio de Janeiro, 2014.

AUSTRALIAN STARNDARD. AS 3700: Masonry structures. Sydney, 2001.

BAKER, J. W.; SCHUBERT, M.; FABER, M. H. On the assessment of robustness.

Structural Safety, Elsevier, v. 30, n. 3, p. 253-267, 2008. 
BARES, R. Tablas para el calculo de placas y vigas pared. Barcelona: Gustavo Gili, 1972. BECK, A. T. StRAnD: structural risk analysis and design. São Carlos: EESC-USP, 2007. BECK, A. T. Curso de confiabilidade estrutural (Notas de aulas). São Paulo: EESC-USP, 2015.

BIONDINI, F.; FRANGOPOL, D. M.; RESTELLI, S. On structural robustness, redundancy and static indeterminacy. In: ASCE Structures Congress 2008. [S.l.: s.n.], 2008. p. $24-26$.

BITTARELLO, G. Colapso progressivo de estruturas de concreto pré-moldado. Dissertação (Monografia) — UTFPR, Pato Branco, 2013.

BOOLE, G. Laws of Thought (American reprint of 1854 edition). New York: Dover, 1854.

BRAGUIM, T. C. Utilização de modelos de cálculo para projeto de edifícios de paredes de concreto armado moldadas no local. Dissertação (Mestrado) — Universidade de São Paulo, São Paulo, 2013.

BREEN, J. E. Summary Report: Research Workshop on Progressive Collapse of Building Structures, Held at Joe C. Thompson Conference Center, the University of Texas at Austin, November 18-20, 1975. [S.1.]: Department of Housing and Urban Development, 1976.

BREITUNG, K. Asymoptotic approximations for multinormal integrals. Journal of Engineering Mechanics, ASCE, v. 110, p. 357-336, 1984.

BREITUNG, K. 40 years form: Some new aspects? Probabilistic Engineering Mechanics, Elsevier, v. 42, p. 71-77, 2015.

BRETT, C.; LU, Y. Assessment of robustness of structures: Current state of research. Frontiers of Structural and Civil Engineering, Springer, v. 7, n. 4, p. 356-368, 2013.

BRITISH STANDARDS INSTITUTION. BS 5628-1: Code of practice for use of masonry - part 1. London, 1992.

CHEN, Y.-L. et al. Assessment of structural robustness under different events according to vulnerability. Journal of Performance of Constructed Facilities, American Society of Civil Engineers, p. 04016004, 2016.

CODA, H. B.; PACCOLA, R. R. AcadFrame: software academêmico para análise de pórticos e treliças plans. São Carlos: EESC-USP, 2006.

CORLEY, W. G. et al. The oklahoma city bombing: Summary and recommendations for multihazard mitigation. Journal of Performance of Constructed Facilities, American Society of Civil Engineers, v. 12, n. 3, p. 100-112, 1998.

CORNELL, C. A. A probability-based structural code. In: ACI. ACI Journal Proceedings. [S.l.], 1969. v. 66, n. 12.

CORRÊA, M. R. S. Aperfeiçoameto de modelos usualmente empregados no projeto de sistemas estruturais de edifícios. Tese (Doutorado) - Escola de Engenharia de São Carlos, Universidade de São Paulo, São Carlos, 1991. 
CORRÊA, M. R. S.; RAMALHO, M. A. Projeto de edifícios de alvenaria estrutural. São Paulo: Pini, 2004.

DAT, P. X.; HAI, T. K.; JUN, Y. A simplified approach to assess progressive collapse resistance of reinforced concrete framed structures. Engineering Structures, v. 101, p. $45-57,2015$.

DEPARTMENT OF DEFENSE. UFC 4-023-03: Design of buildings to resist progressive collapse. Washington, DC, 2009.

DIMAS, T. dos S. Análise de estruturas de edifícios sujeitas a ações acidentais. Dissertação (Dissertação de Mestrado) — Universidade Nova de Lisboa, Lisboa, 2014.

DITLEVSEN, O.; MADSEN, H. O. Structural reliability methods. Engle: John Wiley and Sons, 2007.

DUSENBERRY, D. O.; JUNEJA, G. Review of existing guidelines and provisions related to progressive collapse. In: Workshop on Prevention of Progressive Collapse. [S.l.: s.n.], 2002.

DUTUIT, Y.; RAUZY, A. Efficient algorithms to assess component and gate importance in fault tree analysis. Reliability Engineering 65 System Safety, Elsevier, v. 72, n. 2, p. 213-222, 2001.

EL-DAKHAKHNI, W. et al. Resilient reinforced masonry loadbearing wall system to mitigate progressive collapse. In: . [S.l.: s.n.], 2013. p. 173-181.

EL-DEBS, M. K. Concreto Pré-moldado: Fundamentos e aplicações. São Carlos: EESC-USP, 2000.

ELLINGWOOD, B. Strategies for mitigating risk to buildings from abnormal load events. International Journal of Risk Assessment and Management, v. 6-7, n. 6, p. 828-845, 2007.

ELLINGWOOD, B.; GALAMBOS, T. V. Probability-based criteria for structural design. Structural Safety, Elsevier, v. 1, n. 1, p. 15-26, 1983.

ELLINGWOOD, B.; LEYENDECKER, E. V.; YAO, J. T. P. Probability of failure from abnormal load. Journal of Structural Engineering-Asce, v. 109, n. 4, p. 875-890, 1983.

ELLINGWOOD, B.; LEYENDECKER, E. V.; YAO, J. T. P. Probability of failure from abnormal load - closure. Journal of Structural Engineering-Asce, v. 110, n. 4, p. 933-933, 1984.

ELLINGWOOD, B. et al. Probability based load criteria: load factors and load combinations. Journal of the Structural Division, ASCE, v. 108, n. 5, p. 978-997, 1982.

ELLINGWOOD, B. et al. Disproportionate collapse research needs. Proceedings of the Structures, p. 1896-1907, 2009.

ELLINGWOOD, B. R. Strategies for mitigating risk of progressive collapse. In: Proc. ACSE Structures Congress. [S.l.: s.n.], 2005. v. 1, p. 5-6.

ELLINGWOOD, B. R. Mitigating risk from abnormal loads and progressive collapse. Journal of Performance of Constructed Facilities, v. 20, n. 4, p. 315-323, 2006. 
ELLINGWOOD, B. R. Abnormal loads and disproportionate collapse: Risk mitigation strategies. In: ASCE. Structures Congress 2009@ sDon't Mess with Structural Engineers: Expanding Our Role. [S.1.], 2009. p. 1-8.

ELLINGWOOD, B. R.; DUSENBERRY, D. O. Building design for abnormal loads and progressive collapse. Computer-Aided Civil and Infrastructure Engineering, v. 20, n. 3, p. 194-205, 2005.

EUROPEAN STANDARD. Eurocode 1: Actions on structures. part 1-7: General actions accidental actions. Brussels, 2003.

EUROPEAN STANDARD. Eurocode 6: Design of masonry structures - part 1-1: General rules for reinforced and unreinforced masonry structures. Brussels, 2005.

FELIPE, T. R. C.; HAACH, V. G. Discussões de estratégias aplicadas na simulação numérica de uma viga de concreto armado. Concreto e Construções, v. 84, p. 62-68, 2016.

FIONDELLA, L.; XING, L. Discrete and continuous reliability models for systems with identically distributed correlated components. Reliability Engineering 65 System Safety, Elsevier, v. 133, p. 1-10, 2015.

FRANGOPOL, D. M.; CURLEY, J. P. Effects of damage and redundancy on structural reliability. Journal of Structural Engineering, American Society of Civil Engineers, v. 113, n. 7, p. 1533-1549, 1987.

FU, G.; FRANGOPOL, D. M. Balancing weight, system reliability and redundancy in a multiobjective optimization framework. Structural Safety, Elsevier, v. 7, n. 2-4, p. 165-175, 1990.

GENERAL SERVICES ADMINISTRATION. GSA: Progressive collapse analysis and design guidelines for new federal buildings and major modernization projects. Washington, DC, 2003.

GIONGO, J. S. Concreto armado: análise das resistências das seções transversais de elementos estruturais. São Carlos: EESC-USP, 2015.

GOLLWITZER, S.; RACKWITZ, R. On the reliability of daniels systems. Structural Safety, Elsevier, v. 7, n. 2-4, p. 229-243, 1990.

GONZALEZ, R. L. M. Análise de lajes pela teoria das charneiras plásticas e comparação de custos entre lajes maciças e lajes treliçadas. Dissertação (Dissertação de Mestrado) Escola de Engenharia de São Carlos, Universidade de São Paulo, São Carlos, 1997.

HAACH, V. G. Danos acidentais. In: ___. Construções em alvenaria estrutural: materiais, projeto e desempenho. 1. ed. São Paulo: Blucher, 2015. cap. 7, p. 219-231.

HABERLAND, M.; STAROSSEK, U. Progressive collapse nomenclature. In: ASCE SEI Structures Congress 2009. [S.l.: s.n.], 2009.

HASSOFER, A. M.; LIND, N. C. Exact and invariant second moment code format. Journal of Engineering Mechanics, ASCE, v. 100, p. 111-121, 1974.

HENDRY, A. W. Structural brickwork. [S.l.]: Halsted Press, 1981. 
INGERSLEV, A. The strength of rectangular slabs. Journal of the Institution of Structural Engineers, v. 1, n. 1, p. 3-14, 1923.

JOHAN, R. Limiting the Extent of Localised Failure According to SFS-EN 1991-1-7. Dissertação (Master's Thesis) — Aalto University, Espoo, 2010.

JOHANSEN, K. Moments of rupture in cross-reinforced slabs. Proc. Intern. Assoc. Bridge and Structural Eng, v. 1, p. 277-296, 1932.

JOINT COMMITEE ON STRUCTURAL SAFET. Probabilistic model code: part 1 - basis of design. Denmark, 2001.

KAZDA, I. Finite element techniques in groundwater flow studies: with applications in hydraulic and geotechnical engineering. [S.l.]: Elsevier, 1990.

KIUREGHIAN, A.; LIU, P. Finite-element reliability methods for geometrically nonlinear stochastic structures. [S.l.], 1989.

KIUREGHIAN, A. D.; LIU, P. L. Structural reliability under imcomplete probability information. Journal of Engineering Mechanics, ASCE, v. 112, n. 1, p. 85-104, 1986.

KOUSGAARD, A.; ERDOGMUS, E. State-of-the-art review: Analysis and rehabilitation of existing masonry walls against progressive collapse. In: AEI 2015: Birth and Life of the Integrated Building - Proceedings of the AEI Conference 2015. [S.l.: s.n.], 2015. p. 421-432.

KOZLOVA, P. The phenomenon of progressive collapse according to Russian norms. Dissertação (Bachelor's Thesis) - Saimaa University of Applied Sciences, Lappeenranta, 2013.

LANGENDONCK, T. V. Teoria elementar das charneiras plásticas. [S.l.]: Associação Brasileira de Cimento Portland, 1970. v. 1.

LANGENDONCK, T. V. Teoria elementar das charneiras plásticas. [S.l.]: Associação Brasileira de Cimento Portland, 1975. v. 2.

LARANJEIRAS, A. Colapso progressivo dos edifícios: breve introdução. TQS News, p. 36-48, 2011.

LEYENDECKER, E. V.; ELLINGWOOD, B. Design methods for reducing the risk of progressive collapse in buildings. [S.l.]: US Dept. of Commerce, National Bureau of Standards, 1977.

LIND, N. C. A measure of vulnerability and damage tolerance. Reliability Engineering 85 System Safety, Elsevier, v. 48, n. 1, p. 1-6, 1995.

LONGINOW, A.; MNISZEWSKI, K. R. Protecting buildings against vehicle bomb attacks. Practice Periodical on Structural Design and Construction, American Society of Civil Engineers, v. 1, n. 1, p. 51-54, 1996.

LOPES, G. M. Estudo teórico e experimental de paredes esbeltas de alvenaria estrutural. Dissertação (Dissertação de Mestrado) — Universidade Federal de São Carlos, São Carlos, 2014. 
LUCCIONE, B. M.; AMBROSINI, R. D.; F, D. R. Analysis of buildings collapse under blast loads. Journal Engineering Structures, American Society of Civil Engineers, v. 26, p. 63-71, 2004.

MADSEN, H. O.; KRENK, S.; LIND, N. C. Methods of structural safety, prentice hall inc. New Jersey: Englewood Cliffs, 1986.

MCGUIRE, W. Prevention of progressive collapse. p. 851-865, 1974.

MELCHERS, R. E. Structural reliability analysis and pradiction. 2. ed. New York: John Wiley and Sons, 1999.

MELGES, J. L. P. Padronização das tabelas para o cálculo de lajes retangulares, com carregamento uniforme. São Carlos: EESC-USP, Departamento de Estruturas, Relatório IC-CNPQ, 1993.

NAIR, R. S. Progressive collapse basics. North American Steel Construction Conference, March 24-2\%., Long Beach, 2007.

NASCIMENTO, J. A. N. Investigação das solicitações de cisalhamento em edifícios de alvenaria estrutural submetidos a ações horizontais. Dissertação (Dissertação de Mestrado)

- Escola de Engenharia de São Carlos, Universidade de São Paulo, São Carlos, 1999.

NATIONAL INSTITUTE OF STANDARD AND TECHNOLOGY. NISTIR 7396: Best practices for reducing the potential for progressive collapse in buildings, technology administration. Gaithersburg, MD, 2007.

NOGUEIRA, C. G. Desenvolvimento de modelos mecânicos, de confiabilidade e de otimização para aplicação em estruturas de concreto armado. Tese (Doutorado) - Escola de Engenharia de São Carlos, Universidade de São Paulo, São Carlos, 2010.

NORMA PORTUGUESA. NP EN 1992-1-1: Projeto de estruturas de betão - parte 1-1: Regras gerais e regras para edifícios. Caparica, 2010.

OLIVEIRA, V. M. B. de. Colapso progressivo de estruturas reticuladas espaciais. Dissertação (Dissertação de Mestrado) - Universidade Federal do Rio de Janeiro, Rio de Janeiro, 2002.

PARSEKIAN, G. A.; HAMID, A. A.; DRYSDALE, R. G. Comportamento e dimensionamento de alvenaria estrutural. São Carlos: EdUFSCAR, 2013.

PATE-CORNELL, E. Quantitative safety goals for risk mangement of industrial facilities. Structural Safety, v. 13, n. 3, p. 145-157, 1994.

PINHEIRO, L. M. Análise elástica e plástica de lajes retangulares de edifícios. Tese (Doutorado) - Escola de Engenharia de São Carlos, Universidade de São Paulo, São Carlos, 1988.

PROENÇA, S. P. B. Análise não-linear de estruturas (Notas de aulas). São Carlos: EESC-USP, 2016.

RACWITS, R.; FIESSLER, B. Structural reliability under combined random load sequences. Computer and Structures, v. 9, p. 489-494, 1978. 
RIOS, P. M. Lajes retangulares de edifícios: associação do cálculo elástico com a teoria das charneiras plásticas. Dissertação (Dissertação de Mestrado) - Escola de Engenharia de São Carlos, Universidade de São Paulo, São Carlos, 1991.

SAGRILO, L. V. Análise de confiabilidade estrutural utilizando os métodos analíticos FORM e SORM. Tese (Doutorado) - Universidade de Federal do Rio de Janeiro, COPPE, Rio de Janeiro, 1994.

SANTOS, K. R. dos; BECK, A. T. A benchmark study on intelligent sampling techniques in monte carlo simulation. Latin American Journal of Solids and Structures, SciELO Brasil, v. 12, n. 4, p. 624-648, 2015.

SMITH, P. P.; P, B. M.; GOODE, D. J. Buildings robustness research during world war ii. Journal of Performance of Constructed Facilities, v. 24, n. 6, p. 529-535, 2010.

SONG, J.; KIUREGHIAN, A. D. Bounds on system reliability by linear programming. Journal of Engineering Mechanics, American Society of Civil Engineers, v. 129, n. 6, p. 627-636, 2003.

SORIANO, H. L. Método de elementos finitos em análise de estruturas. [S.l.]: EdUSP, 2003.

STAROSSEK, U. Book. Progressive collapse of structures. [S.l.]: London: Thomas Telford Limited, 2009.

STAROSSEK, U.; HABERLAND, M. Measures of structural robustness-requirements and applications. In: ASCE SEI 2008 Structures Congress, Vancouver, Canada. [S.l.: s.n.], 2008.

STAROSSEK, U.; HABERLAND, M. Disproportionate collapse: terminology and procedures. Journal of Performance of Constructed Facilities, American Society of Civil Engineers, v. 24, n. 6, p. 519-528, 2010.

STAROSSEK, U. et al. Report of the terminology and procedures sub-committee (sc1): recommendations for design against disproportionate collapse of structures. In: Proceedings of the Structures Congress. [S.l.: s.n.], 2011. p. 2090-2103.

STEVENS, D. et al. Dod research and criteria for the design of buildings to resist progressive collapse. Journal of Structural Engineering, American Society of Civil Engineers, v. 137, n. 9, p. 870-880, 2011.

STO. STO 008-02495342: Prevention progressive collapse of reiforced concrete monolithic structures of buildings. Moscow, 2009.

TIMOSHENKO, S.; WOINOSKY-KRIEGER, S. Theory of plates and shells (nd, 1940); v. Z. Vlasov, Thin-walled Elastic Bars, Moscow, 1940.

VASILIEVA, A. Progressive collapse and methods of prevention. Dissertação (Bachelor's Thesis) — Saimaa University of Applied Sciences, Lappeenranta, 2013.

VERZENHASSI, C. C. Otimização de risco estrutural baseada em confiabilidade. Dissertação (Dissertação de Mestrado) - Escola de Engenharia de São Carlos, Universidade de São Paulo, São Carlos, 2008. 
WU, C. Q.; HAO, H. Safe scaled distance for masonry infilled rc frame structures subjected to airblast loads. Journal of Performance of Constructed Facilities, v. 21, n. 6, p. 422-431, 2007.

YAGUI, T. Análise de estruturas de edifícios constituídas de núcleo de concreto armado e pilares ou pendurais de aço (carregamento crítico de instabilidade geral). Limeira: Tese (Livre-docência)-Faculdade Engenharia de Limeira, Universidade Estadual de Campinas, 1978.

YOKEL, F. Y.; WRIGHT, R. N.; STONE, W. C. Progressive collapse: Us office building in moscow. Journal of Performance of Constructed Facilities, American Society of Civil Engineers, v. 3, n. 1, p. 57-75, 1989. 